\title{
Aislamiento y
}

caracterización genética y enológica de levaduras vínicas autóctonas de uva Prieto Picudo y caracterización aromática de sus vinos (D0 «Tierra de León»)
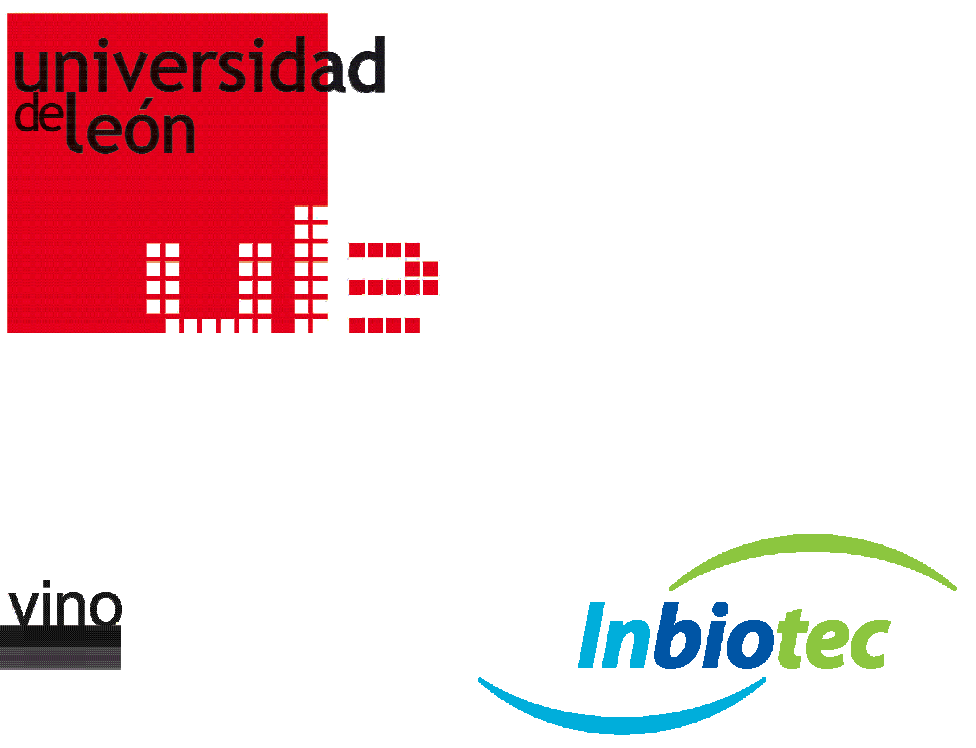

$$
\begin{gathered}
\text { Jose Manuel Álvarez Pérez } \\
\text { León, } 2.011
\end{gathered}
$$





\section{Aislamiento y}

caracterización genética y enológica de levaduras vínicas autóctonas de uva Prieto Picudo y caracterización aromática de sus vinos

(DO «Tierra de León»)

\section{Universidad de Léon}

Jose Manuel Álvarez Perez

León, 2.011 

A mi familia 



\section{Agradecimientos}

Aún recuerdo cuando llegando al laboratorio en una tarde primaveral recibo un inesperado "Enhorabuena", sin saber muy bien a que era debido. Al preguntar cuál era el motivo de esta inesperada bienvenida, me espetaron con cierta gracia: "Te han concedido la beca FPU". En ese momento se abría delante de mí un periodo de cuatro años en el que intentar llevar a cabo el presente trabajo. Cuatro años, 1460 días, que contra todo pronóstico se han pasado más rápido de lo que yo me esperaba. Aquí me veo con el cursor parpadeando delante de mí sin saber muy bien que teclear, tras horas y horas pulsando todas y cada una de ellas.

Llegar hasta aquí no podría haber sido posible sin el apoyo, profesional y sobre todo personal, de muchas personas que sin duda alguna han influido en lo que soy a día de hoy.

En primer lugar al Doctor Juan José Rubio Coque por "elegirme" y permitirme realizar la presente tesis doctoral bajo su excelente dirección.

Al ministerio de Educación y Ciencia por concederme la beca de Formación de Profesorado Universitario (FPU) (AP2006-03056) que me ha permitido desarrollar el presente trabajo dignamente.

Al Dr. Juan Francisco Martín, ex director del Instituto de Biotecnología de León (Inbiotec), así como a la nueva Dirección, por permitirme realizar este trabajo en las magníficas instalaciones del centro.

A la Dra. Maria Luisa Álvarez (Marusela) por enseñarme a desenvolverme en un laboratorio de microbiología. Gracias de todo corazón.

A Andrea, Alcira, Bernabé , Josefina y Bea por el apoyo técnico y logístico. Sin vuestro trabajo y dedicación esto no habría podido llegar a buen puerto.

A la Dra. Amparo Querol por permitirme realizar una estancia predoctoral bajo su supervisión en el Instituto de Agroquímica y Tecnología de los Alimentos (IATA-CSIC). Esto me permitió concocer a grandes personas que hicieron que este tiempo en Valencia fuera un placer. A todos vosotros, daros por aludidos, mil gracias.

A la Dra. Purificación Hernández por abrirme las puertas del Laboratorio de Análisis de Aroma y Enología (LAAE) y permitirme volver a mis orígenes, a la química. Mi corta pero productiva estancia me permitió conocer más acerca del aroma del vino, pero sin duda la mayor aportación fue llegar a conocer a las grandes personas que forman el laboratorio. Temas futbolísticos aparte, no olvidaré los grandes momentos vividos. A todos y cada uno de vosotros gracias por permitirme entrar en vuestras vidas.

Y que voy a decir de la gente que me ha aguantado durante cinco años nada más y nada menos. Un especial recuerdo a mis compañeros de cuarto. A Ana por mostrarme su apoyo y ayuda durante todo este tiempo. A Katarina por estar siempre dispuesta a ayudar y por actuar de segunda conciencia. A Marusela, de nuevo mil gracias. A Ramiro por enseñarme tanto de "informática" y demás que tan útil me ha resultado. A Rosma, aunque coincidiéramos durante poco tiempo. Sin olvidarme de Pin y Pon y otros con paso fugaz. El buen ambiente hacía que pasar horas y horas allí fuera mucho más llevadero.

A Carlos G, Javi, Ramiro y Raúl por esas mini-tertulias improvisadas de primera planta que nos hacían sonreír. A Carlos B. (Charly) por todo su apoyo y los grandes momentos vividos y que espero falten por llegar. A Antonio por estar siempre dispuesto a echar una mano desinteresadamente. A Rebeca por su positividad y peculiaridad, no cambies. Más que compañeros sois amigos. Sois tantos y tantos, entre los que están y ya se han ido, que necesitaría hojas y hojas. A todo vosotros, y sabéis quienes sois, ha sido un placer conoceros y compartir grandes momentos con vosotros. 
Muchísimas gracias a mi familia. En especial a mis padres, ya que soy lo que soy gracias a ellos. Habéis sido el espejo donde mirarme e ir mejorando como persona día a día. Sin vuestro apoyo y soporte quizás no habría llegado hasta aquí. A mis dos hermanitas de las que tan orgulloso estoy por todo el cariño recibido a lo largo de estos años. Un recuerdo especial a mis abuelos que sin lugar a dudas han sido como mis segundos padres. Vuestra aportación ha sido más grande de la que vosotros imagináis.

A mis amigos de siempre y de toda la vida que tengo el placer de tener, a mis amigos de la etapa universitaria y a todos aquellos que he tenido el placer de conocer a lo largo de mi vida, mostraros mi agradecimiento sincero por todo vuestro apoyo, directo e indirecto, muy importante para mí. Vosotros habéis hecho que el largo camino hasta aquí fuera mucho más ameno y llevadero.

Si has llegado hasta aquí y no te encuentras representado en las líneas anteriores, si echas la vista atrás y recuerdas algún momento vivido por ambos, ten en cuenta que para mí sí has sido importante.

Resumiendo, gracias a todos por TODO. 
1.1. Los orígenes de la vid y del vino 3

1.1.1. Especies y variedades de uvas

1.1.1.1. El género Vitis

1.1.1.2. Las especies Vitis

1.2. Denominación de origen "Tierra de León» 6

1.2.1. Zona de producción (Situación geográfica)

1.2.2. Clima

1.2.3. Suelo 8

1.2.4. Variedades englobadas en la DO___ 8

1.2.5. Envejecimiento de vinos ___ 9

1.2.6. Datos de producción ___ 9

1.3. Uva, la materia prima ___ 9

1.3.1. Bayas o granos de uva __ 9

1.3.1.1. Hollejo — 10

1.3.1.2. Pepitas _ 11

1.3.1.3. Pulpa___ 12

1.3.2. Raspón o escobajo___ 12

1.4. Microbiología del vino___ 13

1.4.1. Microorganismos implicados en la elaboración del vino __ 13

1.4.1.1. Levaduras vínicas __ 13

1.4.1.1.a. Levaduras en la superficie de la uva___ 14

1.4.1.1.b. Levaduras en la bodega ___ 15

1.4.1.2. Bacterias en vinos___ 15

1.4.1.3. Hongos en vinos __ 16

1.4.2. Fermentaciones espontáneas versus Fermentaciones dirigidas _ 117

1.4.2.1. Dinámica de poblaciones en fermentaciones espontáneas ___ 18

1.5. Biología de levaduras _ـ 19

1.5.1. Estructura celular__ 19

1.5.1.1. Pared celular_L 20

1.5.1.2. Mitocondrias __ 20

1.5.1.3. Constitución genética___ 20

1.5.1.3.a. ADN nuclear _ 21

1.5.1.3.b. ADN mitocondrial (ADNmt) ___ 21

1.5.1.3.c. ADN plasmídico ___ 21

1.5.1.3.d. Factor "killer" __ 21

1.5.2. Nutrición y crecimiento ___ 22

1.5.3. Ciclo de vida y reproducción ___ 23

1.5.4. Capacidad fermentativa de Saccharomyces cerevisiae respecto a otras levaduras____ 25

1.5.5. Domesticación de S. cerevisiae ___ 27

1.6. Fermentaciones: presente, pasado y futuro ___ 27

1.6.1. Aislamiento y selección de levaduras para controlar el proceso de fermentación ___ _ _ 27

1.6.2. Opciones de fermentación ___ 29

1.7. Técnicas para la caracterización genética de levaduras vínicas ___ 30

1.7.1. Reacción en cadena de la polimerasa (PCR) ___ 31 
1.7.2. Identificación de levaduras a nivel de especie 31

1.7.2.1. Identificación de levaduras a nivel de especie mediante la secuenciación de los dominios D1-D2 del ADNr 26S

1.7.2.2. Identificación de levaduras a nivel de especie mediante análisis del polimorfismo de restricción de la región 5.8S-ITS (RFLP-5.8S-ITS)

1.7.2.3. Identificación mediante PCR y posterior electroforesis con gradiente temporal de temperatura (PCR-TTGE)

1.7.3. Caracterización de cepas de $S$. cerevisiae

1.7.3.1. Caracterización de cepas de S. cerevisiae mediante análisis del polimorfismo de restricción del ADN mitocondrial (RFLP-ADNmt)

1.7.3.2. Caracterización de cepas de $S$. cerevisiae mediante el empleo de técnicas basadas en el uso de la PCR

1.7.3.2.a. Amplificación al azar de ADN polimórfico (RAPD) ___ 34

1.7.3.2.b. Amplificación de elementos delta.___ 35

1.7.3.2.c. PCR de zonas repetitivas del genoma (microsatélites y minisatélites) ___ 35

1.7.4. Caracterización de híbridos de S. cerevisiae __ 36

1.7.5. Otras técnicas para la caracterización de levaduras___ 37

1.7.5.1. Análisis del polimorfismo cromosómico ___ 37

1.7.5.1.a. Polimorfismo cromosómico en levaduras vínicas ___ 37

1.7.5.2. Análisis de patrones electroforéticos de proteínas___ 38

1.7.5.3. Análisis del polimorfismo de la longitud de los fragmentos amplificados (AFLP)___ 39

\subsection{Perfil aromático y sensorial de los vinos __ 39}

1.8.1. Contribución de las levaduras en el perfil aromático y sensorial de los vinos ___ 39

1.8.1.1. Ácidos__ 41

1.8.1.1.a. Ácidos no volátiles ___ 41

1.8.1.1.b. Ácidos volátiles ___ 42

1.8.1.2. Alcoholes _ 42

1.8.1.2.a. Etanol _ 42

1.8.1.2.b. Glicerol _ـ 42

1.8.1.2.c. Alcoholes superiores___ 43

1.8.1.3. Compuestos carbonílicos ___ 43

1.8.1.4. Fenoles volátiles___ 43

1.8.1.5. Ésteres __ 43

1.8.1.6. Compuestos de azufre __ 44

1.8.2. El aroma en los vinos___ 44

1.8.2.1. Estimación de la aportación de un compuesto al aroma final ___ 44

1.8.2.1. Base aromática de los vinos___ 45

1.8.2.2. Efecto tampón del aroma ___ 46

1.8.2.3. Papeles desempeñados por los diferentes compuestos aromáticos ___ 46

1.8.2.4. Clasificación de las moléculas aromáticas en función del papel desempeñado____ 47

2. OBJETIVOS DEL TRABAJO _ _ 51

3. MATERIALES Y MÉTODOS _ 55

3.1. Microorganismos utilizados _ـ_ 57

3.1.1. Cepas de levaduras comerciales ___ 57

3.1.2. Cepas empleadas en el ensayo "killer" ___ 57

3.2. Medios y condiciones de cultivo __ 59

3.2.1. Medio YPD (YEPD) _ـ 59 
3.2.2. Medio GPY 59

3.2.3. Medio WL Nutrient Agar (Scharlau) __ 59

3.2.4. Medio "killer" (YPD-MB-Agar)___ 60

3.2.4.1. Soluciones madre necesarias __ 60

3.2.4.2. Preparación del medio ___ 60

3.2.5. Medio YNB (Difco)___ 60

3.2.6. Medio YE _ 60

3.3. Instrumental utilizado ___ 61

3.4. Software utilizado

3.5. Proveedores de reactivos químicos y material fungible ___ 63

3.6. Soluciones de uso general___ 64

3.7. Muestras: microvinificaciones espontáneas ___ 65

3.7.1. Bodegas objeto de estudio ___ 65

3.7.2. Muestras de mosto natural de uva Prieto Picudo ___ 65

3.7.3. Procedimiento de microvinificación __ 66

3.8. Aislamiento y conservación de levaduras __ 66

3.8.1. Conservación de muestras (Microvinificaciones) ___ 66

3.8.2. Aislamiento de levaduras ___ 67

3.8.2.1. Aislamiento de levaduras a partir de las microvinifiaciones espontáneas ___ _ _ 67

3.8.2.2. Aislamiento de levaduras a partir de uvas de la variedad Prieto Picudo ___ 67

3.8.3. Conservación de las cepas de levadura ___ 67

3.8.3.1. Conservación en viales de glicerol ___ 67

3.8.3.2. Conservación en fresco ___ 68

3.9. Caracterización genética de levaduras __ 69

3.9.1. Extracción enzimática del ADN total de levaduras ___ 69

3.9.2. Identificación de levaduras a nivel de especie mediante análisis del polimorfismo de restricción de la región 5.8S-ITS (RFLP-5.8S-ITS) ___ 70

3.9.3. Identificación de levaduras a nivel de especie mediante la secuenciación de los dominios D1-

D2 del ADNr 26S

71

3.9.4. Caracterización de cepas de $S$. cerevisiae mediante análisis del polimorfismo de restricción

del ADN mitocondrial (RFLP-ADNmt) ___ 72

3.9.5. Análisis de diferentes regiones genómicas: caracterización de levaduras híbridas____ 72

3.9.6. Análisis de fragmentos de ADN mediante electroforesis en geles de agarosa ___ 73

3.9.6.1. Recuperación de fragmentos de ADN separados por electroforesis ___ 74

3.10. Caracterización fenotípica y enológica de las levaduras _ 75

3.10.1. Fermentación de fuentes de carbono ___ 75

3.10.2. Asimilación de fuentes de carbono___ 76

3.10.3. Capacidad fermentativa (Método Rebelein)___ 76

3.10.4. Tolerancia al etanol ___ 78

3.10.4.1. Fundamento del proceso___ 78

3.10.4.2. Desarrollo experimental____ 79

3.10.5. Crecimiento a bajas temperaturas __ 80

3.10.6. Estudio del caracter "killer" ___ 81

3.10.6.1. Ensayo del carácter "killer" en placa ___ 81

3.10.6.2. Análisis del material genético asociado al carácter "killer" ___ 82 
3.10.7. Microfermentaciones con levaduras seleccionadas ___ 83

3.10.7.1. Determinación del nitrógeno asimilable en mosto ___ 84

3.10.7.2. Esterilización del mosto natural____ 84

3.10.7.3. Preparación de microfermentaciones ___ 84

3.10.7.4. Seguimiento de las microfermentaciones ___ 85

3.10.7.5. Análisis de los vinos producidos___ 85

3.10.7.6. Normalización y ajuste de las curvas de fermentación ___ 85

3.11. Caracterización aromática de los vinos __ 87

3.11.1. Microvinificaciones experimentales __ 87

3.11.2. Análisis descriptivo sensorial____ 87

3.11.3. Análisis mediante GC-O ___ 88

3.11.3.1. Preparación de los extractos del vino ___ 88

3.11.3.2. Método de análisis en GC-O___ 89

3.11.3.3. Panel sensorial en GC-O ___ 89

3.11.4. Análisis químico cuantitativo___ 90

3.11.4.1. Compuestos mayoritarios (Microextracción líquido-líquido y Análisis GC-FID) ___ _ 90

3.11.4.2. Compuestos minoritarios (SPE y análisis mediante GC-Trampa de lones-MS) ___ _ 90

3.11.4.3. Mercaptanos polifuncionales (Alquilación en sorbente y GC-NCI-MS)____ _ _ _ 91

\section{RESULTADOS Y ANÁLISIS}

4.1. Aislamiento y caracterización genética de levaduras vínicas autóctonas de la DO «Tierra de León» 95

4.1.1. Bodega Gordonzello S.A.___ 95

4.1.1.1. Aislamiento de levaduras vínicas___ 95

4.1.1.2. Caracterización genética de las levaduras vínicas ___ 95

4.1.1.2.a. Identificación a nivel de especie mediante RFLP-5.8S-ITS ___ 95

4.1.1.2.b. Caracterización de cepas de S. cerevisiae mediante RFLP-ADNmt ___ 97

4.1.2. Cooperativa de los Oteros___ 100

4.1.2.1. Aislamiento de levaduras vínicas___ 100

4.1.2.1. Caracterización genética de las levaduras vínicas___ 101

4.1.2.1.a. Identificación a nivel de especie mediante RFLP-5.8S-ITS ___ 101

4.1.2.1.b. Caracterización de cepas de S. cerevisiae mediante RFLP-ADNmt 101

4.1.3. Bodegas Pedro Casis _ 105

4.1.3.1. Aislamiento de levaduras vínicas____ 105

4.1.3.2. Caracterización genética de las levaduras vínicas___ 105

4.1.3.2.a. Identificación a nivel de especie mediante RFLP-5.8S-ITS __ 106

4.1.3.2.b. Caracterización de cepas de S. cerevisiae mediante RFLP-ADNmt __ 106

4.1.4. Cooperativa Vinícola Ribera del Cea __ 109

4.1.4.1. Aislamiento de levaduras vínicas___ 109

4.1.4.2. Caracterización genética de las levaduras vínicas___ 109

4.1.4.2.a. Identificación a nivel de especie mediante RFLP-5.8S-ITS ___ 109

4.1.4.2.b. Caracterización de cepas de S. cerevisiae mediante RFLP-ADNmt __ 110

4.1.5. Vinícola Valmadrigal __ 113

4.1.5.1. Aislamiento de levaduras vínicas ___ 113

4.1.5.2. Caracterización genética de las levaduras vínicas ___ 113

4.1.5.2.a. Identificación a nivel de especie mediante RFLP-5.8S-ITS ___ 114

4.1.5.2.b. Caracterización de cepas de S. cerevisiae mediante RFLP-ADNmt _ _ 114

4.1.6. Comparación entre las diferentes bodegas estudiadas ___ 117

4.1.7. Análisis de los perfiles de RFLP-ADNmt mediante componentes principales ___ 119 


\subsection{Caracterización fenotípica y enológica de levaduras vínicas autóctonas de la DO} «Tierra de León»

4.3.1. Fermentación de fuentes de carbono ___ 125

4.3.2. Asimilación de fuentes de carbono ___ 127

4.3.3. Capacidad fermentativa (Método Rebelein) ___ 128

4.3.4. Tolerancia al etanol ___ 130

4.3.5. Crecimiento a bajas temperaturas ___ 132

4.3.6. Estudio del carácter "killer" ___ 133

4.3.6.1. Ensayo en placa del carácter "killer" ___ 134

4.3.6.1. Análisis del material genético asociado al carácter "killer" ___ 136

4.3.7. Microfermentaciones con levaduras seleccionadas___ 138

4.3.8. Análisis conjunto de las cepas de levadura analizadas___ 140

4.3.9. Comportamiento de la levadura aislada en viñedos pertenecientes a la DO «Tierra de León»

4.3.10. Estudio global mediante componentes principales __ 144

4.3.11. Asociaciones entre marcadores RFLP y caracteres fenotípicos ___ 145

\subsection{Caracterización aromática de vinos elaborados con uva Prieto Picudo (DO «Tierra de} León»)

4.4.1. Selección de cepas para la posterior caracterización aromática de vinos elaborados en microfermentaciones

4.4.2. Análisis descriptivo sensorial de los vinos experimentales____ 150

4.4.3. Parámetros enológicos convencionales ___ 151

4.4.4. Estudio mediante cromatografía gaseosa-olfatometría (GC-O) ___ 152

4.4.5. Análisis químico cuantitativo de los componentes del aroma ___ 155

4.4.6. Conclusiones del estudio aromático ___ 157

5. DISCUSIÓN GENERAL ___ 161

5.1. Aislamiento y caracterización genética de levaduras vínicas autóctonas ___ 163

5.2. Caracterización fenotípica y enológica de levaduras vínicas autóctonas___ 166

5.2.1. Comportamiento en entornos con etanol___ 166

5.2.2. Fermentaciones a baja temperatura ___ 167

5.2.3. Estudio del fenotipo "killer" _ـ_ 167

5.2.4. Comportamiento en fermentación ___ 168

5.2.5. Comparación entre las cepas aisladas de un entorno fermentativo y la aislada de un entorno natural ___ 170

5.2.6. Idoneidad de cepas como iniciadoras de fermentación ___ 170

5.3. Caracterización aromática____ 171

5.4. Perspectivas futuras ___ 172

6. CONCLUSIONES __ 175

7. BIBLIOGRAFÍA___ 179 

I. Introducción 



\subsection{Los orígenes de la vid y del vino}

La vid ya existía en el mundo cuando el hombre hizo su aparición. Debido a la evolución, los hábitos respecto a esta planta fueron cambiando. Desde el deleite, como alimento fresco, de los dulces granos de uva al final del verano, pasando por la conservación de las uvas en forma de pasas, hasta llegar, de modo accidental, a una nueva y agradable bebida: el vino, que era capaz de calmarle la sed, reconfortarle y, mágicamente, euforizarle.

La uva es única, no solamente por ser uno de los mayores cultivos hortícolas, sino por su histórica conexión con el desarrollo de la cultura humana. Además, el principal producto obtenido de ésta, el vino, ha jugado un papel muy importante en el modo de vida de la población Mediterránea (Blanco, 1997).

En la familia Vitaceae, el género Vitis es el de mayor importancia agronómica. Este género está compuesto por unas 60 especies inter-fértiles que existen casi exclusivamente en el Hemisferio Norte, entre las que Vitis vinífera es la única empleada de modo global en la industria vinícola.

Existen miles de variedades de $\mathrm{V}$. vinífera aunque el mercado mundial de la producción de vino está dominado por un pequeño número de estas variedades. Estas variedades se clasifican de acuerdo al producto final: uva para vino, uva de mesa y pasas. Por el contrario la forma salvaje, posible antecesora de las variedades actuales (Zohary 1995) no es muy común.

El proceso de domesticación de las uvas parece estar ligado al descubrimiento del vino, aunque no está claro que proceso aconteció en primer lugar (McGovern 2004; Royer 1988). La primera evidencia sobre la producción de vino se encontró en Irán, concretamente en Hajji Firuz Tepe, lugar situado al norte de los montes Zagros, sobre el 7.400-7.000 A.C. (McGovern 2004; McGovern et al. 1996). Desde este lugar posiblemente se fue propagando hacia las regiones adyacentes como Egipto y Mesopotamia (allá por el 5.500-5.000 A.C.), para después extenderse por todo el Mediterráneo, así como por las principales civilizaciones (Asiria, Fenicia, Griega, Romana, Etrusca y Cartaginesa). Fueron los romanos los que posibilitaron la expansión continental de $\mathrm{V}$. vinífera, alcanzando su cultivo varias regiones templadas de Europa, incluso el norte de Alemania. En la edad media, la Iglesia Católica tomó el relevo a los Romanos en el proceso de diseminación del cultivo de la uva, sobre todo debido a las cruzadas. La extensión del Islam en el Norte de África, España y en el Medio Este también fue relevante.

Después del renacimiento (siglo $\mathrm{XVI}$ ), V. vinífera colonizó varias regiones donde no era indígena. Los misioneros la introdujeron en América (primero como semillas y luego por esquejes). Mediante esquejes, también se extendió hasta Sudáfrica, Australia y Nueva Zelanda en el siglo XIX, siendo aún más tardía su introducción en el norte de África (Royer, 1988).

A finales del siglo XIX, tras varios milenios de expansión, la filoxera (hemíptero parasito de la vid procedente de América) provocó la destrucción de la mayoría de los viñedos europeos, produciendo un cambio drástico en la diversidad de las especies. De hecho, la diversidad encontrada a día de hoy en $\mathrm{V}$. vinífera es un pobre reflejo de la existente previamente a la aparición de la filoxera. La solución vino del país originario del problema: el uso de especies no viníferas del género Vitis como porta injertos, desarrollándose híbridos inter-específicos resistentes a la enfermedad. El uso de éstos se extendió hasta mediados del siglo XX (This et al., 2006). 
En los años 50 las diferentes variedades de uva sufrieron una drástica disminución en su diversidad, debido principalmente a la globalización de la industria vinícola y la comercialización de un número reducido de variedades conocidas mundialmente que ha producido inevitablemente la desaparición de variedades locales (Pouget, 1988).

\subsubsection{Especies y variedades de uvas}

\subsubsection{El género Vitis}

La vid se engloba dentro del género Vitis, que junto con otros 15 géneros constituyen la familia Vitaceae. Estos últimos predominan en regiones tropicales y subtropicales y presentan un carácter trepador. Sin embargo, el género Vitis predomina en climas templados y se divide en dos sub-géneros, Euvitis y Muscadinia. Dentro del primero se engloban la mayoría de las especies asociadas al género Vitis, ya que el sub-género Muscadinia solo incluye tres especies. (Ver figura 1.1) (Vivier y Pretorius 2000). Existen diferencias notables entre las especies de ambos subgéneros. Las especies pertenecientes al subgénero Euvitis presentan desprendimiento de la corteza, pequeñas lenticelas, zarcillos ramificados, agrupaciones de flores alargadas y semillas en forma de pera. Por el contrario, las especies del género Muscadinia no presentan desprendimiento de la corteza, tienen grandes lenticelas, zarcillos no ramificados y pequeñas agrupaciones de flores y semillas en forma de bote. Las diferencias fenotípicas observadas también se confirman por las diferencias encontradas en la composición cromosomal. Mientras que Euvitis spp. presenta 38 cromosomas, Muscadinia spp. tiene 40. El cruce entre los dos subgéneros es posible, y la descendencia resultante presenta una pobre fertilidad (debida al impreciso emparejamiento meiótico y separación de los cromosomas). Sin embargo, las especies dentro de cada sub-género hibridan adecuadamente obteniéndose una progenie vigorosa y fértil, siendo esta una estrategia empleada por los productores.

\subsubsection{Las especies Vitis}

Diversos autores consideran que las especies Vitis spp. están evolucionando hacia nuevas especies, por lo que deben ser consideradas más bien como ecoespecies, representando poblaciones de vides que son el resultado de un conjunto de adaptaciones a unas condiciones medioambientales determinadas (Mullins et al., 1992). Se ha demostrado que las diferencias cuantitativas encontradas entre las diferentes especies están ampliamente influenciadas por las condiciones medioambientales, de modo que no pueden ser consideradas como descriptores taxonómicos.

La evolución, origen geográfico y distribución de las especies pertenecientes al género Vitis ha sido ampliamente estudiada. Las diferentes especies se encuentran distribuidas por todo el mundo (Vitis vinifera se encuentra únicamente en Europa), lo que parece indicar que la formación de los continentes como hoy los conocemos puede ser el origen de esta distinción. La separación de los continentes habría provocado la diferente evolución desde ancestros comunes.

La mayoría de los viñedos pertenecen a la especie europea Vitis vinífera. Su domesticación ocurrió allá por el año 5000 A.C. en Europa. Se suele hacer una distinción entre vides silvestres (designadas como subespecies "sylvestris", ver figura 1.1) y las domesticadas (designadas como subespecies "sativa"), aunque se cree que las especies silvestres son formas espontáneas de las vides domesticadas. Sin embargo, tanto las semillas como el polen son distinguibles entre ambas especies lo que asienta la base de interpretación de los fósiles existentes (Jackson, 2008). 


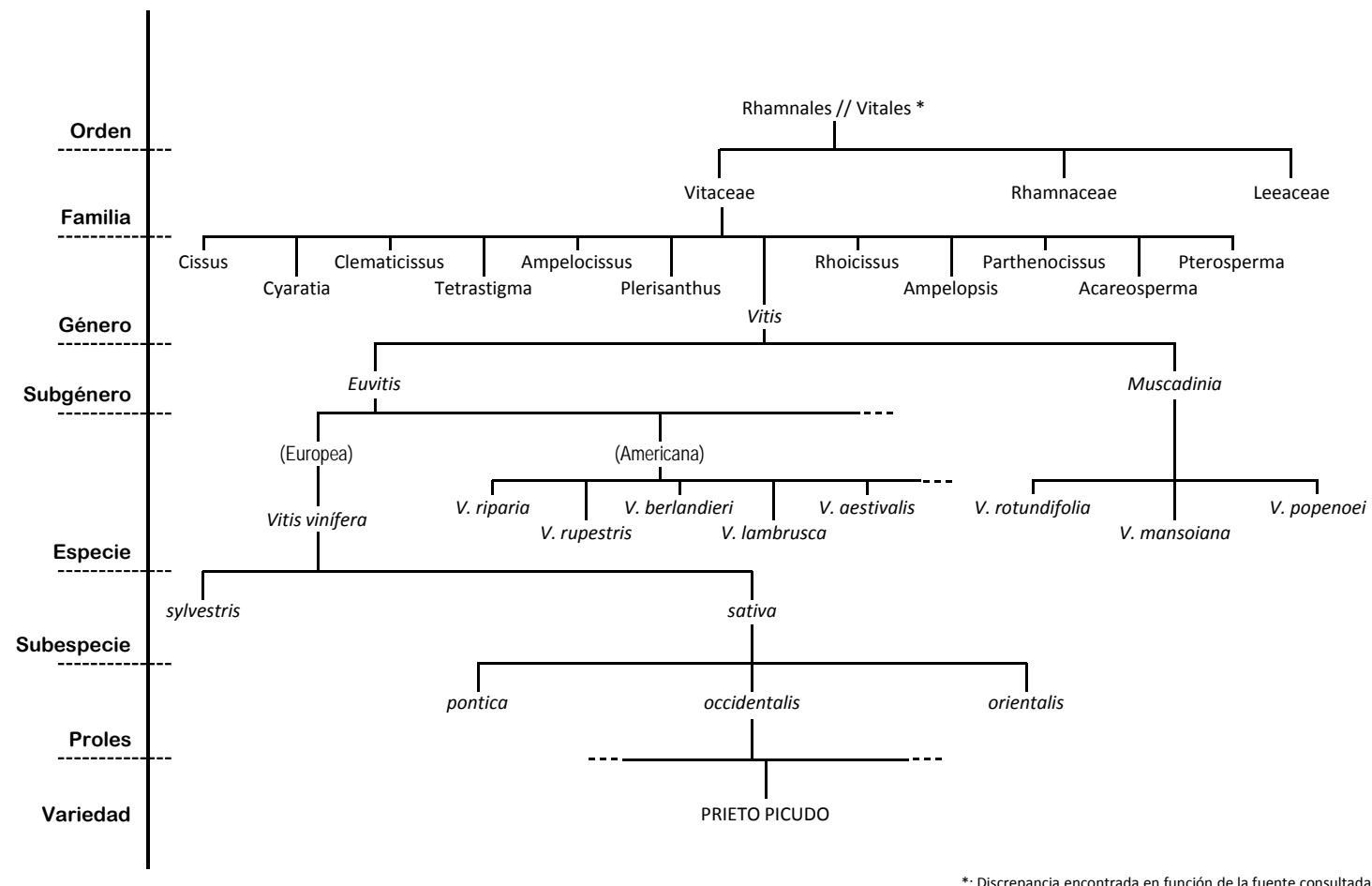

Figura 1.1: Esquema condensado de clasificación de Vitis vinífera. Se muestra la clasificación hasta el nivel de variedad, centrándonos en la que muestra un mayor interés para nosotros, la variedad Prieto Picudo. (Adaptado de Mullins et al., 1992).

A diferencia de otras plantas, el proceso de domesticación ocurre con relativa facilidad en la vid. Esto es debido a varias características como la capacidad para trepar que permiten su cultivo junto con otras plantas con una mínima atención. Debido a sus mínimos requerimientos de minerales y de agua pueden sobrevivir en suelos superficiales y marginales no válidos para otras plantas. Además poseen una gran capacidad de propagación y pueden ser sometidas a procesos de poda, para disminuir su capacidad trepadora y favorecer el monocultivo (Jackson, 2008). El hecho más significativo en el proceso de domesticación fue debido a caracteres reproductivos, ya que las especies salvajes son unisexuales y de éstas se produjo un salto hasta especies con flores autofértiles (Carbonneau 1983; Mullins et al. 1992). Otra característica relacionada con la domesticación es el hecho de que las uvas presentan un bajo índice de semillas mientras que el tamaño de la baya es elevado.

La producción de uva y la elaboración de vino siempre han estado unidas. Además el papel del vino en las actividades religiosas dió un impulso al cultivo de uva y por tanto a la diseminación de la viticultura. Se considera que el origen del vino aconteció en el sur Caucásico comprendiendo regiones del noroeste de Turquía, norte de Irak, Irán, Azerbaiyán y Georgia. También se acepta que $V$. vinífera sufrió un proceso de domesticación en esta región, junto con un proceso de domesticación, de modo independiente, en España (Stevenson 1985; Núñez y Walker 1989). Desde estas áreas se produjo un proceso de diseminación hacia otras regiones. Debido a los movimientos migratorios poblacionales hacia el oeste se produjo el establecimiento de la producción de vino en la región mediterránea, desde donde se produjo su dispersión hacia otras regiones del mundo donde Vitis no era una especie indígena, como Palestina, Alemania, África y Australia. De hecho, a día de hoy, existen 8 millones de hectáreas de viñedo por todo el mundo.

Cuanto más pronto ha sido domesticado un cultivar (y por tanto sometido a un proceso de selección durante un periodo más largo) presenta un mayor número de rasgos relacionados con el proceso de domesticación (bayas de gran tamaño con gran cantidad de zumo y racimos 
con grandes ramas) que los que tienen un origen mucho más reciente. En este hecho se basa la clasificación realizada por Negrul (1938) en proles orientalis, proles pontica y proles occidentalis (ordenadas de mayor a menor origen evolutivo). El grupo orientalis se encuentra principalmente en Asia Central, Afganistán, Irán, Armenia y Azerbaiyán, predominando las uvas de mesa. El grupo pontica se encuentra en Georgia, Asia Menor, Grecia, Bulgaria, Hungría y Rumanía englobándose principalmente uvas para la elaboración de vino y unas pocas uvas de mesa. Los cultivares presentes en Francia, Alemania, España y Portugal son de un origen mucho más reciente y se engloban dentro del grupo occidental is estando formadas principalmente por uvas de vino. Estas denominaciones se redefinieron como "sortotipos"; para agrupar variedades que compartan origen geográfico y varios descriptores morfológicos y agronómicos (Negrul, 1938).

La palabra "cultivar" es una combinación de los términos cultivado y variedad y se debe distinguir de la variedad botánica análoga, que sería una población de plantas que presentan unas características únicas que se dan de modo natural. Es importante resaltar que aunque un cultivar es una única población de plantas, se ha obtenido de modo artificial debido a la mediación humana, pudiendo haberse desarrollado de otro modo (Hartmann et al., 1990). Existen más de 24.000 nombres en uso para cultivares, aunque se piensa que los cultivares de Vitis vinífera verdaderos serían unos 5.000 (Alleweldt, 1988). Dichos cultivares habrían sido originados mediante cruces espontáneos entes especies salvajes y cultivares, procesos de domesticación de especies salvajes o cruces espontáneos de dos cultivares. Sin embargo, los cultivares por cruces controlados se encuentran en baja proporción en el mercado. Esto es debido principalmente a la política conservadora de la industria vinícola. El uso de nuevos cultivares solo es posible en aquellos países donde la producción de vino está menos establecida y regulada (por ejemplo Sudáfrica).

El principal objetivo en cuanto a cruces entre diferentes especies se centra en la posibilidad de eliminar el injerto y de combinar los fenotipos resistentes de los cultivares americanos con los existentes para Vitis vinífera. Debido a su gran éxito y debido a la amenaza que suponen para las especies indígenas esta técnica se ha prohibido en países como Francia, aunque es ampliamente utilizada en otras partes del mundo (Jackson, 2008).

Las especies americanas jugaron un papel muy importante en el control de la epidemia de la filoxera (causada por el insecto Dactylasphaera vitifolia), como ya se ha indicado en el apartado anterior, que devastó la mayoría de los viñedos europeos tanto de uva de mesa como de vino, entre los que se encontraba España. Las especies americanas se habían desarrollado con la filoxera en su hábitat, y por tanto tenían un grado de resistencia mucho más elevado. Es un caso paradójico, ya que tanto el problema como la solución llegaron desde el mismo lugar; se emplearon híbridos entre las diferentes especies con especies americanas obtenidos mediante injerto, de modo que se conseguía resistencia contra la filoxera, nemátodos y otros factores abióticos.

\subsection{Denominación de origen «Tierra de León»}

La Denominación de Origen (DO) “Tierra de León" abarca viñedos localizados mayoritariamente en el sureste de la provincia de León y, en menor medida, en el norte de Valladolid (Castilla y León, España). Las primeras noticias documentales de carácter vitivinícola sobre la región en la que se asienta la DO datan de comienzos del siglo X. Estas indicaban que los viñedos, junto con los molinos para la transformación cerealista, eran las principales fuentes económicas de la zona. 
El sur de la provincia de León, desde la época romana, se convirtió en zona de paso de multitud de viajeros por las dos grandes rutas que discurrían por la actual zona de producción, "La Vía de la Plata" y "El Camino de Santiago". El asentamiento de monasterios al amparo de estas rutas de peregrinación permitió el resurgir de la viticultura en la zona. Según varios documentos de la segunda mitad del siglo $X$, pertenecientes al archivo de la Catedral de León, queda acreditada la adquisición de terrenos para el cultivo de viñas por el monasterio de Santa María y Santiago (Valdevimbre).

Los cultivos típicos de esta región son de la variedad autóctona denominada "Prieto Picudo", presentando una ubicación ancestral en el sur de la provincia de León. Ya las tradicionales "bodegas-cuevas" rupestres, representantes de la arquitectura popular, generaban un microclima ideal, debido a las bajas temperaturas, para la elaboración del tradicional vino de aguja de esta tierra. Sobre este tipo de vino se asienta la cultura vinícola de la zona, aunque actualmente también se producen unos excelentes vinos de crianza bajo esta DO.

En la década de los 80 del pasado siglo, un grupo de cooperativas y bodegas pertenecientes a la zona Valdevimbre - Los Oteros - Cea, dieron los primeros pasos para formar lo que sería una Asociación Profesional de viticultores, elaboradores y embotelladores. Allá por el 2004 se obtuvo la distinción de "Vino de Calidad de Tierra de Léon", culminando el 27 de julio de 2007 el proceso con la concesión de la DO. Con todo esto se persigue la promoción de los vinos, la diferenciación de éstos con respecto a otros $\mathrm{y}$, por supuesto, la mejora continua de su calidad.

\subsubsection{Zona de producción (Situación geográfica)}

La zona de producción se encuentra virtualmente delimitada entre las riberas del rio Esla y del Cea. Concretamente en el sur de la provincia de León junto con una pequeña parte de la provincia de Valladolid, limitando ésta con las provincias de Zamora y Palencia. La superficie de producción asciende a $3.317 \mathrm{~km}^{2}$. Esta superficie estaría compuesta por los terrenos ubicados en los términos municipales de los municipios, que tras superar un estudio se han considerado adecuados para la producción de uva. Se trata de un total de 88 municipios, de los cuales la mayoría, 69, se encuentran en la provincia de León, mientras que el resto se encuentran en la provincia vallisoletana.

La Denominación de Origen cuenta a día de hoy con 33 bodegas, estando situadas 32 en la provincia de León y solamente una en la provincia de Valladolid. Al amparo de la denominación se encuentran inscritos 379 viticultores, que en conjunto cultivan una extensión de viñedo de más de 1.300 hectáreas (datos aportado por el Consejo Regulador de la DO “Tierra de Léon”. Ver www.dotierradeleon.es).

\subsubsection{Clima}

Como se ha indicado, el ámbito geográfico en el que se asienta la DO se encuentra influenciado por dos riberas, la del río Esla y la del Cea. Por la localización, deberíamos de encontrarnos con un clima mediterráneo, en su variante fría. Sin embargo la elevada altitud de la meseta, así como la proximidad de la cordillera cantábrica, modifican las características climáticas dando un carácter de fuerte continentalidad. No existen condiciones de temperatura extrema ni en el periodo estival ni en el invernal. Las heladas no superan los -15 ${ }^{\circ} \mathrm{C}$ (temperatura límite invernal para la vid), mientras que en los periodos cálidos la temperatura es superior, de media, a los $20{ }^{\circ} \mathrm{C}$ (necesaria para la floración y envero de la vid). El periodo otoñal es suave y lluvioso favoreciendo un buen final de maduración. Pero sin duda la característica más importante en lo referente al clima reside en la diferencia extrema 
de temperatura entre el día y la noche. Dicha particularidad favorece la acumulación de polifenoles y por tanto la potenciación de los aromas. Las precipitaciones permiten su cultivo sin riegos, salvo años aislados. Además la cantidad de sol que reciben las bayas es suficiente para producir una maduración uniforme del fruto.

\subsubsection{Suelo}

Los suelos sobre los que se asientan los cultivos se encuentran a una cota por debajo de los 900 metros, sobre terrazas aluviales. En general en esta zona encontramos dos tipos de suelos: los pardos sobre depósitos pedregosos, y los calizos sobre materiales blandos. Estos terrenos son los más adecuados para la producción de viñedo de alta calidad, prueba de ello es que las grandes denominaciones de Castilla y León se asientan en estos mismos suelos.

Las principales características de estos terrenos serían: excelente drenaje interno, aceptable capacidad de retención hídrica, facilidad de aireación y penetrabilidad de raíces, un bajo contenido de sales minerales, caliza en proporciones adecuadas y pobreza en lo que a materia orgánica se refiere.

\subsubsection{Variedades englobadas en la DO}

Las variedades autorizadas bajo esta DO son varias aparte de la ya mencionada Prieto Picudo. Esta última representa el 50 \% de la producción, siendo una variedad tinta, de racimo pequeño y compacto, resistente a la sequía y con una fertilidad media-alta. Mediante la técnica de "madreo", consistente en añadir racimos enteros en la cuba de fermentación, se consigue el afamado vino de aguja, aunque también es adecuada para la producción de vinos jóvenes y envejecidos en roble. Los vinos producidos bajo esta denominación de origen son muy aromáticos, persistentes en boca y se caracterizan por una acidez natural del orden de 7 $\mathrm{g} / \mathrm{L}$ de ácido tartárico.

Además de la variedad principal Prieto Picudo se permiten otras variedades complementarias en la elaboración de los vinos. Entre las variedades tintas destaca la Mencía (17 \% de la superficie cultivada), Tempranillo (12\%) y Garnacha Tinta (2\%). En cuanto a variedades blancas destaca la Verdejo, con un $15 \%$ de la superficie de cultivo, dando como resultado vinos con un característico color amarillo verdoso, adecuada graduación y acidez junto con un notable contenido en glicerol. El Albarín Blanco, con un $5 \%$, da lugar a vinos con aromas cítricos y florales. La variedad Godello produce unos caldos blancos con una acidez media y unos aromas muy frescos. Aparte de las anteriores variedades blancas, existen variedades complementarias para la elaboración de estos caldos, concretamente la variedad Malvasia y Palomino (abarcando un $1 \%$ y $2 \%$ de las superficies cultivadas respectivamente).

La DO elabora tres tipos de vinos. Los criterios respecto a las proporciones de las diferentes variedades para cada tipo de vino serían:

a) Blanco: Elaborado con un mínimo de $50 \%$ de variedades blancas principales (Albarín y Godello), pudiendo ser el resto de las variedades blancas complementarias.

b) Rosado: Elaborados con un mínimo del $60 \%$ de variedades tintas Prieto Picudo y/o mencía. El resto puede ser aportado por las variedades complementarias tintas y/o blancas. La graduación alcohólica mínima será de $11^{\circ}$ (\% vol.)

c) Tinto: Elaborados a partir de un mínimo del $60 \%$ de variedades tintas Prieto Picudo y/o Mecía, mientras el $40 \%$ restante se puede repartir entre el resto de variedades tintas complementarias. 
No obstante conviene destacar que se producen muchos vinos mono-varietales, en cuya elaboración se emplea exclusivamente uva Prieto Picudo.

\subsubsection{Envejecimiento de vinos}

Aparte de los tradicionales vinos de aguja, actualmente se producen vinos envejecidos en barrica de roble. En función del periodo de envejecimiento obtendrán diferente distinción. Así, un vino de "Crianza" será aquel que se someta a un periodo mínimo de envejecimiento de 24 meses, de los cuales seis habrán sido en barricas de madera de roble con capacidad máxima de 330 litros. Las añadas que lo permitan, si el producto final presenta unas características organolépticas adecuadas, pueden ser sometidas a un proceso de envejecimiento superior. Para obtener la distinción de "Reserva" el periodo de envejecimiento asciende hasta los 36 meses, 12 de los cuales deben tener lugar en barrica. Un "Gran Reserva" requiere un periodo mínimo de 60 meses, 18 de los cuales en barrica. En los tres casos mencionados, el periodo no completado en barrica será complementado en botella.

\subsubsection{Datos de producción}

La producción de esta DO está en continuo aumento, en gran medida debido a su juventud, siendo la más nobel en el territorio Nacional. La producción de uva en la cosecha de 2.010 fue de 3.826.050 kilogramos, con un incremento del $45 \%$ en relación al año 2.010. Las botellas puestas en el mercado en la citada cosecha fueron de 1.868 .597 , lo que supone un incremento del 88,8 \% en solo diez años (Datos de la DO, www.dotierradeleon.es). Sin embargo es importante destacar que la producción de esta uva con respecto a la producción total de Castilla y León supone únicamente un 1,87 \% (Servicio de Estadística de la Consejería de Agricultura y Ganadería de la Junta de Castilla y León).

\subsection{Uva, la materia prima}

El fruto de la vid es en realidad un conjunto de frutos en forma de racimo, agrupados por un órgano herbáceo o leñoso conocido como raspón o escobajo que soporta un alto número de bayas o frutos carnosos de pequeño tamaño. En su origen, los racimos lo fueron de flores y tras su desarrollo o fecundación cada flor se transforma, a lo largo de un periodo de maduración, en el correspondiente fruto o grano de uva. Estos racimos son la materia prima que llega a las bodegas. Tras varios procesos se obtiene el mosto natural de uva, y a partir de éste, por un proceso de fermentación, se obtienen los vinos.

Vamos a ver de modo separado los principales componentes en un racimo de uva: el raspón y los granos de uva (Togores, 2003).

\subsubsection{Bayas o granos de uva}

Las característica de las bayas están principalmente influenciadas por la variedad de uva y en menor medida por las condiciones de cultivo del viñedo. Atendiendo a su forma podremos clasificar los granos en función de la morfología (aplastados, esféricos, elípticos, etc.). La variedad Prieto Picudo se definiría como elíptica corta.

El tamaño de las bayas es otro parámetro determinante. Las de gran tamaño presentan una reducida relación superficie del hollejo/volumen de pulpa, estando en clara desventaja con las de menor tamaño, donde la relación es más alta, ya que estas últimas producen vinos 


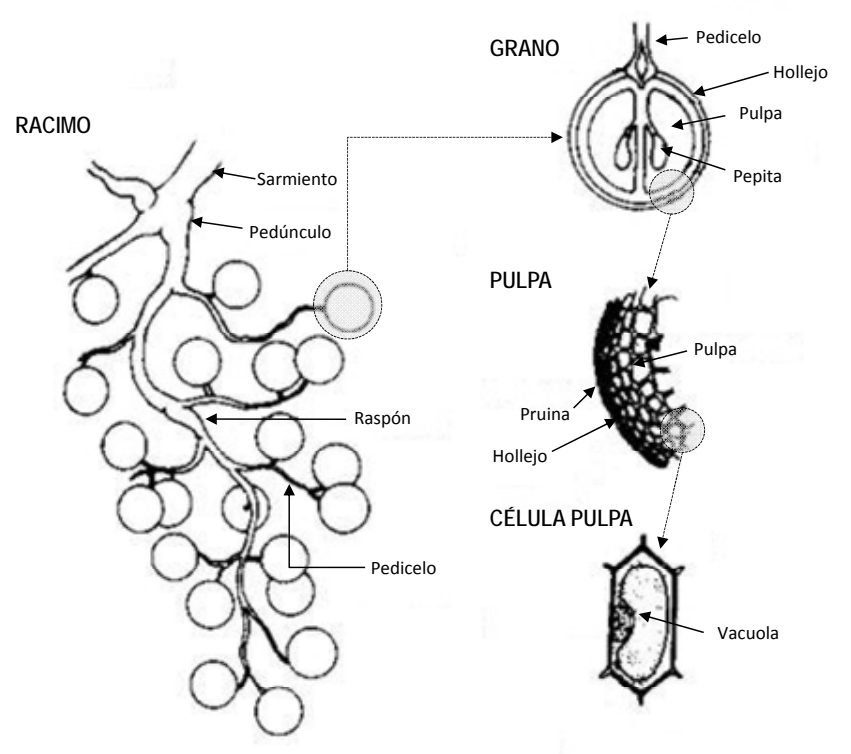

Figura 1.2: Estructura del racimo y de la uva. Se observan las partes más importantes de estas.

de mayor calidad y tipicidad. Se cree que es debido a la mayor facilidad de paso de compuestos de interés desde el hollejo al mosto.

Si atendemos a la coloración las bayas se clasifican en blancas, rosadas, tintas y tintoreras. En las tres primeras los pigmentos varietales se encuentran exclusivamente en el hollejo, mientras que en la última también se encuentran pigmentos en la pulpa. Por tanto, una pulpa coloreada sería indicativa de una variedad tintorera. La uva Prieto Picudo sería tintorera con una coloración negra-azulada.

En cuanto a su estructura, los granos están formados por una película exterior denominada hollejo. La masa que rellena éstos sería la pulpa y en el centro de los granos de uva nos encontramos con un número variable de semillas o pepitas.

\subsubsection{Hollejo}

Es la parte exterior del grano de uva. La misión fundamental es encerrar los tejidos vegetales de reserva que acumula el fruto, proteger la semilla como elemento perpetuador de la especie y defender estas estructuras de las agresiones externas. Está formada por tan solo 6-10 capas de células. En relación al grano de uva representa del 8-20\% del peso total.

La parte exterior del hollejo está recubierta por una capa cerosa denominada pruina, confiriendo a éste un aspecto mate o pulverulento. Su misión, debida a su hidrofobicidad, se centra en proteger a la uva de las inclemencias del tiempo y evitar la evaporación del agua que contiene la pulpa. Otra de las misiones, muy importante desde el punto de vista biológico, es la capacidad de retener microorganismos, principalmente levaduras autóctonas de los viñedos.

La pruina está compuesta en dos terceras partes de ácido oleánico, además de otros compuestos como alcoholes, ésteres, aldehídos, ácidos grasos, parafinas, etc. El ácido oleánico es un factor de crecimiento para las levaduras, favoreciendo el depósito de las levaduras sobre la pruina. Además también interviene en la cinética del desarrollo de las levaduras en la fase pre-fermentativa y fermentativa de la fermentación alcohólica. Este efecto es aprovechado en los procesos de maceración pelicular (principalmente vinos blancos) y en las maceraciones de tinto (Togores, 2003). 
El hollejo es muy rico en polifenoles, dependiendo de la variedad de uva y del grado de maduración, conteniendo del 12 al $61 \%$ del total de la uva. En los vinos tintos destacan los antocianos y los taninos, siendo estos responsables de parte de la coloración. Los antocianos (del griego "anthos", flor, y "kyanos", azul) se encuentran en las vacuolas o en estructuras especializadas (antocianoplastos) de las células del hollejo. Los taninos (3-flavonoles) se encuentran en las vacuolas o asociados a las paredes celulares. Debido a la capacidad fungicida de los taninos, se piensa que su distribución, tanto en el hollejo como en la semilla, atiende a una estrategia de defensa contra enfermedades. Entre los compuestos con capacidad fungicida (conocidas como "fitoalexinas") destaca el resveratrol (trans-3,4',5trihidroxiestilbeno). Es el principio activo de varios "preparados parafarmacéuticos" que se encuentran en el mercado, desde no hace mucho tiempo, a los cuales se les atribuye propiedades anti-envejecimiento, si bien no se ha podido demostrar sobre humanos.

Otros compuestos de gran importancia en el hollejo son los aromas varietales. Estos son principalmente compuestos terpénicos, norisoprenoides, metoxipirazinas, etc. Estos se sitúan principalmente en la hipodermis del hollejo, es decir, en la capa más interna del hollejo muy próxima a la pulpa. Por tanto un cierto contacto entre el mosto y sus hollejos (maceración pelicular) puede favorecer el enriquecimiento aromático de los vinos (más adelante se describirán los mecanismos de liberación de estos compuestos).

En la enología moderna, el hollejo está considerado como la fracción de la uva que contiene los elementos que realmente caracterizan a un vino, a pesar de encontrarse en pequeñas cantidades. Estos reciben el nombre de "compuestos de bondad", mientras que los compuestos de la pulpa (mayoritarios) se denominan "compuestos de cantidad". Por tanto, la superficie de contacto hollejo-mosto es uno de los parámetros determinantes en la elaboración de vinos. En esto último es determinante el tamaño de la uva: cuanto más pequeño es el grano mayor es la relación superficie del hollejo/volumen de pulpa y la maceración será más eficiente. De hecho, existen técnicas de cultivo orientadas a la obtención de uvas de menor tamaño para potenciar dicho efecto (Togores, 2003).

\subsubsection{Pepitas}

Son los elementos encargados de perpetuar la especie por vía sexual. El número varía desde una a cuatro por baya y suele ser inversamente proporcional al tamaño de la uva y al grado de maduración.

Las semillas de uva tienen dos componentes de interés. Uno de ellos es el aceite, compuesto principalmente por ácido oleico y linoleico que tiene excelentes propiedades dietéticas para el ser humano por su bajo contendido en colesterol y por la alta relación entre ácidos grasos insaturados y saturados (9:1). Otros componentes de interés serían los taninos, ascendiendo hasta un $22-56 \%$ de los polifenoles totales del grano de uva. Destacan los leucoantocianos o procianidinas, catequinas, ácido gálico y cafeico entre otros.

En el proceso de maduración de la uva, el contenido de taninos en las pepitas disminuye por la migración de éstos hacia el hollejo. En las semillas se encuentran poco polimerizados resultando ácidos y astringentes. Su contribución es muy importante en la elaboración de los vinos tintos de guarda. En éstos los taninos polimerizan con los antocianos, suavizándose y contribuyendo a la estabilización del color.

En el proceso de elaboración de vinos se debe de poner especial cuidado en la integridad de las semillas. Su rotura podría provocar una sensación de dureza y verdor, además de liberar las sustancias grasas (no deseadas) anteriormente citadas. 


\subsubsection{Pulpa}

Es la parte más voluminosa del grano de uva, representando un $75-85 \%$ de su peso. Las células vegetales que forman la pulpa, están ocupadas en casi todo su volumen por vacuolas, dentro de las cuales se encontraría el mosto. El agua es el componente mayoritario en la pulpa, representando más de un $80 \%$, cuya principal misión es actuar como solvente del resto de componentes ("componentes de cantidad" citados anteriormente). Puede alcanzar una densidad entre 1,065 y $1,100 \mathrm{~g} / \mathrm{mL}$, debido a los azúcares (principalmente glucosa y fructosa) presentes en el mosto, cuyas concentraciones varían entre 150 y $250 \mathrm{~g} / \mathrm{L}$.

Los ácidos orgánicos, junto con los azúcares anteriormente mencionados, son los compuestos más importantes que contiene la pulpa. Destacan el tartárico, el málico y, en menor medida, el cítrico.

Los compuestos nitrogenados representan en la pulpa el 20-25 \% del nitrógeno total del grano de uva. La forma mineral (amoniacal) es la más fácilmente asimilable por las levaduras. El mosto normalmente contiene cantidades suficientes para desarrollas la fermentación alcohólica sin problemas. El nitrógeno asimilable es importante para evitar paradas de fermentación. Si no se alcanzan unas concentraciones adecuadas de nitrógeno asimilable en fermentación (unos $200 \mathrm{mg} / \mathrm{L}$ ), el mosto debe ser suplementado, debido a que el nitrógeno es un factor limitante. Además debe existir una proporción adecuada entre las fuentes de carbono (principalmente azúcares) y las fuentes nitrogenadas (Bell y Henschke 2005).

En cuanto a los polifenoles, estos son fundamentalmente del tipo no flavonoides, destacando los ácidos cinámicos. También nos podemos encontrar con ácidos bezoicos como el ácido gálico. Los polifenoles flavonoides que puedan aparecen en la pulpa provendrán de trazas de los presentes en los hollejos, salvo en las variedades tintoreras que serán responsables de la coloración de la pulpa.

\subsubsection{Raspón o escobajo}

Es el elemento que sirve de soporte a las bayas, además de vía de alimentación de éstas a través de los vasos conductores situados en su interior. En peso representa del orden de un 3-7 \% del peso total del racimo. En la figura 1.2 se puede ver su estructura. La forma del escobajo determina la forma del racimo, principalmente influenciado por la variedad de vid, y en menor medida por factores ambientales o de cultivo.

Si los elementos del raspón son largos, caso de las uvas de mesa, los racimos tienen un aspecto suelto. Si por el contrario los elementos del raspón son cortos, uvas de vinificación, los racimos se vuelven compactos hasta el punto de producirse deformación poligonal en las uvas debido al contacto.

En cuanto a su composición, destaca la gran proporción en polifenoles que presenta. Esto podría ser interesante en los proceso de obtención de vinos tintos con bajos contenidos de estos compuestos en la uva. Sin embargo, los efectos colaterales son mayores a los beneficios obtenidos: aumento de $\mathrm{pH}$, pérdida de alcohol, aromas y sabores herbáceos (alcoholes de seis átomos de carbono) y cierta aspereza. Por tanto se aconseja el despalillado de la vendimia en el proceso de elaboración del vino.

Como se ha indicado, con la variedad Prieto Picudo se emplea una técnica de vinificación denominada "madreo" para obtener los denominados "vinos de aguja". Esta segunda fermentación (lenta) se consigue añadiendo uvas y racimos enteros en la cuba de fermentación. Con esto se consigue que el $\mathrm{CO}_{2}$ disuelto de un cierto carácter a los vinos, sin llegar a ser un vino espumoso. En estos casos es posible una aportación de compuestos 
fenólicos debido al raspón de los racimos, aunque la adición tardía de estos minimiza los posibles efectos colaterales.

\subsection{Microbiología del vino}

Una vez conocida la materia prima para la elaboración de los vinos, analizaremos los microorganismos responsables de este complejo proceso bioquímico. Como se verá, en el proceso entran en juego diferentes especies microbianas con distinto protagonismo, pudiendo tener un impacto positivo, o todo lo contrario, en el producto final.

\subsubsection{Microorganismos implicados en la elaboración del vino}

El simple proceso bioquímico, propuesto por Louis Pasteur, de conversión de mosto de uva en vino llevado a cabo por las levaduras (conversión de azúcares en etanol, dióxido de carbono y otros metabolitos) hoy en día es considerado un proceso mucho más complejo y sofisticado.

La microbiota final encontrada en el mosto de uva se ve afectada, de modo indirecto, tanto por los factores determinantes para los microorganismos "indígenas" del viñedo, como para los propios de la bodega. Además de los anteriores influyen otros muchos factores como son: método de vendimia (manual o mecánico), transporte de las uvas hacia la bodega (tiempo, temperatura uvas), pretratamiento del mosto (higiene del material empleado, aireación, tratamiento enzimático, sulfitado, clarificación, temperatura, inóculo con iniciadores de fermentación, etc.).

Aunque el contenido nutritivo de los mostos es elevado, este sólo puede soportar el crecimiento de un limitado número de microorganismos. El bajo valor de $\mathrm{pH}$ junto con el elevado contenido en azúcares ejercen una elevada selección sobre los microorganismos. Por tanto sólo pueden proliferar un pequeño número de especies de levaduras y bacterias. Si a lo anterior añadimos el efecto del dióxido de sulfuro, como agente antioxidante y antimicrobiano, hace que se estreche más el cerco, disminuyendo la población de microorganismos oxidantes. A medida que avanza el proceso fermentativo el entorno se vuelve más selectivo debido al establecimiento de la anaerobiosis, así como el aumento paulatino del etanol en el medio. Este último impide el desarrollo de las especies alcoholsensibles.

La fermentación es un complejo proceso tanto ecológico como bióquímico en el que entran en juego, de manera secuencial, varios microorganismos: hongos, levaduras, bacterias lácticas, bacterias acéticas, así como los microvirus y los bacteriófagos, que interfieren en la relación uva-microorganismo. De ellos las levaduras son el pilar fundamental sobre el que se asienta el proceso bioquímico de la vinificación.

Algo que se debe de tener en cuenta es, no solo la actuación individual de las diferentes especies indicadas, sino las interacciones entre ellas: interacciones levadura-levadura, levadura-hongo filamentoso y levadura-bacteria (Fleet 2003).

\subsubsection{Levaduras vínicas}

Según la cuarta y última edición, del monográfico "The Yeasts, A Taxonomic Study" de los 100 géneros de levaduras, representados por unas 700 especies, tan solo 15 géneros están relacionados con los proceso de vinificación: Brettanomyces (y su foma sexual "perfecta" Dekkera), Candida, Cryptococcus, Debaryomyces, Hanseniaspora (su homólogo Kloeckera), 
Kluyveromyces, Metschnikowia, Pichia, Rhodotorula, Saccharomyces, Saccharomycodes, Schizosaccharomyces y Zygosaccharomyces (Kurtman y Fell 1998).

En cuanto a los principales hábitats de las levaduras, viñedo y bodega, se debe hacer distinción entre levaduras "autóctonas" (esenciales) y "alóctonas" (transitorias o fortuitas) de las diferentes comunidades en los dos ecosistemas citados. La coexistencia de ambos tipos dependerá en gran medida del entorno. Atendiendo a su grado de especialización, las levaduras se pueden clasificar en "generalistas" cuando están presentes en varios hábitats y "especializadas", que son exclusivas de un único hábitat.

Sin embargo, en un proceso fermentativo, las presiones selectivas sobre las diferentes levaduras favorecen a las que presentan el sistema catabólico fermentativo más eficiente, principalmente especies de S. cerevisiae. Por ello, esta especie suele ser la que lleva a cabo la mayor parte del proceso fermentativo, por lo que se la denomina como la "levadura del vino".

\subsubsection{1.a. Levaduras en la superficie de la uva}

La microbiota que podemos encontrarnos en las uvas depende de varios factores: variedad, condiciones climatológicas, terreno, métodos de cultivo (por ejemplo la poda), grado desarrollo de la uva, daños que presente la uva, fungicidas empleados, etc. La concentración de levaduras en la superficie de la uva se estima en torno a $3 \cdot 10^{5}$ levaduras $/ \mathrm{cm}^{2}$ de superficie uva (Rosini et al., 1982). Otros autores hablan de $10^{4}-10^{6}$ células $/ \mathrm{cm}^{2}$ (Fleet et al. 2002).

Los tres principales géneros encontrados en la superficie de la uva son: Hanseniaspora uvarum (junto con su anamorfo Kloeckera apiculata), Metschnikowia pulcherrima (junto con su anamorfo Candida pulcherrima) y Candida stellata (Bisson y Lucy Joseph 2009). Algunos autores indican que Hanseniaspora es el género dominante (Beltran et al. 2002; Combina et al. 2005; Hierro et al. 2006), hasta el punto de suponer el 50-75 \% de la población total existente (Fleet 1993, 1998). Sin embargo, otros autores indican que el género predominante sería Candida (Clemente-Jimenez et al. 2004; Torija et al. 2001). Se ha demostrado que especies de esta última son capaces de completar el proceso de fermentación en algunos casos (Clemente-Jimenez et al., 2004), concretamente en estudios realizados en climas fríos (Yanagida et al., 1992). En zonas frías también se ha descrito el dominio de los basidiomicetos Cryptococus y Rhodotorula sobre las levaduras tipo ascomiceto nombradas anteriormente. En otros casos, el hongo dimórfico Aureobasidium resultó ser dominante junto con Cryptococcus, seguido de Rhodotorula y Rhodosporidium (Prakitchaiwattana et al. 2004).

El estado sanitario de la uva es un factor determinante de cara a la población de levaduras que nos podemos encontrar en la superficie de la baya. La pérdida de azúcares, ya sea por daños físicos mediados por insectos, pájaros, hongos invasivos, o debido al envejecimiento y desidratación de la uva, favorece el enriquecimiento en ascomicetos (Fleet et al. 2002; Prakitchaiwattana et al. 2004). Saccharomyces se puede detectar en la superficie de la uva, aunque a unos niveles muy bajos (Prakitchaiwattana et al. 2004; Martini et al. 1996) e incluso indetectables. El aislamiento de ésta es mucho más común en uvas que presenten serios daños (Mortimer y Polsinelli 1999; Bisson y Lucy Joseph 2009).

El proceso de maduración de las bayas hace que la población de levaduras sea cambiante en función del momento de desarrollo en que nos encontremos. Así en la maduración temprana predominan las levaduras tipo basidiomiceto (Aureobasidium, Cryptococcus, Rhodosporidium), dando paso a las levaduras tipo ascomiceto (Hanseniaspora, Metschikowia y Candida) según avanza la maduración. 
Aparte de los factores indicados, otros influyen en gran medida en la población encontrada en la superficie de las uvas. Los años calurosos y secos aumenta en gran medida la población de levaduras (Rementeria et al., 2003). La infección por hongos puede provocar variaciones poblacionales, como en el caso del género Botrytis cuyo desarrollo provoca un incremento en tres órdenes de magnitud en la población superficial de levaduras (Nisiotou y Nychas 2007).

Los insectos también tienen un papel importante, comportándose como vectores en los viñedos: los microorganismos se adhieren a su superficie y se depositan en la superficie de los frutos a la par que los insectos viajan por el viñedo (Bisson y Lucy Joseph 2009).

\subsubsection{1.b. Levaduras en la bodega}

Si comparamos la baja proporción de S. cerevisiae en los viñedos frente a la elevada concentración presente en el mosto o en las superficies del equipamiento de las bodegas en contacto con el mosto, podemos hablar de una población de levaduras "residencial" en éstas. De hecho S. cerevisiae es, de lejos, la especie predominante en las superficies de las bodegas. Aparte podemos encontrarnos con otras especies, como Candida, Cryptococcus o Brettanomyces, dependiendo del tipo de superficie, y del grado de limpieza (Pretorius 2000).

Existen muy pocos estudios acerca de la microbiota residencial de las bodegas. En ellos se ha demostrado que la microbiota existente es una fuente de inóculo para el proceso fermentativo (Fleet y Heard 1993; Renouf et al. 2007). Debido a la controversia acerca del origen de las especies de Saccharomyces que llevan a cabo las fermentaciones espontáneas o no-inoculadas se realizaron varios estudios para añadir luz sobre el tema. En el primero se realizaron fermentaciones con uvas recogidas directamente del viñedo y se procesaron sin que fuera posible una contaminación por parte de la flora de la bodega (Valero et al., 2007). Se demostró que un $68 \%$ de los experimentos fueron capaces de iniciar el proceso de fermentación. Sin embargo sólo el 42 \% fue capaz de completar el proceso de fermentación, y sólo en el 28 \% prevalecía Saccharomyces. En otro estudio (Clemente-Jimenez et al., 2004) se demuestra que predomina Candida stellata, mientras que Saccharomyces apenas aparece. Con esto queda demostrado que existen especies de Saccharomyces en los viñedos (son capaces de dirigir una fermentación), pero pone de manifiesto que en la mayoría de los casos la levadura encargada de dirigir las fermentaciones espontáneas deriva de la microbiota residencial de las bodega. La predominancia de la microbiota de la bodega responde a una mayor población comparada con la población indígena que pudiera provenir del viñedo.

Por tanto la levadura predominante en bodega será S. cerevisiae. Su capacidad de producir etanol en grandes proporciones será el factor que controlará el crecimiento de otras especies coexistentes no-Saccharomyces durante la fermentación. Algunas levaduras tienen un soporte alcohólico más elevado, como Candida stellata, que las ha llevado a ser utilizadas como co-iniciadoras de fermentación con S. cerevisiae por su alto poder de producción de glicerol, así como por aportar ciertas características sensoriales a los vinos (Ciani y Ferraro 1998; Soden et al. 2000).

\subsubsection{Bacterias en vinos}

La cantidad de bacterias que pueden influenciar el producto final dependerá del estado sanitario de las uvas. En unas uvas dañadas aumentaría la proporción de bacterias lácticas y acéticas, perjudicando incluso a las levaduras en el proceso fermentativo. Si el inicio de fermentación es vigoroso, la población de bacterias puede reducirse considerablemente. Pero si en los primeros estadillos se produce un crecimiento lento de las levaduras, el desarrollo bacteriano puede provocar una fermentación prolongada, e incluso una parada de fermentación (Fleet 2003). 
Las bacterias más importantes que nos podemos encontrar en los vinos son las bacterias lácticas y las bacterias acéticas. El pH y la tolerancia al etanol de las especies jugarán un papel importante en su incidencia en los ecosistemas de la bodega (Fleet 1993). También es posible encontrarnos en algunos casos con bacilos (Bacillus subtilis, B. coagulans) y otras especies (Actinomyces, Streptomyces y Clostridium).

Las bacterias lácticas son las responsables de la fermentación maloláctica, proceso deseado en los vinos tintos. Las más representativas son los géneros Oenococcus, Pedioccoccus y Lactobacillus (Lonvaud-Funel et al. 1988). Además existen bacteriófagos capaces de infectar estas bacterias lácticas provocando una parada del proceso. La fermentación maloláctica es una importante fermentación secundaria, que suele llevarse a cabo a las dos-tres semanas de la finalización de la fermentación alcohólica (Lonvaud-Funel et al., 1988). La bacteria responsable de este proceso suele ser 0 . oeni (residente en bodega o inoculada), responsable de la transformación del ácido L-málico en ácido L-láctico. La fermentación maloláctica permite potenciar el sabor y complejidad del vino, además de aportar una mayor estabilidad microbiológica ya que se eliminan los nutrientes residuales (Fleet 2001).

Las bacterias acéticas se clasifican en dos géneros, Acetobacter y Gluconobacter. En los vinos encontramos especies como: A. aceti, A. pasterianus, G. oxydans (Drysdale y Fleet 1988), A. liquefaciens y A. hansenii (Du Toit y Pretorius 2000). Son capaces de oxidar el etanol hasta ácido acético produciendo, por tanto, un deterioro del vino si la concentración final de éste es elevada. Valores de ácido acético en torno a $600 \mathrm{mg} / \mathrm{L}$ (Romano, 1990) se consideran aceptables. Otros autores indican sin embargo que la concentración óptima varía entre 700 - 1000 mg/L en función del tipo de vino (Corison et al. 1979; Scanes et al. 1998). Si atendemos a percepción sensorial, Campo et al. (2005), han observado que valores de ácido acético por encima de $450 \mathrm{mg} / \mathrm{L}$ disminuyen la apreciación de notas frutales en los vinos.

\subsubsection{Hongos en vinos}

Las condiciones de anaerobiosis de la fermentación, la presencia de anhídrido sulfuroso (proceso de sulfitado) y las altas concentraciones de etanol, provocan una escasa presencia de hongos en los vinos (Pardo et al. 1989; Querol et al. 1990). Su origen puede estar en el corcho empleado en el embotellado, así como en las barricas usadas para el envejecimiento de los vinos. Algunos de estos hongos son Penicillium, Trichoderma, Cladosporium o Monilia. De entre los hongos que nos podemos encontrar en los mostos y en los vinos, destacar Botrytis cinérea, que provoca la "podredumbre gris" en las uvas (Bayonove, 1989).

Por el contrario, los hongos desarrollados sobre las uvas puede producir varios metabolitos con capacidad de interferir en la ecología y desarrollo de las levaduras durante la fermentación (Fleet, 2003). Existen estudios que indican que Botrytis cinerea, Aspergillus spp. y Penicillium spp. producen metabolitos capaces de retardar el crecimiento de las levaduras en la fermentación (Ribereau-Gayon 1985; Reed y Nagodawithana 1988; Doneche 1993). Así, se ha descrito que el factor anti-levadura liberado por $B$. cinérea tiene naturaleza proteica (Ribereau-Gayon, 1985).

Otros muchos hongos pertenecientes a los géneros Penicillium, Aspergillus, Mucor, Rhizopus, Clodosporium, Alternaria, Uncinula, Plasmopora, etc., infectan las uvas provocando, en el mejor de los casos, una disminución de las características organolépticas de los vinos producidos. (Ough y Amerine 1988; McGrew 1982). Los modos de actuación pueden ir desde una destrucción enzimática de los tejidos de la uva, pasando por un retraso en la maduración de la baya, e incluso, grupos de hongos capaces de producir sabores indeseados ("off flavours") y micotoxinas(Kassemeyer y Berkelmann-Löhnertz 2009)(Kassemeyer y Berkelmann-Löhnertz 2009). 
Se han descrito hongos filamentosos que crecen en el corcho y que son responsable de la producción de compuestos como el 2,4,6-tricloroanisol, el cual aporta un sabor desagradable de tipo fúngico (denominado "cork taint") al vino (Alvarez-Rodríguez et al., 2002). Este producto se transfiere desde el corcho al vino una vez éste ha sido embotellado, y ambos entran en contacto.

Por todo ello algunos autores plantean métodos para controlar el crecimiento de hongos en la superficie de las uvas. Uno de ellos sería el uso de levaduras como agentes de biocontrol (Chalutz y Droby 1998). La capacidad antifúngica de algunas especies, basada en la producción de $\beta$-1,3-glucanasa, capaz de destruir la pared fúngica ha sido demostrada (Fleet 2003).

\subsubsection{Fermentaciones espontáneas versus Fermentaciones dirigidas}

Desde los orígenes del vino se han elaborado vinos mediante la microbiota natural, responsables de las fermentaciones espontáneas. La particularidad de estas fermentaciones radica en la ausencia de inóculo de modo que son las levaduras presentes en la superficie de la uva, así como la microbiota indígena asociada a las superficies de las instalaciones de la bodega las que conducen las fermentaciones naturales (Pretorius 2000).

En 1890 Hansen, en la empresa cervecera Carlsberg en Dinamarca, aisló un cultivo puro de levaduras a partir de una única célula. Sería el botánico y enólogo Müller-Thurgau el primero en introducir el concepto de inocular el mosto con levaduras iniciadoras (Pretorius y Van der Westhuizen 1991). Allá por el año 1965 se pusieron en el mercado las primeras levaduras secas activas (LSAs) para vino (del inglés, ADWY, "active dry wine yeast") producidas en una bodega de California. Las LSAs se pusieron a la venta en todo el mundo para cualquier tipo de proceso fermentativo, aunque su éxito inicialmente fue muy limitado. Hoy en día, existen varias compañías dedicadas a la comercialización de cultivos deshidratados seleccionados de S. cerevisiae. En las fermentaciones dirigidas, el cultivo inciador debe prevalecer respecto a las especies nativas presentes en el mosto natural. Para alcanzar este propósito es necesario alcanzar tasas de inóculo entre $1 \cdot 10^{6}-3 \cdot 10^{6} \mathrm{ufc} / \mathrm{mL}$ (Fugelsang 1997).

Las fermentaciones espontáneas prevalecieron sobre las dirigidas hasta la década de los ochenta del pasado siglo, debido a la creencia que postulaba que los vinos obtenidos con las levaduras asociadas a los viñedos daban un estilo distintivo y un toque de calidad. Aún hoy en día, existen bodegas "selectas" que asumen los riesgos debidos a las fermentaciones espontáneas, con las consecuentes variaciones entre las diferentes añadas. Parece lógico pensar que un vino obtenido con una mezcla de diferentes levaduras dará como resultado un vino con unas características sensoriales diferenciadas. Generalmente estos vinos se caracterizan por un aumento en la cantidad de glicerol y otros polioles producidos por las levaduras indígenas. Además, debido a que presentan una fase inicial del proceso de fermentación (fase "lag", previa al proceso vigoroso de fermentación) bastante larga se permite la reacción del oxígeno con los antocianos y otros fenoles. Esto hace que se estabilice el color en los vinos tintos y rosados además de acelerar los procesos de polimerización de los fenoles (Zoecklein et al., 1999).

El resultado final de un vino elaborado mediante fermentación espontánea poseerá ciertas cualidades debidas a las levaduras indígenas, pero el resultado dependerá de más factores. Aparte de las levaduras que entran en juego en el proceso de elaboración, tendrá importancia el estado sanitario de la uva, proceso de elaboración, etc. Todas estas variables hacen que el resultado final de una fermentación espontánea sea impredecible, junto con un 
grado de reproducibilidad muy bajo, sobre todo si lo comparamos con fermentaciones llevadas a cabo por LSAs.

Con todos los inconvenientes indicados anteriormente, resulta llamativo que los elaboradores de vino de todo el mundo no se pongan de acuerdo acerca del uso de LSAs. Entre los dos extremos, uso de levaduras autóctonas y uso de iniciadores comerciales, existen procedimientos "intermedios". Así, existen elaboradores que inician el proceso con levaduras nativas para posteriormente inocular con levaduras seleccionadas. Otro grupo de enólogos emplea iniciadores comerciales, pero con un inóculo mucho menor al recomendado (Pretorius 2000).

En un proceso de producción de vino a gran escala se debe asegurar que el proceso de fermentación sea rápido y reproducible, de modo que el producto obtenido presente unas ciertas propiedades organolépticas y un grado de calidad predicho. Esto solo es posible mediante el empleo de levaduras seleccionadas que presenten ciertas características que puedan ser trasferidas al producto final. (Pretorius 2000). Así, según Álvarez-Pérez et al. (enviado) queda demostrado que un proceso de selección adecuado en la levadura empleada para el inicio de fermentación puede dar lugar a vinos con unas marcadas diferencias en cuanto a sus características sensoriales.

Ante el reto de seleccionar levaduras para ser usadas como iniciadoras de fermentación, se deben de tener en cuenta, aparte de presentar la característica enológicas deseadas, una total adaptación a las características del mosto, así como a los requerimientos técnicos de la bodega en cuestión (procesos, pre-tratamientos, etc.). Esto solo es posible si se hace una selección "local” de levaduras, asegurándonos la total sintonía de estas con el entorno.

\subsubsection{Dinámica de poblaciones en fermentaciones espontáneas}

Como ya se ha indicado anteriormente, en las fermentaciones espontáneas intervienen tanto las especies que se encuentran en la uva como las especies indígenas de bodega. La fase temprana del proceso fermentativo es dominada mayoritariamente por especies apiculadas de los géneros Kloeckera y Hanseniaspora, y por especies del género Candida, aunque también podemos encontrar de otros géneros como Debaryomyces, Hansenula, Kluyveromyces, Schizosaccharomyces, Torulaspora y Zygosaccharomyces. Estas especies dominan hasta que el contenido en etanol alcanza valores de 3-4\% (v/v), momento en el que son desplazadas por especies de Metschinokowia y Pichia, que pueden tolerar niveles alcohólicos cercanos al $6 \%$. A partir de ese momento es la especie S. cerevisiae la que domina casi en exclusiva el proceso fermentativo, aunque en algunos casos concretos se han detectado cepas de Zygosaccharomyces y Torulaspora capaces de resistir valores de un $10 \%$ ( $\mathrm{v} / \mathrm{v})$ de etanol e incluso cepas de Candida capaces de finalizar la fermentación (EsteveZarzoso et al. 1998; Ciani y Maccarelli 1998; Jolly et al. 2006).

La presencia de muchas de estas especies no siempre es deseada puesto que algunas son capaces de perjudicar las características sensoriales de los vinos obtenidos mediante esta práctica (Pretorius 2000).

En la figura 1.3 se indica de modo esquemático las especies dominantes en un proceso fermentativo espontáneo según va avanzando el proceso de fermentación y por tanto aumentando la concentración de etanol en el medio. Este último juega un papel importante en la dinámica representada ya que la mayoría de las especies presentan una cierta toxicidad al etanol. 


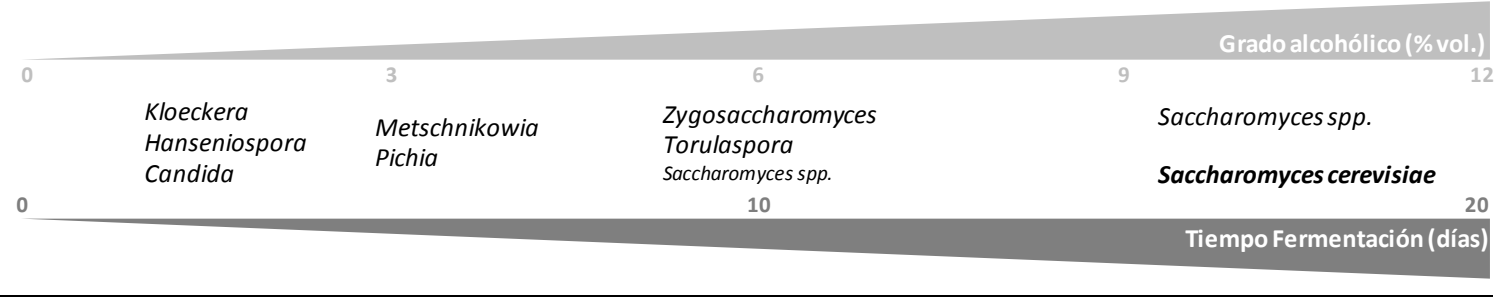

Figura 1.3: Esquema representativo de la dinámica de fermentación en un proceso espontáneo donde entran en juego las levaduras salvajes de la uva, así como las indígenas de la bodega. Se muestran, según avanza el proceso, las especies predominantes. Los tamaños relativos de letra, así como el resaltado en negrita, inciden en la importancia relativa de los géneros y especies en cada una de las fases de la fermentación. Resulta llamativa la preponderancia de S. cerevisiae al final del proceso.

\subsection{Biología de levaduras}

Las levaduras son hongos unicelulares. Su nombre proviene del verbo latino levare (levantar), debido al efecto característico producido en algunos sustratos como es el caso del pan. La descripción se centrará en S. cerevisie por ser la levadura universalmente empleada en vinificación, de ahí que sea conocida como la "levadura del vino" (Swiegers et al., 2005).

Filogenéticamente, S. cerevisiae se clasifica dentro de los hongos ascomicetos, debido a que presentan sus esporas sexuales o ascosporas en el interior de una bolsa o asca. Los hongos ascomicetos pueden aparecer en dos formas: teleomórficas o anamórficas. La primera sería la forma imperfecta o asexual, mientras que la segunda sería la forma perfecta o sexual.

La clasificación taxonómica de esta sería:

Reino: Fungi

Filo: Ascomycota

Subfilo: Saccharomycotina

Clase: Saccharomycetes

Orden: Saccharomycetales

Familia: Saccharomycetae

Género: Saccharomyces

Especie: Saccharomyces cerevisiae

\subsubsection{Estructura celular}

Las levaduras son

organismos eucariotas que contienen un núcleo definido, cuya membrana separa los cromosomas del resto de orgánulos que se encontrarán dispersos en el citoplasma. En la figura 1.4 vemos un diagrama con la distribución típica de los componentes y orgánulos en una levadura. A continuación se detallaran los aspectos

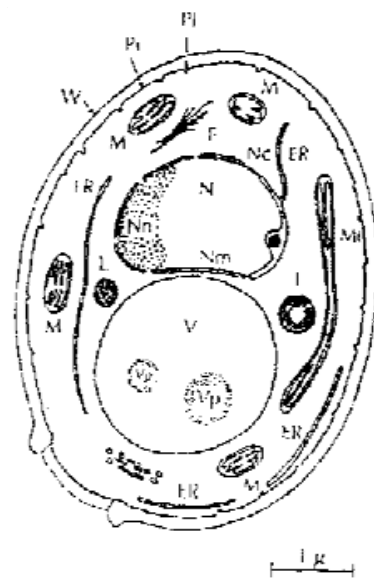

Figura 1.4: Diagrama de una célula de levadura de la especie Saccharomyces cerevisiae en reposo divisional. ER, retículo endoplasmático; $F$, filamentos; $G$, aparato de Golgi; L, granulo de lípidos (esferosoma); M, mitocondrias; Mt, mitocondrias filiformes; $\mathrm{N}$, núcleo; $\mathrm{Nc}$, placa centriolar, $\mathrm{Nm}$; membrana nuclear; $\mathrm{Nn}$, nucléolo; $\mathrm{Pi}$, invaginación; $\mathrm{PI}$ membrana plasmática; $\mathrm{V}$, vacuola; $\mathrm{Vp}$, granulo de polimetafosfato (volutina); W, pared celular. 


\subsubsection{Pared celular}

Su principal función es la protección de la célula del medio externo. Además presenta en su estructura enzimas de vital importancia para el organismo, muchas con carácter hidrolítico.

Está constituida básicamente por $\beta$-glucanos y $\alpha$-mananos, conteniendo cierta cantidad de proteínas, lípidos, y minoritariamente sustancias inorgánicas, hexosaminas y quitina (Hough, 1990). Los glucanos se encuentran unidos a la proteína, representando el componente estructural más abundante, siendo su disposición la cara interna de la pared. El manano también se encuentra ligado a la proteína, a veces a través de la hexosamina, pero su disposición suele ser externa. Por tanto, en su superficie, nos encontraremos con grupos carboxilo y fosfato que, al $\mathrm{pH}$ del mosto, conferirán una fuerte carga negativa a la superficie de esta. Debido a la presencia de algún grupo amino, podemos encontrarnos regiones locales con carga positiva.

Las manoproteinas forman parte de la pared celular (Klis et al., 2006), presentando la capacidad de modular el perfil sensorial de los vinos, durante la fermentación alcohólica, mediante un proceso de bioadsorción de los componentes de la uva. Su contribución se basa en la estabilización coloidal debida a su interacción con los tartratos y proteínas de las uvas (Fleet, 2008). La estructura de las manoproteinas varía significativamente entre las diferentes levaduras, pudiendo varíar sus propiedades de bioadsorción (Klis et al., 2006).

La pared celular también es atravesada por algunas enzimas segregadas por la levadura como la invertasa, capaz de degradar la sacarosa en sus monómeros (glucosa y fructosa) para que puedan penetrar y ser útiles, o la fosfatasa (Hough, 1990).

Un adecuado tratamiento de las levaduras con enzimas líticas procedentes de otros organismos (como el caracol comestible, Helix pomatia, o del hongo filamentoso Trichoderma harzianum), en una solución estabilizada osmóticamente, permite la degradación total o parcial de la pared obteniéndose, respectivamente protoplastos o esferoplastos. En las levaduras se hablará de esferoplastos, ya que las enzimas líticas no son capaces de producir una degradación total de ésta (Kocková-Kratochvílová, 1990). Los esferoplastos han permitido el estudio en profundidad de los orgánulos, así como la propia estructura de la pared. También ha sido muy importante en los procesos de fusión y transformación de estos con material genético exógeno (van Solingen y van der Plaat 1977).

\subsubsection{Mitocondrias}

El número de mitocondrias por célula y su morfología (esférica o filamentosa), depende tanto de la especie, como de la fase del ciclo de vida, como la forma de cultivo del microoranismo. En una célula diploide de S. cerevisiae nos podemos encontrar entre 15 y 29 mitocondrias, mientras que si se trata de una célula haploide el número disminuye entre 7 y 17 unidades (Kocková-Kratochvílová, 1990).

Las mitocondrias albergan los citocromos, enzimas respiratorios y el sistema responsable de la biosíntesis del ATP. Son, por tanto, responsables del metabolismo oxidativo de los azúcares (degradación hasta dióxido de carbono y agua) y de la acumulación de energía por formación de ATP. En condiciones anaeróbicas, o cuando la concentración de glucosa es alta parecen atrofiarse y perder, al menos temporalmente, su actividad (Hough, 1990).

\subsubsection{Constitución genética}

El material genético de las levaduras se divide en genoma nuclear, genoma mitocondrial y los plásmidos citoplasmáticos. Además de los anteriores, pueden aparecer en el citoplasma moléculas de ARN bicatenario relacionadas con el factor "killer". 


\subsubsection{3.a. ADN nuclear}

En una célula diploide de S. cerevisiae presenta un tamaño de $2 \cdot 10^{4} \mathrm{~kb}$, cerca del $80 \%$ del material genético total. Está repartido en 32 cromosomas lineales (16 parejas) cuyos tamaños oscilan entre 200 y $2200 \mathrm{~kb}$. El cromosoma de mayor tamaño es el XII, siendo además el más variable ya que presenta el ADN ribosómico, es decir, se encuentran los genes que codifican para las distintas subunidades que forman el ARN ribosómico (26S, 18S, $5.8 \mathrm{~S}$ y 5S) que darán lugar a los ribosomas. Estos genes se encuentran repetidos en tándem alrededor de 100 veces en el cromosoma (Eickbush y Eickbush 2007).

\subsubsection{3.b. ADN mitocondrial (ADNmt)}

Constituido por una único cromosoma circular de doble cadena con un tamaño comprendido entre 75 y $85 \mathrm{~kb}$ (Foury et al., 1998), variable de una cepa a otra. La mayor parte del material genético no codifica para ninguna proteína, salvo las proteínas implicadas en la cadena respiratoria. La parte no codificante tiene una alta proporción en $A+T$.

Existen mutantes mitocondriales denominados petite en los que la mayor parte de la síntesis de proteínas mitocondriales es abolida debido a largas deleciones en el ADNmt. No son capaces de realizar los procesos de respiración, aunque pueden crecer en entornos anaeróbicos (fermentación). El término petite es acuñado debido al pequeño tamaño de estos mutantes en medio sólido respecto a las células silvestres, tanto en condiciones aerobias como anaerobias (Madigan et al., 2004).

\subsubsection{3.c. ADN plasmídico}

En S. cerevisiae se conoce la existencia de un plásmido de ADN bicatenario circular con un tamaño de $6,3 \mathrm{~kb}$ y conocido como plásmido de $2 \mu \mathrm{m}$, del cual podemos encontrar entre 30 y 50 copias en el núcleo. Este plásmido no confiere ningún fenotipo a la célula. Su principal interés radica en su uso como vector de clonación para genes foráneos (Madigan et al., 2004).

\subsubsection{3.d. Factor "killer"}

El denominado factor "killer" guarda relación con moléculas de ARN bicatenario asociadas a los virus (VLPs, virus-like particles). Las diferentes toxinas de $\mathrm{S}$. cerevisiae son codificados por los correspondientes satélites $M$ de ARN de doble cadena, que se encuentran en el citoplasma encapsidados como si de una partícula vírica se tratara. Para su replicación, así como encapsidación, es necesaria la ayuda de los denominados virus L-A (pertenecientes a la familia de los virus Totiviridae). Por tanto, la presencia de un satélite $M$ de ARN bicatenario junto con la coinfección de un virus L-A será responsable del carácter "killer" de una levadura en particular (Marquina et al., 2002). El tamaño del genoma del satélite $M$ varía entre 1,5 y 1,9 kb en función de la toxina para la que codifique. Sin embargo, el tamaño del genoma del virus auxiliar (al igual que el anterior, de doble cadena de ARN) asciende a 4,6 kb (Magliani et al., 1997). Es importante indicar que estos virus se transmiten hereditariamente tanto verticalmente (de madres a hijas), como horizontalmente (conjugación) (Magliani et al., 1997).

Existen varias toxinas killer descritas, aunque las más importantes son la K1 y la K2. La mayoría de las cepas "killer" pertenecen a estas clases, matándose mutuamente, pero siendo inmunes a su propia toxina. El mecanismo de acción para estas toxinas, tras la liberación al medio, pasa por la unión a la pared celular de la célula sensible (mediada por los B-glucanos) para posteriormente ser transferida a la membrana celular. En esta será capaz de generar un canal transmembrana a través del cual se producirá, en un principio, una pérdida de iones, y posteriormete de moléculas de mayor tamaño como el ATP, provocando su muerte (Magliani 
et al. 1997; Marquina et al. 2002). Este mecanismo es posible bajo el postulado de la existencia de un hipotético receptor en la membrana de la célula sensible.

El mecanismo de acción de la toxina K28 difiere del anterior. En este caso la toxina entra por endocitosis en la célula (ruta contraria a la de secreción), bloqueando la síntesis de ADN y secuestrando a la célula en la fase temprana S del ciclo celular (Schmitt y Breinig 2002; Rodriguez-Cousino et al. 2011).

Recientemente se ha identificado una nueva toxina con carácter "killer", Klus. Esta es debida al virus Mlus (con un tamaño genómico comprendido entre 2,1 y 2,3 kb), dependiente del virus L-A para su mantenimiento y replicación (Rodriguez-Cousino et al., 2011). La particularidad de esta toxina reside en su capacidad de eliminar las levaduras "killer" conocidas, así como otras levaduras que podrían provocar deterioro en los vinos (por ejemplo Kluveromyces lactis y Candida albicans). Por tanto esta toxina presenta un rango de acción más amplio que las anteriormente descritas (se reducen básicamente a especies dentro del mismo género que sean sensibles a la citada toxina) ya que actúan sobre varias especies de levaduras.

La mayoría de los estudios realizados hasta el momento se han centrado en la toxina K1. Según estudios, el pH óptimo de producción y estabilidad varía desde 4,6 a 4,8, estando estos valores muy por encima de los rangos de pH de vinificación. Sin embargo, la toxina K2 tiene un rango de $\mathrm{pH}$ entre 2,9 y 4,9; lo que sugiere su posible utilidad en la industria vinícola (Marquina et al., 2002).

En los procesos de fermentación espontánea varias de las levaduras implicadas presentan carácter "killer". Se sabe que las levaduras con carácter "killer" productoras de la toxina K2 son capaces de prolongar e incluso detener un proceso de fermentación (van Vuuren y Wingfield 1986), sobre todo si la cepa que soporta el mayor peso del proceso fermentativo es sensible a esta toxina.

Por tanto, lo más adecuado es usar como iniciador de fermentación una levadura con carácter "killer", con propiedades enológicas adecuadas, para controlar el resto de la población de levaduras en las fases tempranas de fermentación (Marquina et al., 2002). Existen estudios que han demostrado que una levadura iniciadora con carácter "killer" con una proporción entre el 2-10\%, puede asegurar el desarrollo adecuado de la fermentación, evitando interacciones indeseadas en el inicio de fermentación (Pérez et al., 2001).

\subsubsection{Nutrición y crecimiento}

Las levaduras necesitan de una nutrición adecuada para su crecimiento y reproducción. Los nutrientes pueden ser de dos tipos:

- Indispensables o esenciales: Sin estos la célula no puede crecer y han de estar necesariamente en el medio. Destinados principalmente a la construcción de la estructura celular.

- No indispensables: Son utilizados por la célula si se encuentran en el medio, aunque pueden ser sustituidos por otros.

Los nutrientes básicos en levaduras serían los siguientes:

- Fuentes de carbono:el crecimiento se realiza por vía heterótrofa a partir de compuestos orgánicos, principalmente azúcares. Estos pueden ser metabolizados tanto por vía aerobias como anaerobias. Otras fuentes de carbono pueden ser el etanol, glicerina, ácidos orgánicos (levaduras de flor), etc. 
- Fuentes de nitrógeno: Las fuentes de nitrógeno que llegan a las células proceden de las sales de amonio (sulfato, fosfato y nitrato). Otro aporte sería a partir de los ácidos orgánicos y aminoácidos, siendo a su vez fuente de carbono. Durante el proceso de fermentación alcohólica el nitrógeno puede considerarse como un factor limitante en función de la relación fuente de carbono/fuente de nitrógeno presente en el mosto (Bell y Henschke 2005).

- Macronutrientes: Necesarios e indispensables para la fabricación de nuevos componentes celulares, destacando el oxígeno, azufre, fósforo y magnesio.

- Micronutrientes: Necesarios en cantidades muy pequeñas. Destacan el potasio, calcio, silicio, azufre, hierro, cloro, boro, cobre, iodo, manganeso, molibdeno y cinc.

- Factores de crecimiento: No son sintetizados por las levaduras y son requeridas por estas. Son principalmente vitaminas como la biotina, pantotenato cálcico, tiamina, etc.

En el crecimiento vegetativo de una levadura en un cultivo discontinuo se pueden distinguir tres fases, principalmente:

1. Fase de latencia. La fase de latencia es un periodo de adaptación de la levadura al nuevo entorno (nutrientes, temperatura, $\mathrm{pH}$, etc.), durante el cual el número de células inoculadas permanece constante, $\mathrm{o}$ incluso disminuye. La duración de esta fase depende del número de células inoculadas y del estado fisiológico de las mismas.

2. Fase exponencial. Se intensifica la actividad metabólica respecto a la fase anterior. Durante esta etapa del crecimiento, el número de divisiones celulares crece con progresión geométrica. La duración de esta fase depende de la especie de levadura, así como de las condiciones ambientales. En esta etapa se calcula el tiempo de duplicación celular o tiempo de generación, t, a partir de la cual es posible determinar la tasa máxima de crecimiento o velocidad máxima de crecimiento ( $\mu$ max).

3. Fase estacionaria. Esta fase comienza cuando los nutrientes comienzan a ser escasos. Se alcanza un equilibrio entre células no viables (muertas) y células viables, que aún se siguen dividiendo, de manera que el número de individuos vivos permanece constante. Cuando se agotan los nutrientes, las levaduras comienzan a sintetizar metabolitos secundarios (no esenciales para mantener su viabilidad), algunos de los cuales pueden ser perjudiciales para la propia levadura.

4. Fase de muerte. El número de células no viables supera al número de células viables. El efecto conjunto se traduce en una disminución constante del número de células vivas hasta la desaparición total de las mismas.

\subsubsection{Ciclo de vida y reproducción}

Las células de $\mathrm{S}$. cerevisiae tienen un ciclo de vida complejo, teniendo la capacidad de reproducirse como haploides, diploides y de formar zigotos entre células haploides.

La reproducción es normalmente por gemación, un tipo de reproducción asexual, donde el núcleo se divide por mitosis con idéntica dotación genética (dos dotaciones cromosómicas) entre la célula madre e hija. Tras la formación y crecimiento de la yema se produce la separación de las células, quedando en la célula madre la denominada cicatriz de gemación. Es posible encontrar cadenas de células debido a la asusencia de separación, aunque no es común encontrar nunca cadenas superiores a tres individuos (Hough, 1990). 


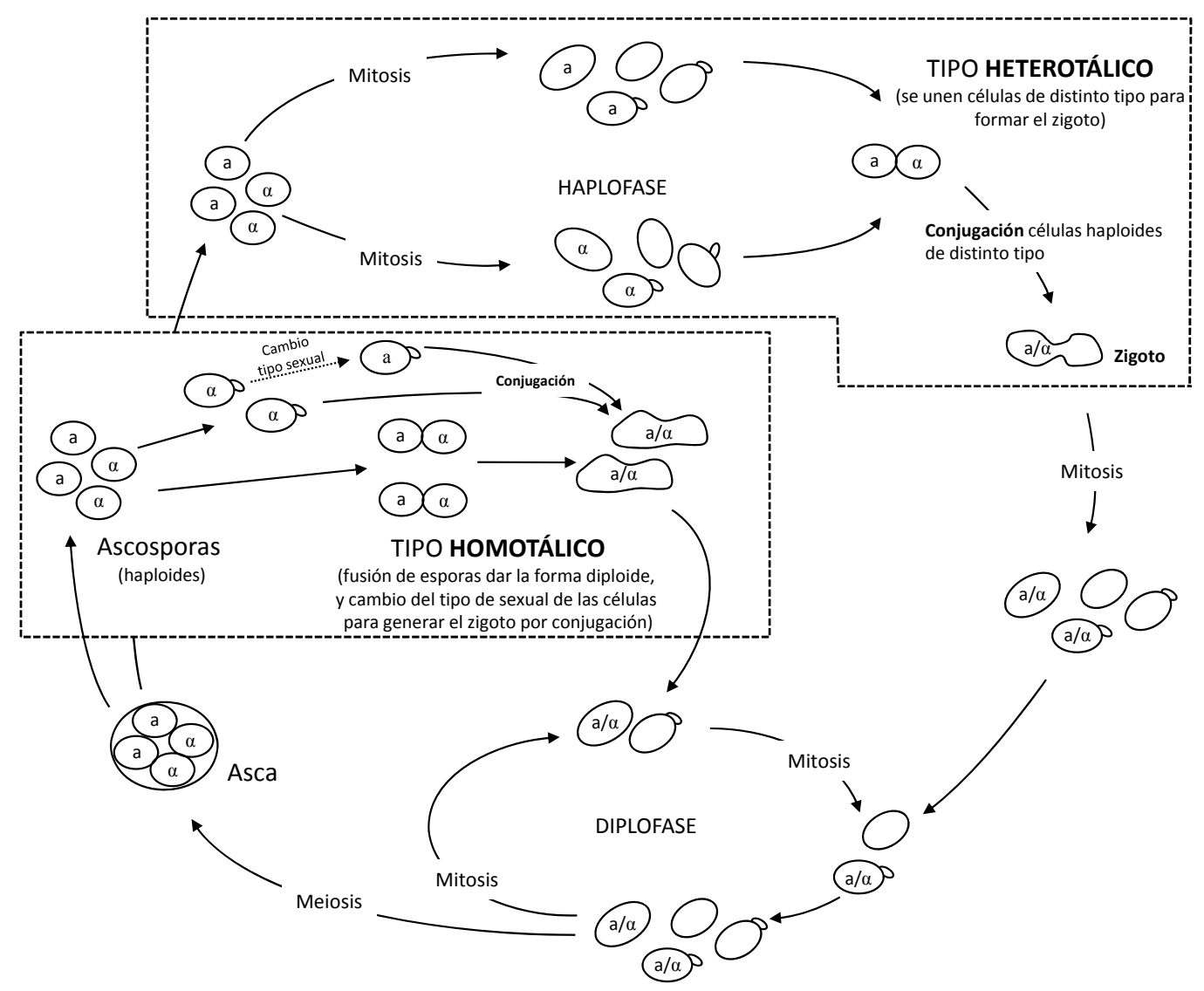

Figura 1.5: Ciclo de vida de Saccharomyces cerevisiae: a y a hacen referencia a los genes (tipos sexuales) que controlan la respuesta a la conjugación o reproducción sexual.

En circunstancias adversas, así como en la fase estacionaria donde existe privación de nutrientes, se induce el proceso de esporulación o reproducción sexual. A partir de una célula diploide, por meiosis, se formarán cuatro ascosporas haploides encerradas en un asca. Dos serán del tipo sexual a y dos del tipo sexual $\alpha$. Los tipos sexuales estarán controlados por un locus en el cromosoma III, denominado MAT (Kocková-Kratochvílová, 1990). En las levaduras, a diferencia de en otros microorganismos los gametos no se diferencian de la célula vegetativa (Suárez e íñigo 1992).

Las células de tipo a y $\alpha$ se conjugan entre sí para dar lugar a zigotos del tipo a/ $\alpha$, cuya eficiencia de apareamiento es mucho más alta que entre las del mismo tipo (muy baja o no se da). En relación a esto, pueden existir dos tipos de levaduras, las homotálicas y las heterotálicas. En las primeras se produce la formación del zigoto a partir de dos ascosporas que se encuentran en la misma asca. En las segundas, es posible que las células se mantengan estables varias generaciones como haploides, pudiendo formar, por conjugación entre dos células haploides de distinto tipo, una célula vegetativa diploide (Ver figura 1.5). Además las levaduras homotálicas pueden cambiar el tipo sexual (mating type) para así facilitar la conjugación con otra de tipo sexual contrario, regenerando la forma diploide. En las heterotálicas el tipo sexual es estable, siendo necesaria una conjugación con otra célula haploide para generar la forma diploide (Sipiczki, 2010).

El proceso de esporulación (reproducción sexual) se suele dar al final de proceso de fermentación. Se podría decir que la falta de nutrientes es capaz de provocar este tipo de reproducción. En el proceso fermentativo, durante el crecimiento vegetativo (asexual), se producen mutaciones, reordenamientos, etc., de modo que obtendremos clones con genomas 
diferentes. Estos cambios se producen de modo espontáneo, aunque favorecidos en gran medida por los factores estresantes del medio. Por ello en los heterocigotos se acumulan mutaciones en los alelos pudiendo llegar a ser letales. Tras el proceso meiótico, la mayoría de las esporas que hereden los alelos perjudiciales morirán. Por el contrario las eporas que no reciban estos alelos, serán capaces de sobrevivir hasta la siguiente cosecha, donde germinarán para dar una célula vegetativa con capacidad de conjugación (formación de la forma diploide). Se podría decir que este proceso es capaz de producir una "purificación del genoma" (Sipiczki, 2010).

\subsubsection{Capacidad fermentativa de Saccharomyces cerevisiae respecto a otras levaduras}

La principal característica de las levaduras empleadas en la elaboración de cerveza y vino reside en su capacidad de degradar carbohidratos, generalmente compuestos de seis carbonos $\left(C_{6}\right)$ como la glucosa, hasta compuestos de dos carbonos $\left(C_{2}\right)$, en particular etanol, sin producir una oxidación completa hasta $\mathrm{CO}_{2}$, incluso en presencia de oxígeno, como hacen las mayoría de levaduras (Piskur et al. 2006).

Las levaduras capaces de acumular etanol incluso en presencia de oxígeno se denominan levaduras "Crabtree" positivas, destacando Saccharomyces cerevisiae y Schizosaccharomyces pombe. Levaduras como Kluyveromyces lactis y Candida albicans, que producen la degradación directa de azúcares hasta $\mathrm{CO}_{2}$ se denominan levaduras "Crabtree" negativas (Pronk et al., 1996)

Durante la producción de etanol, la energía necesaria para el crecimiento celular es aportada por el proceso de glicólisis (conjunto de reacciones que conducen desde glucosa $\left(\mathrm{C}_{6}\right)$ hasta piruvato $\left(C_{3}\right)$ produciendo ATP y NADH dando mayor importancia al proceso de fermentación respecto a la ruta de respiración oxidativa (figura 1.6). En $\mathrm{S}$. cerevisiae el efecto Crabtree se basa en la represión del circuito de la glucosa, concretamente la respiración, si en el medio se encuentran carbohidratos $C_{6}$ como la glucosa (De Deken 1966; Johnston 1999). Esta no es la vía más eficiente para degradar glucosa hasta compuestos $C_{2}$. De hecho, una vez que se consume el remanente en glucosa existente en el medio se produce un cambio en el metabolismo de las levaduras Crabtree positivas. El etanol producto de la fermentación se convierte en sustrato y es degradado si existe oxígeno. Este proceso se denomina "Diauxic shift" (Pronk et al., 1996)

Como se puede observar en la figura 1.6, en el proceso de fermentación (aeróbica o anaeróbica) se produce, con aporte de NADH, la conversión de acetaldehído en etanol. Este proceso (bidireccional pero con diferente eficiencia) esta catalizado mediante una enzima alcohol deshidrogenasa (Adh). En S. cerevisiae la actividad de esta enzima esta codificada por dos genes, $A D H 1$ y $A D H 2$, que surgieron debido a un evento de duplicación de genes. El primero se expresa constitutivamente, mientras que el segundo lo hace cuando la concentración interna de azúcares disminuye. El enzima Adh1 tiene un elevado valor de Km para el etanol, mientras que el valor para Adh2 es diez veces menos. Esto indica que en el primer caso el etanol será su producto, y en el segundo será su sustrato. Es decir, la primera cataliza la reacción de acetaldehído hasta etanol mientras que la otra lo hace en el sentido contrario (Piskur et al. 2006). La duplicación del gen ADH y especialización en dos nuevas enzimas se calcula que tuvo lugar hace menos de 80 millones de años (Thomson et al., 2005). Este proceso fue posterior a la duplicación del genoma completo de $\mathrm{S}$. cerevisiae que se estima en unos doscientos millones de años (Wolfe y Shields 1997; Kellis et al. 2004)

La existencia de genes duplicados, junto con la capacidad de fermentar glucosa y acumular etanol incluso en presencia de etanol (Alexander y Jeffries 1990), asientan las bases 
de la estrategia de "producción-acumulación-consumo" de etanol. Esto confirió al ancestro de Saccharomyces una gran ventaja debido a la toxicidad del etanol para otros microorganismos. Saccharomyces producía etanol eliminando a sus competidores, consumiendo posteriormente el etanol producido (Piskur et al. 2006).

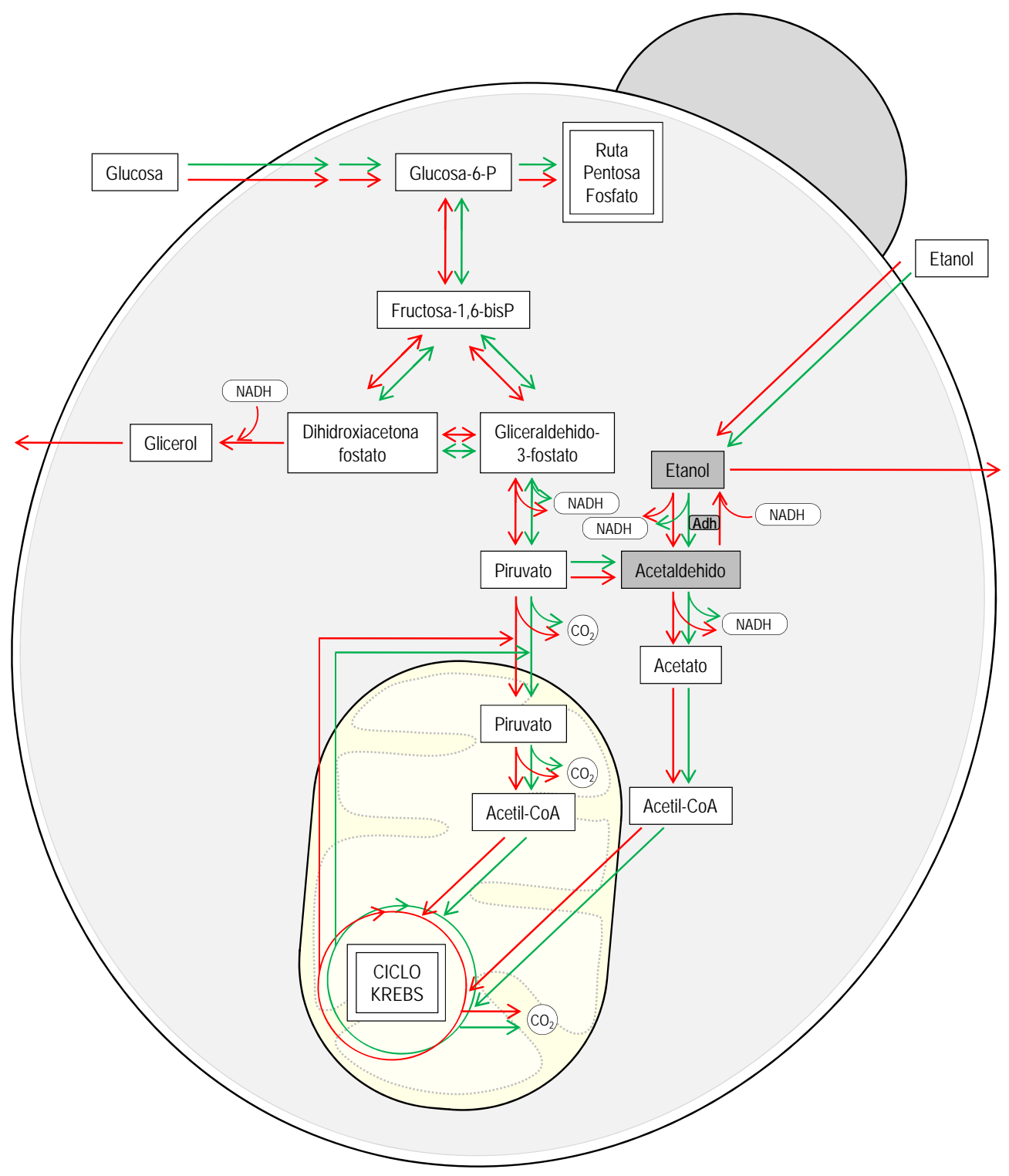

Figura 1.6: Esquema de las rutas involucradas en la asimilación de glucosa y etanol en condiciones aeróbicas. Se observan las diferencias entre levaduras "Crabtree" positivas, como Saccharomyces cerevisiae (flechas rojas), frente a las levaduras "Crabtree" negativas (flechas verdes). Las primeras son capaces de acumular etanol, mientras que las segundas producen la degradación directa a $\mathrm{CO}_{2}$. La conversión entre acetaldehído y etanol esta catalizada por la enzima alcohol deshidrogenasa, Adh (en gris). Esquema modificado de Piskur et al. (2006)

Las levaduras del género Saccharomyces deben su competitividad a una combinación de propiedades como son: rápido crecimiento, represión eficiente por glucosa, gran habilidad de producir y de consumir etanol y, en gran medida, la tolerancia al estrés del entorno (alta concentración de etanol y un bajo contenido de oxígeno) (Piskur y Langkjaer 2004). Las propiedades anteriores están distribuidas de modo desigual entre diferentes levaduras modernas, pero están combinadas, especializadas, coordinadas y reguladas a través de una eficiente red en S. cerevisiae y las especies más cercanas a éstas (Verstrepen et al. 2004; Ihmels et al. 2005). Quizás una "regulación eficiente" de la citada red sea la principal 
característica diferenciadora entre las cepas de Saccharomyces, siendo este el principal criterio por el cual se seleccionan las cepas para la fermentación industrial (Hansen y Piskur 2004).

\subsubsection{Domesticación de S. cerevisiae}

S. cerevisiae se encuentra principalmente asociado a las actividades humanas, particularmente en la producción de bebidas alcohólicas. Sin embargo, S. paradoxus, la especie más cercana a S. cerevisiae, se encuentra en los exudados y en la corteza de los árboles caducos, así como en los suelos sobre los que se asientan estos árboles. Esto parece indicar que S. cerevisiae es una especie domesticada especializada en la fermentación de bebidas alcohólicas, y que por tanto, los aislados de S. cerevisiae de otras fuentes simplemente representan migraciones desde estas fermentaciones (Fay y Benavides 2005). De hecho el proceso de domesticación, es decir la diferenciación entre cepas salvajes y domesticadas, de las levaduras vínicas se estima en unos 2.700 años por los citados autores.

En el proceso evolutivo de las levaduras, estas han sufrido varias presiones selectivas (alta concentración de azúcares, etanol en el medio, entorno reductor, etc.) que las han llevado a adaptarse a las condiciones de fermentación (Querol et al. 2003). Estos eventos han desencadenado en el, aun desconocido por completo, proceso de "domesticación" de las levaduras. Las cepas domesticadas presentan unas propiedades fisiológicas y genéticas muy diferentes de las que presentan las especies salvajes (Liti et al., 2009).

Acorde con lo anterior, cabe reseñar el origen desconocido de las levaduras en los viñedos, y por tanto en las uvas. Se desconoce a ciencia cierta su origen, aunque todo parece indicar que podría ser debido a una contaminación y diseminación por los insectos. Lo que parece claro es que el origen de las levaduras de la bodega, que derivarían de las encontradas en las uvas, es debido a procesos de domesticación y evolución, alcanzando características óptimas para el proceso fermentativo (Fleet 2008; Mortimer y Polsinelli 1999).

\subsection{Fermentaciones: presente, pasado y futuro}

El fenómeno de fermentación (del latin "fervere", hervir) para la obtención de vinos consiste, en esencia, en la transformación de los azúcares presentes en el mosto en etanol y dióxido de carbono con la mediación de microorganismos. Se trata de uno de los procesos biotecnológicos más antiguos del mundo, con una historia de unos 8000 años (Pizarro et al., 2007).

Debido a su larga historia muchos han sido los cambios, tendencias y evoluciones de este proceso hasta el día de hoy, principalmente debido al mayor estudio de todos los aspectos relacionados con el mismo: el aspecto biológico (relacionado con la microbiota implicada), el aspecto bioquímico (características sensoriales) y las relaciones entre ambos.

\subsubsection{Aislamiento y selección de levaduras para controlar el proceso de fermentación}

Dos son las principales técnicas para elaborar vinos: una de ellas pasa por realizar una fermentación espontánea, que será conducida por la población de levaduras presentes en la superficie de la uva, así como en las superficies de las instalaciones de bodega. La otra pasaría por la inoculación del mosto con LSAs, que desplazan a las autóctonas (Pretorius 2000). 
Según los estudios de dinámicas de poblaciones (apartado 1.4.2.1) en las fermentaciones espontáneas el etanol, junto con otros factores, juega un papel muy importante de cara a la viabilidad de las diferentes especies en la fermentación, puesto que resulta tóxico para la mayoría de las especies autóctonas de levaduras, dando como resultado un dominio en la fase final de la fermentación por S. cerevisiae. Esto ha llevado a realizar un proceso de selección de cepas de esta especie, y también de $\mathrm{S}$. bayanus (especie cercana) con propiedades enológicas adecuadas para ser usadas como iniciadores de fermentación a escala industrial (Fleet 2008).

Se conocen levaduras vínicas no-Saccharomyces capaces de incidir positivamente en las características de los vinos (Romano et al., 2003). Por ejemplo, los terpenos se encuentran en las uvas unidos covalentemente a azúcares, resultado inodoros (precursores). Sin embargo sabemos que ciertas levaduras tienen la capacidad de producir glicosidasas que serán capaces de liberar estos terpenos, pasando a tener impacto en el aroma final del vino. S. cerevisiae presenta esta capacidad, aunque se sabe que otras levaduras como Hanseniapora, Debaryomyces y Dekkera presentan una mayor capacidad de producción de estas enzimas (Swiegers et al., 2005). Por tanto no parece descabellado pensar en la posibilidad de emplear en los procesos fermentativos mezclas de cepas e incluso diferentes especies de levaduras con el objetivo de producir un producto con las características deseadas o que demande el mercado (Fleet 2008).

Con la intención de innovar en cuanto a nuevas cepas iniciadoras de fermentación, dos serían las posibilidades: la selección natural de nuevas cepas y la mejora genética de las ya existentes. La selección natural implica buscar levaduras directamente en los viñedos (uvas), así como en las fermentaciones espontáneas. Lógicamente, es necesario un proceso de caracterización enológica que asegure su buen comportamiento de cara a su uso (Fleet 2008).

Mediante ingeniería genética y metabólica es posible, a día de hoy, modificar un microorganismo para mejorar sus propiedades, o bien para eliminar aquellas que pudieran ser perjudiciales (Pretorius 2000; Giudici et al. 2004). Sin embargo las técnicas recombinantes de ADN no están permitidas para la modificación de microorganismos que posteriormente se van a emplear en la industria alimentaria, es decir, no obtienen el reconocimiento GRAS (del inglés "Generally Regarded As Safe", reconocidos como seguros). No obstante, una cepa recombinante de S. cerevisiae ha recibido la aprobación de comercialización en USA. Se trata de una levadura que contiene el gen malato-permeasa de Schizosaccharomyces pombe y el gen maloláctico de la bacteria Oenococcus oeni. La ventaja de esta cepa respecto al resto de levaduras comerciales radica en que permite eliminar la fermentación maloláctica producida por las bacterias tras la fermentación alcohólica (Main et al., 2007). Destacar otra cepa considerada como GRAS, en la que se han empleado técnicas recombinantes para disminuir la producción de carbamato de etilo (producto cancerígeno) (Coulon et al., 2006).

Existen otras técnicas no recombinantes de modificación de cepas que no tienen problemas con la legislación vigente: hibridación, evolución adaptativa y la biología de sistemas (Fleet 2008). La hibridación consiste en la conjugación de levaduras en el laboratorio (Belloch et al. 2008; González et al. 2006, 2007, 2008). Mediante esta técnica conseguimos aumentar la tolerancia de las cepas a los agentes estresantes, principalmente etanol y temperatura (Belloch et al. 2008).

La evolución adaptativa consiste en cultivar de modo repetitivo una levadura bajo ciertas condiciones de interés, en función del fin a conseguir. Así, un ensayo de cultivo durante 300 500 generaciones en un medio con limitaciones de glucosa, consiguió una reducción en los azúcares residuales, así como una disminución en un orden de magnitud del grado alcohólico de los vinos obtenidos (Ferea et al., 1999). La biología de sistemas aprovecha el conocimiento 
del genoma y mediante métodos bioinformáticos se seleccionan y desarrollan levaduras en función de ciertos criterios deseados (Fleet 2008; Pizarro et al. 2007). Esta técnica se encuentra aún en fase de desarrollo.

La mejora de cepas para fermentación, mediante cualquiera de las técnicas citadas no debe estar orientada únicamente a la obtención de un producto con unas propiedades enológicas adecuadas, por ejemplo potenciar las características organolépticas deseables (glicerol, ésteres totales, etc.) disminuyendo las indeseadas (alcoholes superiores, fenoles, etc.) (Pizarro et al., 2007). También se debe dirigir la mejora de éstas hacia la obtención de vinos "saludables", es decir, vinos que potencien los beneficios y minimicen los riesgos asociados a un consumo responsable. Así por ejemplo se podría pensar en vinos que presenten una mayor cantidad de antioxidantes (resveratrol), baja concentración de sustancias tóxicas o bajo contenido en etanol.

\subsubsection{Opciones de fermentación}

Los procesos de fermentación pueden llevarse a cabo principalmente mediante dos configuraciones: por lotes (batch) y los procesos en continuo. Tradicionalmente y de modo convencional, la primera es la elegida para la obtención de los vinos. El mosto de uva se introduce dentro de un recipiente (madera o acero inoxidable) donde se mantiene hasta el final del proceso fermentativo (Fleet 2008). En este tipo de configuración, como ya se ha indicado, podremos decantarnos por un proceso de fermentación espontánea o bien por la adición de un cultivo incitador comercial (Pretorius 2000). Las ventajas de la fermentación en "batch" radican en la facilidad de control de los parámetros clave para el proceso de vinificación, avalado por la gran cantidad de conocimiento existente sobre este tipo de proceso. Un largo periodo de fermentación, la eliminación de la lías producidas en fermentación y la imposibilidad de utilizar el contenedor para una nueva fermentación hasta que esta no ha terminado (nuevo "lote") son algunas de las desventajas de esta configuración (Fleet 2008).

Mediante la inmovilización de microorganismos en una matriz sólida, en una concentración similar a la encontrada en una fermentación convencional, es posible realizar una fermentación alcohólica en un biorreactor con una velocidad 10-100 veces mayor a la obtenida con los procesos mencionados previamente (Verbelen et al., 2006). Aparte de una mayor velocidad del proceso fermentativo, la recuperación y reutilización de las levaduras (en su soporte sólido) son los principales puntos a favor.

Debido a la configuración de los biorreactores (columnas o membranas) es posible que el material sólido que contiene el mosto, así como las bacterias o levaduras indígenas del mosto, produzcan obstrucciones y por tanto detengan el proceso. La clarificación y pasteurización del mosto será necesaria previamente al proceso, teniendo esto gran impacto en el coste económico y en las características organolépticas del producto final. Además, el comportamiento de las levaduras será diferente si tenemos un proceso por lotes tradicional o un proceso en continuo, traduciendose en vinos con diferentes perfiles aromáticos y sensoriales. Parece lógico pensar que sería un necesario un proceso de selección y optimización de cepas orientadas a este proceso en particular (Fleet 2008).

Esta estrategia fermentativa también se está empleando para la realización de la fermentación maloláctica, tanto con bacterias como levaduras. Resulta llamativa la utilización de Schizosaccharomyces pombe en geles de arginato para eliminar los excesos de acidez de los vinos, principalmente ácido málico (Fleet 2008). 
Mediante las variaciones indicadas, tanto en la microbiota empleada, como en el proceso fermentativo, podremos obtener vinos cuya principal característica sea la ausencia de uniformidad. Esto no es, ni mucho menos, un inconveniente, sino todo lo contrario. Se abre ante nuestros ojos un nuevo abanico de productos que podrán ocupar una pequeña parte del mercado, pero serán capaces de satisfacer las preferencias y necesidades de cada consumidor. Sería algo así como elaborar un "vino a la carta", donde se potenciarán algunos matices eliminando los indeseados.

\subsection{Técnicas para la caracterización genética de levaduras vínicas}

El trabajo de identificación de microorganismos suele ser largo y tedioso y requiere cierta experiencia, ya que se precisan numerosas pruebas para la correcta identificación de levaduras aisladas a partir tanto de uva como de vino. A lo anterior se suman los diferentes cambios producidos en las clasificaciones taxonómicas de las levaduras en los últimos años, sobre todo en las ligadas a los procesos enológicos. Así, especies como Saccharomyces capensis, S. italicus, o S. chevalieri, entre otras, han sido agrupada en una única especie, S. cerevisiae, reduciendo el gran número de especies que se incluían en este género (Kurtman y Fell 1998). De hecho a día de hoy el género Saccharomyces está formado únicamente por ocho especies: tres están asociadas a procesos fermentativos (S. bayanus, S. cerevisiae y S. pastorianus) y las otras cinco aisladas de entornos naturales (S. arboriculus, S. cariocanus, $\mathrm{S}$. kudriavzevii, S. mikatae y S. paradoxus) (Kurtzman 2003; Wang y Bai 2008). De entre las anteriores destaca S. cerevisiae por ser la especie con mayor importancia en la fermentación alcohólica.

Existen infinidad de cepas dentro de la especie S. cerevisiae que intervienen en el proceso de fermentación, pudiendo presentar unas características variables y en muchos casos con cierto interés tecnológico. De este modo, la velocidad de fermentación, caracteres aromáticos de los vinos producidos, productos secundarios, etc., serán dependientes de las levaduras que han intervenido en el proceso. El estudio ecológico de los microorganismos responsables del proceso fermentativo, espontáneo, permitirá seleccionar aquellas con las propiedades adecuadas, con el objetivo de ser usadas como iniciadores de fermentación. Eso sí, se requiere un paso previo: caracterización inequívoca de las levaduras implicadas, principalmente S. cerevisie.

Las técnicas de caracterización clásicas se basan en el estudio de la morfología y fisiología de éstas, destacando entre las últimas la fermentación de fuentes de carbono y la asimilación tanto de fuentes de carbono como de nitrógeno (Barnett, 1992). De hecho, existen en el mercado kits comerciales para la identificación de levaduras en función de la asimilación de diferentes fuentes de carbono (Api 20C, Biomérieux, Durham, USA). La identificación mediante estas técnicas no tiene en cuenta el proceso de mutación. Ante dos perfiles diferentes, no se podría distinguir si nos encontramos ante dos cepas diferentes o ante la misma con un diferente comportamiento nutricional.

Siempre que aparecía un nuevo fenotipo, se proponía un nuevo género. Hoy en día se sabe, a través de estudios moleculares, que un fenotipo a menudo no se puede predecir ni siquiera a partir del genotipo. Debido a este cambio de tendencia, las pruebas de fermentación y los test de asimilación no pueden ser usados para definir especies, como ya se ha reseñado, pero si tienen cierto interés. El resultado de estas pruebas pondrá de manifiesto las diferentes propiedades fisiológicas de las especies estudiadas, siendo estas de gran valor para los ecólogos, biotecnólogos u otros con interés en el uso de un determinado sustrato (Kurtzman 2003) 
Desde la década de los 80 del siglo pasado hasta el día de hoy, se han desarrollado varias técnicas rápidas que nos permiten la identificación inequívoca de levaduras. Esto fue posible al gran avance sufrido en esta época de la Genética, así como de la Biología Molecular.

\subsubsection{Reacción en cadena de la polimerasa (PCR)}

La PCR es una técnica con infinidad de aplicaciones en Biología Molecular, entre ellas su empleo como herramienta para la identificación de levaduras de interés enológico (Versavaud et al. 1995; de Barros Lopes et al. 1996).

Consiste en la amplificación "in vitro" de un fragmento concreto de un ADN utilizando oligonucleótidos iniciadores específicos ("primers") de la zona del genoma que se desea amplificar. Es una técnica altamente específica, pues únicamente se amplifican las regiones flanqueadas entre los sitios donde hibridan los iniciadores.

El proceso de amplificación comienza por la desnaturalización del ADN, es decir, las dos hebras complementarias de la cadena de ADN se separan por efecto de un calentamiento. Los iniciadores, se unen en lugares específicos de cada hebra. A partir de estos cebadores, la ADN polimerasa cataliza la unión de los nucleótidos, tomando como molde cada hebra. El resultado son dos nuevas hebras completas y complementarias.

Los productos de PCR pueden ser analizados mediante electroforesis en geles de agarosa, o bien ser secuenciados, aumentando el poder de resolución de esta técnica en estudios de caracterización molecular.

Las principales ventajas de esta técnica se pueden resumir en los siguiente puntos:

- Requiere poca cantidad de ADN

- Permite analizar muchas muestras.

- Es altamente selectiva, ya que los cebadores se unen únicamente a los extremos de la secuencia que se desea amplificar.

La reacción en cadena de polimerasa (PCR) tendrá mucha importancia en la identificación de levaduras, ya que esta puede darse directamente a partir del producto (por secuenciación de este) o mediante tratamiento con enzimas de restricción de este (RFLP).

\subsubsection{Identificación de levaduras a nivel de especie}

\subsubsection{Identificación de levaduras a nivel de especie mediante la secuenciación de los dominios D1-D2 del ADNr 26S}

Los genes ribosomales (ADNr) codifican los ARN ribosomales que forman parte de los ribosomas en los que tiene lugar la síntesis de proteínas.

En levaduras como S. cerevisiae (microorganismos eucariotas o con núcleo verdadero) los genes ribosomales $18 \mathrm{~S}, 5.8 \mathrm{~S}, 26 \mathrm{~S}$ y $5 \mathrm{~S}$ se agrupan en tándem como podemos ver en la figura 1.7 formando bloques o unidades de transcripción que se repiten entre 100 y 200 veces (Eickbush y Eickbush 2007) en el genoma.

Cada bloque está separado del anterior y posterior por espaciadores intergénicos, llamados regiones NTS, que no son transcritos a ARN. A su vez, cada uno de estos bloques, está delimitado por un espaciador externo o región ETS que se transcribe, mientras que los genes $18 \mathrm{~S}, 5.8 \mathrm{~S}$ y $26 \mathrm{~S}$ están separados por los espaciadores intergénicos o regiones ITS (también transcritos). 
Los genes ribosomales $18 \mathrm{~S}, 5.8 \mathrm{~S}$ y $26 \mathrm{~S}$, así como los espaciadores ITS y NTS son herramientas muy importantes para la identificación de levaduras y cepas debido a la existencia de secuencias conservadas a lo largo de la evolución, de tal modo que la similitud de esta región es mayor dentro de una misma especie y menor entre especies diferentes.

Así la técnica más empleada para identificar levaduras es la secuenciación parcial de los dominios D1 y D2 del ADNr 26S. Se trata de dos cortas regiones próximas al extremo 5' del gen y evolutivamente muy conservadas. Cuando al secuenciar esta región encontramos una homología igual o superior al $99 \%$ con secuencias depositadas en bases de datos (Kurtzman y Robnett 1998), una levadura puede ser identificada como perteneciente a una especie determinada.

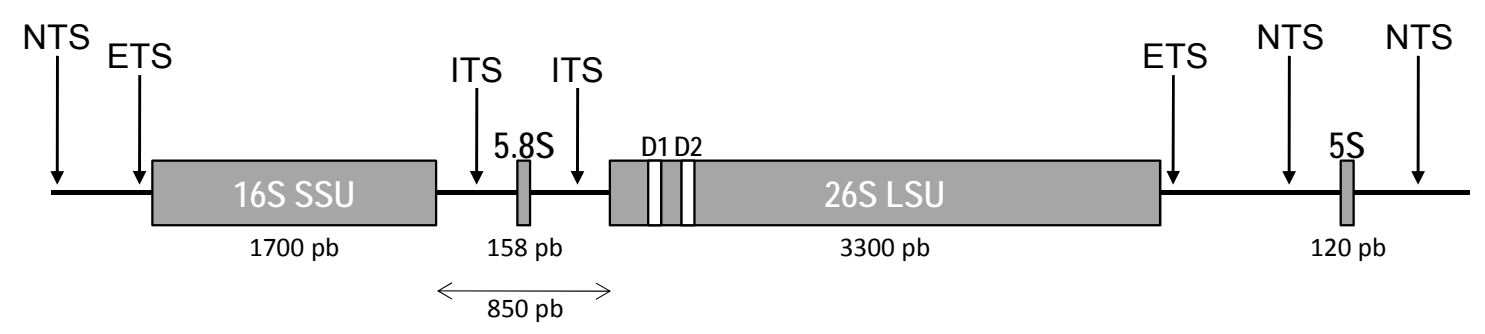

Figura 1.7: Esquema de la organización típica de los genes ribosomales en una levadura.

1.7.2.2. Identificación de levaduras a nivel de especie mediante análisis del polimorfismo de restricción de la región 5.8S-ITS (RFLP-5.8S-ITS)

Esta técnica consiste en amplificar por PCR la región del ADNr 5.8S-ITS, esto es el gen 5.85 y las regiones intergénicas ITS1 e ITS2 (ver figura 1.7).

Una vez amplificada esta región, el producto de PCR es digerido con distintas enzimas de restricción y los fragmentos obtenidos separados por electroforesis en geles de agarosa para determinar su tamaño. Por tanto se estudia el patrón obtenido para cada caso.

Mediante esta técnica y en función de los tamaños obtenidos con cada enzima es posible identificar a nivel de especie un gran número de levaduras diferentes presentes en bebidas y alimentos de forma inequívoca según los patrones descritos en varias publicaciones (Guillamón et al. 1998; Esteve-Zarzoso et al. 1999; Fernádez-Espinar et al. 2000; N'guessan et al. 2011).

Para las especies pertenecientes al género Saccharomyces el tamaño del amplificado corresponde a $850 \mathrm{pb}$. Con el objetivo de simplificar el método de identificación, se puede recurrir, únicamente, a tres digestiones con las enzimas de restricción Haelll, ScrFI y Accl (González et al. 2006). En entornos fermentativos la cepa mayoritaria sería S. cerevisiae, pudiendo ser identificada inequívocamente realizando las dos primeras digestiones reseñadas. La última digestión sería únicamente necesaria para discernir entre el resto de las posibles especies pertenecientes al género Saccharomyces (ver tabla 1.1).

\subsubsection{Identificación mediante PCR y posterior electroforesis con gradiente temporal de temperatura (PCR-TTGE)}

Esta técnica consiste en la amplificación de una región determinada del genoma, cuyo producto es sometido a una electroforesis empleando un gradiente lineal de temperatura y una concentración constante de un agente desnaturalizante para separar fragmentos de ADN que presenten las misma longitud pero diferente secuencia de nucleótidos. Esto es, dos fragmentos que presenten la misma longitud, misma temperatura de fusión, o condiciones de 
desnaturalización, serán dependientes de la proporción y de la posición de los pares de bases GC (Úbeda et al. 2009).

El análisis de RPLP-5.8S-ITS (descrito anteriormente) falla en la distinción entre S. bayanus y S. pastorianus (Úbeda et al. 2009). Mediante análisis usando TTGE se obtiene una buena discriminación entre ambas. Además esta técnica permite la discriminación entre varias especies pertenecientes al género Saccharomyces. Por el contrario esta técnica no tiene capacidad para discriminar entre diferentes cepas dentro de la especie $\mathrm{S}$. cerevisiae.

Otros autores aseguran la capacidad intrínseca de discriminar entre cepas de $\mathrm{S}$. cerevisiae si se optimizan las condiciones de amplificación (Manzano et al., 2005).

Tabla 1.1: Longitud, en pares de bases, de los fragmentos obtenidos al realizar la restricción con las enzimas indicadas de la región 5.8S-ITS. Como se observa, se obtienen dos posibles patrones (A y B) para cada enzima, de modo que la discriminación ente diferentes especies se reduce a la realización, en el orden reseñado, de las digestiones indicadas. En los casos de especies muy cercanas de Saccharomyces donde la presente técnica no permite discriminar, como es el caso de $S$. bayanus y $S$. pastorianus, se ha recurrido al estudio del gen de la actina (ACT1, cromosoma VI, 1436 pb.) (Josepa et al., 2000).

\begin{tabular}{llll}
\hline Enzima & Patrón & Fragmentos restricción $(\mathrm{pb})$ & Especies Saccharomyces \\
\hline \multirow{2}{*}{ Haelll } & A & $320+230+175+125$ & S. cerevisiae, S. paradoxus \\
& B & $495+230+125$ & S. bayanus, S. kudriavzevii, S. mikatae, S. pastorianus \\
\cline { 2 - 4 } ScrFl & A & $400+320+120$ & S. cerevisiae, S. bayanus, S. kudriavsevii, S. pastorianus \\
& B & $530+320$ & S. paradoxus, S. mikatae \\
\cline { 2 - 4 } Accl & A & 850 & S. bayanus, S. cerevisiae, S paradoxus, S. mikatae \\
& B & $730+110$ & S. kudriavzevii \\
\hline
\end{tabular}

\subsubsection{Caracterización de cepas de S. cerevisiae}

Una vez identificada una levadura como perteneciente a la especie S. cerevisiae será necesaria una técnica que nos permita distinguir los diferentes individuos pertenecientes a una población determinada. A continuación se muestran algunas de las técnicas empleadas para tal fin.

\subsubsection{Caracterización de cepas de S. cerevisiae mediante análisis del polimorfismo de restricción del ADN mitocondrial (RFLP-ADNmt)}

El ADN mitocondríal (ADNmt) de $\mathrm{S}$. cerevisiae es una molécula circular de ADN de un tamaño de 65 a 80 kilobases cuyo grado de variabilidad puede ser puesto de manifiesto mediante análisis con enzimas de restricción. Así, el alto grado de polimorfismo que presenta esta molécula entre diferentes cepas vínicas de $\mathrm{S}$. cerevisiae hace que su análisis sea uno de los más aplicados para su caracterización.

Una serie de características hacen que el ADN mitocondrial sea el sustrato más adecuado para estos estudios:

- No presenta metilación en ninguna de sus bases nitrogenadas por lo que es un sustrato idóneo sobre el que actúan las enzimas de restricción.

- Por su pequeño tamaño es ideal para este tipo de estudios, pero además es lo suficientemente grande como para ofrecer resultados significativos.

- El ADN mitocondrial posee una alta proporción de bases A+T. La digestión con enzimas de restricción cuyas dianas sean ricas en bases $\mathrm{G}+\mathrm{C}$ producen fragmentos de restricción de gran tamaño en el ADNmt y degradan completamente el genoma nuclear. Al realizar la electroforesis de los productos de digestión, los pequeños fragmentos cromosómicos avanzan con el frente del gel, no 
interfiriendo con las bandas correspondientes a los fragmentos mitocondriales por su mayor tamaño. El bandeo obtenido podría considerarse la "huella dactilar" de una determinada cepa.

Básicamente como podemos ver en la figura 1.8, este método consiste en extraer el ADN total de una levadura, purificarlo, digerirlo con determinadas endonucleasas de restricción, y separar los fragmentos obtenidos mediante electroforesis en gel de agarosa para su posterior visualización en gel. Se trata de una técnica utilizada de manera rutinaria por muchos autores (Vezinhet et al. 1990; Versavaud et al. 1995; López et al. 2001; Lopes et al. 2006) debido a su alta fiabilidad, repetitividad entre laboratorios y metodología relativamente sencilla (aunque laboriosa) que permite el análisis simultáneo en un mismo gel de numerosas cepas. Si el estudio comprende gran cantidad de individuos es necesario recurrir a medios bioinformáticos que nos permitan hacer un tratamiento estadístico de los patrones obtenidos, ante la imposibilidad de realizar una comparación de todos ellos en un mismo gel.
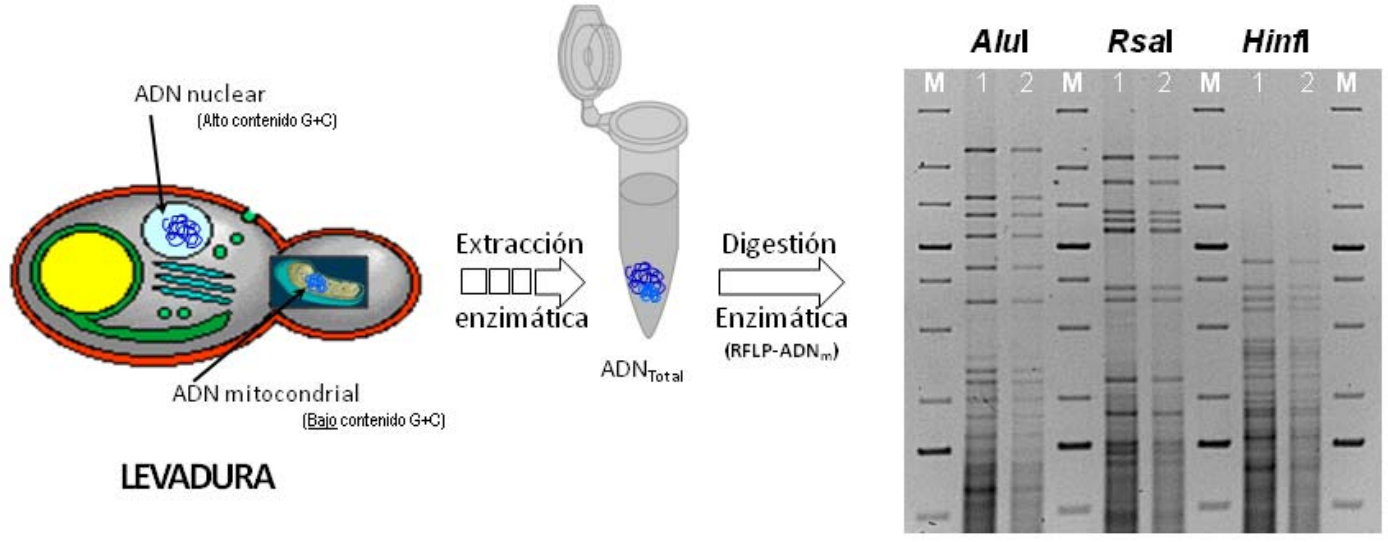

Figura 1.8: Esquema resumido de análisis RFLP-ADNmt. El proceso consiste de una extracción del ADN total (nuclear y mitocondrial, indicados con diferente color) y el posterior tratamiento de éste con enzimas de restricción. El número de bandas, junto con su tamaño, será un indicador inequívoco de la identidad de las diferentes cepas.

\subsubsection{Caracterización de cepas de S. cerevisiae mediante el empleo de técnicas basadas en el uso de la PCR}

La técnica descrita en el apartado anterior es la que ofrece más garantías a la hora de identificar cepas de S. cerevisiae, sin embargo es una técnica laboriosa y tediosa para analizar un gran número de clones por lo que se han desarrollado una serie de técnicas basadas en el empleo de la PCR, mucho más rápidas, esquematizadas en la figura 1.9 y que pasaremos a citar a continuación.

\subsubsection{2.a. Amplificación al azar de ADN polimórfico (RAPD)}

Esta técnica se basa en el empleo de un único oligonucleótido iniciador muy corto (unos 10 nucleótidos) con una secuencia arbitraria (Williams et al. 1990). La reacción de PCR se realiza a una baja temperatura de anillamiento $\left(37^{\circ} \mathrm{C}\right)$, de manera que la hibridación con el ADN de la levadura estará determinada por la corta y arbitraria secuencia del oligo, iniciándose la amplificación de diversos fragmentos de ADN distribuidos a lo largo de todo el genoma. El resultado es un patrón de productos amplificados característicos de las diferentes cepas analizadas (ver figura 1.9).

La principal ventaja de esta técnica radica en la no necesidad de información previa sobre la secuencia para el diseño del oligonucleótido. Sin embargo, tiene el inconveniente de la inestabilidad de los perfiles de amplificación obtenidos para cada cepa y por tanto, supone 


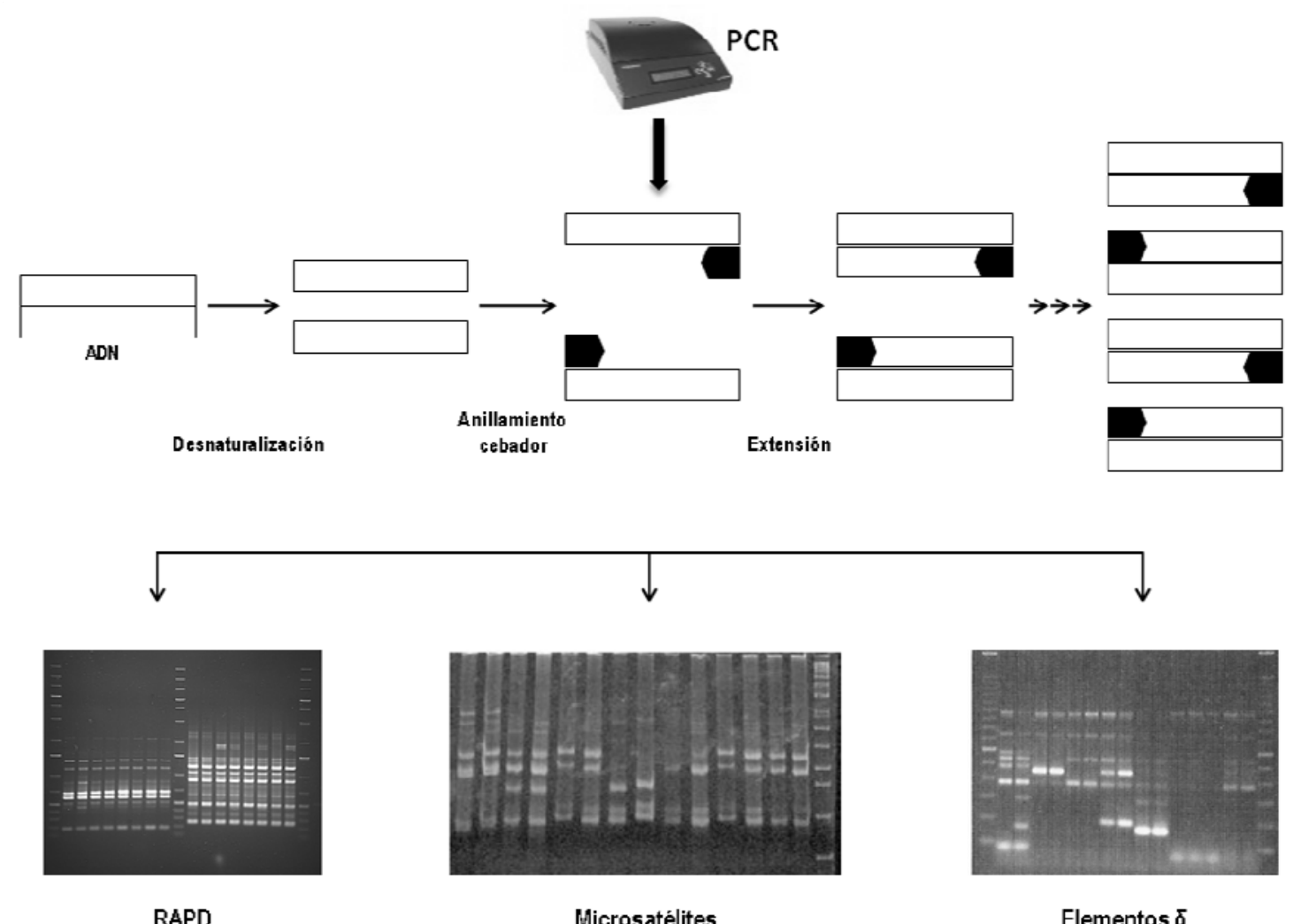

Figura 1.9: Métodos de tipaje y análisis molecular de cepas de levaduras mediante el empleo de técnicas basadas en la PCR.

una gran dificultad para comparar experimentos diferentes. Por tanto es necesario repetir el experimento varias veces para tener sólo en cuenta las bandas comunes a varios experimentos.

Existen varios trabajos donde además de emplear RAPDs, se usan otras técnicas que permitan identificar diferentes cepas. Así Corte et al. (2005) emplearon en un estudio conjunto los perfiles de RAPDs junto con la sensibilidad de las cepas a toxinas "killer".

\subsubsection{2.b. Amplificación de elementos delta.}

Las secuencias o elementos delta $(\delta)$ son elementos de sólo $0.3 \mathrm{~kb}$ que flanquean los elementos genéticos móviles llamados retrotransposones Ty1. En el genoma de S. cerevisiae existen de media unos 100 elementos $\delta$ cuya localización es ligeramente variable.

El diseño de distintos cebadores que anillan específicamente en estos elementos y su empleo en reacciones de PCR permite obtener para cada cepa un patrón de bandas característico (Legras y Karst 2003).

Como ventaja indicar que esta técnica tiene una variabilidad mayor que otras y permite distinguir más cepas. Sin embargo, como inconveniente, una misma cepa puede dar patrones diferentes en función de parámetros tales como la cantidad de ADN molde utilizado o las condiciones de PCR, por lo que la comparación entre diferentes laboratorios es difícil.

\subsubsection{2.c. PCR de zonas repetitivas del genoma (microsatélites y minisatélites)}

Los microsatélites y los minisatélites son zonas repetidas en el genoma que se repiten en tándem de manera abundante y al azar, por lo que son adecuadas para la diferenciación de cepas debido a la variabilidad que presentan. 
Los microsatélites tienen una longitud inferior a 10 pares de bases, mientras que los minisatélites oscilan entre 10 y 100 pares de bases.

La amplificación y variabilidad de estas secuencias se puede poner de manifiesto empleando oligonucleótidos específicos como $(\mathrm{GTG})_{5},(\mathrm{GAG})_{5},(\mathrm{GACA})_{4}$ ○ M13 (Lieckfeldt et al., 1993) en reacciones de PCR.

Se trata de una técnica de alto poder de resolución y gran reproducibilidad. Para una resolución óptima de los fragmentos amplificados es necesario el análisis en geles de poliacrilamida, lo que la convierte en una técnica tediosa para el análisis de un gran número de muestras de manera rutinaria.

\subsubsection{Caracterización de híbridos de S. cerevisiae}

Las cepas industriales de Saccharomyces son organismos altamente especializados, debido principalmente a los diferentes procesos de domesticación sufridos. Uno de estos mecanismos ha sido la generación de híbridos interespecíficos entre diferentes especies del género Saccharomyces (de Barros Lopes et al. 2002). Los híbridos tendrán, por tanto, un genoma que será la mezcla de los correspondientes a sus parentales. Así, los híbridos adquieren propiedades correspondientes a ambos progenitores: por ejemplo la alta tolerancia al etanol y azúcares de S. cerevisiae y a las bajas temperaturas de S. kudriavzevii (González et al. 2006). Además varios autores han realizado de modo artificial, en laboratorio, la generación de híbridos interespecíficos con el objetivo de mejorar sus propiedades enológicas (de Barros Lopes et al. 2002; Sato et al. 2002; Bellon et al. 2011).

Los primeros híbridos entre $\mathrm{S}$. cerevisiae y $\mathrm{S}$. bayanus fueron identificados hace unas décadas (Kodama et al. 2005). Debemos distinguir entre los híbridos S. cerevisiae x S. bayanus var bayanus, aislado de cerveza, y los híbridos S. cerevisiae $\times \mathrm{S}$. bayanus var. uvarum que fueron aislados a partir de vino (Masneuf et al. 1998; Naumova et al. 2005; González et al. 2006; Le Jeune et al. 2007).

En los últimos años, se han caracterizado un nuevo tipo de híbridos, entre S. cerevisiae $\mathrm{x}$ S. kudriavzevii aislados de entornos fermentativos relacionados con la cerveza y el vino (Bradbury et al. 2006; González et al. 2006, 2008; Lopandić et al. 2007; Peris et al., enviado). De hecho, uno de los híbridos caracterizados corresponde con una de las cepas aisladas en el presente trabajo, cepa PB7, en la Cooperativa de Los Oteros durante la cosecha de 2005 (Peris et al., enviado).

Su caracterización consiste en un análisis de restricción de hasta 36 genes localizados en diferentes cromosomas (Ver figura 1.10) (González et al. 2008), acompañado de la secuenciación del gen nuclear MET6 y del gen mitocondrial COX2 (Peris et al., enviado).
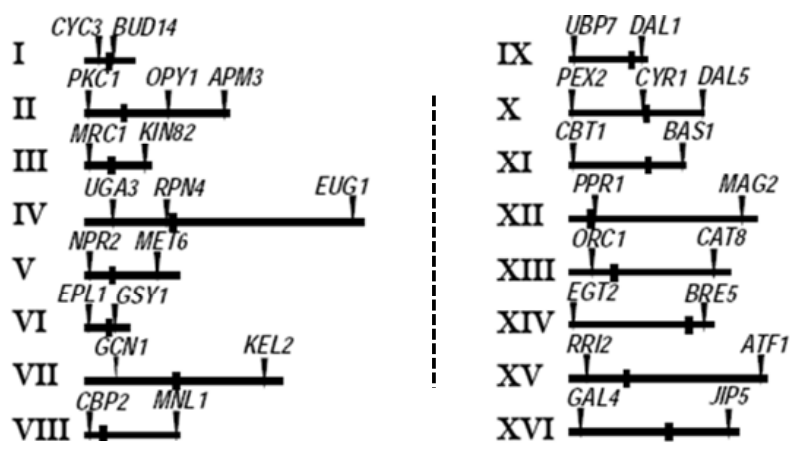

Figura 1.10: Distribución en los cromosomas de los genes diana empleados en el análisis de restricción, con el fin de caracterizar los híbridos de S. cerevisiae (Modificado de Peris et al., enviado). 


\subsubsection{Otras técnicas para la caracterización de levaduras}

Incluir en este apartado las técnicas que se desarrollarán a continuación responde a su capacidad de discriminación tanto a nivel de especie como a nivel de cepa. Por un lado aportan una mayor cantidad de información aunque su capacidad discriminatoria, a veces, no es concluyente, y en este caso necesitamos recurrir a cualquiera de las técnicas reseñadas en el apartado anterior para confirmar el pronóstico.

\subsubsection{Análisis del polimorfismo cromosómico}

Inicialmente la determinación del número de cromosomas presentes en un microorganismo se realizaba mediante observación directa al microscopio o mediante el establecimiento de relaciones de ligamiento entre genes conocidos. Estos procesos, sin embargo, resultan ser lentos y ciertamente complejos.

Un paso adelante fue la aparición del análisis de Polimorfismo de Longitud de Cromosomas (CLP, "Chromosome Length Polymorphism) (Degre et al., 1989), también conocida como técnica de Electroforesis en Campo Pulsante (PFE, "Pulsed Field Electrophoresis") (Querol et al. 1992).

En estas técnica es necesaria la preparación de las muestras para adecuarlas a las condiciones del tratamiento, básicamente consistente en la liberación de los cromosomas del interior del núcleo. Tanto en sistemas de preparación de muestras con producción de esferoplastos (levaduras desprovistas de la pared celular por acción enzimática) o sin ellos, el resultado final serán bloques de agarosas (plugs) listos para cargar en el gel que contendrán el genoma nuclear a estudiar.

En los sistemas de electroforesis en campo pulsante, los cromosomas son sometidos a un campo eléctrico pulsante aplicado en dos orientaciones diferentes que van cambiando. Estos migrarán a través de la matriz de agarosa dependiendo del tamaño y de su estructura tridimensional. Por tanto se resuelve el genoma en bandas cromosómicas obteniendose un cariotipo electroforético.

Desde el primer cariotipo descrito (Schwartz et al. 1984) se han descrito varios modelos con la intención de mejorar la resolución. Un salto cualitativo fue la descripción del sistema instrumental denominado CHEF (Electroforesis en campo eléctrico homogéneo, del inglés "Contour-clamped Homogeneus Electric Fields") descrito por Chu et al. (1986). El sistema constaba de un hexágono formado por 24 electrodos, capaz de producir un campo homogéneo alterno entre dos direcciones orientadas 120 grados. Estos autores fueron capaces de resolver el cariotipo de S. cerevisiae en quince bandas. A partir de entonces se ha empleado para la determinación del cariotipo de numerosas especies.

Actualmente existen mejoras de este sistema que permiten una mejor resolución en un menor tiempo. En estos es posible una orientación de los campos en direcciones diferentes de 120 grados, aparte de la modificación de diferentes parámetros.

\subsubsection{1.a. Polimorfismo cromosómico en levaduras vínicas}

Las cepas de levaduras vínicas muestran una amplia variación en sus patrones en Electroforesis en Gel de Campo Pulsante (PFGE). Cepas con diferente patrón se indicarán como diferentes, mientras que si presentan el mismo patrón, existe una alta posibilidad de que se trate del mismo clon. Esto se debería comprobar con otras técnicas como por ejemplo RFLP ADNmt.

Si bien, como se indica anteriormente, no podremos asegurar si nos encontramos o no con dos cepas diferentes al ver un resultado de PFGE, si podemos asegurar si nos encontramos 
ante una cepa de $\mathrm{S}$. cerevisiae o no. Aquellos cariotipos que presenten cuatro bandas diferentes (por tanto cuatro cromosomas) con un tamaño inferior a $500 \mathrm{~kb}$ nos aseguran su pertenencia a esta especie (de Jonge et al., 1986).

Yamamoto et al. (1991) consiguieron mediante PFGE diferenciar 51 patrones diferentes de 77 cepas vínicas industriales analizadas. Estos autores afirman que cepas con idéntico patrón electroforético del cariotipo pueden ser la misma cepa, aunque para asegurarnos sería necesario recurrir a técnicas como el RFLP-ADNmt. Otros autores también han empleado esta herramienta para diferenciar e identificar levaduras (Querol et al. 1992).

Los polimorfismos cromosómicos se deben a delecciones, inserciones y translocaciones, tanto intracromosómicos como intercromosómicos, de fragmentos de ADN con un tamaño suficiente para ser detectado mediante electroforesis (mínimo $10 \mathrm{~kb}$ ). En S. cerevisiae la reorganización cromosómica tiene lugar por recombinación entre secuencias homólogas muy repetidas en el genoma como por ejemplo los transposones de la familia Ty, regiones teloméricas y subteloméricas $\left(\mathrm{Y}^{\prime} \mathrm{y} X\right)$ y, en menor medida, los genes del ARN ribosómico y ARN transferente (Aguilera et al. 1993).

La citada técnica tiene un elevado poder de discriminación cuando se compara con otras técnicas moleculares, hasta el punto que algunos autores la erigen como la mejor técnica para discriminar entre diferentes cepas de S. cerevisiae (Schuller et al., 2004). Algo que no deja opción a duda es que esta técnica tiene el poder de revelar la existencia de grandes reordenamientos, principalmente mediados por la rápida evolución que sufren las cepas en los entornos industriales (Infante et al. 2003; Querol et al. 2003).

Algo que se debe de tener en cuenta en las cepas silvestres es la inestabilidad cariotípica. Estas reorganizaciones cromosómicas pueden dar lugar a polimorfismo cromosómico entre clones de una misma cepa o entre sus derivados meióticos. Este fenómeno tiene gran importancia desde el punto de vista industrial, ya que el uso de una cepa de levadura seleccionada que presente inestabilidad no garantiza la reproducibilidad en el producto final. La forma de detectar este fenómeno sería mediante análisis del cariotipo electroforético de un amplio número de clones aislados tras muchas generaciones en crecimiento vegetativo (Adams et al. 1992; Longo y Vezinhet 1993; Nadal et al. 1999).

Un reciente estudio ha empleado esta técnica para monitorizar la dinámica de poblaciones en fermentaciones espontáneas, así como en posteriores fermentaciones dirigidas por algunas de las levaduras seleccionadas en las primeras fermentaciones indicadas (Rodríguez et al. 2010). Tras un largo y exhaustivo estudio, durante nueve cosechas en laboratorio y a escala industrial, obtuvieron una cepa que era capaz de dominar en los procesos de fermentación y que confería al producto final unas características organolépticas destacadas. A la vista de estos resultados, la bodega en cuestión, optó por usar esta cepa como iniciadora de fermentación (previamente optaban por un proceso espontáneo de fermentación).

\subsubsection{Análisis de patrones electroforéticos de proteínas}

Esta metodología de identificación de levaduras consiste en el análisis de patrones electroforéticos de proteínas solubles celulares totales.

El primer paso para aplicar esta técnica pasa por la extracción de las proteínas totales de las células, la desnaturalización de aquellas y por último, su análisis, en un gel de poliacrilamida. En éste, las proteínas migrarán en función de su peso molecular, obteniéndose un patrón de bandas que podrá ser característico de un género, especie o cepa en particular. 
Aunque esta técnica nos permite un análisis bastante rápido de muestras, los complejos patrones de bandas obtenidos resultan difíciles de analizar. Esta técnica parece útil para caracterizar individualmente las cepas de levaduras empleadas en procesos industriales (Van Vuuren et al. 1987). Otros autores no encontraron diferencias, mediante esta técnica, entre las cepas de levaduras aisladas en una misma bodega (Guillamón et al. 1993).

Otros han descrito la escasa capacidad para discriminar cepas pertenecientes a una misma bodega, ya que sólo resultó útil para un pequeño número de cepas (Izquierdo et al., 1996). Estos mismos autores encontraron la relación entre el origen geográfico y ecológico de las levaduras analizadas y su perfil de proteínas. Además ponen de manifiesto la relación entre el cariotipo electroforético y el patrón proteico de estas levaduras vínicas. (AFLP)

1.7.5.3. Análisis del polimorfismo de la longitud de los fragmentos amplificados

Este método se ha empleado principalmente para el análisis de marcadores moleculares, así como en estudios de taxonomía y relaciones genéticas. Se realiza en cuatro etapas. En la primera el ADN genómico se corta o digiere con dos enzimas de restricción. Generalmente una de ellas es de corte no común, que reconoce de 6 a 8 pares de bases y otra de corte frecuente, que reconoce 4 pares de bases. En una segunda etapa, unos fragmentos de ADN llamados "adaptadores" se ligan de forma específica a los extremos de los fragmentos obtenidos en el paso anterior. En una tercera etapa se amplifican selectivamente fragmentos por PCR, ya que los oligonucleótidos empleados tendrán una secuencia complementaria a los adaptadores, además de uno a tres nucleótidos selectivos adicionales en su extremo 3'. La cuarta y última etapa del ensayo AFLP involucra el análisis de los fragmentos amplificados. Dos son las posibilidades descritas: el empleo de geles de poliacrilamida desnaturalizante (junto con un método revelado adecuado), o mediante un secuenciador automático (si uno de los iniciadores lleva un marcado fluorescente) (Vos et al., 1995).

La principal ventaja de este método radica que aprovechan el poder de la técnica de $\mathrm{PCR}$, junto con la innecesaridad de tener información previa de la secuencia. Además, los oligonucleótidos empleados son prácticamente universales y su uso puede ser extendido a cualquier especie. La laboriosidad de esta técnica podría ser uno de sus inconvenientes.

Esta técnica ha sido empleada en el estudio de levaduras (de Barros Lopes et al. 1999). Los resultados de este estudio ponen de manifiesto las relaciones genéticas entre las diferentes especies y cepas de levadura estudiadas. Junto a esto, queda demostrada su capacidad de discriminación tanto a nivel de especie como de subespecie. Recientemente se ha descrito una nueva metodología que no precisa oligonucleótidos marcados y el producto puede ser analizado mediante electroforesis en gel (Esteve-Zarzoso et al. 2010).

\subsection{Perfil aromático y sensorial de los vinos}

\subsubsection{Contribución de las levaduras en el perfil aromático y sensorial de los vinos}

La composición química de un vino es la base de su carácter sensorial y está determinada por varios factores como son: variedad de uva, condiciones geográficas de los cultivares, ecología microbiana en la uva y en fermentación y la prácticas de vinificación (Fleet 2003).

Los microorganismos tienen un papel muy importante en la composición química de los vinos. Así en el caso de S. cerevisiae, empleando diferentes cepas, es posible obtener vinos con diferentes propiedades organolépticas (variaciones en la producción de glicerol, ácido 
acético, etc.) (Henschke 1997), así como perfiles sensoriales y aromáticos distintos(ÁlvarezPérez et al., enviado).

En una fermentación alcohólica, la contribución de una levadura a las características organolépticas finales de un vino puede ser debida a cinco aspectos diferentes (Henschke 1997; Swiegers et al. 2005):

- La utilización de los constituyentes sólidos del mosto

- Producción de etanol y otros solventes que ayudarán a la extracción de los componentes aromáticos contenidos en la uva.

- Producción de enzimas capaces de transformar compuestos aromáticamente neutros (los denominados precursores) de la uva, en compuestos de gran aromaticidad.

- Producción de cientos de metabolitos secundarios aromáticos (alcoholes, ésteres, aldehídos, compuestos volátiles sulfurados, etc.).

- Degradación autolítica de las levaduras muertas.

En los vinos se han identificado más de un millar de compuestos volátiles, y de ellos, más de 400 son producidos por las levaduras en los procesos de fermentación (Nykänen, 1986), cuya naturaleza y concentración dependerá de las levaduras que realicen el proceso fermentativo. La singularidad e individualidad de la contribución de las diferentes levaduras dependerá de la ecología de fermentación y de los factores que determinen dicha ecología (Radler 1993; Fleet 2001).

El aroma final de un vino está compuesto por una amplia variedad de compuestos con diferentes propiedades aromáticas. Así podemos distinguir entre los compuestos originados a partir de las uvas (aromas varietales), compuestos formados en los procesos de obtención del mosto (aromas pre-fermentativos), compuestos producidos por levaduras o bacterias durante la fermentación alcohólica o maloláctica (aromas fermentativos), y por último los compuestos que pueden aparecer en los procesos de envejecimiento de los vinos (aromas postfermentativos) (Schreier 1979; Boulton et al. 1995; Rapp 1998; Romano et al. 2003). El perfil aromático estará dominado por los compuestos fermentativos, indicando por tanto la capacidad de las levaduras para producir vinos con distintas características organolépticas (Romano et al., 2003).

Destacar que los productos mayoritarios del metabolismo de las levaduras, etanol y dióxido de carbono, realizan una contribución escasa al aroma final de los vinos. Por contra, los ácidos orgánicos, alcoholes superiores, ésteres y, en menor medida, el acetaldehído, forman el denominado "fermentation bouquet" (Swiegers et al., 2005). Si bien, una concentración excesiva de estos compuestos puede resultar indeseable.

Algunos autores afirman que cuando se comparan vinos realizados con diferentes levaduras, aparecen diferencias cuantitativas en vez de cualitativas (Romano, 1997). Es decir, los productos obtenidos en las fermentaciones serían idénticos, variando únicamente las cantidades relativas de los diferentes compuestos. Los compuestos producidos por las levaduras se pueden dividir en dos clases. En la primera, se incluirían los compuestos que no varían significativamente dentro de una misma especie, aunque si lo hacen entre diferentes especies. Como ejemplo se podrían indicar el acetato de etilo y los alcoholes superiores. En la segunda clase estarían aquellos compuestos que se generan con amplia variabilidad dentro de una misma especie. Como ejemplo de estos compuestos podíamos indicas el isobutanol y el alcohol isoamílico (Romano et al., 2003). 
Como se ha mencionado, la levadura ejerce un papel importante en la formación de compuestos aromáticos, bien a partir de precursores inodoros o a partir del proceso fermentativo. Para conocer un poco mejor la relación existente entre levadura y variedad de uva (mosto precursor) se han diseñado experimentos con este fin. Tras realizar microvinificaciones con las mismas levaduras sobre mostos de diferente origen, se comprobó una variación importante en los perfiles aromáticos obtenidos (Romano et al., 2003). Adicionalmente, se realizaron microvinificaciones empleando diferentes cepas de $\mathrm{S}$. cerevisiae sobre la misma variedad de mosto y de nuevo se obtuvo una gran variabalidad en los compuestos analizados. Por tanto se podría indicar que la calidad final de un vino es el resultado de la interacción entre la levadura y la composición del mosto de uva. Este mismo resultado fue obtenido por Álvarez-Pérez et al. (enviado) en su estudio realizado sobre la variedad de uva Prieto Picudo (autóctona de la provincia de León, España), empleando diferentes levaduras autóctonas aisladas de microvinificaciones espontáneas de esta variedad.

A continuación se verán por separado las familias aromáticas más importantes y la contribución directa que ejercen las levaduras sobre éstas, tanto en su producción como en su modificación.

\subsubsection{1. Ácidos}

\subsubsection{1.a. Ácidos no volátiles}

La acidez de un mosto o un vino tiene un impacto directo sobre su calidad sensorial y su estabilidad física, bioquímica y microbiológica (Fowles, 1992). Los ácidos pueden tener un impacto tanto positivo como negativo en el aroma y sabor, dependiendo de la concentración, tipo y estilo de vino. Los ácidos orgánicos no-volátiles predominantes serán el ácido tartárico y el ácido málico ( $90 \%$ de la acidez valorable en un mosto). El ácido cítrico y el ácido láctico también contribuyen a la acidez del mosto. El ácido succínico y los cetoácidos se encuentran presentes en trazas en el mosto, aunque su concentración aumenta en los vinos debido a la fermentación (Fowles 1992; Radler 1993).

Un desequilibrio en la acidez puede dar lugar al desarrollo de compuestos ácidos y a su modificación física y microbiológica durante el proceso de vinificación. Un vino con una acidez no equilibrada puede ser considerado defectuoso. En los climas fríos se suele hacer un ajuste del producto final para acondicionarlo a las premisas del mercado mediante neutralización con carbonato cálcico y precipitación. En los climas calientes, el ajuste a realizar va en la dirección de aumentar la acidez valorable, adicionando principalmente ácido tartárico (también es posible la adición ácido cítrico y/o ácido málico en función de la legislación). Esta práctica influye en el producto final con una bajada del $\mathrm{pH}$.

El ácido tartárico es estable a la acción de los microorganismos, de hecho, se producen ligeros cambios en su concentración durante el proceso de fermentación. La mayoría de las levaduras pueden utilizar el ácido málico: Saccharomyces cerevisiae es capaz de degradar entre el 3-45 \% de ácido málico, mientras que otras especies de levadura (Schizosaccharomyces) son capaces de degradarla por completo a dióxido de carbono y etanol (Radler 1993; Giudici et al. 1995). El ácido succínico es el principal ácido dicarboxílico producido en fermentación (hasta $2 \mathrm{~g} / \mathrm{L}$ ) (Radler 1993; Coulter et al. 2004). A éste se le atribuye un sabor "salado y amargo". Los cetoácidos, principalmente el ácido pirúvico y el ácido $\alpha$-cetoglutárico juegan un papel importante en la estabilidad y calidad final del vino debido a su capacidad de unir dióxido de azufre y de reaccionar con los fenoles (Rankine 1967, 1968; Rankine y Pocock 1969). La cepa de levadura tiene influencia en la formación de éstos, aunque el contenido y el tipo de nitrógeno del medio también juegan un papel importante. 
El ácido láctico, principal producto de la fermentación maloláctica, puede estar presente en vino en cantidades de hasta $6 \mathrm{~g} / \mathrm{L}$. Este no es eficientemente producido por S. cerevisise (producción de pequeñas cantidades) debido a la ineficiencia que presentan sus lactato deshidrogenasas mitocondriales (Dequin y Barre 1994).

\subsubsection{1.b. Ácidos volátiles}

Son ácidos orgánicos volátiles con una corta cadena carbonada. Suelen encontrarse en concentraciones entre 500-1000 mg/L (10-15\% del contenido total de ácidos). De ellos el ácido acético supone el 90\% (Fowles 1992; Radler 1993). El resto de ácidos (principalmente propiónico o hexanoico) son producidos a través del metabolismo de ácidos grasos de levaduras y bacterias.

Es importante indicar que aunque S. cerevisiae tiene la capacidad de producir ácido acético, una concentración excesiva de éste suele ser debida al metabolismo aeróbico del etanol por bacterias acéticas. El ácido acético tendrá importancia en el producto final, influyendo en gran medida su concentración. Los rangos de concentración óptimos de este parámetro pueden variar dependiendo del tipo de vino (Campo et al. 2005; Corison et al. 1979; Romano 1990; Scanes et al. 1998).

\subsubsection{Alcoholes}

\subsubsection{2.a. Etanol}

Debido a la gran cantidad de azúcares presentes en las uvas (elevada madurez), los vinos producidos alcanzan tasas muy elevadas de etanol, superando incluso el $15 \%(\mathrm{v} / \mathrm{v})$. La presencia de etanol es esencial para potenciar los atributos sensoriales presentes en los vinos. Sin embargo un exceso puede producir un efecto "picante" e incluso enmascarar el paladar y aroma de los vinos (de Barros Lopes et al. 2003).

Son varias las estrategias encaminadas a la reducción del etanol final en los vinos, debido a la demanda de mercado. La mayoría de los procesos físicos empleados son de alto coste y conllevan una disminución en el aroma y sabor debido a la perdida y/o modificación de estos compuestos en los citados procesos (Swiegers et al., 2005). Otra estrategia sería emplear levaduras con una menor tolerancia al etanol, de manera que cuando se alcanza cierta tasa de etanol el desarrollo de éstas es inviable produciéndose una parada del proceso fermentativo, resultando un vino con menor grado alcohólico. Debido a la imposibilidad de modificar genéticamente los microorganismos para usarlos en vinificación, la obtención de cepas con estas capacidades pasa por una selección de cepas con estas características (Jia et al., 2010). El problema asociado a esta estrategia sería la eliminación de los azúcares residuales en el producto final, ya que estos pueden provocar efectos indeseados (segunda fermentación, proliferación de microorganismos indeseados, etc.), por tanto se hace necesario la eliminación de éstos por métodos químicos. Otra estrategia a emplear sería la desalcoholización durante el proceso de fermentación, obteniendo un vino de menor grado alcohólico (Aguera et al., 2010).

\subsubsection{2.b. Glicerol}

El glicerol es un polialcohol incoloro, inodoro y con un elevado carácter viscoso. Tiene un sabor ligeramente dulce con una sensación en boca aceitosa y pesada. En los vinos secos 0 semi-dulces se encuentra en concentraciones entre 5 y $14 \mathrm{~g} / \mathrm{L}$ (mayor cantidad en vinos tintos que en blancos). En los vinos elaborados a partir de uva con botritis puede llegar a alcanzar valores de hasta $25 \mathrm{~g} / \mathrm{L}$ (Ough et al. 1972; Scanes et al. 1998). El glicerol no tiene impacto sobre las características aromáticas de los vinos, sólo en algunos casos podría tener efecto sobre la dulzura aparente de éstos (Noble y Bursick 1984). Para que se produzca un aumento 
en la viscosidad de un vino son necesario valores de glicerol superiores a $25 \mathrm{~g} / \mathrm{L}$ (Noble y Bursick 1984). Por tanto las lágrimas que se aprecian en las copas de vino no tienen relación directa con la concentración de glicerol (Swiegers et al., 2005).

\subsubsection{2.c. Alcoholes superiores}

También conocidos como alcoholes de fusel. Son metabolitos secundarios de las levaduras en la fermentación alcohólica. Pueden tener un impacto positivo (notas frutales) pero también negativo (picante) en función de las concentración en la que se encuentren en los vinos. Se dividen en alcoholes alifáticos y aromáticos (Swiegers et al., 2005). Su concentración en vinos vendrá influenciada principalmente por dos factores; por un lado la levadura empleada en fermentación (Giudici et al. 1990) y por otro la concentración de aminoácidos (precursores de los alcoholes superiores) en el mosto (Schulthess y Ettlinger 1978). Además otros factores que influyen en menor medida serán la concentración de etanol, la temperatura de fermentación, composición del mosto, aireación, madurez de la uva, etc. (Fleet y Heard 1993).

\subsubsection{Compuestos carbonílicos}

El acetaldehído es el compuesto con mayor importancia dentro de esta familia, encontrándose en los vinos en concentraciones que oscilan entre 10-75 mg/L (Schreier, 1979). La nota aromática aportada por este compuesto a los vinos suele ser definida como "manzana magullada", "nuez", aunque suele ser una señal que indica que el vino está oxidado (Swiegers et al., 2005). Factores como la oxidación de etanol o la aireación, influirán en su concentración en los vinos (Fleet y Heard 1993), al igual que la cepa empleada y la temperatura a la que se realiza la fermentación.

Otro compuesto carbonílico de gran importancia es el diacetilo (butano-2,3-diona) que evoca claramente a "mantequilla". Las levaduras son capaces de sintetizar pequeñas cantidades de este compuesto $(0,2-0,3 \mathrm{mg} / \mathrm{L})$, aunque cuando aparece a concentración excesiva será debida a la acción de las bacterias lácticas (Bartowsky y Henschke 2004).

\subsubsection{Fenoles volátiles}

Sus precursores son los ácidos hidrocinámicos presentes en las uvas y transformados por las levaduras en los correspondientes fenoles volátiles a lo largo de la fermentación (Fleet 2008). Presentan un bajo umbral de detección, y aunque su contribución al aroma final puede ser positiva, su contribución negativa es la más conocida. Los etilfenoles (4-etilguaiacol y 4etilfenol) producen aromas a "cuadra", "establo", mientras que los vinilfenoles (4-vinilfenol y 4-vinilguaiacol) producen olor a "medicamento" (Dubois, 1983).

Los ácidos fenólicos pueden ser descarboxilados para dar lugar a fenoles volátiles, aunque esta actividad enzimática tiene una baja eficiencia en la mayoría de las cepas de $\mathrm{S}$. cerevisiae (Barthelmebs et al., 2000). La levadura Brettanomyces es capaz de producir etilfenoles con alta eficiencia, siendo necesario el control de este microorganismo al final de la fermentación para evitar el deterioro del producto final (Coulon et al. 2010). Otra fuente importante de etilfenoles, principalmente 4-etilguaiacol y 4-etilfenol, es el proceso de envejecimiento en roble (Rayne y Eggers 2007; 2008).

\subsubsection{5. Ésteres}

La producción de ésteres durante la fermentación juega un papel muy importante en las notas frutales de los vinos. Los más importantes son el acetato de etilo (frutal, disolvente), acetato de isoamilo (acetato de isopentilo, pera, plátano), acetato de isobutilo (plátano), caproato de etilo (hexanoato de etilo, manzana) y acetato de feniletilo (miel, frutal, floral) (Swiegers et al., 2005). 
Las cepas de levadura juegan un papel importante en la producción de los ésteres en el proceso de fermentación, aunque también tiene gran importancia la variedad de uva. Esto es debido a que los ésteres son sintetizados por las levaduras a partir de los precursores presentes en aquellas. Esta es la razón por la que el espectro de ésteres que nos encontramos en los diferentes vinos varía significativamente. Se podría hablar de un efecto sinérgico entre el metabolismo de la levadura y la uva dando como resultado un perfil determinado de ésteres en un vino en particular (Ferreira 2010; Swiegers et al. 2005).

\subsubsection{Compuestos de azufre}

Aparecen en los vinos en muy bajas concentraciones, aunque debido a su bajo umbral de detección, confieren, por lo general, características negativas a los vinos. Se dividen principalmente en cinco familias: sulfuros, polisulfuros, compuestos heterocíclicos, tioésteres y tioles. La mayoría de estos compuestos son asociados con descriptores negativos (basura, huevos podridos, ajo, cebolla, etc.), mientras que otros contribuyen a la complejidad de los vinos aportando notas apreciadas por los consumidores (fruta de la pasión, mango verde, boj, pomelo, etc.) (Darriet et al. 1995; Tominaga et al. 1996, 2000). En la tabla 1.3 aparecen los diferentes compuestos azufrados junto con su descriptor aromático.

\subsubsection{El aroma en los vinos}

El aroma de los vinos es uno de los más complejos que nos podemos encontrar en la naturaleza. Las razones son varias, destacando (Ferreira y Cacho 2009):

- Existen una gran cantidad de vinos diferentes, cada uno con un aroma distinto.

- Los vinos exhiben aromas cambiantes con el tiempo, bien durante el periodo que permanecen embotellados o simplemente desde que es servido en copa hasta que es consumido.

- La diferente percepción que cada consumidor puede hacer de un mismo vino. Normalmente un vino no presenta un aroma característico, sino una ammplia paleta de suaves matices difíciles de definir, que con toda seguridad tendrá diferente percepción entre individuos diferentes.

En realidad el aroma de un producto es el resultado de un complejo equilibrio entre diferentes compuesto químicos. Así, por ejemplo, productos como el vino, el café o el cacao pueden presentar más de 1.000 moléculas volátiles (Maarse y Vischer 1989), sin embargo, sólo unas pocas aportarán los matices importantes y distinguibles.

\subsubsection{Estimación de la aportación de un compuesto al aroma final}

Una sustancia química se considerará aromática si es capaz de interactuar con nuestra pituitaria provocando una respuesta sensorial. Por la disposición de la pituitaria, esto sólo es posible si estamos hablando de moléculas volátiles. Sabemos que todas las moléculas aromáticas son volátiles (Leffingwell, 2002), pero también es verdad que casi todas las moléculas volátiles son aromáticas (salvo los gases nobles, el agua, y un limitado número de moléculas sencillas). Otro parámetro a tener en cuenta es la diferente respuesta de nuestro epitelio olfativo a los diferentes compuestos, con variaciones en varios órdenes de magnitud en las concentraciones que serán detectadas.

Por tanto es necesario definir unos parámetros que nos indiquen la capacidad de los diferentes compuestos de interferir en el aroma final:

- Umbral: Indica la concentración a partir de la cual un compuesto tiene la capacidad de interaccionar con la pituitaria. Este parámetro tiene cierta utilidad 
si está calculado en solución acuosa, ya que la mayoría de los odorantes están disueltos en una matriz de la cual son liberados. La facilidad de obtención de este parámetro hace que sea de uso general e incluso se encuentre tabulado.

- $\underline{\text { OAV }}$ (Valor de aroma, del inglés "Odour Activity Value"): Será el cociente entre la concentración de un compuesto en un producto y el umbral de ese compuesto en una matriz lo más similar posible (Grosch, 1993). Se puede afirmar que una concentración de un producto, diez órdenes de magnitud por debajo de su umbral $(O A V>0,1)$ no es relevante para el aroma. Sin embargo, una concentración de un compuesto por encima de su umbral $(O A V>1)$ es necesaria para que un compuesto sea significativo, aunque no siempre es suficiente. No debemos olvidarnos que este índice es una mera aproximación de la aportación de un compuesto al aroma final. En estudios realizados por Ferreira et al. (2003) se ha demostrado como dos compuestos ( $\beta$-damascenona y 4-metil-4mercaptopentanona) con la misma intensidad olfativa presentaban dos valores muy diferentes de OAV. En el primero de los casos se sobreestimaba su valor de actividad del olor, mientras que en el segundo se infraestimaba.

Los parámetros indicados varían entre diferentes individuos, llegando a existir una diferencia de un orden de magnitud (Punter, 1983). No nos podemos olvidar de los individuos insensitivos a determinados compuestos (anosmia) donde las diferencias pueden llegar hasta cinco órdenes de magnitud (Amoore, 1977).

\subsubsection{Base aromática de los vinos}

Como ya se ha indicado, de los varios cientos de compuestos volátiles que podemos encontrar en un vino, las moléculas verdaderamente significativas en el aroma final del vino oscilan en torno a 20-70. Entre estas moléculas existen varias que se encuentra en todos los vinos. Se trata de 27 compuestos fermentativos (Tabla 1.2), los cuales se encuentran en concentraciones superiores a sus umbrales y que en conjunto aportan el denominado aroma "vinoso" (Ferreira 2010). Junto con estos compuestos, aunque su origen no es fermentativo, se debe de incluir la B-damascenona ya que se encuentra en todos los vinos por encima de su concentración umbral.

La composición relativa de los compuestos que forman parte de esta base varía en función de varios parámetros como son: concentración de azúcares, cepa de levadura empleada, grado de anaerobiosis en el proceso, etc.

Tabla 1.2: Compuestos de la base del aroma del vino (Ferreira 2010).

\begin{tabular}{|c|c|c|c|c|c|c|}
\hline Varios & $\begin{array}{l}\text { Alcoholes } \\
\text { de fusel }\end{array}$ & $\begin{array}{l}\text { Ácidos } \\
\text { Orgánicos }\end{array}$ & Isoácidos & $\begin{array}{l}\text { Ésteres etilo } \\
\text { ácidos orgánicos }\end{array}$ & $\begin{array}{l}\text { Acetatos de } \\
\text { alcoholes }\end{array}$ & $\begin{array}{l}\text { Ésteres etilo } \\
\text { isoácidos }\end{array}$ \\
\hline Etanol & Isobutanol & $\begin{array}{l}\text { Ácido } \\
\text { acético }\end{array}$ & $\begin{array}{l}\text { Ácido } \\
\text { isobutírico }\end{array}$ & Acetato etilo & $\begin{array}{l}\text { Acetato } \\
\text { de isobutilo }\end{array}$ & $\begin{array}{l}\text { Isobutirato } \\
\text { de etilo }\end{array}$ \\
\hline Diacetilo & $\begin{array}{l}\text { Alcohol } \\
\text { isoamílico }\end{array}$ & $\begin{array}{l}\text { Ácido } \\
\text { butírico }\end{array}$ & $\begin{array}{l}\text { Ácido } \\
\text { 2-metilbutírico }\end{array}$ & Butirato etilo & $\begin{array}{l}\text { Acetato } \\
\text { isoamilo }\end{array}$ & $\begin{array}{l}\text { Butirato de } \\
\text { 2-metiletilo }\end{array}$ \\
\hline \multirow[t]{3}{*}{ Acetaldehido } & Hexanol & $\begin{array}{l}\text { Ácido } \\
\text { hexanoico }\end{array}$ & $\begin{array}{l}\text { Ácido } \\
\text { isovaleriánico }\end{array}$ & Hexanoato etilo & $\begin{array}{l}\text { Acetado } \\
\text { de } \beta \text {-feniletilo }\end{array}$ & $\begin{array}{l}\text { Isovalerato } \\
\text { de etilo }\end{array}$ \\
\hline & $\beta$-feniletanol & $\begin{array}{l}\text { Ácido } \\
\text { octanoico }\end{array}$ & & Octanoato etilo & & \\
\hline & Metionol & $\begin{array}{l}\text { Ácido } \\
\text { decanoico }\end{array}$ & & Decanoato etilo & & \\
\hline
\end{tabular}




\subsubsection{Efecto tampón del aroma}

Se denomina de este modo tan peculiar atendiendo a la similitud encontrada con los tampones ácido-base por todos conocidos. De igual manera que estos últimos son capaces de contrarrestar la adición de pequeñas cantidades de un ácido o base, el tampón aromático tendrá la capacidad de contrarrestar la omisión de uno de sus componentes (Ferreira et al. 2002) o la adición a la mezcla de algún componente (Escudero et al. 2004). En el primero de los casos no se observaban apenas diferencias, salvo para la $\beta$-damascenona (se observaba una disminución en la nota frutal, debido a su efecto potenciador de esa nota en particular). En el segundo de los casos, el efecto de la adición de compuestos supuso desde ningún efecto, hasta la disminución de algunos atributos básicos (salvo para el acetato de isoamilo, con un olor característico a plátano).

La mayoría de los vinos que nos encontramos en los mercados presentan notas aromáticas que se alejan de las que aporta la base "vinosa" anteriormente mencionada. Es decir, de algún modo se ha conseguido romper el efecto tampón reseñado. Este se puede romper mediante cuatro mecanismos principalmente (Ferreira 2010):

- Mediante una única molécula con una concentración lo suficientemente grande. Por ejemplo mediante el acetato de isoamilo.

- Mediante una familia de compuestos aromáticos. Por ejemplo las $y$-lactonas en algunos vinos tintos

- Grupos de compuestos no pertenecientes a la misma familia aromática pero que presentan un descriptor aromático similar, por ejemplo la nota dulce. Así se podrían indicar el linalol, las $\mathrm{y}$-lactonas y los cinamatos de etilo en los vinos blancos.

- Mediante un potenciador de aroma, de modo que la nota aromática puede ser debida al propio potenciador o a alguno de los compuestos sobre los que actúa.

\subsubsection{Papeles desempeñados por los diferentes compuestos aromáticos}

El modo de conocer el efecto de un compuesto en un aroma complejo, sólo es posible mediante los experimentos sensoriales de reconstitución, adición u omisión (Grosch, 1993). En los experimentos de reconstitución se realiza una mezcla sintética de aromas a concentraciones similares a las encontradas en los vinos. A continuación, en mezclas similares a las anteriores, se añadirá o se omitirá un compuesto (o familia de compuestos). Posteriormente, las diferentes mezclas obtenidas serán analizadas por un panel sensorial para conocer el efecto producido.

Tras la realización de estos experimentos, podemos asegurar que el papel que puede jugar un compuesto, o familia de compuestos, sería uno de los siguientes (Ferreira 2010):

- Compuesto de impacto auténtico: Aquellos compuestos individuales que en concentraciones lo suficientemente altas son capaces de transmitir al vino sus específicas notas aromáticas.

- Contribuidor principal: Compuestos individuales o familias de compuestos, presentes en el vino en concentraciones suficientemente altas para transmitir a los vinos un descriptor genérico primario (fruta roja, cítrico, etc.). Es importante reseñar que si el compuesto, o la familia de ellos, es eliminada, el efecto sensorial será muy intenso tanto cuantitativamente como cualitativamente.

- Contribuidor neto: Compuestos individuales o familias, capaces de transmitir un descriptor genérico (dulce, frutal, etc.). Si se elimina el compuesto o el conjunto de compuestos que forman parte de la familia, se producirá una disminución en la nota 
aromática, aunque no se producirá un gran cambio cualitativo en el perfil aromático.

- Contribuidor secundario: Compuestos individuales o familias de aromas que se encuentran en los vinos a una concentración inferior a la necesaria para transmitir de modo individual su carácter genérico. El efecto aromático de estos compuestos tiene cierta importancia debido a su actuación conjunta con otras familias de compuestos. Si se elimina alguno de estos compuestos de un vino, su efecto puede ser muy sutil e incluso nulo.

- Potenciador del aroma: Son compuestos que no tienen la capacidad de aportar una nota aromática a los vinos, pero que tienen la capacidad de potenciar el aroma de otra molécula o grupo de moléculas. A veces el efecto potenciador produce un nuevo aroma en los vinos, producto de la mezcla de los aromas base con el potenciador. Por supuesto, si se elimina el potenciador aromático, la intensidad de la nota aromática que resultaba potenciada se verá afectada. Un ejemplo de este tipo de compuesto sería la $\beta$-damascenona, capaz de potenciar las notas frutales debidas a los ésteres (Escudero et al. 2007).

- Depresor del aroma: Sería el efecto contrario al anterior, un compuesto o una familia de compuestos serían capaces de disminuir la intensidad de una nota aromática. Por supuesto, si el depresor es eliminado del vino, se producirá un aumento en la nota que había resultado reducida. El 4-etilfenol en altas concentraciones provoca en los vinos un aroma indeseado (cuero, animal), mientras que si se encuentra a baja concentración (por debajo de su umbral de reconocimiento) es capaz de disminuir la nota frutal de un vino (Aznar et al., 2003).

\subsubsection{Clasificación de las moléculas aromáticas en función del papel desempeñado}

En la tabla 1.4 se presenta, de modo resumido, la clasificación de los diferentes compuestos que juegan un papel importante en el aroma final de un vino. Se dividen en dos subgrupos, "Compuesto de Impacto" y "Familias Homogéneas de Aromas". Los primeros se dividirán en tres subgrupos en función del origen de estos. Las familias aromáticas, con origen principalmente fermentativo, actuarán de modo aditivo en el aroma final de los vinos de los que formen parte (Ferreira 2010).

Así, a partir de la paleta de 26 diferentes olores descrita (16 compuestos de impacto y 10 familias) se podría explicar la mayoría de los perfiles aromáticos de cualquier vino que nos pudiéramos encontrar en el mercado. 
Tabla 1.3: Compuestos de azufre encontrados de modo general en los vinos. Se indica, junto al compuesto, su concentración típica en los vinos, el umbral de detección y por último la descripción aromática (Modificado de Swiegers et al. (2005))

\begin{tabular}{|c|c|c|c|}
\hline Compuesto & Concentración vino $(\mu \mathrm{g} / \mathrm{L})$ & Umbral aromático $(\mu \mathrm{g} / \mathrm{L})$ & Descriptor \\
\hline Sulfuro de hidrógeno & Trazas $\rightarrow 80$ & $10-80$ & Huevo podrido \\
\hline Metanotiol (metil mercaptano) & $2,1-5,1$ & 0,3 & Repollo cocido, cebolla, putrefacción, goma \\
\hline Etanotiol (etil mercaptano) & $1,9-18,7$ & 1,1 & Cebolla, goma, gas natural \\
\hline Sulfuro de dimetilo & $1,4-61,9$ & 25 & Espárragos, maíz, melaza \\
\hline Sulfuro de dietilo & $4,1-31,8$ & 0,93 & Vegetales cocidos, cebolla, ajo \\
\hline Disulfuro de dimetilo & 2 & 15,29 & Col cocida, cebolla (intenso) \\
\hline Disulfuro de dietilo & Trazas $\rightarrow 85$ & 4,3 & Ajo, goma quemada \\
\hline 3-(metiltio)propanol (metionol) & $140-5000$ & 500 & Coliflor, col, patata \\
\hline Benzotiazol & 11 & 50 & Goma \\
\hline Tiazol & $0-34$ & 38 & Palomita, cacahuete \\
\hline 4-metiltiazol & $0-11$ & 55 & Avellana verde \\
\hline 2-furanometanotiol & $0-350 \mathrm{ng} / \mathrm{L}$ & $1 \mathrm{ng} / \mathrm{L}$ & Café tostado, goma quemada \\
\hline Tiofeno-2-tiol & $0-11$ & 0,8 & Quemado, goma quemada, café tostado \\
\hline 4-mercapto-4-metilpentan-2-ona (4MMP) & $0-30 \mathrm{ng} / \mathrm{L}$ & $3 \mathrm{ng} / \mathrm{L}$ & Orina de gato, boj, grosella negra, \\
\hline 3-mercaptohexanol (3MH) & $50-5000 \mathrm{ng} / \mathrm{L}$ & $60 \mathrm{ng} / \mathrm{L}$ & Fruta de la pasión, pomelo \\
\hline Acetato de 3-mercaptohexilo (3MHA) & $1-100 \mathrm{ng} / \mathrm{L}$ & $4 \mathrm{ng} / \mathrm{L}$ & Fruta de la pasión, boj, nota característica vinos Riesling \\
\hline
\end{tabular}




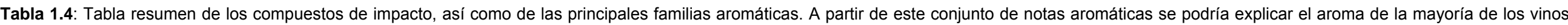
existentes (Ferreira 2010)

\begin{tabular}{|c|c|c|c|c|c|}
\hline \multicolumn{6}{|c|}{ COMPUESTOS DE IMPACTO } \\
\hline \multicolumn{2}{|r|}{ Compuestos de impacto varietal } & \multicolumn{2}{|c|}{ Compuestos de impacto fermentativo } & \multicolumn{2}{|c|}{ Compuestos de impacto relacionado con el añejamiento } \\
\hline Compuesto & Nota aromática & Compuesto & Nota aromática & Compuesto & Nota aromática \\
\hline Linalol & $\begin{array}{l}\text { Nota floral e incluso cítrica en variedades } \\
\text { blancas (Campo et al. 2005; Palomo et al. 2006) }\end{array}$ & Diacetilo & Mantequilla (Bartowsky y Henschke 2004) & (E)-Whiskylactona & Madera \\
\hline Óxido de rosa cis & Carácter floral (Guth, 1997) & Acetato de isoamilo & Plátano (Ferreira et al. 2000) & $\begin{array}{l}\text { Sotolón (3-hidroxi-4,5-dimetil- } \\
2(5 \mathrm{H}) \text {-furanona) }\end{array}$ & $\begin{array}{l}\text { Curry, alhova, caramelo (Masuda et } \\
\text { al. 1984; Moreno et al. 2005; Campo et } \\
\text { al. 2008) }\end{array}$ \\
\hline$\beta$-damascenona & $\begin{array}{l}\text { Potenciador aromas frutales (Escudero et al. 2007) } \\
\text { Compuesto clave vinos de Pedro Jiménez (Campo et } \\
\text { al. 2008) }\end{array}$ & & & Furfuriltiol (FFT) & $\begin{array}{l}\text { Café. Formado por la reacción } \\
\text { del furfuril del roble y el ácido } \\
\text { sulfídrico de fermentación } \\
\text { (Blanchard et al., 2001) }\end{array}$ \\
\hline $\begin{array}{l}\text { 4-mercapto-4- } \\
\text { metilpentan-2-ona }\end{array}$ & $\begin{array}{l}\text { Aroma a boj. Característico de vinos Sauvignon } \\
\text { Blanc y Prieto Picudo (Darriet et al. 1995; Álvarez-Pérez et } \\
\text { al., enviado) }\end{array}$ & & & $\begin{array}{l}\text { Bencilmercaptano } \\
\text { (bencenometanotiol) }\end{array}$ & Aroma tostado (Tominaga et al. 2003) \\
\hline 3-mercaptohexan-1-ol & $\begin{array}{l}\text { Mango verde, boi y goma (Bouchilloux et al. } 1998 \text {; } \\
\text { Campo et al. 2008; Álvarez-Pérez et al., enviado;PPérez et al., } \\
\text { enviado) }\end{array}$ & & & Dimetilsulfuro (DMS) & $\begin{array}{l}\text { Defecto (olor azufre) (Silva Ferreira et } \\
\text { al., 2003)- Potenciador notas } \\
\text { frutales (Escudero ef al. 2007) }\end{array}$ \\
\hline $\begin{array}{l}\text { Acetato de 3- } \\
\text { mercaptohexilo }\end{array}$ & Fruta tropical (Campo et al. 2005) & & & Metional (3-(metiltio)propanal) & $\begin{array}{l}\text { Olor desagradable (Escudero et al. } \\
\text { 2000)- Notas apreciadas en vinos } \\
\text { complejos (Ferreira et al. 2005) }\end{array}$ \\
\hline Rotundona & Notas especiadas (Wood et al., 2008) & & & Fenilacetaldehido & Miel (Campo et al. 2008) \\
\hline
\end{tabular}

Ésteres de etilo de ácidos grasos

Y-lactonas alifáticas

Fenoles volátiles (guaicol, eugenol, 2,6-dimetoxifenol

Vainillas (vainillina, vainillato de metilo, vainillato de etilo, etc.)

Compuestos Azúcar-quemado (furaneol, homofuraneol, maltol)

Acetatos de alcoholes de fusel

Aldehidos alifáticos ( 8,9 y 10 átomos de $\mathrm{C}$ )

Aldehidos ramificados (2-metilpropanal, 2-metilbutanal, 3-metilbutanal)

Ésteres de etilo de ácidos grasos ramificados o cíclicos

Etil cinanmato y dietilcinamato
Nota aromática

Notas frutales vinos blancos (manzana, etc.) (Ferreira et al. 1995)

Aroma a melocotón (Ferreira et al., 2004) y notas frutales (Loscos et al., 2007)

Notas fenólicas y tostadas (Escudero et al. 2007)

Notas dulces florales (Loscos et al., 2007)

Notas dulces de los vinos (Ferreira et al. 2005)

Notas florales y/o notas frutales de vinos blancos (Campo et al. 2005)

Notas cítricas (Culleré, 2005)

Contribución al aroma de vinos envejecidos (Culleré, 2005)

Notas frutales vinos tintos (Ferreira et al. 2009)

Notas dulces y florales (Loscos et al. 2007 y 2009) 

II. Objetivos del Trabajo 

La tendencia actual en la industria vitivinícola pasa por el uso de levaduras comerciales como iniciadoras de fermentación (LSAs). Si bien, por un lado, están demostradas las ventajas de esta práctica con respecto a las fermentaciones espontáneas (proceso controlado, reproducible y con unas características del producto final acorde a lo esperado), existen inconvenientes asociados a esta estrategia productiva. Desde el año 1965, cuando se comercializaron las primeras levaduras comerciales con fines industriales, hasta el día de hoy existen un número elevado de LSAs en el mercado con diferententes propiedades enológicas. Sin embargo, debido al gran número de variedades, denominaciones, tipos de vinos, etc., se podría afirmar que el número de LSAs es ciertamente limitado y su uso ha pasado a ser "universal", de manera que un reducido grupo de cepas se usan a nivel mundial.

En la revisión hecha hasta el momento, se ha puesto de manifiesto la gran influencia ejercida por las levaduras en los vinos producidos, sobre todo en lo que se refiere a sus características sensoriales. Si sobre dos variedades diferentes se emplea una misma levadura parece lógico pensar que ciertas características del producto final puedan presentar cierta similitud. Es decir, las características de los vinos podrían "estandarizarse" perdiendo la tipicidad asociada a la variedad en cuestión.

En el presente trabajo se plantea la posibilidad de seleccionar levaduras autóctonas de bodegas que elaboran vinos con la variedad Prieto Picudo para poder ser usadas en un futuro como cultivos iniciadores de los vinos bajo la DO «Tierra de León». La regionalidad de las cepas nos garantizará la total adaptación de éstas a las características del mosto y a las condiciones climáticas de la región, dotando a los vinos de unas características únicas. Estas características harán que el producto sea "claramente diferenciable" del resto.

Por tanto, los obj etivos planteados para el presente trabajo serían:

1. Aislar levaduras autóctonas de la variedad de uva Prieto Picudo (DO «Tierra de León»)

2. Realizar una caracterización genética de las diferentes levaduras aisladas durante el estudio.

3. Realizar una caracterización fenotípica de las levaduras, analizándose mediante pruebas bioquímicas su comportamiento respecto a diversos parámetros relacionados con el proceso de fermentación.

4. Proceder a la caracterización enológica de las diferentes levaduras aisladas.

5. Realizar la caracterización aromática de vinos experimentales, producidos empleando levaduras aisladas y caracterizadas, mediante un estudio aromático sensorial y un análisis químico cuantitativo.

6. Proceder a la caracterización aromática de los vinos comerciales de la variedad Prieto Picudo (DO «Tierra de León»). 

III. Materiales y Métodos 



\subsection{Microorganismos utilizados}

Durante el presente trabajo se han empleados varios microorganismos aparte de los aislados a partir de las microvinificaciones espontáneas realizadas en el laboratorio. Dichos microorganismos se dividen principalmente en los dos grupos que se indican a continuación.

\subsubsection{Cepas de levaduras comerciales}

Entre las modalidades de fermentación existentes (ver el apartado 1.4.2), las bodegas objeto de estudio (apartado 3.7.1), se decantan por un proceso fermentativo dirigido mediante el empleo de levaduras iniciadoras (LSAs). Debido a que uno de los objetivos del trabajo es caracterizar las cepas de levadura autóctonas de la variedad de uva y/o de las bodegas estudiadas, se debe asegurar que las levaduras aisladas no son realmente levaduras comerciales. Así, las bodegas estudiadas nos han proporcionado las levaduras comerciales empleadas en la producción de todos sus vinos. A partir de estas muestras se ha podido comprobar de modo inequívoco si alguna de las cepas aisladas era en realidad un iniciador comercial, siendo descartada automáticamente para posteriores estudios.

Las levaduras comerciales empleadas por las diferentes bodegas se muestran en la tabla 3.1.

\subsubsection{Cepas empleadas en el ensayo "killer"}

Con el objetivo de realizar un estudio sobre la capacidad de producción de las diferentes toxinas "killer" descritas (apartado 1.5.1.3.d) son necesarias diferentes cepas certificadas: por un lado las que presenten la capacidad de producir las diferentes toxinas, y por otro las que presenten sensibilidad demostrada a las toxinas de interés según los estudios a realizar.

Las cepas empleadas han sido las siguientes:

- Cepa 1101: S. cerevisiae con fenotipo "killer" por producción de la toxina K1

- Cepa 5X47: S. cerevisiae con fenotipo "killer sensible"

- Cepa EX73: S. cerevisiae con fenotipo "killer" por producción de la toxina K2

- Cepa F182: S. cerevisiae con fenotipo "killer" por producción de la toxina K28

- Cepa EX198: S. cerevisiae con fenotipo "killer" por producción de la toxina Klus

- Cepa EX33: S. cerevisiae con fenotipo "killer sensible" libre de cualquier tipo de virus ARN de doble cadena.

Las dos primeras cepas fueron cedidas por el Dr. Cantoral del Laboratorio de Microbiología y Genética, CASEM, del Departamento de Biomedicina, Biotecnología y Salud Pública de la Universidad de Cádiz (Cádiz, España). Las cuatro últimas cepas fueron cedidas por el Dr. Ramírez del Departamento de Ciencias Biomédicas (Área de Microbiología) de la Facultad de Ciencias de la Universidad de Extremadura (Badaj oz, España). 


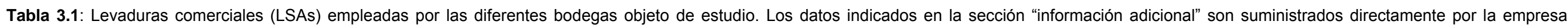
comercializadora a través de las correspondientes fichas técnicas.

\begin{tabular}{|c|c|c|c|c|}
\hline Bodega & Nombre/Denominación & Casa Comercial & Uso en bodega & Información adicional \\
\hline & IOC 18-2007 & $\begin{array}{l}\text { Central Enológica M. S.L. } \\
\text { (Manzanares, Ciudad Real, España) }\end{array}$ & Tintos, rosados y blancos & $\begin{array}{l}\text { Saccharomyces cerevisiae } \\
\text { Fenotipo "killer" } \\
\text { Seleccionada por el "Institut Oenologique de Champagne" } \\
\text { (Épernay, Francia) }\end{array}$ \\
\hline & Uvaferm VN & Lallemand (Tolouse, Francia) & Tintos & $\begin{array}{l}\text { S. cerevisiae } \\
\text { Fenotipo "killer" } \\
\text { Seleccionada por el IVICAM (La Mancha, España) }\end{array}$ \\
\hline Gordonzello S.A. & $\begin{array}{l}\text { Levuline Primeur } \\
\text { (GLO 7477) }\end{array}$ & Oenofrance (Bordeaux, Francia) & Varios vinos & $\begin{array}{l}\text { S. cerevisiae } \\
\text { Fenotipo "killer neutro " frente a toxina K2 } \\
\text { Seleccionada por Oenofrance }\end{array}$ \\
\hline \multirow{5}{*}{ Cooperativa de los Oteros } & Uvaferm CS2 & DANSTAR Ferment AG (Zug, Suiza) & Única empleada & $\begin{array}{l}\text { S. cerevisiae } \\
\text { Seleccionada en Alsacia por el INRA (Narbonne, Francia) }\end{array}$ \\
\hline & Enoferm QA23 & Lallemand & Tintos, rosados y blancos & $\begin{array}{l}\text { S. bayanus var. bayanus } \\
\text { Fenotipo "killer" } \\
\text { Seleccionada en Portugal por la UTAD (Vila Real, Portugal) }\end{array}$ \\
\hline & Uvaferm BM45 & Lallemand & Tintos & $\begin{array}{l}\text { S. cerevisiae } \\
\text { Fenotipo "killer" } \\
\text { Seleccionada por el "Consorzio del Vino Brunello di Montalcino" } \\
\text { (Montalcino, Italia) y la Universidad de Siena (Siena, Italia). }\end{array}$ \\
\hline & Maurivin Primeur & AB Mauri (Londres, Inglaterra) & Tintos y rosado & $\begin{array}{l}\text { S. cerevisiae } \\
\text { Seleccionada por el INRA }\end{array}$ \\
\hline & Maurivin AWRI 350 & AB Mauri & Rosados & $\begin{array}{l}\text { S. cerevisiae } \\
\text { Perteneciente a la colección de cultivos de "The Australian Wine Research } \\
\text { Institute" (AWRI, Urrbrae, Australia) }\end{array}$ \\
\hline \multirow{5}{*}{ Cooperativa Vinícola Ribera del Cea } & Fermicru 4F9 & DSM (Moorebank, NSW, Australia) & Vinos Prieto Picudo & $\begin{array}{l}\text { S. cerevisiae } \\
\text { Fenotipo "killer" } \\
\text { Aislada y seleccionada en Nantes (Francia) por el "Centre Technique } \\
\text { Interprofessionnel de la Vigne et du Vin" (Gard, Francia) }\end{array}$ \\
\hline & Enoferm BDX & Lallemand & Vinos plurivarietales & $\begin{array}{l}\text { S. cerevisiae } \\
\text { Fenotipo "killer sensible" a la toxina K2 } \\
\text { Aislada en Francia }\end{array}$ \\
\hline & Uvaferm WAN & Lallemand & Blancos & $\begin{array}{l}\text { S. cerevisiae } \\
\text { Fenotipo "killer" } \\
\text { Seleccionada por la Universidad de Palencia }\end{array}$ \\
\hline & IOC 18-2007 & Central Enológica M. S.L. & Tintos, rosados y blancos & $\begin{array}{l}\text { S. cerevisiae } \\
\text { Fenotipo "killer" } \\
\text { Seleccionada por el "Institut Oenologique de Champagne" }\end{array}$ \\
\hline & Levuline Synergie & Oenofrance & Rosados y blancos & $\begin{array}{l}\text { S. cerevisiae } \\
\text { Fenotipo "killer neutro" a la toxina K2 } \\
\text { Combinación de dos levaduras: Levuline C19 y L. ALS }\end{array}$ \\
\hline
\end{tabular}




\subsection{Medios y condiciones de cultivo}

En este apartado se describen los medios de cultivo empleados en el presente trabajo. Además de su composición detallada se indicará el modo de preparación. Si no se indica lo contrario, la preparación requiere un esterilizado en autoclave (121 으, 20 minutos)

\subsubsection{Medio YPD (YEPD)}

Medio complejo que se utiliza para el crecimiento/aislamiento de cepas de levaduras (Lodder, 1970). En nuestro caso, en su variante líquida ha sido usado de modo rutinario para el crecimiento de las levaduras vínicas. La variante sólida (YPD-Agar) se emplea para el aislamiento de colonias y su posterior conservación en fresco.

Para obtener el medio sólido (YPD-Agar) es necesaria la adición de $20 \mathrm{~g} / \mathrm{L}$ de agar a la composición que se detalla a continuación.

\begin{tabular}{|ll|}
\hline YPD (líquido), en g/L & \\
\hline Extracto de levadura & 10,0 \\
Peptona Bacteriológica & 20,0 \\
Glucosa & 20,0 \\
\hline
\end{tabular}

\subsubsection{Medio GPY}

Este medio es en realidad una modificación del citado anteriormente. Es un medio rico adecuado para el crecimiento de levaduras (Belloch et al., 2008). Su uso, mayoritariamente en estado líquido, se restringió a la realización de pre-inóculos en diversos experimentos.

\begin{tabular}{|lr|}
\hline GPY (líquido), en $\mathrm{g} / \mathrm{L}$ & \\
Extracto de levadura & 5,0 \\
Peptona Bacteriológica & 5,0 \\
Glucosa & 20,0 \\
\hline
\end{tabular}

Para obtener el medio en estado sólido (GPY-Agar), se adicionará agar a razón de $20 \mathrm{~g} / \mathrm{L}$.

\subsubsection{Medio WL Nutrient Agar (Scharlau)}

El medio WL (Wallersteins Nutrient Agar) se ha empleado de modo tradicional para el aislamiento e identificación de diferentes levaduras por la morfología y coloración que presentan. En nuestro caso fue utilizado para el aislamiento de levaduras desde muestras de vino. También se ha empleado para la conservación en fresco de las colonias aisladas.

El crecimiento de bacterias es inhibido por la adición del antibiótico cloranfenicol (a partir de una solución stock de $100 \mathrm{mg} / \mathrm{mL}$ en DMSO), una vez esterilizado el medio, y cuando se encuentre a una temperatura de unos $50^{\circ} \mathrm{C}$.

\begin{tabular}{|ll|ll|}
\hline \multicolumn{2}{|l|}{ WL Nutrient Agar (sólido), en $\mathrm{g} / \mathrm{L}$} & & \\
\hline Extracto de levadura & 4,0 & $\mathrm{FeCl}_{2}$ & 0,0025 \\
Triptona & 5,0 & $\mathrm{MnSO}_{4}$ & 0,0025 \\
Glucosa & 50,0 & Verde de bromocresol & 0,022 \\
$\mathrm{KH}_{2} \mathrm{PO}_{4}$ & 0,55 & Agar & 20,0 \\
$\mathrm{CaCl}_{2}$ & 0,125 & Cloranfenicol (mL/L) & 1,5 \\
$\mathrm{KCl}$ & 0,425 & & \\
\hline
\end{tabular}




\subsubsection{Medio “killer" (YPD-MB-Agar)}

Medio empleado para determinar el carácter "killer" de las diferentes cepas objeto de estudio en relación a las cepas control. Es un medio complejo, tamponado y de un color azul intenso debido a la adición de azul de metileno (del inglés "Methylene Blue"). El tamponado se realiza mediante la adición de tampón citrato-fosfato.

\subsubsection{Soluciones madre necesarias}

- Tampón citrato-fostafo. Se preparará a partir de:

- Solución A: Ácido cítrico 0,1 M

- Solución B: $\mathrm{Na}_{2} \mathrm{HPO}_{4}$ 0,2 M

Para conseguir una solución tamponada con un pH de 4,4 se realizará una mezcla de las soluciones anteriores con agua según las proporciones indicadas:

$$
\text { Sol. A / Sol. B / Agua } \rightarrow \text { 27,8 / 22,2 / } 50
$$

- Solución azul de metileno: Solución de azul de metileno al 3 \%(p/v).

\subsubsection{Preparación del medio}

Por tratarse de un medio tamponado es necesario disolver todos los componentes en tampón citrato-fosfato. Se disuelven los componentes necesarios en agua, se añaden las proporciones correspondientes de las soluciones que componen el tampón y por último se completa hasta el volumen deseado con agua.

Los componentes, disueltos en tampón citrato-fosfato son los siguientes:

\begin{tabular}{|lr|}
\hline YPD-MB-Agar (sólido), en $\mathrm{g} / \mathrm{L}$ & \\
\hline Extracto de levadura & 3,0 \\
Peptona Bacteriológica & 5,0 \\
Extracto de malta & 3,0 \\
Glucosa & 10,0 \\
$\mathrm{NaCl}$ & 10,0 \\
Azul de metileno 3\% (mL) & 6,7 \\
Agar & 20,0 \\
\hline
\end{tabular}

\subsubsection{Medio YNB (Difco)}

El medio YNB ("Yeast Nitrogen Base") es un medio mínimo que contiene los componentes nitrogenados esenciales para el desarrollo y crecimiento de las levaduras. Por tanto, en función del ensayo a realizar, será necesario suplementar el medio con la fuente de carbono adecuada. La esterilización de este medio se realiza mediante filtración (tamaño de poro 0,22 $\mu \mathrm{m})$.

A continuación se indica la preparación de este medio, empleando glucosa como fuente de carbono:

\begin{tabular}{|lr|}
\hline YNB (glucosa), en g/L & \\
\hline YNB (producto comercial) & 6,67 \\
Glucosa & 20,00 \\
\hline
\end{tabular}

\subsubsection{Medio YE}

Medio mínimo que se suplementará con diferentes azúcares al $2 \%$ (p/v). Su composición es la siguiente: 


\begin{tabular}{|ll|}
\hline YE , en g/L & \\
\hline Extracto de levadura & 5,0 \\
Azúcar & 20,0 \\
Púrpura de Bromocresol & 0,0250 \\
\hline
\end{tabular}

\subsection{Instrumental utilizado}

A lo largo de este trabajo se han utilizado los siguientes equipos:

- Agitador horizontal Heidolph Promax 1020 (Heidolph Instruments GmbH \& Co. KG, Schwabach, Alemania).

- Autoclave (J P Selecta, Barcelona, España).

- Balanzas:

- Balanza granataria Sartorius AW-4202 (Sartorius AG, Goettingen, Alemania).

- Balanza analítica Ohaus Adventurer (Ohaus Corporation, Parsippany, Nueva J ersey, USA).

- Bloque térmico: Thermomixer compact (Eppendorf, Hamburgo, Alemania).

- Centrifugas:

- Centrifuge 5415D (Eppendorf).

- $\quad$ Allegra $^{\mathrm{TM}} X-22 R$ centrifuge (Beckman Coulter, California, USA).

- Centra-MP4R (IEC, Needham, Massachusetts, USA).

- Centrifuge 5415R (Eppendorf).

- Estufa de cultivos $30^{\circ} \mathrm{C}$ y $37^{\circ} \stackrel{\circ}{ }$ (JP Selecta).

- Campanas de flujo laminar:

- MDH Contamination Control (MDH Limited, Andover, Hampshire, Inglaterra)

- Telstar AV-100 (Telstar, Terrassa, España).

- Cromatógrafos:

- Cromatografo de gases Trace GC (Termoquest, Milán, Italia) equipado con un detector de ionización en Ilama (FID) y un puerto olfatométrico ODO-I (SGE, Ringwood, Australia).

- Cromatógrafo de gases Hewlett-Packard 5890 Series II equipado con un detector FID (Hewlett-Packard Company, Palo Alto, California, USA).

- Cromatógrafo de gases CP-3800 equipado con un espectrómetro de masas de trampa iónica Saturn 2200 (Varian, Sunnyvale, California, USA).

- Cromatógrafo de gases Shimadzu QP-2010Plus acoplado a un espectrómetro de masas cuadrupolo (Shimadzu, Kyoto, Japón).

- HPLC Agilent 1200 series, con detectores RID y VWD (Agilent Technologies, Santa Clara, California, USA).

- Equipo de electroforesis:

- Cubeta Horizon 11.14 (Gibco BRL Life Technologies/Biometra, Goettingen, Alemania).

- Cubeta Horizon 20.25 (Gibco BRL Life Technologies/Biometra).

- CubetaSub-cell ${ }^{\circledR} G T$ (BIO-RAD, California, USA).

- Cubeta Mini sub-cell ${ }^{\circledR} \mathrm{GT}$ (BIO-RAD). 
- Fuente de alimentación Power pac 300 (BIO-RAD).

- Espectrofotómetro U-2900 (Hitachi, Tokio, Japon).

- Incubadoras orbitales:

- Orbital Incubator Cooled (Gallenkamp/SANYO E\&E Europe BV, Londres, Inglaterra).

- Incubador orbital Ecotrón Infors AG CH-4103 (Infor SHT, Bottminjen, Basel, Suiza).

- Lectores de placas:

- SPECTROstar Omega instrument (BMG Labtech, Offenburg, Alemania).

- Genios Plus (Tecan, Grödig, Austria).

- Bio-Tek Synergy HT (BioTek, Winooski, Vermont, USA).

- Microondas T.D.S. (Samsung, Daegu, Corea del Sur).

- Micropipetas:

- Micropipetas monocanal (2, 20, 200 y $1000 \mu \mathrm{L}$ ) (Gilson, Middleton, Wisconsin, USA).

- Micropipeta multicanal (20-200 $\mu \mathrm{L}$ ) Ergonomic High-Performance (VWR, Barcelona, España).

- Microscopio óptico: Olympus CX40 (Olympus, Shinjuku, Tokyo, Japón).

- $\quad$ H-metro Sentix 41 (WTW, Alemania).

- Sistema revelado geles de agarosa:

- Geneflash (Syngene, Cambridge, Reino Unido).

- Impresora Sony UP-860CE (Sony Corporation, Tokyo, Japón).

- Sistema SPE VAC ELUT 20 (Varian).

- Termocicladores:

- Mastercycler gradient (Eppendorf).

- Biometra TGradient (Biometra, Goettingen, Alemania).

\subsection{Software utilizado}

El software empleado en la elaboración del presente trabajo ha sido:

- $\quad$ Agilent Chemstation for LC systems Rev. B. 04.02[118] (Agilent Technologies).

- Chromas Lite versión 2.33 (Technelysium Pty Ltd).

- CorelDRAW X3 (Corel Corporation, Ottawa, Canadá).

- $\quad$ InforQuest ${ }^{\mathrm{TM}}$ FP Software Version 4.5 (BIO-RAD).

- Mega4 (Tamura K, Dudley J, Nei M \& Kumar S (2007) MEGA4: Molecular Evolutionary Genetics Analysis (MEGA) software version 4.0. Molecular Biology and Evolution 24: 1596-1599).

- Microsoft Office 2007 (paquete ofimático: Word, Excel, PowerPoint, etc.). (Microsoft Corporation, Redmond, Washington, USA).

- OriginPro 8 (OriginLab Corporation, Northampton, Massachusetts, USA).

- SigmaPlot 12 (Systat Software, Inc., San J osé, California, USA). 
- Software Varian Saturn GC-MS versión 6. 3 (Varian).

- SPAD Software versión 5.5 (CISIA-CERESTA, Montreal, Francia).

- SPSS Statistics 17.0 (Chicago, Illinois, USA).

- Statistica 7 (StatSoft, Inc., Tulsa, Oklahoma, USA).

\subsection{Proveedores de reactivos químicos y material fungible}

Los principales proveedores de reactivos químicos y material fungible empleado durante el presente trabajo han sido suministrados por los siguientes proveedores:

AGILENT TECHNOLOGIES (Santa Clara, California, USA).

ALDRICH (Steinheim, Alemania)

AMERSHAM BIOSCIENCES (Buckinghamshire, Reino Unido).

BIOMÉRIEUX (Durham, USA)

BIO-RAD (California, USA).

COSTAR (Washington DC, USA).

DIFCO LABORATORIES INC. (Detroit, Michigan, USA).

EPPENDORF (Hamburgo, Alemania).

FERMENTAS (Glen Burnie, Maryland, USA)

FLUKA, (Buchs, Suiza).

GIBCO BRL (Eggenstein, Alemania).

INVITROGEN CORPORATION (Carlsbad, California, USA).

J \& W SCIENTIFIC (Folson, California, USA).

MERCK (Darmstadt, Germany).

MILLIPORE (Billerica, Massachusetts, USA).

NEW ENGLAND BIOLABS INC. (Beverly, Massachusetts, USA).

NUNC (Thermo Scientific, Waltham, Massachusetts, USA).

OXOID LTD. (Hanpshire, Reino Unido).

PANREAC QUIMICA S.A. (Barcelona, España).

PROMEGA CORPORATION (Madison, Wisconsin, USA)

PRONADISA (Madrid, España).

SHARLAU (Sentmenat, Barcelona, España).

SIGMA-ALDRICH (St. Louis, Misuri, USA).

SUPELCO (Bellefonte, Pensilvania, USA).

TAKARA BIO INC. (Shiga, J apón).

THERMO SCIENTIFIC (Waltham, Massachusetts, USA).

VWR INTERNATIONAL EUROLAB S. L (Barcelona, España). 


\subsection{Soluciones de uso general}

Las soluciones empleadas de modo rutinario a lo largo del presente trabajo son las siguientes:

Acetato potásico $3 \mathrm{M}$. Para un volumen final de $200 \mathrm{~mL}$ pesar $58,89 \mathrm{~g}$ de acetato potásico y disolver en agua completando el volumen. Esterilizar en autoclave.

Acetato potásico $5 \mathrm{M}$. Para un volumen final de $200 \mathrm{~mL}$ pesar $98,15 \mathrm{~g}$ de acetato potásico, disolver en agua y completar el volumen deseado. Esterilizar en autoclave.

ARNasa (Ribonucleasa A): Disolver ribonucleasa A (Sigma-Aldrich), a una concentración de $10 \mathrm{mg} / \mathrm{mL}$, en agua milli-Q. Hervir durante 15 minutos y dejar enfriar lentamente hasta temperatura ambiente. Se reparte en alícuotas y se conserva a $-20^{\circ} \mathrm{C}$ hasta su uso.

Bromuro de etidio. Se prepara a una concentración de $10 \mathrm{mg} / \mathrm{mL}$ en agua y se conserva a $4 \stackrel{\circ}{ } \mathrm{C}$, evitando la exposición a la luz. La solución de tinción empleada contendrá $150 \mu \mathrm{L}$ de la disolución anterior por cada litro de agua. Por tanto su concentración final será de 1,5 mg/ L.

Cicloheximida $100 \mathbf{~ m g} / \mathbf{m L}$. Pesar un gramo y disolver en etanol hasta completar un volumen de $10 \mathrm{~mL}$. Esterilizar por filtración amicróbica (tamaño de poro 0,22 $\mu \mathrm{m}$ ). Conservar a $4 \stackrel{\circ}{\circ}$.

Cloranfenicol $100 \mathrm{mg} / \mathbf{m L}$. Pesar un gramo y disolver en DMSO hasta completar un volumen de $10 \mathrm{~mL}$. Esterilizar por filtración amicróbica (tamaño de poro 0,22 $\mu \mathrm{m}$ ). Conservar a $-20 \stackrel{\circ}{ } \mathrm{C}$.

Cloroformo-isoamílico (CIA). Mezcla de 24 partes de cloroformo y una parte de alcohol isoamílico.

Etanol $70 \%$ (v/v). $70 \mathrm{~mL}$ de etanol, completando con agua hasta un volumen final de 100 $\mathrm{mL}$.

Fenol neutro. Pesar $200 \mathrm{~g}$ de fenol cristalizado y disolver con agitación en $200 \mathrm{~mL}$ de Tris-HCL $0,5 \mathrm{M}, \mathrm{pH}=8,0$. Disuelto por completo el fenol, dejar reposar la solución para facilitar la separación de las fases. Eliminar la fase acuosa (superior) y alamacenar a $4^{\circ} \mathrm{C}$ en un recipiente opaco.

Glicerol $80 \%$ (v/v). Tomar $80 \mathrm{~mL}$ de glicerol y completar el volumen con agua hasta los $100 \mathrm{~mL}$. Esterilizado en autoclave.

$\mathrm{NaOH}$ 0,25 M y 0,025 M. Pesar 1,0 g y 0,1 g, respectivamente, y disolver en agua en un volumen final de $100 \mathrm{~mL}$.

SDS $10 \%$ (p/v). Para preparar $200 \mathrm{~mL}$ pesar 20 gramos de SDS, disolver en agua y enrasar al volumen indicado. Esterilizar en autoclave.

Solución 1: EDTA $50 \mathrm{mM}, \mathrm{pH}=7,5$. Pesar 3,72 g de EDTA, disolver en agua y ajustar el pH. Por último se enrasa a un volumen final de $200 \mathrm{~mL}$. Esterilizar en autoclave.

Solución 2: Tris- $\mathrm{H}_{2} \mathrm{SO}_{4} 50 \mathrm{mM}, 1 \%$ (v/v) 2-mercaptoetanol, $\mathrm{pH}=9,3$. Pesan $1,21 \mathrm{~g}$ de Tris(hidroximetil)aminometano (Merck) y disolver en agua. A la mezcla se añaden 2,0 $\mathrm{mL}$ de 2-mercaptoetanol (Sigma), y ajustar el pH por adicón de $\mathrm{H}_{2} \mathrm{SO}_{4}$ diluido. Por último se completa el volumen hasta los $200 \mathrm{~mL}$. Esterilizar en autoclave.

Solución 3: $\mathrm{NaCl} 0,1 \mathrm{M}$, Tris- $\mathrm{HCl} 10 \mathrm{mM}$, EDTA $10 \mathrm{mM}, 0,2 \%(\mathrm{p} / \mathrm{v}) \mathrm{SDS}, \mathrm{pH}=7,5$. Para un volumen final de $200 \mathrm{~mL}$ pesar $1,17 \mathrm{~g}$ de $\mathrm{NaCl}, 0,24 \mathrm{~g}$ de Tris(hidroximetil)aminometano y 0,4 
$\mathrm{g}$ de SDS. Disolver en agua y ajustar el pH por adición de $\mathrm{HCl}$ diluido. Enrasar al volumen final deseado. Esterilizar en autoclave.

Solución 4: Acetato potásico 3M. Para un volumen final de $100 \mathrm{~mL}$, pesar $29,45 \mathrm{~g}$ de acetato potásico, disolver por completo y enrasar al volumen final indicado. Esterilizar en autoclave.

Solución A: Sorbitol $1 \mathrm{M}$, EDTA 0,1 M, pH = 7,5. Para preparar un volumen de $200 \mathrm{~mL}$ pesar 36,43 g de sorbitol y 7,44 g de EDTA. Ajustar el pH por adición de $\mathrm{NaOH} 3 \mathrm{M}$. Esterilizar en autoclave.

Solulción B: Tris 50mM, EDTA $20 \mathrm{mM}, \mathrm{pH}=7,4$. El volumen final será de $200 \mathrm{~mL}$. Se parte de soluciones stock: Tris $1 \mathrm{M}$ y EDTA 0,5 M. Se toman $10 \mathrm{~mL}$ de Tris $1 \mathrm{M}$ y $8 \mathrm{~mL}$ de EDTA 0,5 M. $\mathrm{El}$ ajuste del $\mathrm{pH}$ se realiza por adición con $\mathrm{HCl} 1 \mathrm{~N}$. Esterilizar en autoclave

Solución salina $(\mathrm{NaCl} \mathbf{0 , 9} \%(\mathbf{p} / \mathbf{v}))$. Pesar $0,9 \mathrm{~g}$ de cloruro sódico, disolver en agua y aj ustar a un volumen final de $100 \mathrm{~mL}$. Esterilizar en autoclave.

Tampón TAE (50x). Mezclar 57,1 ml de ácido acético glacial, $100 \mathrm{~mL}$ de EDTA 0,5 M (pH $8,0), 242 \mathrm{~g}$ de Tris- $\mathrm{HCl}$ y agua destilada hasta completar el volumen final de un litro.

Tampón TE: Tris- $\mathrm{HCl} 10$ mM, EDTA $1 \mathrm{mM}(\mathrm{pH}$ 8,0). Esterilizar en autoclave

\subsection{Muestras: microvinificaciones espontáneas}

Con el objetivo de aislar levaduras autóctonas de la variedad de uva Prieto Picudo, se realizaron microvinificaciones espontáneas a temperatura ambiente utilizando mosto suministrado por las bodegas que se indican a continuación.

\subsubsection{Bodegas obj eto de estudio}

Para llevar a cabo el presente estudio se seleccionaron cinco bodegas de la Denominación de Origen "Tierra de León" con diferente distribución geográfica. Las bodegas seleccionadas fueron las siguientes:

Gordonzello S.A. (Elaborador/Embotellador). Travesía del Rosario, S/ N. 24294 Gordoncillo (León). Castilla y León. España

Cooperativa de los Oteros (Elaborador/Embotellador). La bodega, S/ N. 24209 Pajares de los Oteros (León). Castilla y León. España

Bodegas Pedro Casis (Elaborador/Embotellador). Bodegas, S/ N. 24325 Gordaliza del Pino (León). Castilla y León. España

Cooperativa Vinícola Ribera del Cea (Elaborador/Embotellador). Avda. Panduro y Villafañe, S/ N. 24220 Valderas (León). Castilla y León. España

Vinícola Valmadrigal (Elaborador/ Embotellador). Constitución, 16. 24323 Castrotierra de Valmadrigal (León). Castilla y León. España

\subsubsection{Muestras de mosto natural de uva Prieto Picudo}

Las microvinificaciones espontáneas se realizaron a partir de mosto natural de la variedad de uva Prieto Picudo. La toma de muestra se realizó tras el estrujado y despalillado de la uva, previo al inóculo con levaduras comerciales. Para la toma de muestra se emplearon botellas estériles de 2 litros de capacidad. 
El estudio se realizó durante, al menos, tres años para cada una de las bodegas. Por tanto, se hicieron tres tomas de muestra por bodega, en cosechas diferentes. En la tabla 3.2 se recogen, para cada bodega y cosecha, las características del mosto natural empleado en las microvinificaciones espontáneas.

Tabla 3.2: Características generales [densidad y el grado alcohólico probable esperado (valor teórico)] de los mostos naturales empleados en las microvinificaciones espontáneas. Datos aportados por las propias bodegas.

\begin{tabular}{lccc}
\hline Bodega & Cosecha & Densidad $(\mathrm{g} / \mathrm{mL})$ & Grado alcohólico probable (\% vol.) \\
\hline & 2005 & 1,108 & 15,2 \\
Gordonzello S.A. & 2006 & 1,096 & 13,3 \\
& 2007 & 1,089 & 12,9 \\
Cooperativa Oteros & 2005 & 1,105 & 14,7 \\
& 2006 & $\mathrm{n} . \mathrm{d}$. & $\mathrm{n} . \mathrm{d}$. \\
Vinícola Valmadrigal & 2007 & 1,097 & 13,4 \\
\hline & 2006 & 1,112 & 15,9 \\
& 2007 & 1,102 & 14,3 \\
Bodega Pedro Casis & 2008 & 1,097 & 13,4 \\
\hline & 2006 & 1,092 & 12,6 \\
& 2007 & 1,095 & 13,1 \\
Coop. Ribera del Cea & 2009 & n.d. & 15,2 \\
\hline
\end{tabular}

n.d.: indica la no disponibilidad de datos relativos al mosto.

\subsubsection{Procedimiento de microvinificación}

Una vez recogidas las muestras de mosto natural de las diferentes bodegas, se realizaron las fermentaciones espontáneas. Como su propio nombre indica, el proceso fermentativo se produce sin necesidad de inóculo o cualquier otra intervención en el proceso. El proceso se realizó a temperatura ambiente (entre 21 y $24,5 \stackrel{\circ}{\circ}$ ).

El seguimiento y control del proceso se realizó visualmente, controlando la producción de espuma y desprendimiento de $\mathrm{CO}_{2}$. Cuando se apreció una reducción significativa en la producción de dióxido de carbono, se realizó diariamente una medida de la densidad de la microvinificación. El estancamiento en valores inferiores a $1,0 \mathrm{~g} / \mathrm{mL}$ indica que el proceso fermentativo ha finalizado. La disminución es debida a la progresiva desaparición de azúcares en el medio durante la fermentación.

\subsection{Aislamiento y conservación de levaduras}

\subsubsection{Conservación de muestras (Microvinificaciones)}

Finalizadas las diferentes microvificaciones espontáneas, se toma parte del vino obtenido y se precipitan las células por centrifugación, conservándolas por si fuera necesario su uso en un futuro.

El protocolo es el siguiente (proceso por triplicado):

- Recoger $50 \mathrm{~mL}$ del vino procedente de la microvinificación en un tubo tipo Falcon ${ }^{\circledR}$.

- Centrifugar: $5.800 \mathrm{rpm} / 6 \mathrm{~min} / 4 \stackrel{\circ}{ } \mathrm{C}$. Eliminar el sobrenadante. 
- Resuspender el precipitado en $600 \mu \mathrm{L}$ de glicerol $80 \%$ más $400 \mu \mathrm{L}$ de YPD.

- Conservar a $-20 \stackrel{\circ}{ }{ }^{C}$ en criotubos.

\subsubsection{Aislamiento de levaduras}

\subsubsection{Aislamiento de levaduras a partir de las microvinifiaciones espontáneas}

Confirmada la finalización de las fermentaciones espontáneas se procede al aislamiento de las levaduras existentes en el vino obtenido. Debido a la elevada población de levaduras en los vinos obtenidos, se realizan diluciones seriadas (figura 3.1) en solución salina.

Un volumen de $100 \mu \mathrm{L}$ de las diluciones seleccionadas (generalmente las tres más diluidas) se siembra sobre placas de WL en césped. Se incuban las placas a $30^{\circ} \mathrm{C}$ durante 72 horas. Posteriormente, se hace un recuento del número de colonias obtenidas en cada una de las diluciones. El recuento, o titulación correspondiente a cada microvinificación, se hará a partir de las placas que contengan un número de colonias comprendido entre 20-200.

De entre todas las colonias aisladas en cada microvinificación, se seleccionarán 60 , tanto las que presenten morfología típica de Saccharomyces cerevisiae (colonia color crema, aspecto mantecoso, lisa, circular y muy prominente) como otra diferente. Las colonias seleccionadas se replicarán en otra placa de medio WL, identificando cada una de ellas con un código inequívoco, que además, aporte cierta información (Tabla 3.3).

\subsubsection{Aislamiento de levaduras a partir de uvas de la variedad Prieto Picudo}

Partiendo de uvas recogidas asépticamente en los viñedos adscritos a las bodegas que son objeto de estudio (apartado 3.7.1) se procederá tal como se indica:

- Por cada muestra de uva, preparar dos tubos tipo Falcon ${ }^{\circledR}$. Tomar el peso inicial de uno de ellos.

- Introducir uvas hasta la mitad de su capacidad. Estrujar con la ayuda de una micropipeta (condiciones de esterilidad). Tomar la masa del tubo una vez contiene la uva.

- Conocida la masa de uva estrujada contenida en uno de los tubos, añadir un $5 \%$ de etanol $(p / p)$.

- Incubar ambos tubos a $10 \stackrel{\circ}{ } \mathrm{C}$ en estático.

- A tiempo cero y en periodos quincenales, realizar diluciones seriadas (figura 3.1) de cada uno de los tubos. Se siembran las diluciones adecuadas en medio sólido WL. Incubar las placas a $10 \stackrel{\circ}{ }{ }^{C}$ hasta la aparición de colonias aisladas.

- Replicar a placas de YPD-Agar aquellas que presenten morfología características del género Saccharomyces. Incubar a $28 \stackrel{\circ}{\circ}$.

\subsubsection{Conservación de las cepas de levadura}

Se utilizaron básicamente dos métodos de conservación, detallados a continuación.

\subsubsection{Conservación en viales de glicerol}

Este método de conservación asegura el mantenimiento de los microorganismos, en un estado óptimo, durante un largo periodo de tiempo. Para preparar los viales se parte de un cultivo líquido de la cepa de interés. Previa preparación del vial se comprobará, mediante observación en microscopio óptico, la no contaminación y pureza del cultivo. 
El protocolo es el siguente:

- Realizar un cultivo líquido en $10 \mathrm{~mL}$ de YPD con la cepa de interés. Incubar a 200 $\mathrm{rpm} / 24 \mathrm{~h} / 28 \stackrel{\circ}{\mathrm{C}}$.

- En un criotubo, añadir $300 \mu \mathrm{L}$ glicerol $80 \%$ más $900 \mu \mathrm{L}$ cultivo líquido.

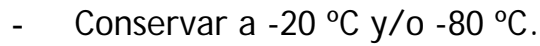

\subsubsection{Conservación en fresco}

Esta técnica es adecuada para un manejo rutinario y rápido de los clones y está especialmente pensado para el mantenimiento durante un corto periodo de tiempo. Las colonias se conservan en placas de medio WL y/ o YPD. Cada dos meses es necesario refrescar las colonias en placas nuevas. El inconveniente de este método de conservación radica en la facilidad de contaminación que presenta, así como la rápida deshidratación de las placas y la consecuente pérdida de viabilidad de las cepas.

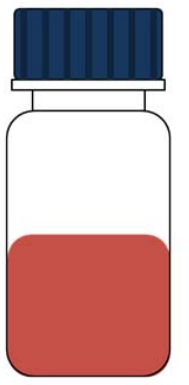

Muestra Microvinificación espontánea

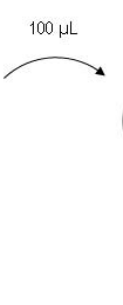

$10^{-1}$

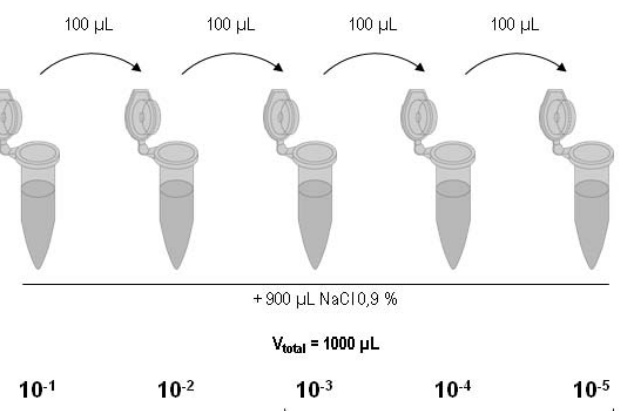

SIEMBRA

Figura 3.1: Esquema explicativo de la realización de diluciones seriadas. Se seleccionan las tres más diluidas para realizar una siembra en medio WL y así aislar las levaduras responsables de la microfermentación espontánea.

Tabla 3.3: Codificación empleada en las colonias aisladas en las diferentes microvinificaciones. Además de servir para identificar las colonias, la simpe observación del código nos aportará información acerca de su origen, morfología y fecha de aislamiento.

\begin{tabular}{llll}
\hline & & XW \# / \#\# & NUMERACIÓN \\
\hline BODEGA & MORFOLOGÍA & COSECHA & Numeración consecutiva \\
G: Gordonzello S.A. & B: Colonia blanca & $\mathbf{6 : 2 . 0 0 6}$ & $\mathbf{7 : 2 . 0 0 7}$ \\
P: Coop. Pajares & V: Colonia verde & $\mathbf{8 : ~} 2.008$ & $\mathbf{9 : 2 . 0 0 9}$ \\
C: B. Pedro Casis & & \\
V: Vin. Valmadrigal & & & \\
R: Coop. Vin. Ribera Cea & & & \\
\hline
\end{tabular}




\subsection{Caracterización genética de levaduras}

Como se ha indicado en el apartado 1.7 existen un conj unto bastante amplio de técnicas moleculares destinadas a la identificación de levaduras, tanto a nivel de especie como a nivel de cepa. Allí se reseñaron las posibles técnicas a emplear para realizar un estudio sobre la microbiota implicada en los procesos de fermentación. A continuación se desarrollarán las técnicas empleadas en el presente trabajo para analizar las levaduras aisladas a partir de las microvinificaciones espontáneas realizadas.

\subsubsection{Extracción enzimática del ADN total de levaduras}

A continuación se detalla el proceso empleado para obtener el conjunto de ADN presente en las levaduras (ADNtotal). Está formado por el ADN genómico (contenido en el nucleo) y por el ADN mitoncodrial (ADNmt, material genético contenido en las mitocondrias).

El protocolo es el siguiente:

- Realizar un cultivo líquido en $10 \mathrm{~mL}$ de YPD con la cepa de interés. Incubar a 200 $\mathrm{rpm} / 24 \mathrm{~h} / 28 \stackrel{\circ}{\circ} \mathrm{C}$.

- Recoger $5 \mathrm{~mL}$ de cultivo en un tubo de $10 \mathrm{~mL}$. Precipitar las células mediante centrifugación a $4.400 \mathrm{rpm} / 5 \mathrm{~min} / 4$ ํ․ Eliminar el sobrenadante.

- Añadir $400 \mu \mathrm{L}$ de Sol. A (Sorbitol 1M, EDTA 0,1 M, pH = 7,5). Resuspender las células con la ayuda del Vortex. Trasvasar el contenido a microtubos eppendorf ${ }^{\circledR}$.

- Añadir $50 \mu \mathrm{L}$ de Zimoliasa $20 \mathrm{~T}$ ( $5 \mathrm{mg} / \mathrm{mL}$ en solución A). Incubar en bloque térmico o baño de agua durante una hora a $37 \stackrel{\circ}{\circ}$. Voltear los tubos manualmente cada 10 minutos.

- Recoger los protoplastos por centrifugación a 10.000 rpm / 1 min / Ta Amb. Eliminar el sobrenadante.

- Añadir $400 \mu \mathrm{L}$ de Sol. B (Tris 50 mM, EDTA 20 mM, pH = 7,4). Resuspender suavemente con la micropipeta.

- Añadir $10 \mu \mathrm{L}$ de SDS $20 \%$ Homogeneizar e incubar, en bloque térmico o baño de agua, durante 10 minutos a $65 \stackrel{\circ}{\circ}$.

- Añadir $160 \mu \mathrm{L}$ de acetato potásico $5 \mathrm{M}$ frío (4º). Agitar vigorosamente e incubar en hielo durante 10 minutos.

- Centrifugar a $13.300 \mathrm{rpm} / 15 \mathrm{~min} / 4$ ㅇ․ Los ácidos nucleicos se encuentran en solución, por tanto, se transfiere el sobrenadante a otro microtubo eppendorf ${ }^{\circledR}$.

- Añadir $1,0 \mu \mathrm{L}$ de ARNasa ( $10 \mathrm{mg} / \mathrm{mL}$ ) e incubar durante 20 minutos a 37 ㅇ.

- Extracción líquido-líquido mediante adición de un volumen de fenol-CIA. Agitar vigorosamente. Separación de fases favorecida por centrifugación a $12.000 \mathrm{rpm} /$ $12 \mathrm{~min} / \mathrm{Ta}$ Amb. Tomar la fase acuosa (fase superior) y transferirla a un nuevo microtubo eppendorf ${ }^{\circledR}$.

- Adición de un volumen de isopropanol, para producir la precipitación de los ácidos nucleicos. Incubación durante, al menos, 10 minutos a temperatura ambiente.

- Centrifugar a 13.200 rpm / $10 \mathrm{~min} /$ To Amb. Eliminar el sobrenadante. 
- Limpiar el precipitado por adición de $1 \mathrm{~mL}$ de etanol $70 \%$ Centrifugar a 13.200 rpm / 1 min / Ta Amb. Eliminar el sobrenadante.

- Secar los ácidos nucleicos mediante vacío.

- Resuspender en $20 \mu \mathrm{L}$ de TE. Incubar a $4 \stackrel{0}{ } \mathrm{C}$ para facilitar la resuspensión.

- Conservar a -20 ํ.

\subsubsection{Identificación de levaduras a nivel de especie mediante análisis del polimorfismo de restricción de la región 5.8S-ITS (RFLP-5.8S-ITS)}

Esta técnica consiste en amplificar por PCR la región del ADNr 5.8S-ITS que incluye el gen 5. 8 y y las regiones intergénicas ITS1 e ITS2 (ver figura 1.7) (White et al., 1990).

Los oligonucleótidos iniciadores empleados son los siguientes:

\section{ITS 1 : 5'-TCC GTA GGT GAA CCT GCG G-3 \\ ITS4 : 5'-TCC TCC GCT TAT TGA TAT GC-3'}

La reacción de PCR se realiza como se indica en la tabla 3.4, mientras el programa de amplificación empleado se detalla en la tabla 3.5. El tamaño de los productos de PCR para especies del género Saccharomyces será de $850 \mathrm{pb}$. Seguidamente mediante la digestión de este producto con diferentes enzimas de restricción (Haelll, ScrFly Accl) podremos dilucidar la especie atendiendo a los patrones obtenidos (Ver tabla 1.1). La reacción de digestión de los productos de PCR se describe en la tabla 3.6.

Tabla 3.4: Reacción de amplificación de la región 5.8S-ITS

\begin{tabular}{lc}
\hline Reactivo & Volumen $(\mu \mathrm{L})$ \\
\hline Tampón 5x & 10,0 \\
$\mathrm{MgCl}_{2}(25 \mathrm{mM})$ & 3,0 \\
Ceabador ITS 1 (10 $\mu \mathrm{M})$ & 2,5 \\
Cebador ITS4 (10 $\mu \mathrm{M})$ & 2,5 \\
dNTP's 2mM & 2,5 \\
Taq polimerasa $(5 \mathrm{U} / \mu \mathrm{L})$ & 0,4 \\
Agua (MQ) & 28,1 \\
ADNtotal (dilución 1:40) & 1,0 \\
$\mathrm{~V}_{\text {TOTAL }}$ & 50,0 \\
\hline
\end{tabular}

Tras incubación de las digestiones durante 12-24 horas, el producto se carga en un gel (agarosa $3 \%(p / v)$ - TAE $1 x$ ) y se procede a la separación electroforética de los fragmentos obtenidos.

Tabla 3.5: Programa amplificación de la región 5.8S-ITS

\begin{tabular}{lcc}
\hline Etapa & $\mathrm{T}^{\mathrm{a}}\left({ }^{\circ} \mathrm{C}\right)$ & Tiempo $(\mathrm{s})$ \\
\hline Desnaturalización inicial & 95 & 180 \\
Amplificación (30x) & & \\
$\quad$ Desnaturalización: & 94 & 60 \\
Anillamiento: & 52 & 40 \\
Extensión: & 72 & 60 \\
Extensión final & 72 & 600 \\
Conservación & 4 & $\infty$ \\
\hline
\end{tabular}


Tabla 3.6: Reacción de digestión del producto de PCR de la región 5.8S-ITS. (*) Se empleará, para cada enzima, el tampón recomendado por el fabricante.

\begin{tabular}{lc}
\hline Reactivo & Volumen $(\mu \mathrm{L})$ \\
\hline Tampón $^{*} 10 \mathrm{x}$ & 2,5 \\
Enzima $(10 \mathrm{U} / \mu \mathrm{L})$ & 1,0 \\
Agua (milli-Q) & 11,5 \\
Producto PCR & 10,0 \\
V $_{\text {TOTAL }}$ & 25,0 \\
\hline
\end{tabular}

\subsubsection{Identificación de levaduras a nivel de especie mediante la secuenciación de los dominios D1-D2 del ADNr 265}

La secuencia de los dominios D1-D2 es altamente específica para cada una de las especies de levaduras. Cuando esta secuencia se compara con las depositadas en las bases de datos y se obtiene una homología igual o superior al $99 \%$ la levadura será identificada como perteneciente a una especie en particular.

Los oligonucleótidos iniciadores empleados para el proceso de amplificación serán los siguientes (Kurtzman y Robnett 1998):

\section{NL1: 5'-GCA TAT CAA TAA GCG GAG GAA AAG-3' \\ NL4: 5'-GGT CCG TGT TTC AAG ACG G-3'}

La reacción de amplificación será idéntica a la presentada en la tabla 3.4, salvo por los oligonucleótidos que serán sustituidos por los citados. El programa de amplificación empleado para este propósito se describe en la tabla 3.7. El producto obtenido se comprueba mediante electroforesis en gel de agarosa. Para ello una pequeña alícuota $(1,0 \mu \mathrm{L})$ se carga en un gel (agarosa $1,0 \%(p / v)$ - TAE $1 x$ ). De este modo obtenemos el tamaño del amplificado (por comparación con los marcadores de peso molecular) y la calidad de éste (cantidad, presencia de una o más bandas, etc. ).

El producto de PCR es luego purificado mediante microcolumnas GFX (kit comercial, Amersham-Biosciences) y se secuencia en el Servicio de Secuenciación de Inbiotec / Universidad de León.

Tabla 3.7: Programa amplificación de los dominios D1-D1 ADNr $26 \mathrm{~S}$.

\begin{tabular}{lcc}
\hline Ełapa & $\mathrm{T}^{\mathrm{a}}\left({ }^{\circ} \mathrm{C}\right)$ & Tiempo $(\mathrm{s})$ \\
\hline Desnaturalización inicial & 95 & 300 \\
Amplificación (40x) & & \\
$\quad$ Desnaturalización: & 94 & 40 \\
Anillamiento: & 52 & 40 \\
Extensión: & 72 & 30 \\
Extensión final & 72 & 600 \\
Conservación & 4 & $\infty$
\end{tabular}




\subsubsection{Caracterización de cepas de $S$ cerevisiae mediante análisis del polimorfismo de restricción del ADN mitocondrial (RFLP-ADNmt)}

Debido a la particularidad que presenta el ADNmt respecto al ADN genómico, como es us alto contenido en bases $A+T$ (ver apartado 1.7.3.1), el uso de las endonucleasas de restricción adecuadas permitirá discriminar entre cepas previamente identificadas dentro de la especie S. cerevisiae.

Las enzimas de restricción empleadas tendrán la particularidad de producir cortes en zonas ricas en $\mathrm{G}+\mathrm{C}$. Usando como sustrato ADNtotal, estas enzimas serán capaces de degradar el ADN genómico (gran cantidad de cortes), obteniendo un número muy limitado de cortes en el ADNmt. El bandeo obtenido a partir del ADNmt nos permite identificar inequívocamente entre las diferentes cepas. En caso de duda, o para asegurar el resultado, se recurre al empleo de más de una enzima de restricción (tabla 3.8).

\begin{tabular}{|c|c|}
\hline Enzima & Secuencia / Sitio de corte \\
\hline Alul & $\begin{array}{l}\mathrm{A} \quad \mathrm{G} / \mathrm{C} \quad \mathrm{T} \\
\mathrm{T} \mathrm{C} / \mathrm{G}\end{array}$ \\
\hline Hinfl & $\begin{array}{l}G A / N T C \\
C T N A / G\end{array}$ \\
\hline Rsal & $\begin{array}{l}G T / A C \\
C A / T G\end{array}$ \\
\hline
\end{tabular}

La reacción enzimática se describe a continuación:

\begin{tabular}{|c|c|}
\hline Reactivo & Volumen ( $\mu \mathrm{L})$ \\
\hline Tampón $^{*} 10 x$ & 2,5 \\
\hline Enzima $(8 \mathrm{U} / \mu \mathrm{L})$ & 1,0 \\
\hline Agua (milli-Q) & 18,5 \\
\hline ADNtotal & 3,0 \\
\hline$V_{\text {TOTAL }}$ & 25,0 \\
\hline
\end{tabular}

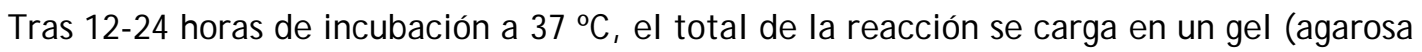
$0,8 \%(p / v)$ - TAE $1 x)$, con el objetivo de producir la separación electroforética de los fragmentos de ADN. Se procede a realizar una tinción con bromuro de etidio y se observa el bandeo obtenido (fluorescencia emitida por estas tras excitación con luz ultravioleta). La imagen digitalizada nos servirá para discernir visualmente entre cepas o bien para realizar un análisis informático con la ayuda del software correspondiente (InfoQuest FP, Bio-Rad).

\subsubsection{Análisis de diferentes regiones genómicas: caracterización de levaduras híbridas}

Tal como se ha indicado en el apartado 1.7.4 es posible realizar un estudio sobre algunas cepas susceptibles de tratarse de híbridos interespecíficos. Para ello, se amplifican ciertas regiones de algunos genes nucleares, sometiendo el producto a secuenciación o a un análisis de restricción con las endonucleasas adecuadas. En el presente estudio se han amplificado 
diversas regiones génicas, empleando para ello los oligonucleótidos iniciadores adecuados (tabla 3.10).

Tabla 3.10: Oligonucleótidos iniciadores de PCR para amplificar varias regiones de los genes nucleares indicados

\begin{tabular}{|c|c|c|}
\hline Gen & Oligonucleótido & Secuencia \\
\hline \multirow[t]{2}{*}{ BRE5 } & BRE5-5 & 5'-TGATTATAGCCACGGGTGARATGTTYTGG-3' \\
\hline & BRE5-3 & 5'-TTCATTCATCAACTTTGAGGCCCATGTCAT-3' \\
\hline \multirow[t]{2}{*}{ CAT8 } & CAT8-5 & 5'-TCCAATATTAGTATCAACAACTTTCTATAYCARAAYGA-3' \\
\hline & CAT8-3 & 5'-CTACTTGGCRTTTTGCCAYTGRAA-3' \\
\hline \multirow[t]{2}{*}{ CYR1 } & CYR1-5 & 5'-CTACGAAGGAAAGTGTCCTCTTTRGTTCGTGG-3' \\
\hline & CYRI-3 & 5'-CCGTGTGTAGAATTTAGTGTAGAATTGACRGC-3' \\
\hline \multirow[t]{2}{*}{ EGT2 } & EGT2n-5 & 5'-CAGATCATTGGTTCATAATAGAAGGKCAAYTGT-3' \\
\hline & EGT2n-3 & 5'-CCAGGCGGTRTTATTAGTTTTGTATATRCCACC-3' \\
\hline \multirow[t]{2}{*}{ GSY1 } & GSY1-5 & 5'-ATTGGAAAAAGAATTTTCGAGCAYACRATGAG-3' \\
\hline & GSY1-3 & 5'-AATTTCTTGCCACCGGCAAGGGTATTCATATT-3' \\
\hline \multirow[t]{3}{*}{ MET6 } & MET6-5 & 5'-CTAGACCTGTCCTATTGGGTCCAGTTTCTTACTT-3' \\
\hline & MET6-3 & 5'-TTAGCTTCTAGGGCAGCAGCAACRTCTTGACC-3' \\
\hline & MET6-3 $\mathrm{K}^{*}$ & 5'-GCGTTAGCTTCTAGAGCAGCAGTGACATTGC-3' \\
\hline \multirow[t]{2}{*}{ OPY1 } & OPY $1-5$ & 5'-CCGCGGACAACAGACCAYCATTAYTGGTGYGT-3' \\
\hline & OPY1-3 & 5'-CTCTTGAAATTTATTATCCARTCCACCATRTCYTG-3' \\
\hline
\end{tabular}

La reacción de PCR se realiza tal como se indica en la tabla 3.4, sustituyendo la pareja de oligonucleótidos iniciadores por la correspondiente a la región nuclear a amplificar. A continuación se indica el programa de amplificación de PCR empleado (tabla 3.11).

Tabla 3.11: Programa amplificación de los diferentes genes nucleares.

\begin{tabular}{lcc}
\hline Etapa & $\mathrm{T}^{\mathrm{a}}\left({ }^{\circ} \mathrm{C}\right)$ & Tiempo $(\mathrm{s})$ \\
\hline Desnaturalización inicial & 95 & 300 \\
Amplificación (40x) & & \\
Desnaturalización: & 94 & 60 \\
Anillamiento: & $55,5^{*}$ & 120 \\
Extensión: & 72 & 120 \\
Extensión final & 72 & 600 \\
Conservación & 4 & $\infty$ \\
*: Para el gen CAT8 se emplea una temperatura de anillamiento de $50,0{ }^{\circ} \mathrm{C}$.
\end{tabular}

\subsubsection{Análisis de fragmentos de ADN mediante electroforesis en geles de agarosa}

La electroforesis se define como la migración de solutos iónicos bajo la influencia de un campo eléctrico. Estas partículas migran hacia el cátodo o ánodo, en función de su carga, peso molecular y estructura tridimensional. La velocidad de migración electroforética depende de la densidad de carga de la molécula (relación carga/ peso), del voltaje aplicado y de la porosidad del gel de electroforesis.

Para la separación y análisis de los fragmentos de ADN obtenidos por cualquiera de las técnicas reseñadas, se empleará la electroforesis en geles de agarosa. Los geles se preparan disolviendo agarosa (Pronadisa) en TAE $1 x$ (facilitado por calentamiento), con concentraciones comprendidas entre el 0,8-3\%(p/v). La concentración de agarosa es inversamente proporcional al tamaño de los fragmentos a separar. A mayor concentración, el tamiz generado por la agarosa dificulta la movilidad de las moléculas de ADN y viceversa. 
Los geles se sumergen, dentro de la cubeta electroforética, en tampón TAE 1x. La carga de muestras en los geles es facilitada por la adición de tampones de carga. Estos producen un aumento de la densidad de la muestra a cargar, además de facilitar el seguimiento de la electroforesis. Esto es debido a que incluyen uno o varios colorantes (cargados) que avanzan con un ritmo equivalente a un fragmento de DNA de un tamaño determinado (facilitado por el fabricante). Se empleó un tampón de carga comercial (Takara) que se encuentra concentrado (10x) y por tanto el volumen a emplear será una décima parte del volumen total de la muestra a cargar en el gel. Una vez cargada la muestra en los geles, se aplican voltajes comprendidos entre $1-5 \mathrm{~V} / \mathrm{cm}$.

Finalizada la electroforesis, el gel se sumerge en una solución del agente intercalante de ADN, bromuro de etidio ( $1,5 \mathrm{mg} / \mathrm{L}$ ). Esta partícula es fluorescente por excitación con luz UV, por tanto se observarán las bandas de ADN. Mediante un sistema fotográfico acoplado a un transiluminador (luz UV), se tomará la imagen en formato papel y/ o digital.

La estimación del tamaño de las bandas se realiza mediante comparación con marcadores de peso molecular, cuyos tamaños están certificados. Los marcadores de peso molecular empleados en el presente trabajo han sido:

- $\quad \lambda$ HindIII: ADN del fago $\lambda$ digerido con HindIII (Fermentas)

- Escalera $25 \mathrm{pb}$ (Invitrogen $\left.{ }^{\mathrm{Tm}}\right)$

- Escalera 100 pb (InvitrogenTw)

- Escalera $1 \mathrm{~kb}$ (Invitrogentm)

- Escalera certificada 1 kb: Generuler ${ }^{\top m} 1 \mathrm{~kb}$ DNA Ladder Plus (Fermentas)

\subsubsection{Recuperación de fragmentos de ADN separados por electroforesis}

Los fragmentos de ADN separados en una electroforesis pueden ser recuperados a partir del bloque de agarosa que lo contiene. De este modo se conseguiría purificar una porción de ADN determinada del conjunto total. Se han empleado dos métodos, un método tradicional y otro comercial. En ambos casos los resultados obtenidos son similares.

- Método de congelación rápida (Freeze-squeeze)

Técnica tradicional basada en la congelación rápida de la banda de agarosa y posterior centrifugación a través de una matriz de retención de los ácidos nucleicos. El protocolo original (Tautz y Renz 1983) ha sido modificado, eliminando la lana de vidrio (nociva por inhalación) por algodón hidrófilo. El porcentaje de recuperación es del $70 \%$ aproximadamente.

El protocolo es el siguiente:

- Una vez separado el ADN mediante electroforesis, cortar el taco del gel que contiene la banda de interés (con la menor cantidad de agarosa posible). Introducir el fragmento de agarosa en un microtubo de $1,5 \mathrm{~mL}$ y congelar a $-80 \stackrel{\circ}{\circ} \mathrm{C}$ durante 10-15 minutos.

- Colocar un microtubo, al que se le ha realizado un orificio en el fondo y se ha obturado con algodón hidrófilo, sobre otro microtubo. Situar la banda congelada en el conjunto y centrifugar a $11.000 \mathrm{rpm} / 7 \mathrm{~min}$. / Ta Amb.

- Recoger la fase acuosa recolectada en el tubo inferior. Limpiar y precipitar el ADN tal como se describe en el protocolo de extracción de ADNtotal (apartado 
2.8.1,a partir de la extracción líquido-líquido por adición de un volumen de fenol-CïA).

- Resuspender el precipitado en 10-20 $\mu \mathrm{L}$ de agua milli-Q.

- Método de purificación por columnas GFX

Se realiza mediante el "GFXTM PCR DNA and Gel Band Purification Kit" (Amersham Biosciences). Este kit emplea un agente caotrópico que desnaturaliza las proteínas, disuelve la agarosa y promueve la unión del ADN de doble cadena (0,1-48 kbp) a la matriz de la columna suministrada. Una vez el ADN se encuentra retenido, las proteínas y sales son eliminadas mediante un lavado. El ADN se eluye por adición de una solución de baja fuerza iónica (es posible usar agua MQ). El porcentaje de recuperación ronda el 60 \%

El protocolo es el siguiente:

- Una vez separado el ADN mediante electroforesis, cortar el taco del gel que contiene la banda de interés (con la menor cantidad de agarosa posible). Introducir en un microtubo previamente pesado. Pesar el conjunto, deduciendo la masa de agarosa.

- Adicionar solución de captura en función de la cantidad de agarosa (según recomendaciones de fabricante). Incubar a $60 \stackrel{\circ}{\mathrm{C}}$ durante $15 \mathrm{~min}$ para favorecer la disolución de la agarosa.

- Transferir a una columna GFX. Incubar 1 min a Ta Amb.

- Centrifugar a $10.000 \mathrm{rpm} / 1 \mathrm{~min} / \mathrm{T}$ a Amb.

- Descartar el efluente y adicionar en la columna $500 \mu \mathrm{L}$ de la solución de lavado. Centrifugar a $10.000 \mathrm{rpm} / 30 \mathrm{~s} / \mathrm{T}$ a $\mathrm{Amb}$.

- Transferir la columna a un microtubo de $1,5 \mathrm{~mL}$ y adicionar sobre esta $15-20 \mu \mathrm{L}$ de la solución de elución elegida (por ejemplo agua milli-Q). Incubar 1 min a Tạ Amb.

- Centrifugar a $10.000 \mathrm{rpm} / 1 \mathrm{~min} / \mathrm{Ta}$ Amb. El efluyente arrastra el DNA purificado.

\subsection{Caracterización fenotípica y enológica de las levaduras}

\subsubsection{Fermentación de fuentes de carbono}

La caracterización de levaduras vínicas suele requerir una prueba para determinar su capacidad de fermentar diferentes fuentes de carbono, es decir, diferentes azúcares. El protocolo es el siguiente:

- En tubos de $10 \mathrm{~mL}$ añadir $5 \mathrm{~mL}$ de medio YE (suplementado con los diferentes azúcares) y una campana Durham (estéril).

- Inocular directamente la cepa de levadura desde placa con la ayuda de un asa de siembra.

- Incubar a 30 ํ/ 5 días.

La aparición de gas en la campana Durham, junto con el cambio de color del medio (debido a la acidificación por la producción de $\mathrm{CO}_{2}$ ) nos indicará la capacidad de fermentar dicha fuente de carbono por una levadura en particular (figura 3.2). 


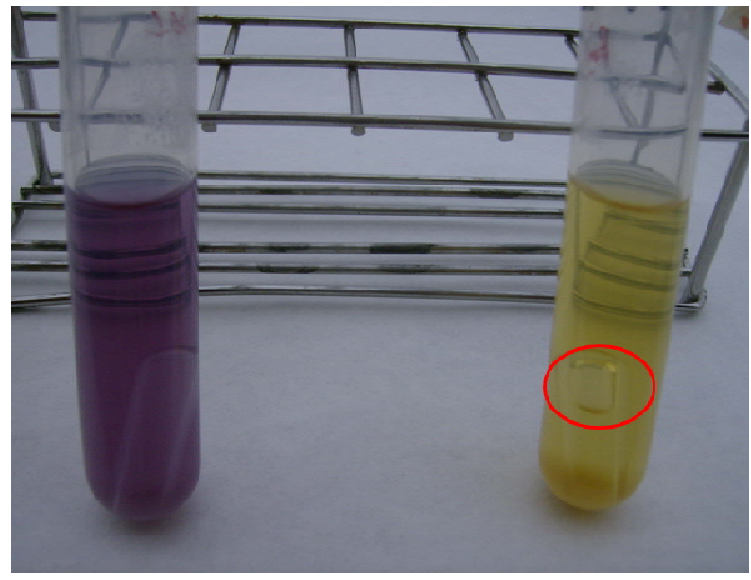

Figura 3.2: Resultado de la prueba de fermentación de fuentes de carbono. A la izquierda se observa un resultado negativo, mientras que a la derecha se observa uno positivo. Se ve claramente la producción de gas dentro de la campana Durham (circulo rojo) y el cambio de color del medio debido a la acidificación.

\subsubsection{Asimilación de fuentes de carbono}

Esta prueba nos permite determinar si la levadura en cuestión asimila diferentes fuentes de carbono, concretamente: D-glucosa, D-maltosa, D-sacarosa, D-galactosa, glicerol, Dcelibiosa, D-lactosa, D-trehalosa, D-melezitosa, D-rafinosa y 2-ceto-gluconato cálcico. Se realiza mediante el kit comercial $\mathrm{Api}^{\circledR} 20 \mathrm{C}$ (Biomérieux). El protocolo es el siguiente:

- Realizar una suspensión de células con una densidad óptica a $600 \mathrm{~nm}\left(\mathrm{DO}_{600}\right)$ de 0,1 en solución salina. Añadir $100 \mu \mathrm{L}$ de la suspensión anterior en el medio suministrado (kit). Homogeneizar.

- Repartir en los diferentes pocillos, cada uno de los cuales contiene una posible fuente de carbono.

- Incubar a $30 \stackrel{\circ}{ } \mathrm{C}$.

La lectura de los resultados se realiza a las 48 y 72 horas. La aparición de turbidez, respecto a un control negativo, indica la capacidad de asimilar una fuente de carbono en particular.

\subsubsection{Capacidad fermentativa (Método Rebelein)}

El método Rebelein es el método oficial de la OIV (Oficina Internacional de la Viña y el Vino) para la determinación de los azúcares totales (principalmente glucosa y fructosa) tanto en un vino como en un mosto. Este método puede ser útil para conocer el azúcar inicial de un mosto, controlar el avance de una fermentación o conocer los azúcares residuales del vino obtenido. Se realizó con el kit comercial "Rebelein Vinikit" (Panreac). Se basa en las propiedades reductoras de los azucares sobre soluciones cúpricas. Los azúcares son oxidados, a temperatura de ebullición, por un exceso de $\mathrm{Cu}^{2+}$, reduciéndose éste a su vez a $\mathrm{Cu}^{+}$. $\mathrm{El} \mathrm{Cu}^{2+}$ excedente se valora por iodometría tras la adición, también en exceso, de KI. Es decir se trata de una valoración redox indirecta.

Las reacciones que tienen lugar son:

- Oxidación de los azúcares por un exceso de solución alcalina de $\mathrm{Cu}^{2+}\left(\mathrm{T}^{\mathrm{a}} \mathrm{eb}.\right)$

$$
\text { Azúcar }+\mathrm{Cu}^{2+} \rightleftarrows \text { Azúcar }_{\text {ox. }}+\mathrm{Cu}^{+}+\mathrm{Cu}^{2+} \text { exc }
$$


- Reducción del $\mathrm{Cu}^{2+}$ en exceso con $\mathrm{KI} \rightarrow$ Producción de $\mathrm{I}_{2}$ equivalente:

$$
\begin{gathered}
2 \mathrm{Cu}^{2+}{ }_{\text {exc }}+2 \mathrm{e}^{-} \rightleftarrows 2 \mathrm{Cu}^{+} \\
2 \mathrm{I}^{-} \rightleftarrows \mathrm{I}_{2}+2 \mathrm{e}^{-} \\
2 \mathrm{Cu}^{2+}{ }_{\text {exc }}+2 \mathrm{I} \rightleftarrows 2 \mathrm{Cu}^{+}+\mathrm{I}_{2}
\end{gathered}
$$

- Titulación del yodo producido con tiosulfato sódico:

$$
\begin{gathered}
\mathrm{I}_{2}+2 \mathrm{e}^{-} \rightleftarrows 2 \mathrm{I}^{-} \\
2 \mathrm{~S}_{2} \mathrm{O}_{3}{ }^{2-} \rightleftarrows \mathrm{S}_{4} \mathrm{O}_{6}{ }^{2-}+2 \mathrm{e}^{-} \\
\mathrm{I}_{2}+2 \mathrm{~S}_{2} \mathrm{O}_{3}{ }^{2-} \rightleftarrows 2 \mathrm{I}^{-}+\mathrm{S}_{4} \mathrm{O}_{6}{ }^{2-}
\end{gathered}
$$

El protocolo es el siguiente:

- Realizar un cultivo líquido en $10 \mathrm{~mL}$ de YPD con las cepas de interés. Incubación a

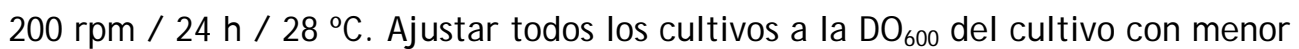
valor.

- En un matraz erlenmeyer añadir $100 \mathrm{~mL}$ de mosto. Inocular con $1 \mathrm{~mL}$ de los cultivos cuya $\mathrm{DO}_{600}$ ha sido aj ustada.

- Incubar los cultivos en estático a $28 \stackrel{\circ}{\circ}$, realizando una toma de muestra cada 24 horas hasta el final de la fermentación.

- Realizar para cada muestra la medida de los azúcares remanentes mediante el método Rebelein.

El método Rebelein consiste en:

- En un matraz erlenmeyer introducir de forma sucesiva $2 \mathrm{~mL}$ de vino (o mosto), 10 $\mathrm{mL}$ de solución cúprica y $5 \mathrm{~mL}$ de la solución alcalina. Además se añaden algunos fragmentos de piedra pómez.

- Tapar el erlenmeyer y calentar sobre la placa calefactora hasta ebullición, manteniéndolo durante $3 \mathrm{~min}$.

- Enfriar bajo el chorro del grifo y añadir de forma sucesiva $10 \mathrm{~mL}$ de la solución de yoduro de potasio, $10 \mathrm{~mL}$ solución de ácido sulfúrico y $10 \mathrm{~mL}$ de solución engrudo de almidón.

- Realizar un blanco con todos los reactivos excepto el vino (o mosto) que se sustituye por agua destilada.

- Valoración, utilizando una bureta, con la solución de tiosulfato hasta obtener una coloración amarillo crema.

Sean $\mathrm{v}$ los $\mathrm{mL}$ de tiosulfato gastados en el blanco y $\mathrm{v}^{\prime}$ los del problema, la cantidad de azucares totales se calcularán acorde a la siguiente expresión:

$$
\text { Azúcares totales, } g / L=\left(v-v^{\prime}\right)
$$

Mediante este diseño experimental, no solamente podemos conocer los azúcares remanentes en el vino final, sino que podemos seguir la evolución del proceso fermentativo. Como conocemos los azúcares en el mosto y los azúcares en cada punto muestreado, podemos representar, para cada levadura analizada, el porcentaje de azúcares consumidos frente al tiempo. Las curvas obtenidas se pueden ajustar a un modelo matemático mediante la 
“Ecuación de Gompertz Reparametrizada" (figura 3.3). Esta ecuación vendrá definida por tres parámetros:

$$
\% \text { Azucar total consumido }=A^{\prime} \cdot e^{-e^{\left(\left(\frac{m^{\prime 2} \cdot 2,718282}{A}\right) \cdot(1-t)+1\right)}}
$$

A': Asíntota horizontal. Indica el porcentaje máximo de azúcares consumido

m': Pendiente máxima. Indica la máxima velocidad de fermentación $(\mathrm{g} / \mathrm{L} \cdot \mathrm{h})$

I': Latencia. Indica el tiempo que ha durado en arrancar el proceso fermentativo.

A

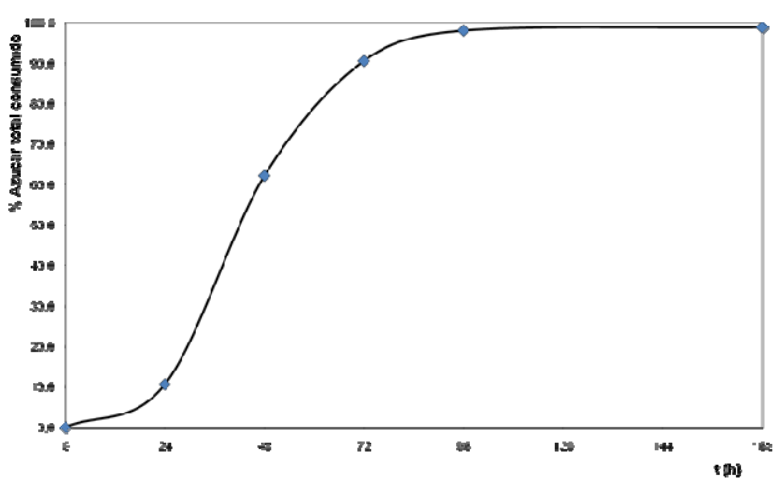

B

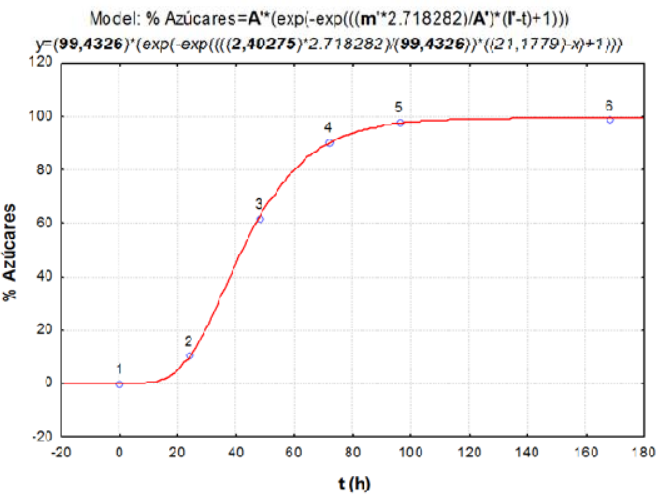

Figura 3.3: Ejemplo de los resultados experimentales obtenidos en el seguimiento de una fermentación mediante el métdo Rebelein (A). En B se observa el ajuste matemático (mediante la ecuación de Gompertz Reparametrizada), así como los parámetros obtenidos con el ajuste, que serán característicos de cada cepa ensayada.

\subsubsection{Tolerancia al etanol}

Debido a las tendencias de mercado acerca de las características de los vinos, uno de los parámetros con cierta importancia es el etanol que presentan. La tendencia actual va orientada a la obtención de vinos con una menor graduación alcohólica. Por tanto, no parece descabellado ensayar la capacidad de las cepas aisladas para soportar diferentes grados alcohólicos, es decir, ver el rango de concentraciones de etanol donde su desarrollo es óptimo y el valor a partir del cual su desarrollo se ve afectado.

\subsubsection{Fundamento del proceso}

Se tratará de obtener dos parámetros experimentales que nos darán información acerca de tolerancia de las levaduras al etanol: MIC y NIC (Lambert y Pearson 2000). La "mínima concentración inhibitoria" (MIC) es aquella concentración a partir de la cual no se observa crecimiento, es decir, la concentración de etanol en el medio que hace inviable el desarrollo de la levadura. Por el contrario la "concentración no inhibitoria" (NIC) es la concentración de etanol en el medio a partir de la cual se ve alterado, de modo negativo, el crecimiento y desarrollo del citado microorganismo.

Con el objetivo de determinar ambos parámetros se realizan curvas de crecimiento con diferentes concentraciones de etanol para cada una de las cepas a ensayar. Para tal fin se mide la $\mathrm{DO}_{600}$ periódicamente (cada hora) durante 72 horas. Seguidamente se calcula el área de cada una de las curvas de crecimiento, dividiendo cada valor obtenido entre el área obtenida en el ensayo realizado sin etanol (área fraccional, AF). El ajuste matemático (mediante la ecuación de Gompertz modificada) de la curva obtenida al refresentar el AF respecto al logaritmo de la concentración de etanol correspondiente nos permitirá obtener 
dichos parámetros (figura 3.4). Concentraciones de etanol inferior al NIC no afectarán al crecimiento de la levadura. Por el contrario, concentraciones superiores al MIC no permitirán el desarrollo, provocando su muerte. El rango de concentraciones comprendidos entre el valor NIC y el valor MIC influirán de modo progresivo en el desarrollo de las cepas.
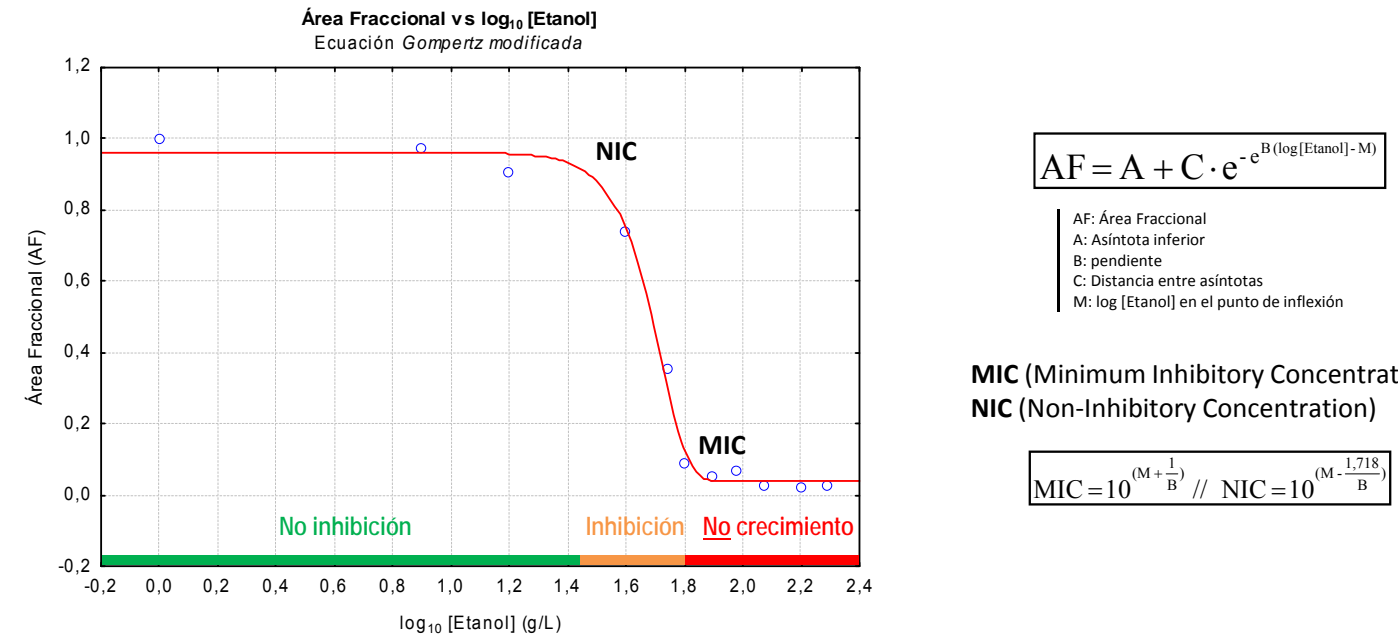

MIC (Minimum Inhibitory Concentration) NIC (Non-Inhibitory Concentration)

$$
\mathrm{MIC}=10^{\left(\mathrm{M}+\frac{1}{\mathrm{~B}}\right)} / / \mathrm{NIC}=10^{\left(\mathrm{M}-\frac{1,718}{\mathrm{~B}}\right)}
$$

Figura 3.4: Análisis para determinar la tolerancia al etanol de levaduras. Ajuste matemático experimental del Área Fraccional (AF) respecto al logaritmo de la concentración de etanol. Se indican las expresión matémáticas para el cálculo del NIC y el MIC, así como su representación gráfica. En fución del valor de estos parámetros, nos encontramos con tres intervalos de concentración de etanol. Los valores inferiores al NIC (intervalo marcado en verde) no provocan inhibición en el crecimiento. Los valores comprendidos entre el NIC y el MIC (en naranja) confieren inhibición en el desarrollo de las levaduras. Por último, valores iguales o superiores al MIC (indicado en rojo) impedirán el crecimiento y por tanto su muerte.

\subsubsection{Desarrollo experimental}

El desarrollo experimental del proceso se ha realizado de acuerdo al método propuesto por Arroyo-López et al. (2010). El experimento se realiza en microplacas (Nunc) de 96 pocillos con tapa, estériles. La ventaja de las microplacas respecto a las configuraciones tradicionales radica en la facilidad de manejo, aumento de número de réplicas y el menor gasto fungible.

El protocolo será el siguiente:

- Preparar 12 medios con diferente concentración de etanol [entre 0 - $25 \%$ (v/v)] a partir de YNB (Glucosa). Añadir $200 \mu \mathrm{L}$ por pocillo, de acuerdo con la plantilla mostrada en la figura 3.5.

- Cultivos de las levaduras a ensayar en $1 \mathrm{~mL}$ de GPY (microtubos). Incubar: 200 $\mathrm{rpm} / 24 \mathrm{~h} / 28 \stackrel{\circ}{\mathrm{C}}$.

- Centrifugar: $10.000 \mathrm{rpm} / 5 \mathrm{~min} / \mathrm{T}$ a Amb. Eliminar el sobrenadante.

- Añadir $500 \mu \mathrm{L}$ de solución salina. Resuspender y centrifugar de nuevo. Eliminar el sobrenadante.

- Añadir $500 \mu \mathrm{L}$ de solución salina. Resuspender.

- Inócular con $1 \cdot 10^{6}$ células/ $\mathrm{mL}$ por pocillo, a partir de la suspensión de células anterior.

- Incubar durante 72 h / 30 o C. Medir la $\mathrm{DO}_{600}$ cada hora.

- Realizar un tratamiento de datos y ajuste matemático correspondiente para la obtención de los correspondientes valores NIC y MIC. 
A

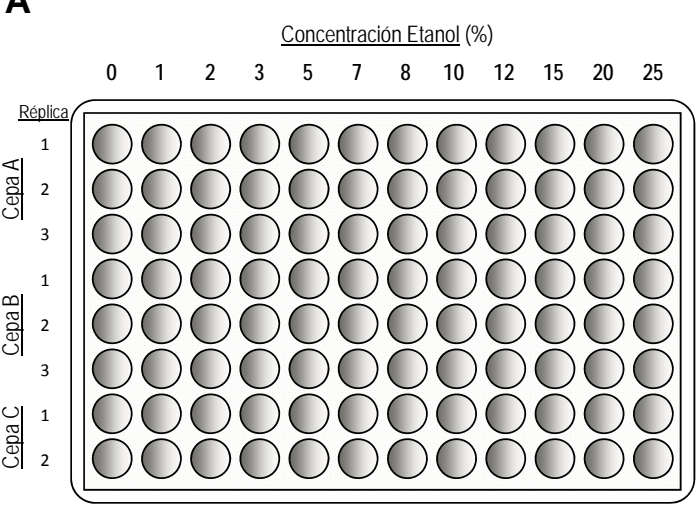

B

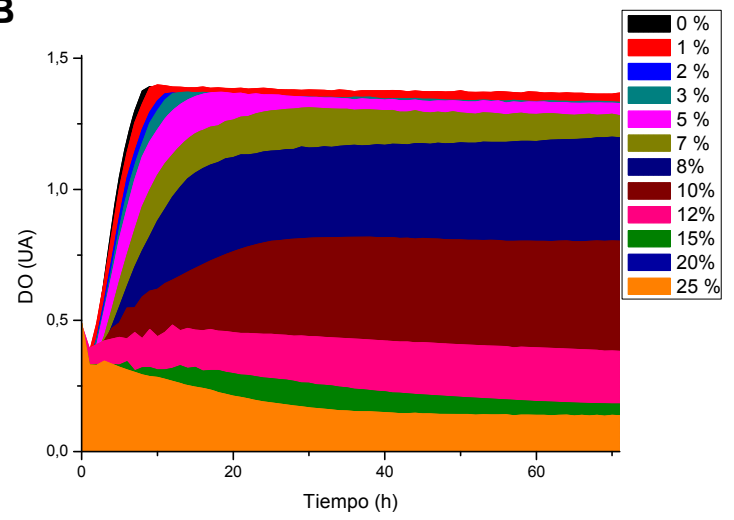

Figura 3.5: Diseño experimental para el análisis de la tolerancia al etanol de las levaduras. En A se observa la distribución de los diferentes medios empleados, así como de las cepas ensayadas (A y B por triplicado y C por duplicado) en la microplaca de 96 pocillos. En B se representan las curvas de crecimiento obtenidas experimentalmente para una réplica de las cepas estudiadas.

\subsubsection{Crecimiento a bajas temperaturas}

Mediante este estudio, se analiza el comportamiento de las levaduras aisladas en condiciones de baja temperatura. El interés radica en su uso en fermentaciones a baja temperatura, donde los perfiles aromáticos de los vinos producidos son más complejos y presentan una mayor intensidad.

El diseño experimetal, al igual que para la técnica anterior, esta basado en el uso de microplacas de 96 pocillos. El protocolo detallado es el siguiente:

- Realizar un cultivo líquido en $3 \mathrm{~mL}$ de GPY (tubos de $10 \mathrm{~mL}$ ) con la cepa de interés. Incubar a $150 \mathrm{rpm} / 24 \mathrm{~h} / 28 \stackrel{\circ}{\circ} \mathrm{C}$

- Ajustar a $\mathrm{DO}_{600}=6,0 ; \mathrm{V}=1 \mathrm{~mL}$

- Centrifugar las células: 10.000 rpm / 5 min / Ta Amb. Eliminar el sobrenadante.

- Añadir $1 \mathrm{~mL}$ de solución salina y resuspender (vortex). Centrifugar de nuevo y eliminar el sobrenadante.

- Resuspender las células en $1 \mathrm{~mL}$ de solución salina.

- Añadir $200 \mu \mathrm{L}$ de medio YNB (Glucosa) por pocillo.

- Inocular con $10 \mu \mathrm{L}$ de la suspensión de células previamente preparada.

- Incubar a $15 \stackrel{\circ}{ } \mathrm{C}$.

- Medida de la $\mathrm{DO}_{600}$ a diferentes tiempos.

De esta manera se obtendrán curvas de crecimiento a baja temperatura correspondientes a las cepas ensayadas. Previa normalización de las curvas, podemos ajustar las curvas a un modelo no lineal (figura 3.6). El parámetro que nos aportará información relativo a su comportamiento a bajas temperaturas será la pendiente $(m)$ que nos indica la velocidad máxima de crecimiento bajo las citadas condiciones. El experimento se realizará por triplicado para cada una de las levaduras estudiadas. 


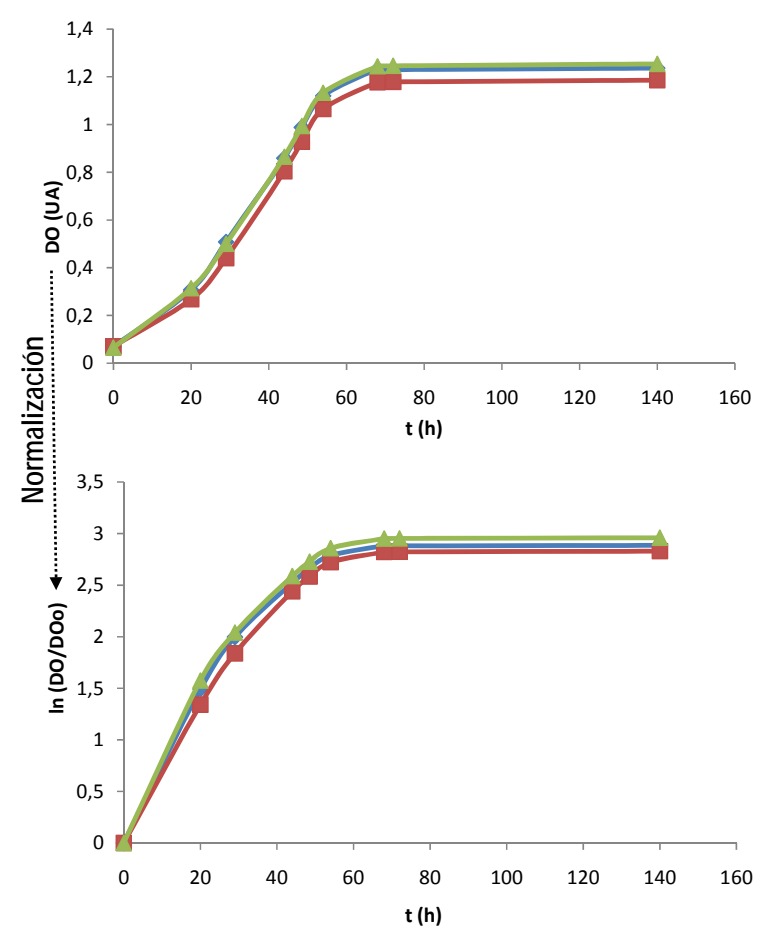

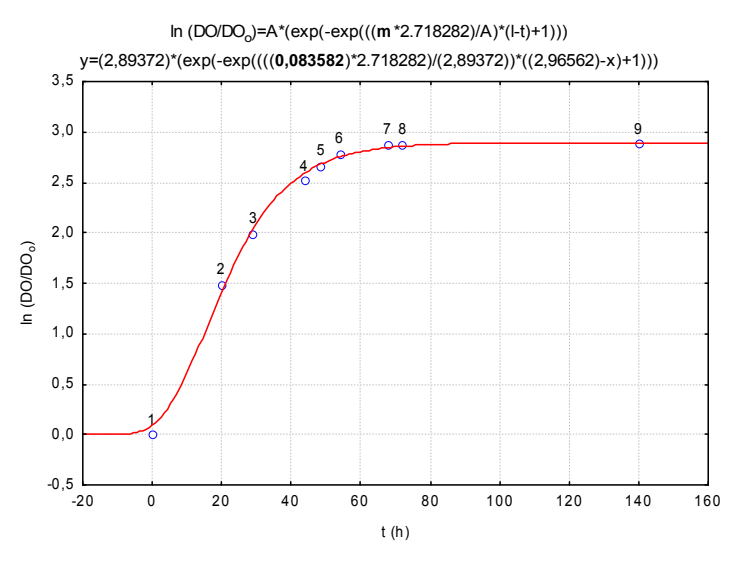

Figura 3.6: Protocolo experimental para el crecimiento a bajas temperaturas. En la parte superior izquierda se observan curvas de crecimiento (por triplicado) a baja temperatura. La normalización consiste en dividir cada medida entre el valor inicial $\left(\mathrm{DO}_{0}\right)$, y aplicar al resultado el logaritmo neperiano. Se obtienen curvas que pasan por el origen (izquierda, abajo). En la parte superior se observa el ajuste a un modelo no lineal (Ec. Gompertz Rep.). En negrita aparece resaltada la pendiente de dicho ajuste.

\subsubsection{Estudio del caracter "killer"}

Las prácticas enológicas actuales optan por fermentaciones dirigidas mediante el uso de iniciadores comerciales (LSAs). Como se ha indicado en el apartado 1.5.1.3.d ciertas levaduras tienen la capacidad de producir toxinas, de naturaleza proteica, capaces de "matar" las levaduras competidoras que presenten sensibilidad a la citada toxina. Con el objetivo de seleccionar levaduras autóctonas para ser usadas como iniciadoras de fermentación, se debe optar por cepas que presenten carácter "killer" para controlar las levaduras competidoras en el inicio de fermentación (Marquina et al., 2002). Alternativamente se podrían emplear cepas iniciadoras no sensibles a estas toxinas, ya que en caso contrario, se producirían fermentaciones lentas, e incluso una parada en el proceso (Van Vuuren y Wingfield 1986).

El carácter "killer" se estudiará desde dos puntos de vista. Por un lado se determinará la capacidad matadora, mediante ensayos en placa, respecto a cepas sensibles certificadas. Por otro lado se realiza una búsqueda y estudio del material genético asociado al citado carácter.

\subsubsection{Ensayo del carácter "killer" en placa}

De todas las toxinas "killer" descritas, en el presente estudio se han seleccionada las más conocidas, las toxinas K1 y K2. De estas dos, la segunda tiene una mayor importancia en vinificación mientras que la primera es predominante en la industria cervecera.

Las cepas empleadas para el presente estudio han sido:

- Cepa 1101: Productora de la toxina K1 (matadora).

- Cepa 5X47: Cepa sensible $\left(K_{0}\right)$.

- Cepa EX33: Cepa sensible $\left(\mathrm{K}_{0}\right)$ libre de partículas de ARN de origen vírico.

- Cepa EX73: Productora de la toxina K2.

- Cepa EX198: Productora de la toxina Klus.

- Cepa F182: Productora de la toxina K28. 
El protocolo de análisis es el siguiente:

- Realizar cultivos en $2 \mathrm{~mL}$ de YPD de las cepas a ensayar, junto con las cepas control (matadoras y sensibles). Incubación a 150 rpm / 48 h / 30 ํC.

- Realizar diluciones 1:100 en agua destilada estéril de los cultivos anteriores.

- En una placa de Petri añadir $1 \mathrm{~mL}$ de la suspensión de células, junto con $12 \mathrm{~mL}$ del medio de cultivo YPD-MB-Agar. El medio debe mantenerse a una temperatura de 50-55 $\stackrel{\circ}{ }$, asegurando su estado líquido para favorecer la mezcla, sin producir daño en las células. Dejar solidificar las placas.

- Sobre las placas anteriores, realizar estrías con las cepas cuya capacidad matadora se quiere chequear. Existe la posibilidad de realizar varias estrías sobre la misma placa.

- Incubar las placas a 18-20 ํ durante 3-5 días.

La cepa incorporada en el medio de cultivo será sensible cuando alrededor de alguna de las estrías realizadas, con una cepa "killer" certificada, se observe un halo de inhibición de crecimiento. Del mismo modo, si en el medio se incorpora una cepa sensible certificada, se puede ensayar la capacidad matadora de las cepas si alrededor de sus estrías aparecen los citados halos.

\subsubsection{Análisis del material genético asociado al carácter "killer"}

Como se ha indicado, las toxinas "killer" son codificadas por satélites (M) de doble cadena de ARN, cuyo mantenimiento, duplicación y encapsidación pasa por la coinfección de las levaduras por un virus L-A (también de doble cadena de ARN) (Marquina et al., 2002).

Mediante el método descrito por Maqueda et al. (2010), es posible realizar un aislamiento conjunto de ADNnuclear, ADNmt y las moléculas de doble cadena de ARN. Por tanto, es posible predecir, o bien asegurar (por un resultado positivo en el test en placa), el carácter "killer" de una levadura si presentan cualquiera de los satélites identificados en bibliografía, junto con el material genético del virus auxiliar.

El protocolo es el siguiente:

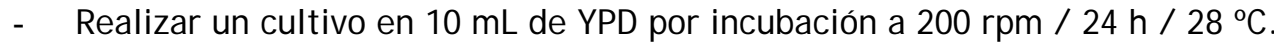

- Tomar $5 \mathrm{~mL}$ del cultivo anterior y pasar a un tubo de $10 \mathrm{~mL}$ de capacidad. Centrifugar para recoger las células: $4400 \mathrm{rpm} / 5 \mathrm{~min} /$ Tạ Amb. Eliminar el sobrenadante.

- Resuspender las células en $1 \mathrm{~mL}$ de Sol. 1 (EDTA $50 \mathrm{mM}, \mathrm{pH}=7,5$ ). Centrifugan de nuevo (4400 rpm / 5 min / Ta Ambiente). Eliminar el sobrenadante.

- Resuspender las células en $1 \mathrm{~mL}$ de Sol. 2 (Tris- $\mathrm{H}_{2} \mathrm{SO}_{4} 50$ mM, 1 \% 2 mercaptoetanol, $\mathrm{pH}=9,3)$. El contenido del tubo se pasa a un microtubo eppendorf ${ }^{\circledR}$ de $2 \mathrm{~mL}$. Incubar 15 minutos a temperatura ambiente.

- Centrifugar las células (10.000 rpm / $5 \mathrm{~min} / \mathrm{Ta}$ Amb.), eliminando el sobrenadante. Resuspender las células en $700 \mu \mathrm{L}$ de Sol. 3 ( $\mathrm{NaCl}$ 0,1M, Tris- $\mathrm{HCl} 10$ $\mathrm{mM}$, EDTA 10mM, 0,2\%SDS, pH=7,5). Añadir $700 \mu \mathrm{L}$ de fenol. Incubar 30 minutos a temperatura ambiente con agitación.

- Centrifugar (10.000 rpm / 10 min. / Ta Amb.) para facilitar la separación de las fases. Los ácidos nucleicos se encuentran en la fase acuosa (aprox. $700 \mu \mathrm{L}$ ), por 
tanto recuperar la fase superior y pasar ésta a otro microtubo eppendorf ${ }^{\circledR}$ de 2 $\mathrm{mL}$.

- Añadir 1 volumen de fenol-ClA. Agitar vigorosamente para favorecer la extracción. Centrifugar (12.000 rpm / $10 \mathrm{~min} . /$ Ta Amb.) para favorecer la separación de las fases.

- De nuevo, tomar la fase acuosa (superior) y transferirla a un microtubo de $1,5 \mathrm{~mL}$ de capacidad.

- Añadir 1/ 10 del volumen de la Sol. 4 (Acetato potásico 3M), y un volumen de isopropanol frío $(-20 \stackrel{\circ}{-})$. Homogenización por inversión suave y continuada de los tubos (observación del ovillo de ácidos nucleicos). Incubar a temperatura ambiente durante 10 minutos.

- Centrifugar los tubos (13.300 rpm / $10 \mathrm{~min} /$ Ta Amb.). Eliminar el sobrenadante.

- Lavar mediante adición de $1 \mathrm{~mL}$ de EtOH 70 \% (v/ v). Centrifugar (13.300 rpm / 3 min / Ta Amb. ). Eliminar el sobrenadante.

- Secar y evaporar los solventes mediante una bomba de vacío (aprox. $5 \mathrm{~min}$ ).

- Resuspender los ácidos nucleicos en $50 \mu \mathrm{L}$ de TE.

Cargar una alícuota $(4 \mu \mathrm{L})$ de la solución anterior en un gel (agarosa 1,0\%(p/v) - TAE 1x). Estimar el tamaño de las moléculas de doble cadena de ARN mediante comparación con los marcadores de peso molecular, y con el bandeo obtenido a partir de las cepas "killer" certificadas (K1, K2, K28 y Klus).

Adicionalmente, es posible tratar una alícuota del eluido con una ADNasa (DNAsa RQ1, Promega), consiguiendo que tras la electroforesis se observe únicamente las moléculas de ARN. La reacción enzimática correspondiente (tabla 3.12) se incuba durante 30 minutos a $37 \stackrel{\circ}{C}$. Pasado este periodo se inactiva la nucleasa mediante incubación a 65 oC durante 10 minutos.

Tabla 3.12: Reacción enzimática empleada en el análisis del material genético asociado al factor "killer". (*) Se empleará, para cada enzima, el tampón recomendado por el fabricante.

\begin{tabular}{lc}
\hline Reactivo & Volumen $(\mu \mathrm{L})$ \\
\hline Tampón & 2,0 \\
Enzima (DNAsa RQ1) & 2,0 \\
Agua (milli-Q) & 11,0 \\
ADNtotal + ARN (eluido) & 5,0 \\
V $_{\text {TOTAL }}$ & 20,0
\end{tabular}

\subsubsection{Microfermentaciones con levaduras seleccionadas}

Hasta el momento todas las pruebas descritas en este apartado tenían por objetivo determinar las propiedades de las cepas autóctonas aisladas en relación a parámetros individuales. Mediante la realización de microfermentaciones empleando estas cepas comprobaremos sus capacidades para la producción de vinos.

Las microfermentaciones se realizan a partir de mosto natural de uva Prieto Picudo. Para

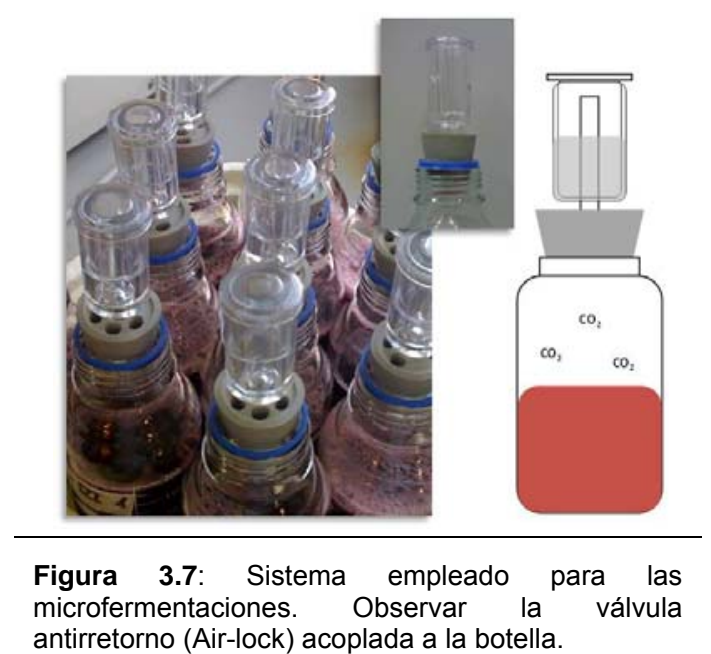


asegurar que la fermentación es llevada a cabo por una cepa en particular, es necesario someter al mosto a un proceso de esterilizado. El sistema empleado para realizar la fermentación serán botellas de $250 \mathrm{~mL}$ de capacidad a las que se acopla una válvula antirretorno (Air-lock), que permite la salida del dióxido de carbono producido, imposibilitando a su vez la entrada de aire (figura 3.7).

En las fermentaciones no solamente son determinantes los azúcares presentes en el mosto (fuentes de carbono). También es importante la cantidad de nitrógeno asimilable presente en el mosto, llegando a ser un factor determinante (Bell y Henschke 2005). Si el mosto no presenta un mínimo de $200 \mathrm{mg} / \mathrm{L}$ de nitrógeno asimilable, este deberá ser suplementado hasta alcanzar esta tasa.

\subsubsection{Determinación del nitrógeno asimilable en mosto}

Se realiza mediante la determinación del índice de formol. El protocolo es el siguiente:

- Ajustar el pH de una solución de formaldehido (comercial, mínimo $35 \%$ ) a un pH de 8,1 mediante la adición de hidróxido sódico 0,25 M.

- Añadir $25 \mathrm{~mL}$ de mosto en un vaso de precipitados, añadir $10 \mathrm{~mL}$ de la solución de formaldehido anterior y mantener la mezcla en agitación. Introducir un pHmetro en la solución, en modo de medida continuo.

- Valorar (bureta) con hidróxido sódico 0,025 M hasta que el pH de la mezcla sea de nuevo de 8,1. El volumen de $\mathrm{NaOH} \mathrm{0,025} \mathrm{M} \mathrm{gastado} \mathrm{(en} \mathrm{mL}$ ) será equivalente al índice de formol.

El nitrógeno asimilable del mosto se calcula de acuerdo con la siguiente expresión:

Nitrógeno asimilable $(\mathrm{mg} / \mathrm{L})=14 \cdot$ índice de formol

Cuando los mostos contengan menos de $200 \mathrm{mg} / \mathrm{L}$ de nitrógeno asimilable se suplementarán con $\left(\mathrm{NH}_{4}\right)_{2} \mathrm{SO}_{4}$. La relación entre la cantidad de suplemento y el nitrógeno asimilable es de 5:1. Por tanto, la cantidad a suplementar (con sulfato amónico), para suplir cierta deficiencia en nitrógeno asimilable, se multiplicará por cinco.

\subsubsection{Esterilización del mosto natural}

La esterilización se realiza por adición de dimetil dicarbonato, DMDC, (éster dimetílico del ácido pirocarbónico) (Sigma-Aldrich). Este se emplea en la industria alimentaria para realizar "esterilización en frío" en las bebidas no alcohólicas (aditivo E242), no resultando tóxico para el consumidor ya que se descompone en solución.

El proceso de esterilizado en frío consistirá en:

- $\quad$ Adición de $1 \mathrm{~mL}$ de DMDC por cada litro de mosto natural.

- Incubación a 4 ํC durante al menos 48 horas. El mosto se almacenará a esta temperatura hasta el momento de su uso.

\subsubsection{Preparación de microfermentaciones}

Se realizan por duplicado. El protocolo es el siguiente:

- Realizar un cultivo líquido en 5 mL de GPY. Incubar a 200 rpm / 24 h / 28 ㄷ․

- Medir la $\mathrm{DO}_{600}$ de los cultivos anteriores. Ajustar todos los cultivos a la $\mathrm{DO}_{600}$ de menor valor.

- Realizar un segundo cultivo líquido: $1 \mathrm{~mL}$ del cultivo anterior en $17 \mathrm{~mL}$ de GPY. Incubar a $200 \mathrm{rpm} / 24 \mathrm{~h} / 28 \stackrel{\circ}{\mathrm{C}}$ 
- Centrifugar a $3.000 \mathrm{rpm} / 5 \mathrm{~min} /$ Tạ Amb. Eliminar el sobrenadante.

- Lavar las células con $5 \mathrm{~mL}$ de agua, resuspender y centrifugar (3.000 rpm / 5 min / Tạ Amb.). Eliminar el sobrenadante.

- Añadir $6 \mathrm{~mL}$ de mosto natural estéril. Resupender las células.

- Añadir $175 \mathrm{~mL}$ de mosto natural estéril por botella. Inocular, por réplica, con 3 $\mathrm{mL}$ de la suspensión de células anterior. Acoplar la válvula antirretorno (Airlock).

- Medir la masa inicial de cada una de las microfermentaciones.

- Incubar a 22 ํC hasta el final de fermentación. Medir la masa cada 24 h.

- Finalizada la fermentación, mantener cada una de ellas durante $24 \mathrm{~h}$ a 4 으.

- Centrifugar los vinos obtenidos para eliminar las lías a 4.000 rpm / 5 min / Ta Amb.

- Conservar a -20 드 hasta el momento de análisis.

\subsubsection{Seguimiento de las microfermentaciones}

A medida que avanza el proceso de fermentación, los azúcares son transformados principalmente en etanol y dióxido de carbono. La eliminación progresiva de azúcares hace que disminuya la densidad del mosto-vino, y por tanto exista una mengua en la masa total. Se podría decir que la pérdida de masa es directamente proporcional al avance de la fermentación. De hecho, se estima que se ha alcanzado el final de fermentación alcohólica cuando la pérdida de masa sea ínfima o inapreciable.

Para ello se mide la masa inicial de cada fermentación, y periódicamente (cada 24 h) se repite la medida. Se considera finalizada la fermentación cuando la pérdida de masa en 5 días sea igual o inferior a $0,3 \mathrm{~g}$.

La representación gráfica de la pérdida de masa acumulada respecto al tiempo en que se han tomado las medidas, nos permitirá observar visualmente (e incluso con fines comparativos) el avance del proceso.

\subsubsection{Análisis de los vinos producidos}

El análisis de los vinos producidos se realiza mediante HPLC. Para ello se usa un cromatógrafo con dos detectores, uno de índice de refracción (RID) y otro de longitud de onda variable (VWD). El equipo está equipado con una columna HyperREZ XP Carbohydrate $\mathrm{H}^{+}$ $(8 \mu \mathrm{m}, 300 \times 7.7 \mathrm{~mm})$ y una pre-columna HyperREZ XP carbohydrate $\mathrm{H}^{+}$(Thermo Scientific), ambas mantenidas a $50 \stackrel{\circ}{\circ}$.

Diluciones 1:5 de los vinos experimentales y 1:25 del mosto natural, se filtran a través de filtros de acetato de celulosa con 0,45 $\mu \mathrm{m}$ de tamaño de poro (Costar, Washington DC, USA). La cuantificación de los azúcares (glucosa y fructosa), glicerol y etanol es llevada a cabo de por el detector RID, mientras que el ácido acético se determina mediante el detector VWD (210 nm). Se utiliza un flujo de $0,8 \mathrm{~mL} / \mathrm{min}$ y $\mathrm{H}_{2} \mathrm{SO}_{4} 1,5 \mathrm{mM}$ como fase móvil (volumen de inyección $25,0 \mu \mathrm{L}$ ). La cuantificación se realiza de acuerdo a las áreas de los diferentes picos, en relación a las rectas de calibración obtenidas empleando los correspondientes estándares.

\subsubsection{Normalización y ajuste de las curvas de fermentación}

Las microfermentaciones realizadas empleando diferentes levaduras tienen un fin último comparativo. El seguimiento realizado se basa en el registro de la pérdida de masa durante el proceso, pero la masa inicial de cada microfermentación es diferente. Por tanto, es necesario 
un sistema que permita estandarizar los resultados obtenidos, y así poder confrontar los diferentes comportamientos observados.

Una vez conocemos los azúcares contenidos en el mosto y residuales en los vinos, se puede hacer un cambio de variable: de masa acumulada perdida a porcentaje de masa acumulada perdida (Z). De este modo conseguimos normalizar las diferentes curvas obtenidas:

$$
Z=\frac{P_{p}(S-R)}{P_{f} \cdot S} \cdot 100
$$$$
\begin{array}{|l|}
P_{\mathrm{p}}: \text { Pérdidade masa en cada punto (acumulado) }(\mathrm{g}) \\
\mathrm{P}_{\mathrm{f}} \text { : Pérdida de masa en el punto final }(\mathrm{g}) \\
\mathrm{S} \text { : Concentración de azúcaresen el mosto }(\mathrm{g} / \mathrm{L}) \\
\mathrm{R}: \text { Concentracóón de azúcaresresidual en el vino }(\mathrm{g} / \mathrm{L})
\end{array}
$$

Las nuevas curvas normalizadas pueden ser ajustadas a un modelo no lineal (Gompertz Rep.), cuyos parámetros de ajuste nos darán información acerca del tiempo de latencia (I), velocidad máxima de fermentación (m) y el porcentaje fermentado (A). Estos parámetros pueden ser sometidos a comparación, aportando información del comportamiento de las diferentes levaduras (fig. 3.8).
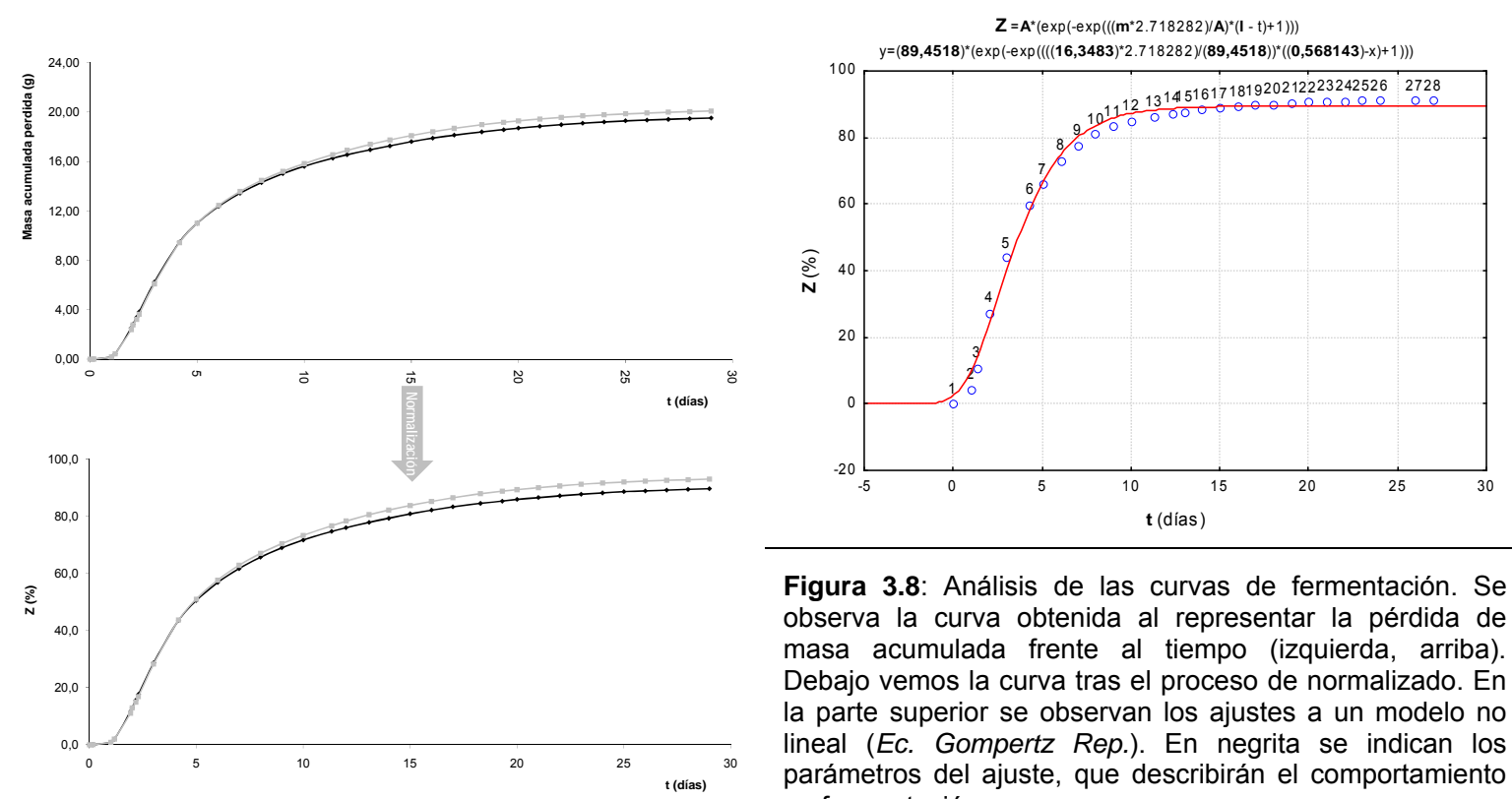

Figura 3.8: Análisis de las curvas de fermentación. Se observa la curva obtenida al representar la pérdida de masa acumulada frente al tiempo (izquierda, arriba). Debajo vemos la curva tras el proceso de normalizado. En la parte superior se observan los ajustes a un modelo no lineal (Ec. Gompertz Rep.). En negrita se indican los parámetros del ajuste, que describirán el comportamiento en fermentación. 


\subsection{Caracterización aromática de los vinos}

\subsubsection{Microvinificaciones experimentales}

El método empleado para obtener los vinos a partir de mosto natural empleando levaduras locales seleccionadas, es similar al indicado en el apartado 3.10.7, pero con algunas variaciones. A continuación se indicará de modo resumido el proceso para obtener los vinos que posteriormente se someterán a una caracterización aromática completa.

Las microvinificaciones, por triplicado, se realizaron en botellas de $500 \mathrm{~mL}$ de capacidad, conteniendo $350 \mathrm{~mL}$ de mosto. El mosto se esteriliza por filtración empleando filtros con 0,22 $\mu \mathrm{m}$ de tamaño de poro (Millipore). El preinóculo se prepara a partir de un cultivo líquido en

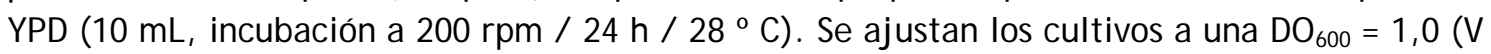
$=6 \mathrm{~mL}$ ). Se realiza un lavado con solución salina y las células se resuspenden en $5 \mathrm{~mL}$ de mosto natural estéril. Cada una de las botellas se inoculan con $1,5 \mathrm{~mL}$ de las supensión anterior. La fermentación se lleva a cabo a una temperatura de 20 ㅇ․ El proceso es monitorizado mediante el registro diario de la pérdida de masa en cada una de las botellas. Finalizada la fermentación (pérdida menor o igual a $0,3 \mathrm{~g}$. en 5 días). Se mantienen a 4 o $\mathrm{C}$ durante $24 \mathrm{~h}$. Posteriomente se procede al centrifugado de los vinos $(5.000 \mathrm{rpm} / 5 \mathrm{~min} /$ Tạ Amb.) transfiriéndolos a nuevos recipientes. Las alícuotas que se sometan a análisis cuantitativo se almacenan a $-20 \stackrel{\circ}{ } \mathrm{C}$ hasta su análisis. Sin embargo las muestras cuyo fin sea el análisis sensorial (análisis descriptivo sensorial y análisis mediante GC-0) se almacenan a $4 \stackrel{\circ}{\circ}$ en atmósfera inerte de nitrógeno.

\subsubsection{Análisis descriptivo sensorial}

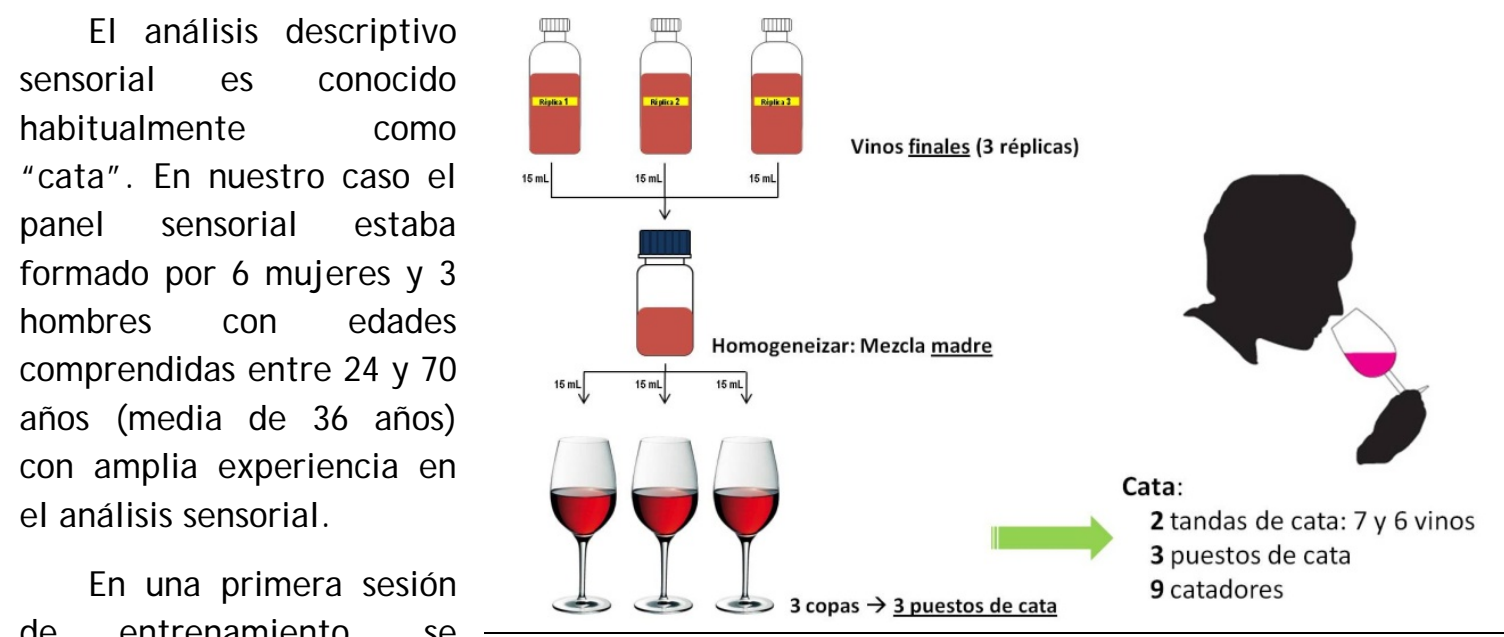
realizó una "cata libre"

Figura 3.9: Esquema de preparación de las muestras y organización de la cata. sobre diferentes vinos comerciales, tintos y rosados, pertenecientes a la Denominación de Origen "Tierra de León". En otras dos sesiones de entrenamiento, se presentaron al panel de cata los diferentes estándares que definen los principales aromas en los vinos. Tras las tres primeras sesiones se obtienen los ocho atributos aromáticos a valorar en los vinos experimentales (ver tabla 3.13). En la cuarta y última sesión de entrenamiento, los estándares anteriores son valorados por los miembros del panel de acuerdo a una escala de siete niveles, donde se permiten los valores intermedios $(0=$ no detectado, $1=$ débil, nota difícilmente reconocible, 2 = nota clara pero no intensa, $3=$ nota intensa).

Tras el entrenamiento, los vinos se someten a una cata ortonasal. En todos los casos, 15 $\mathrm{mL}$ de vino a $20 \stackrel{\circ}{ } \mathrm{C}$ se presentan en copas cubiertas con una placa de Petri. Las muestras se 
presentan, en cada puesto de cata, codificadas con un código numérico y dispuestas de modo aleatorio. Cada uno de los atributos es valorado según la escala citada anteriormente. El tratamiento de datos se realiza con la fórmula propuesta por Dravnieks (1985) para calcular la "frecuencia modificada" [MF (\%)] de cada atributo, $M F(\%)=\sqrt{F(\%) \times I(\%)}$. En la anterior expresión, $F(\%)$ es la frecuencia de detección de un atributo aromático, expresado en porcentaje, en relación al número total de jueces. El parámetro I (\%) es la intensidad media, expresada en porcentaje, en relación a la máxima intensidad.

Tabla 3.13: Atributos aromáticos seleccionados para el análisis descriptivo sensorial, así como la composición de los correspondientes estándares de referencia. ${ }^{a}$ Las cantidades especificadas se añaden en $40 \mathrm{~mL}$ de un vino tinto joven neutral (no presenta ningún atributo aromático marcado).

\begin{tabular}{ll}
\hline Atributo & Estándar de referencia a \\
\hline Fruta Fresca & $2 \mathrm{~mL}$ de cada uno: jugo de pera, plátano, fresa y piña \\
Fruta Madura & $1 \mathrm{~mL}$ de jugo de ciruela $+5 \mathrm{~mL}$ de salmuera de higos en lata \\
Fruta Exótica & $2 \mathrm{~mL}$ de cada uno: jugo de piña, mango y fruta de la pasión \\
Vegetal/terroso & $5 \mathrm{~g}$ de pimiento en rodaja en remojo durante $15 \mathrm{~min}+5 \mathrm{~mL}$ de salmuera de \\
& judías verdes en lata \\
Hierbas Aromáticas & $3 \mathrm{~g}$ de cada una: menta y hierbabuena mantenidos en remojo durante 15 \\
& minutos \\
Tostado & 1 gota de la muestra 48 (tostado) y una gota de la muestra 49 (almendras \\
& tostados) de "Le Nez du Vin" (Jean Lenoir) \\
Dulce & $1 \mathrm{~mL}$ de aroma de vainilla + $1 \mathrm{~mL}$ de aroma a caramelo \\
Especiado & Una pizca de pimienta negra +2 clavos \\
Reducción & $1 \mathrm{gota}$ de la muestra 6 (azufre) y una gota de la muestra 9 (col, repollo) de \\
& "Le Nez du Vin" (Jean Lenoir) \\
\hline
\end{tabular}

\subsubsection{Análisis mediante GC-0}

La Cromatrografía Gaseosa-Olfatometría (GC-0) es la mejor técnica para conocer y diferenciar las moléculas aromáticamente activas del resto de moléculas volátiles. En esta técnica, la nariz humana actúa como detector sobre los eluidos que salen de la columna montada en el cromatógrafo de gases (Ferreira y Cacho 2009).
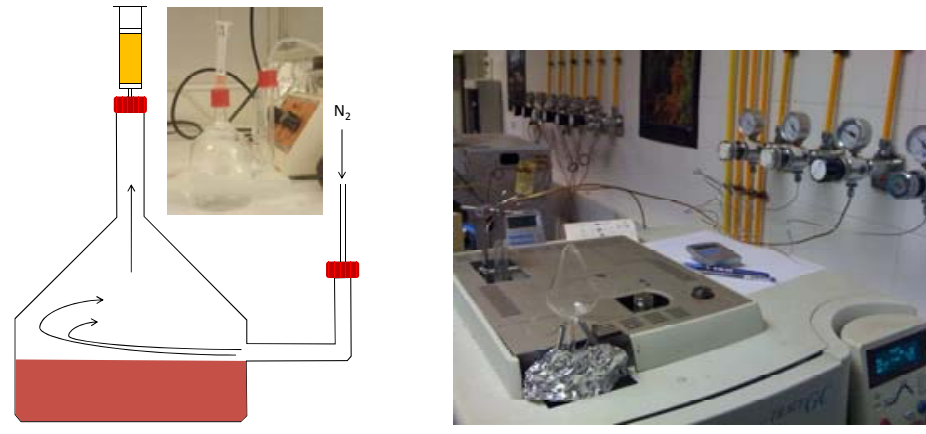

Figura 3.10: Representación esquemática y en imagen real del dispositivo empleado en la obtención de los extractos para el análisis mediante GC-O (izquierda). A la derecha, se observa el GC-FID con puerto olfatométrico donde se realizan las olfatometrías.

\subsubsection{Preparación de los extractos del vino}

Se llevaron a cabo mediante el acoplamiento de muestreo dinámico en espacio de cabeza y extracción en fase sólida (SPE), según el método validado descrito por San-Juan et al. (2010). Para tal fin se empleó un diseño de purga y trampa que permite obtener un extracto representativo de los vapores que alcanzan la pituitaria al oler un vino en copa (figura 3.10). Es decir, las intensidades obtenidas en olfatometría de dicho extracto simulan con fidelidad la intensidad aromática que cada compuesto químico presenta en la copa de vino. 
El protocolo para la preparación de los extractos es el siguiente:

- Un cartucho estándar de $\operatorname{SPE}(0,8 \mathrm{~cm}$ de diámetro interno, $3 \mathrm{~mL}$ de volumen interno) relleno con $400 \mathrm{mg}$ de resina LiChrolut EN (Merck) se lava con $20 \mathrm{~mL}$ de diclorometano (DCM) y posteriormente se seca mediante el paso de aire a través de él (presión negativa de 0,6 bares, 10 minutos).

- El cartucho se conecta a la parte superior del recipiente, que contiene $80 \mathrm{~mL}$ del vino a temperatura ambiente ( $21^{\circ} \mathrm{C}$ aproximadamente).

- Una corriente de nitrógeno (500 mL/ min) se aplica sobre la superficie del líquido, arrastrando los componentes volátiles del espacio de cabeza. Estos volátiles quedarán retenidos en la resina de los cartuchos. Se mantiene el flujo durante 100 minutos.

- Seguidamente se desmonta el sistema y se procede al secado del cartucho mediante el paso, a través de la resina, de una corriente suave de nitrógeno.

- Posteriormente se eluyen los analitos mediante adición (gota a gota) de 3,2 mL de DCM con un $5 \%(v / v)$ de metanol.

- Finalmente se realiza una concentración del extracto, bajo una corriente suave de nitrógeno puro, hasta un volumen final de $200 \mu \mathrm{L}$.

\subsubsection{Método de análisis en GC-0}

El análisis mediante GC-O se llevo a cabo mediante un cromatografo Trace GC (Termoquest) equipado con un detector de ionización en llama (FID) y un puerto olfatométrico ODO-I (SGE) (fig. 2.10). Este instrumento está equipado con una columna capilar DB-WAX (polietienglicol) (J \&W Scientific), $30 \mathrm{~m} \times 0,32 \mathrm{~mm}$ d.i., 0,5 $\mu \mathrm{m}$ de espesor de fase estacionaria; y una pre-columna ( $3 \mathrm{~m} \times 0,32 \mathrm{~mm}$ d.i.) (Supelco). Las condiciones cromatográficas empleadas son las siguientes: hidrógeno como gas portador (3,5 $\mathrm{mL} / \mathrm{min})$; inyección splitless (tiempo de splitless $60 \mathrm{~s}$ ); volumen de inyección, $1 \mu \mathrm{L}$; temperatura del inyector, $250^{\circ} \mathrm{C}$; temperatura del detector, $250^{\circ} \mathrm{C}$. El programa de temperatura del horno es el siguiente: $40 \stackrel{\circ}{\circ} \mathrm{C}$ durante $5 \mathrm{~min}$, aumento a razón de $4 \stackrel{\circ}{\circ} \mathrm{C} / \mathrm{min}$ hasta los $100 \stackrel{\circ}{\circ} \mathrm{C}$ y a $6 \stackrel{\circ}{\circ} \mathrm{C} / \mathrm{min}$ hasta los $220^{\circ} \mathrm{C}$, seguido de 20 minutos a $220^{\circ} \mathrm{C}$.

El puerto olfatométrico está equipado con un humidificador (para evitar el resecado de las fosas nasales) y con un reostato artesanal que permite un aumento gradual de temperatura, impidiendo la condensación de los compuestos con un elevado punto de ebullición.

\subsubsection{Panel sensorial en GC-O}

Un total de seis jueces (dos hombres y cuatro mujeres, con edades comprendidas entre 26 y 33 años) serán los encargados de realizar la olfatometría a partir de los correspondientes extractos. Previo al inicio del análisis de GC-O, los miembros del panel sensorial siguen un periodo de entrenamiento descrito por Ferreira et al. (2003). El tiempo de "esnifado" por análisis es de unos cuarenta minutos, sometiéndose cada analista a una única sesión por día para evitar fatiga.

Para cada uno de los eluidos percibidos a través de puerto olfatométrico, los analistas deben indicar un descriptor que caracterice el olor percibido y valorar su intensidad mediante una escala de siete niveles $(0=$ no detectado, $1=$ débil, nota difícilmente reconocible, $2=$ nota clara pero no intensa, 3 = nota intensa; permitidos los valores intermedios). Para cada odorante, tendremos diferentes intensidades y frecuencias de detección, que serán procesadas, al igual que en el análisis descriptivo sensorial (apartado 3.11.2), mediante el 
cálculo de su "frecuencia modificada": $M F(\%)=\sqrt{F(\%) \times l(\%)}$; donde $F(\%)$ es la frecuencia de detección de un atributo aromático, expresado en porcentaje, respecto al número total de jueces, y $1(\%)$ es la intensidad media, expresada como porcentaje, de la intensidad máxima.

Los odorantes son identificados, inequívocamente, mediante comparación de su olor e índice de retención en una columna DB-WAX con los obtenidos a partir de los correspondientes compuestos puros de referencia.

\subsubsection{Análisis químico cuantitativo}

\subsubsection{Compuestos mayoritarios (Microextracción líquido-líquido y Análisis GC-FID)}

La cuantificación de los compuestos mayoritarios (concentraciones del orden de $\mathrm{mg} / \mathrm{L}$ ) presentes en los vinos se realiza a través del método propuesto y validado por Ortega et al. (2001). El protocolo de preparación de los extractos es el siguiente:

- En un tubo para centrifuga de $10 \mathrm{~mL}$ de capacidad añadir: 4,1 g de sulfato amónico, $2,7 \mathrm{~mL}$ de vino, $6,3 \mathrm{~mL}$ de agua, $20 \mu \mathrm{L}$ de la solución de estándares internos (butan-2-ol, 4-metilpentan-2-ol, 4-hidroxi-4-metilpenta-2-ona, ácido heptanoico y octan-2-ol a $200 \mu \mathrm{g} / \mathrm{mL}$ en etanol) y 0,250 $\mathrm{mL}$ de DCM.

- Agitar los tubos a $90 \mathrm{rpm} / 90 \mathrm{~min} /$ Ta amb.

- Centrifugar los tubos a $2.500 \mathrm{rpm} / 10 \mathrm{~min} /$ Ta Amb. para favorecer la separación de las fases.

- Recuperar la fase orgánica (DCM) con la ayuda de una jeringa de 0,5 mL, y transferir a un vial de $0,3 \mathrm{~mL}$ de capacidad.

Los extractos son analizados mediante GC en un cromatógrafo de gases (HewlettPackard) equipado con un detector FID. Este instrumento esta equipado con una columna capilar DB-WAX (30 m x 0,32 mm d.i., 0,5 $\mu \mathrm{m}$ espesor fase estacionaria) (J \&W Scientific), precedido por una pre-columna sin recubrimiento $(2 \mathrm{~m} \times 0,53 \mathrm{~mm})$. Las condiciones cromatográficas son las siguientes: hidrógeno como gas portador $(2,2 \mathrm{~mL} / \mathrm{min})$; inyección de 3 $\mu \mathrm{L}$ en modo split (relación 1:10); temperatura del inyector y detector de $250{ }^{\circ} \mathrm{C}$. El programa del horno (columna): $40 \stackrel{\circ}{\circ} \mathrm{C}$ durante $2 \mathrm{~min}$, calentamiento hasta los $200 \stackrel{\circ}{\circ} \mathrm{C}$ a $2 \stackrel{\circ}{\circ} \mathrm{C} / \mathrm{min}$, manteniendo esta durante $30 \mathrm{~min}$. Los datos cuantitativos se obtienen por interpolación de las áreas relativas (picos) en las gráficas de calibración logradas tras el análisis de vinos sintéticos con concentraciones conocidas de los analitos.

\subsubsection{Compuestos minoritarios (SPE y análisis mediante GC-Trampa de lones-MS)}

El análisis de los compuestos minoritarios (concentraciones del orden de $\mu \mathrm{g} / \mathrm{L}$ ) es Ilevado a cabo mediante el método propuesto y validado por López et al. (2002), con algunas modificaciones. El protocolo de análisis es el siguiente:

- Por cada muestra a analizar, colocar un cartucho SPE relleno con 200 mg de resina LiChrolut EN en un sistema múltiple de extracción mediante vacio [VAC ELUT 20 de (Varian)]. Los cartuchos son acondicionados haciendo pasar a través de ellos consecutivamente $4 \mathrm{~mL}$ de DCM, $4 \mathrm{~mL}$ de metanol y $4 \mathrm{~mL}$ de una solución agua-etanol al $12 \%$ (v/ v).

- A continuación, sin que se seque la resina, se percolan $50 \mathrm{~mL}$ del vino a analizar, conteniendo $26 \mu \mathrm{L}$ de la solución de surrogados. Esta solución contendrá octan-3ona, $\beta$-damascenona y ácido heptanoico (todos ellos a una concentración de 200 
$\mu \mathrm{g} / \mathrm{mL}$ en etanol). La mezcla (vino + solución surrogados) pasará por los cartuchos a una velocidad aproximada de $2 \mathrm{~mL} / \mathrm{min}$ ).

- Lavar la resina mediante la adición de $5 \mathrm{~mL}$ de agua-metanol al 30 \% (v/ v), $\mathrm{NaHCO}_{3} 1 \%(p / v)$.

- Secar la resina mediante el paso de aire (presión negativa de 0,6 bares, $10 \mathrm{~min}$ )

- Eluir los analitos en un vial de $2 \mathrm{~mL}$, mediante adición de 1,6 mL de DCM con $1 \%$ (v/ v) de metanol. Añadir $34 \mu \mathrm{L}$ de la solución de estándares internos ( $300 \mathrm{mg} / \mathrm{L}$ de 4-hidroxi-4-etilpentan-2-ona y octan-2-ol) a cada uno de los eluidos.

Los extractos se analizan mediante un cromatógrafo de gases CP-3800 equipado con un espectrómetro de masas de trampa iónica Saturn 2200 (Varian). El equipo está equipado con una columna DB-WAX (60 m x 0,25 mm d.i., 0,5 $\mu \mathrm{m}$ espesor fase estacionaria) (J \&W Scientific), precedida de una pre-columna no recubierta $(3 \mathrm{~m} \times 0,25 \mathrm{~mm}$, desactivada, polaridad media) (Supelco). Se emplea helio (He) como gas portador a un flujo de $1 \mathrm{~mL} / \mathrm{min}$. El programa de temperaturas del horno es el siguiente: 3 minutos a $40{ }^{\circ} \mathrm{C}$, elevación hasta los $90 \stackrel{\circ}{\circ} \mathrm{C}$ a $10 \stackrel{\circ}{\circ} / \mathrm{min}$, calentamiento hasta los $230 \stackrel{\circ}{\circ} \mathrm{C}$ a una velocidad de $2 \stackrel{\circ}{\circ} / \mathrm{min}$, manteniendo esta temperatura durante 37 minutos. El inyector se mantiene a $35 \stackrel{\circ}{\circ} \mathrm{C}$ durante 0,3 min y se aplica un pulso de $25 \mathrm{psi}$ durante $2,6 \mathrm{~min}$. Posteriormente, se produce un calentamiento hasta los $250 \stackrel{\circ}{\circ} \mathrm{C}$ a una velocidad de $200 \stackrel{\circ}{\circ} / \mathrm{min}$. Se inyectan $4 \mu \mathrm{L}$ en modo splitless (tiempo de splitless de 2,60 $\mathrm{min})$. Se registró el rango de masas $(\mathrm{m} / \mathrm{z})$ comprendido entre 40-220. Los datos cromatográficos se analizaron con la ayuda del software Varian Saturn GC-MS Version 6. 3. La cuantificación se realiza a partir de las gráficas de calibración construidas a partir de soluciones de DCM con concentraciones conocidas de los patrones y de los estándares internos.

\subsubsection{Mercaptanos polifuncionales (Alquilación en sorbente y GC-NCI-MS)}

El análisis del 2-metilfuran-3-tiol (MF), 4-mercapto-4-metilpentan-2-ona (4MP), acetato de 3-mercaptohexilo (3MH), 3-mercaptohexanol (MH) y bencilmercaptano (BM) se lleva a cabo mediante el método propuesto por Mateo-Vivaracho et al. (2010). El protocolo de análisis es el siguiente:

- En un vial roscado, de $24 \mathrm{~mL}$ de capacidad, se adicionan $23 \mathrm{~mL}$ del vino a analizar enriquecido con $0,2 \mathrm{~g}$ de EDTA $(5 \mathrm{~g} / \mathrm{L})$ y $0,6 \mathrm{~g}$ de clorhidrato de L-cisteina $(0,1$ M). Mantener en agitación durante 2 minutos.

- Transferir una parte del vino anterior a un matraz aforado de $20 \mathrm{~mL}$ de capacidad. Añadir $15 \mu \mathrm{L}$ de 2 -feniletanotiol $(1.400 \mu \mathrm{g} / \mathrm{L}$, en etanol) como patrón interno. Agitar hasta completa disolución. Enrasar con el vino anterior. Este volumen es transferido a un nuevo vial de $24 \mathrm{~mL}$.

- Añadir 0,2 g de 0-metilhidroxilamina. Agitar durante $15 \mathrm{~s}$. El vial se purga con una corriente de nitrógeno puro, se sella, y se incuba en baño de agua a $55 \stackrel{\circ}{\circ}$ durante 45 minutos.

- Transferir $6 \mathrm{~mL}$ de la muestra anterior a un cartucho de SPE Bond Elut-ENV (Agilent Technologies) (previamente acondicionado con $1 \mathrm{~mL}$ de DCM, $1 \mathrm{~mL}$ de etanol y $1 \mathrm{~mL}$ de agua).

- Algunos de los volátiles más importantes de los vinos son eliminados mediante adición de $4 \mathrm{~mL}$ de una solución al $40 \%$ metanol/agua de tampón fosfato 0,2 M a pH 7,7. A continuación se añade $1 \mathrm{~mL}$ de agua. 
- Añadir un segundo patrón directamente en la columna [20 $\mu \mathrm{L}$ de una solución de 4-metoxy- $\alpha$-toluentiol ( $150 \mu \mathrm{g} / \mathrm{L}$, en etanol) mezclados con $200 \mu \mathrm{L}$ de agua].

- Los mercaptanos retenidos en la resina son directamente derivatizados por adición de $1 \mathrm{~mL}$ de una solución acuosa $(6,7 \%$ de 1,8-diazabiciclo[5.4.0]undec-7eno (DBU) (Aldrich), y a continuación por la adición de $50 \mu \mathrm{L}$ de una solución de bromuro de 2,3,4,5,6-pentafluorobencilo (PFBBr) (Fluka) en hexano (2.000 $\mathrm{mg} / \mathrm{L}$ ). Mantener el cartucho embebido con el reactivo durante 20 minutos a temperatura ambiente ( $25 \stackrel{\circ}{\circ}$ ).

- Eliminar el exceso de reactivo por adición de $100 \mu \mathrm{L}$ de una solución de mercaptoglicerol $(2.000 \mathrm{mg} / \mathrm{L}$, disuento en solución acuosa de DBU al 6,7 \%), dejando de nuevo el cartucho embebido a temperatura ambiente durante 20 minutos.

- Lavar los cartuchos por adición de $4 \mathrm{~mL}$ de una solución al 40 \% metanol/agua de $\mathrm{H}_{3} \mathrm{PO}_{4} 0,2 \mathrm{M}$, y posteriormente con $1 \mathrm{~mL}$ de agua.

- Eluir los analitos derivatizados por la adición de $600 \mu \mathrm{L}$ de una mezcla de disolventes ( $25 \%$ de hexano en dietil éter). Al extracto obtenido se añaden $10 \mu \mathrm{L}$ de la solución de estándares internos $(22,5 \mu \mathrm{g} / \mathrm{L}$ de octafluoronaftaleno (OFN) en hexano)

- Lavar el eluido (cinco veces) con $1 \mathrm{~mL}$ de salmuera $(200 \mathrm{mg} / \mathrm{L}$ de $\mathrm{NaCl}$ en solución acuosa) y se transfiere a un vial estándar de $2 \mathrm{~mL}$ de capacidad, enriqueciéndose la muestra con una pequeña cantidad de sulfato sódico anhidro.

- Finalmente inyectar $4 \mu \mathrm{L}$ en modo splitless frío en un sistema GC-ionización química negativa ( $\mathrm{NCl}$ )-MS

El análisis se realiza en un cromatógrafo de gases Shimadzu QP-2010Plus (Shimadzu) acoplado a un espectrómetro de masas cuadrupolo. El inyector es un Shimadzu PTV provisto de un tubo de vidrio (liner) relleno de lana de vidrio silanizada. La temperatura inicial del inyector es de $65 \stackrel{\circ}{\circ}$, y después de $25 \mathrm{~s}$, aumenta su temperatura a razón de $16 \stackrel{\circ}{\circ} / \mathrm{s}$ hasta los $260 \stackrel{\circ}{\circ}$, manteniéndose esta temperatura hasta el final del análisis. El gas portador es He, con un flujo a través de la columna durante el tiempo de splitless $(4,15 \mathrm{~min})$ de 2,69 $\mathrm{mL} / \mathrm{min}$. Una vez la válvula split se abre el flujo se establece a $1,44 \mathrm{~mL} / \mathrm{min}$. La columna capilar empleada es una DB-5 (20 m x 0,18 mm d.i., 0,18 $\mu \mathrm{m}$ espesor fase estacionaria) (J \&W Scientific). La temperatura inicial de columna es de $40 \stackrel{\circ}{\circ}$ durante $4,15 \mathrm{~min}$, se calienta hasta $140 \stackrel{\circ}{\circ} \mathrm{C}$ a 25 ${ }^{\circ} \mathrm{C} / \mathrm{min}$, después hasta $180{ }^{\circ} \mathrm{C}$ a $15{ }^{\circ} \mathrm{C} / \mathrm{min}$, seguido de un calentamiento hasta $210{ }^{\circ} \mathrm{C}$ a 30 o $\mathrm{C} / \mathrm{min}$, y por último se eleva la temperatura hasta $280 \stackrel{\circ}{\circ} \mathrm{C}$ a una velocidad de $250 \stackrel{\circ}{\circ} \mathrm{C} / \mathrm{min}$, manteniéndose esta temperatura durante 10 minutos. En la generación de iones, mediante la ionización química negativa $(\mathrm{NCl})$, se emplea metano a una presión de 3 bares. La temperatura de la fuente de iones es de $220{ }^{\circ} \mathrm{C}$, mientras la interfase se mantiene a $270{ }^{\circ} \mathrm{C}$. El registro de iones, tanto de los analitos como los estándares internos, se realiza mediante monitorización de un único ión (SIM, "single ion monitoring") entre los minutos 5,5 y 17 a $0,18 \mathrm{~s} /$ punto: $\mathrm{FFT}$, con un tiempo de retención de $11,18 \mathrm{~min}$, cuantificado con el ión $\mathrm{m} / \mathrm{z} 274$ (113 como ión calificador); MP, 11,88 min, m/z de 160 (194); MHA, 12, $25 \mathrm{~min}, \mathrm{~m} / \mathrm{z}$ de175 (194); MH, 12,03 min, m/z de 133 (194); y BM, 12,13 min, m/z 284 (162). Los patrones internos: 2-feniletanotiol, $12.48 \mathrm{~min}, \mathrm{~m} / \mathrm{z}$ de 135 (194); 4-metoxy- $\alpha$-toluentiol, $12.835 \mathrm{~min}$, $\mathrm{m} / \mathrm{z}$ de 314; OFN, $\mathrm{m} / \mathrm{z}$ de 272 . La cuantificación se realiza mediante la medida de las áreas relativas (entre analitos y los correspondientes patrones internos), en relación a curvas de calibración obtenidas a partir de soluciones con concentraciones conocidas. 
IV. Resultados y Análisis 



\section{1. Aislamiento y caracterización genética de levaduras vínicas autóctonas de la DO «Tierra de León»}

El estudio de aislamiento y caracterización de cepas de levaduras se ha llevado a cabo en cinco bodegas diferentes durante al menos tres cosechas distintas y ha consistido en un estudio individualizado de cada una de las bodegas para finalmente realizar una comparación entre ellas. El aislamiento se realizó en todos los casos a partir de microfermentaciones alcohólicas finalizadas ya que nuestro interés era aislar fundamentalmente cepas de $\mathrm{S}$. cerevisiae que pudieran tener una posible aplicación industrial.

\subsubsection{Bodega Gordonzello S.A.}

\subsubsection{Aislamiento de levaduras vínicas}

Como hemos indicado anteriormente el aislamiento se realizó en todos los casos a partir de microfermentaciones de mosto natural finalizadas. Tras realizar diluciones seriadas, estas se plaquearon en medio WL que permite cierta diferenciación fenotípica. En concreto se detectaron colonias balncas y verdes (tabla 4.1).

Tabla 4.1: Datos básicos de las microvinificaciones espontáneas realizadas con mosto suministrado por la bodega Gordonzello S.A. Se indica, para cada cosecha, el tiempo necesario para llevar a cabo la fermentación, la densidad final del vino obtenido, el número final de levaduras por unidad de volumen y el fenotipo (en porcentaje) de las colonias aisladas.

\begin{tabular}{|c|c|c|c|c|c|}
\hline \multirow[b]{2}{*}{ Cosecha } & \multirow[b]{2}{*}{ Periodo microvin. (días) } & \multirow[b]{2}{*}{ Densidad $(\mathrm{g} / \mathrm{ml})$} & \multirow[b]{2}{*}{ Recuento (u.f.c. /mL vino) } & \multicolumn{2}{|c|}{ Coloración (\%) } \\
\hline & & & & Blancas & Verdes \\
\hline 2.005 & 13 & 0,9940 & $1,1 \cdot 10^{6}$ & 86,4 & 13,6 \\
\hline 2.006 & 11 & 0,9949 & $6,1 \cdot 10^{6}$ & 37,0 & 67,0 \\
\hline 2.007 & 16 & 0,9770 & $6,1 \cdot 10^{6}$ & 55,0 & 45,0 \\
\hline
\end{tabular}

\subsubsection{Caracterización genética de las levaduras vínicas}

La caracterización genética se llevó a cabo para unas 60 colonias por bodega y año. Se seleccionan tanto colonias verdes como colonias blancas para la realización del estudio. De hecho en la nomenclatura que se da a cada una de las colonias se tiene en cuenta este aspecto fenotípico (ver tabla 3.3). En la tabla que se presenta a continuación se indican las colonias analizadas en cada cosecha, así como su coloración (tabla 4.2).

Tabla 4.2: Colonias seleccionadas para su caracterización genética en la bodega Gordonzello S.A. Se indica, para cada cosecha, el número total de colonias analizadas junto con la coloración que presentaban.

\begin{tabular}{cccc}
\hline Cosecha & Número total de colonias & Blancas & Verdes \\
\hline 2.005 & 58 & 39 & 19 \\
2.006 & 59 & 29 & 30 \\
2.007 & 60 & 30 & 30 \\
\hline
\end{tabular}

\subsubsection{2.a. Identificación a nivel de especie mediante RFLP-5.8S-ITS}

El fundamento de esta técnica se describe en el apartado 1.7.2.2, mientras que el desarrollo experimental se indica en el apartado 3.9.2. Se realizó el estudio para todas las cepas indicadas anteriormente, para las que se amplificó la región 5.8S-ITS y los productos de la reacción de PCR se sometieron a un análisis de restricción empleando las endonucleasas Haelll, ScrFl y Accl. 
Todos los clones estudiados, durante las tres cosechas, dieron un resultado idéntico (figura 4.1) que indicaba que en todos los casos se trataba de clones de S. cerevisiae, salvo los clones con morfología verde aislados en la cosecha del año 2.006. En estos últimos el patrón de restricción con la endonuclesa Haell no mostraba las cuatro bandas características de 320, 230,175 y 125 pb típicas de S. cerevisiae sino que presentaba, aparentemente, únicamente tres bandas claramente diferenciadas.

En un principio se pensó que se podía tratar de una levadura híbrida ya que su bandeo no correspondía con ninguna de las especies pertenecientes al género Saccharomyces. Así se amplificaron diversos genes para posteriormente realizar un análisis de restricción según lo propuesto por González et al. (2006). Se amplificaron los genes MET6, OPY1, CYR1, GSY1 y CAT8 y tras el análisis de restricción se obtuvieron los patrones correspondientes a $\mathrm{S}$. cerevisiae (figura 4.2). Adicionalmente se amplificaron diferentes regiones genómicas conservadas para proceder a su secuenciación, concretamente la región 5.8S-ITS, los dominios D1 y D2 del ADNr 26S, la región BRE5 y la región EGT2 (figura 4.3). La comparación de estas secuencias frente a las bases de datos nos indicó inequívocamente que nos encontrabamos ante la especie S. cerevisiae. Cuando sobre la secuencia del amplificado de la región 5.8S-ITS realizamos una búsqueda de la secuencia reconocida por el enzima de restricción Haelll vimos que los fragmentos obtenidos varíaban significativamente con lo esperado para un clon de $\mathrm{S}$. cerevisiae. Ello se debe a que una mutación puntual genera un corte adicional en la secuencia, de forma que la banda esperada de $175 \mathrm{pb}$ se desbobla en una banda de 144 y otra de $29 \mathrm{pb}$. Por tanto en el gel se observan las dos bandas de mayor tamaño, que se mantienen invariables, mientras que en un tamaño en torno a $130 \mathrm{pb}$ aparece una banda, aunque realmente se trata de una banda doble (una de $125 \mathrm{pb}$ y otra de $144 \mathrm{pb}$ ). La banda de $29 \mathrm{pb}$ resultante puede pasar desapercibida en algunas electroforesis debido a su pequeño tamaño (en la figura 4.1 se observa claramente).

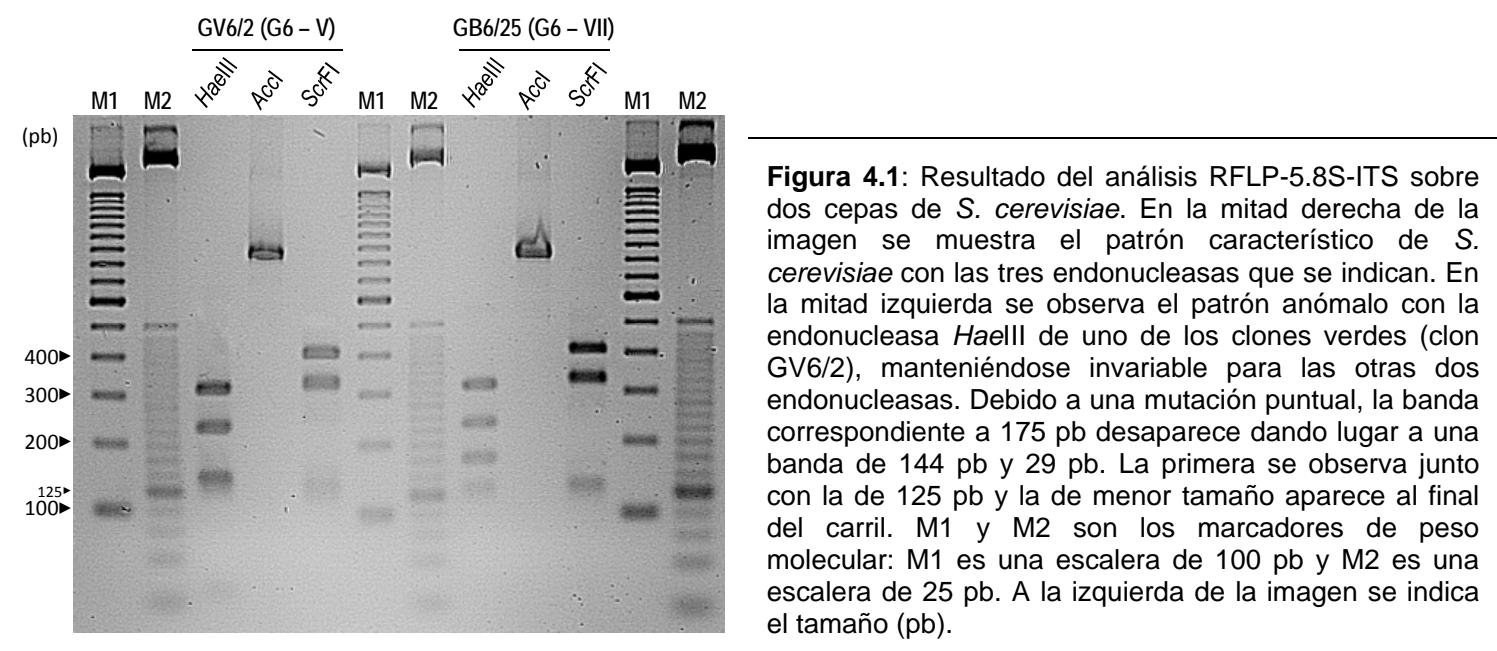

Por tanto se puede concluir que todas las cepas aisladas en esta bodega pertenecían a la especie S. cerevisiae, aunque destacando que todos los clones verdes detectados en la cosecha 2.006 pertenecían al mismo tipo o cepa (G6-V) (ver figura 4.5) y mostraban una mutación puntual en la región 5.8S-ITS que provocaba que el polimorfismo detectado con el enzima Haelll fuera anómalo. 

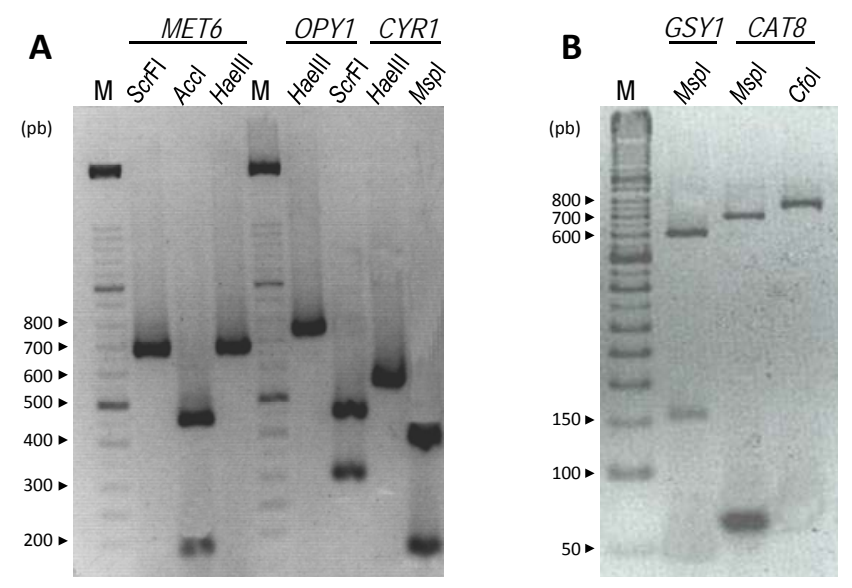

Figura 4.2: Análisis de restricción sobre los fragmentos amplificados de las regiones genómicas MET6, OPY1 y CYR1 (A) y GSY1 y CAT8 (B) del clon verde GV6/2 (G6 - V). Los patrones obtenidos son típicos de $S$. cerevisiae, descartando la posibilidad de encontrarnos ante una levadura híbrida. Los fragmemos típicos de S. cerevisiae (en pb) se indican a continuación: MET6(ScrFI y HaellI), 680; MET6(Accl), 450, 150, 60; OPY1(HaellI), 750; OPY1(ScrFI), 450, 300; CYR1(HaellI), 560; CYR1(Mspl), 400, 170; GSY1(Mspl), 610, 160; CAT8(Mspl), 690, 70, 50; CAT8(Cfol), 810. M es un marcador de peso molecular, mezcla de una escalera de 50 y 100 pb.

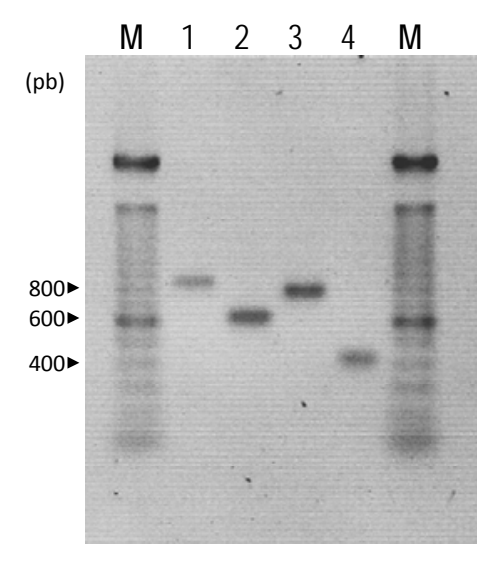

Figura 4.3: Productos de amplificación, mediante PCR, de varias regiones genómicas conservadas correspondientes al clon verde GV6/2. En el carril 1 se muestra el amplificado de la región 5.8S-ITS, con un tamaño de $850 \mathrm{pb}$; en el carril 2 se muestra el amplificado de los dominios D1-D2 del ADNr, con un tamaño aproximado de $600 \mathrm{pb}$; en el carril 3 se muestra el amplificado del gen BRE5, cuyo tamaño está en torno a $780 \mathrm{pb}$; en el carril 4 se muestra el amplificado del gen EGT2, con un tamaño aproximado de $430 \mathrm{pb}$. M es el marcador de peso molecular: escalera de $100 \mathrm{pb}$. A la izquierda de la imagen se indica el tamaño $(\mathrm{pb})$.

\subsubsection{2.b. Caracterización de cepas de S. cerevisiae mediante RFLP-ADNmt}

Una vez comprobado que todos los clones aislados pertenecían a la especie S. cerevisiae, para diferenciar entre las diferentes cepas aisladas en las diferentes cosechas recurrimos a la técnica de RFLP del ADNmt cuyo fundamento (apartado 1.7.3.1) y metodología (apartado 3.9.4) ya se han descrito. Ya que el fin último era aislar levaduras autóctonas, se tuvieron en cuenta las levaduras comerciales empleadas en bodega (tabla 3.1) con el fin de descartar que las cepas aisladas pudieran ser en realidad LSAs. Seguidamente detallaremos el estudio individualizado por cosecha, para posteriormente realizar una comparación entre las diferentes cosechas.

La comparación de un número elevado de clones requirió el empleo de una herramienta informática adecuada para la comparación de clones analizados en geles diferentes. Los análisis se normalizaron mediante el empleo del programa Infoquest FP (Bio-Rad) que permite comparara los distintos polimorfismos de bandas obtenidos. Se obtienen unos dendogramas (tipo UPGMA) basados en un coeficiente de similitud mediante la aplicación del algoritmo DICE.

\section{Cosecha 2.005}

Se analizaron un total de 58 colonias seleccionadas al azar de las aisladas en placa a partir de las microvinificaciones. Los clones en función del polimorfismo detectado se distribuyeron en seis tipos o cepas diferentes de $\mathrm{S}$. cerevisiae con diferentente representatividad. Al comparar estos perfiles de RFLP-ADNmt con los correspondientes a las 
levaduras comerciales empleadas por la bodega se comprobó que uno de los tipos, G5-V, era en realidad una de las levaduras comerciales empleadas en bodega, concretamente la cepa IOC 18-2007 (figura 4.4). Su bajo porcentaje respecto al total indica una implantación pobre sobre la microbiota de la bodega.

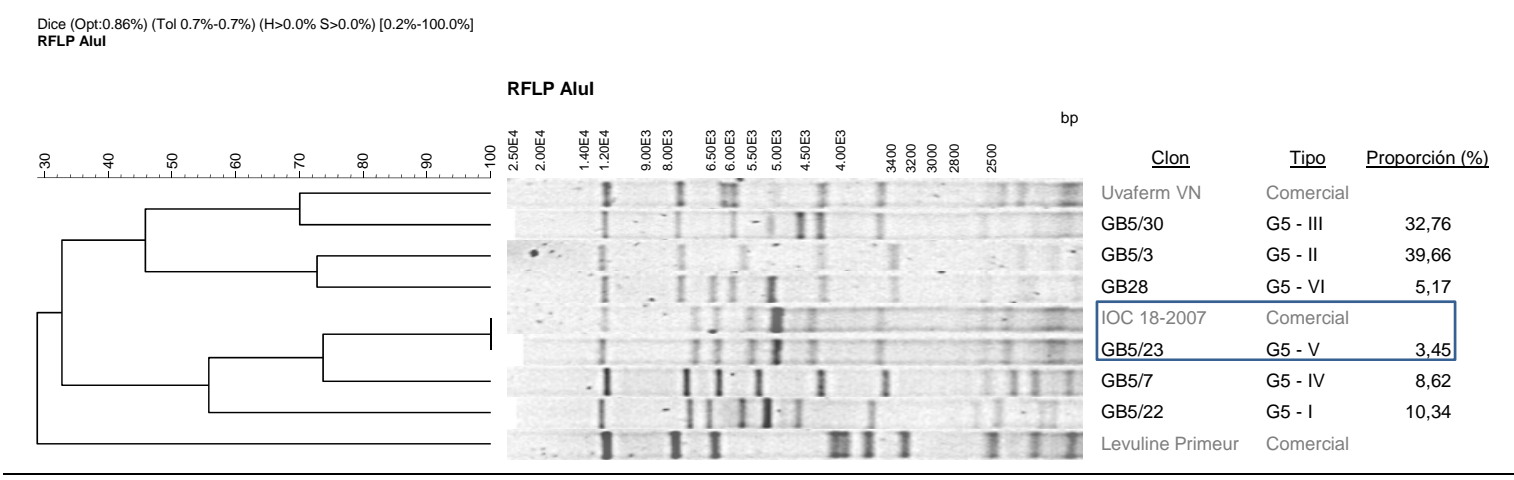

Figura 4.4: Resultado de la caracterización de cepas de la bodega Gordonzello S.A. en la cosecha de 2.005 mediante RFLP-ADNmt obtenido con la endonucleasa Alul (centro). En función de la distribución del bandeo obtenido se obtiene (izquierda) un dendograma que informa de la similitud entre las diferentes cepas. A la derecha se indica el clon, el tipo donde queda englobado y el porcentaje de los diferentes tipos. Una de las cepas aisladas y caracterizadas (recuadro) resultó ser una LSA empleada por la bodega.

\section{Cosecha 2.006}

Durante esta cosecha se analizaron un total de 59 colonias de levadura. El estudio permitió distribuir los clones analizados en un total de siete grupos (tipos) diferentes. La particularidad encontrada en esta cosecha radica en que todas las cepas con morfología verde resultaron ser la misma cepa y por tanto dan lugar al "tipo" con mayor representación en la población analizada, G6-V. Este tipo, además, presentaba una mutación puntual en la región 5.8S-ITS indicada en el apartado anterior (figura 4.4) que determinaba que el polimorfismo de la región 5.8S-ITs para el enzima Haelll no fuera el esperado para una cepa típica de S. cerevisisae. En esta cosecha ninguna de las levaduras aisladas fue alguna de las LSAs empleadas en bodega (figura 4.5).

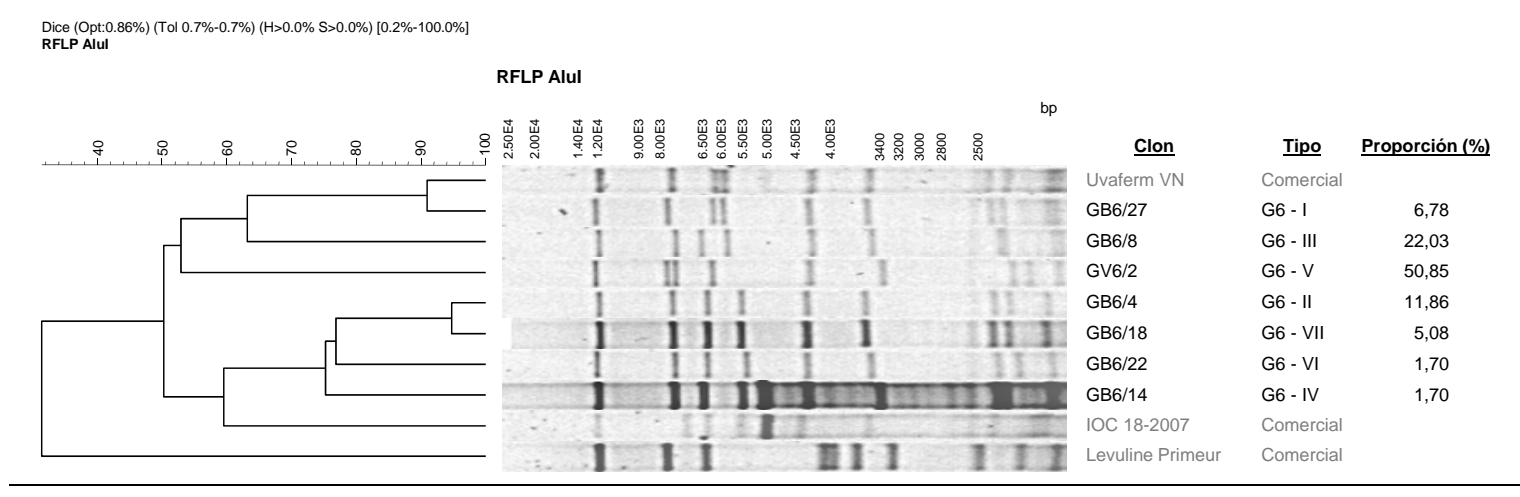

Figura 4.5: Resultado de la caracterización de cepas de la bodega Gordonzello S.A. en la cosecha de 2.006. Se observan los perfiles de RFLP-ADNmt obtenidos con la endonucleasa Alul (centro). En función del bandeo obtenido se obtiene (izquierda) un dendograma que informa de la similitud entre las diferentes cepas. A la derecha se indica el clon, el tipo donde queda englobado y la representación de los diferentes tipos.

\section{Cosecha 2.007}

En la tercera cosecha analizada de esta bodega las 60 colonias estudiadas se distribuyeron en 14 tipos diferentes. Al igual que en la cosecha 2.005 uno de los tipos aislados, G7-VII, resultó ser una LSA empleada en bodega, aunque con poca representación debido a su bajo porcentaje en la población analizada (figura 4.6). 

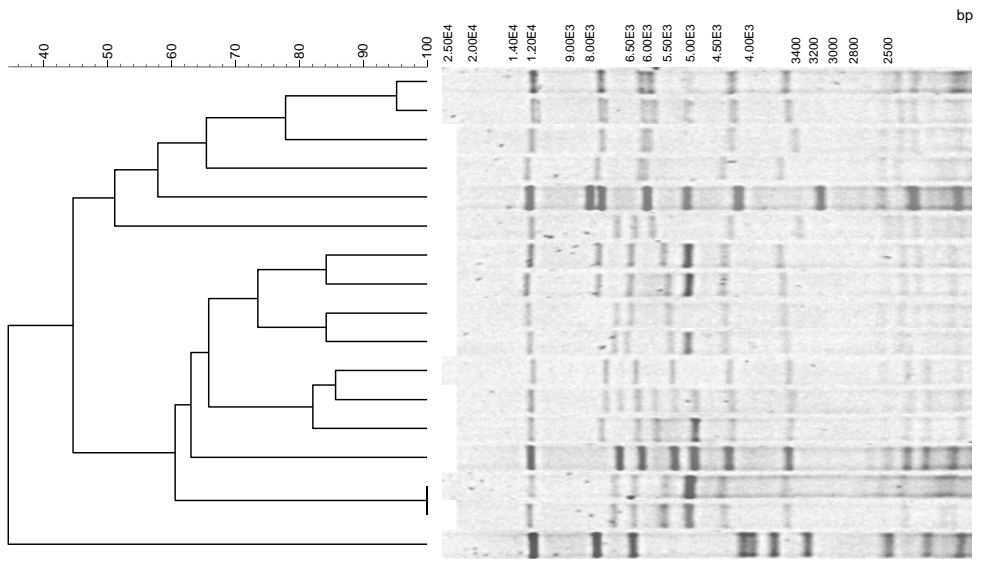

\begin{tabular}{lll}
\multicolumn{1}{c}{ Clon } & \multicolumn{1}{c}{ Tipo } & Proporción (\%) \\
Uvaferm VN & Comercial & \\
GB7/1 & G7 - I & 38,32 \\
GV7/9 & G7 - VIII & 10,00 \\
GV7/15 & G7 - XIII & 1,67 \\
GV7/19 & G7 - X & 1,67 \\
GV7/7 & G7 - VI & 3,33 \\
GV7/22 & G7 - XIV & 13,33 \\
GV7/29 & G7 - XV & 1,67 \\
GV7/13 & G7 - IX & 5,00 \\
GV7/26 & G7 - XII & 1,67 \\
GB7/12 & G7 - III & 6,67 \\
GB7/9 & G7 - IV & 1,67 \\
GV7/2 & G7 - II & 10,00 \\
GB7/10 & G7 - V & 3,33 \\
\hline IOC 18-2007 & Comercial \\
GB7/25 & G7 - VII & \\
Levuline Primeur & Comercial &
\end{tabular}

Figura 4.6: Resultado de la caracterización de cepas de la bodega Gordonzello S.A. en la cosecha de 2.007. Se observan los perfiles de RFLP-ADNmt obtenidos con la endonucleasa Alul (centro). En función del patrón de bandas obtenido se genera (izquierda) un dendograma que informa de la similitud entre las diferentes cepas. Se indica el clon, el tipo donde queda englobado y la representación de los diferentes tipos (derecha). Con un recuadro se indica la cepa que resultó ser una de las levaduras comerciales empleadas en bodega.

\section{Comparación entre cosechas}

Una vez analizada por separado cada una de las cosechas, parece lógico realizar una comparación conjunta a fin de detectar cepas que pudieran aparecer en diferentes cosechas. El resultado del estudio global en la bodega Gordonzello S. A. se muestra en la figura 4.7.

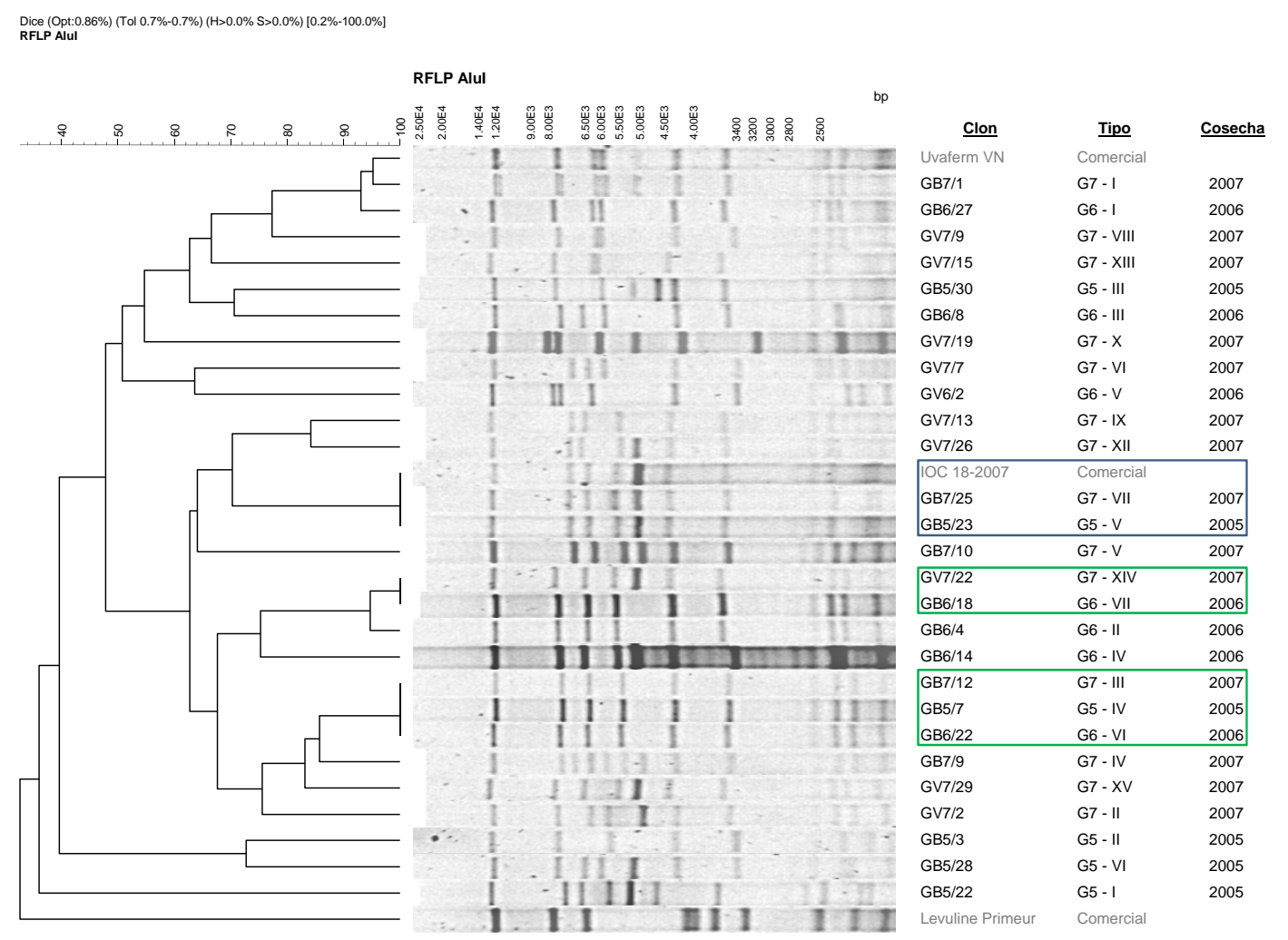

Figura 4.7: Caracterización de cepas de la bodega Gordonzello S.A. durante tres cosechas consecutivas (2.005, 2.006 y 2.007). Se muestran los perfiles de RFLP-ADNmt obtenidos con la endonucleasa Alul (centro), así como el dendograma obtenido a partir de éste (izquierda). Se indica el clon representado en el gel, el tipo que lo engloba y la cosecha donde fueron aislados (derecha). En un recuadro azul aparecen resaltadas las levaduras que en realidad eran LSAs. En color verde se indican aquellas levaduras que han aparecido en, al menos, dos de las cosechas estudiadas. 
A la vista de este análisis, se pueden extraer varias conclusiones parciales:

- De todas las levaduras analizadas en las tres cosechas estudiadas, únicamente dos resultaron ser levaduras comerciales, cepas G5-V y G7-VII, y aparecían en bajo porcentaje en la población analizada $(3,45 \%$ y $1,67 \%$. Este dato indica que la implantación de estas levaduras comerciales sobre la microbiota autóctona de la bodega es muy pobre.

- Algunas cepas aparecen en al menos dos cosechas, resultando de gran interés el tipo G7-III que se detectó en las tres cosechas estudiadas (ver figura 4.8 derecha), mientras que el tipo G7-I apareció en dos de las cosechas (figura 4.8 izquierda). Cuando existen cepas coexistentes en más de una cosecha, esta cepa se denominará igual que la cepa que haya sido aislada más recientemente.

- Se han analizado 177 colonias de levadura en los tres años en los que se ha llevado a cabo el estudio. Si se tienen en cuenta las coincidencias con LSAs y la coexistencia de algunas cepas en diferentes cosechas, se puede concluir que para esta bodega se han aislado un total de $\mathbf{2 2}$ cepas de $\mathbf{S}$. cerevisiae.

A

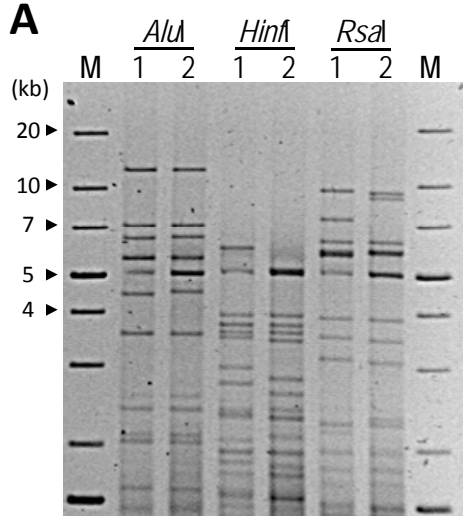

B

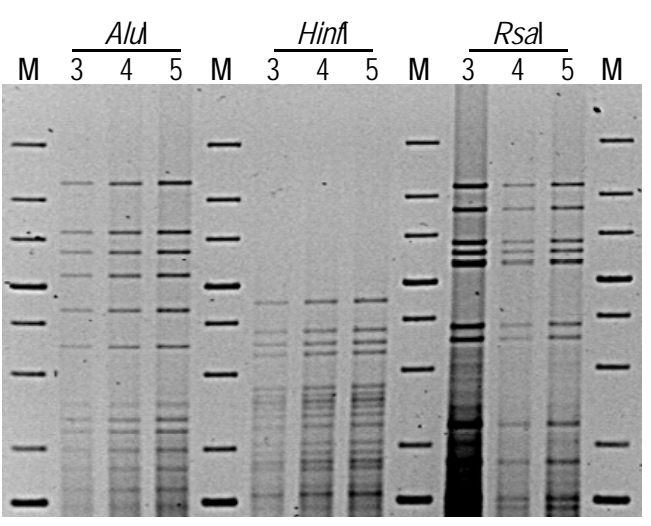

Figura 4.8: Análisis de RFLP-ADNmt de las cepas coexistentes en varias cosechas. Se observan los patrones coincidentes para una misma cepa (mismo número) empleando tres endonucleasas diferentes (indicadas sobre los carriles). Carriles: 1, cepa G6 - VII; 2, G7 - XIV; 3, G7 - III; 4, G6 - VI; 5 , G5 - I. M es el marcador de peso molecular escalera de $1 \mathrm{~kb}$ (Generuler $\left.{ }^{\mathrm{TM}}\right)$. A la izquierda de las imágenes se indica el tamaño de los fragmentos $(\mathrm{kb})$.

\subsubsection{Cooperativa de los Oteros}

\subsubsection{Aislamiento de levaduras vínicas}

El proceso analítico empleado en esta bodega es idéntico al indicado para la bodega anterior. El estudio se desarrolló durante tres cosechas diferentes. Los datos básicos relativos a las microvinificaciones espontáneas se recogen en la tabla 4.3. Resulta llamativo el resultado obtenido en la cosecha de 2.007, ya que aunque el periodo de fermentación se prolongó más de lo habitual, la densidad no bajó de $1,033 \mathrm{~g} / \mathrm{mL}$. Todo parece indicar que se produjo una parada de fermentación que pudo ser debida a diversos factores (indicados en apartados anteriores). También los valores finales de levaduras en el vino final $\left(6,7 \quad 10^{5}\right.$ u.f.c./ $\mathrm{mL}$ vino) son sensiblemente inferiores, si los comparamos con las otras cosechas estudiadas. Esto puede ser debido a la muerte de las levaduras tras el largo periodo de fermentación. 


\subsubsection{Caracterización genética de las levaduras vínicas}

De entre las levaduras aisladas en placa, se seleccionan un número determinado de clones (tabla 4.4) para proceder a su caracterización genética, tanto a nivel de especie como a nivel de individuo (cepa).

Tabla 4.3: Datos básicos de las microvinificaciones espontáneas realizadas a partir de mosto suministrado por la bodega Cooperativa de los Oteros.

\begin{tabular}{cccccc}
\hline & & & & \multicolumn{2}{c}{ Coloración (\%) } \\
\cline { 5 - 6 } Cosecha & Periodo microvin. (días) & Densidad $(\mathrm{g} / \mathrm{mL})$ & Recuento (u.f.c./mL vino) & Blancas & Verdes \\
\hline 2.005 & 12 & 0,953 & $1,54 \cdot 10^{6}$ & 88,6 & 11,4 \\
2.006 & n.d. & 0,9928 & $9,0 \cdot 10^{6}$ & 95,9 & 4,1 \\
2.007 & 30 & 1,033 & $6,7 \cdot 10^{5}$ & 25,4 & 74,6 \\
\hline
\end{tabular}

Tabla 4.4: Colonias seleccionadas para la caracterización genética en la bodega Cooperativa de los Oteros. Se indica, para cada cosecha, el número total de colonias analizadas junto con la coloración que presentaban.

\begin{tabular}{cccc}
\hline Cosecha & Número total de colonias & Blancas & Verdes \\
\hline 2.005 & 50 & 32 & 18 \\
2.006 & 57 & 43 & 14 \\
2.007 & 60 & 30 & 30 \\
\hline
\end{tabular}

\subsubsection{1.a. Identificación a nivel de especie mediante RFLP-5.8S-ITS}

Tal como se ha indicado en el apartado 3.9.2, se procedió a la amplificación de la región 5.8S-ITS de cada uno de los clones seleccionados y se realizó sobre ellos el tratamiento con las endonucleasas de restricción correspondientes. El patrón de bandas obtenido corresponde inequívocamente con la especie S. cerevisiae (figura 4.1, derecha). Sin embargo, uno de los clones aislados en la cosecha de 2.005, PB5/ 7 (ó PB7) presentaba un patrón anómalo para la enzima de restricción Haelll (figura 4.9). Este patrón no había sido descrito con anterioridad para ninguna especie del género Saccharomyces. Era necesario, por tanto, un estudio en profundidad sobre esta cepa. Así, Peris et al. (enviado), tras el estudio de restricción de 36 genes nucleares y la secuenciación del gen nuclear MET6 y del mitocondrial COX2, obtuvieron que realmente se trataba de un hibrido interespecífico. Concretamente un híbrido $\mathrm{S}$. cerevisiae x S. kudriavzevii. La secuenciación del gen COX2 indica que presenta un nuevo tipo de secuencia mitocondrial no descrita hasta el momento, aunque cercana al grupo de levaduras cerveceras y a un triple híbrido ( $\mathrm{S}$. cerevisiae $\times$ S. kudriavzevii $\mathrm{x}$ S. bayanus var. uvarum) procendente de la elaboración de sidra (Peris et al., enviado).

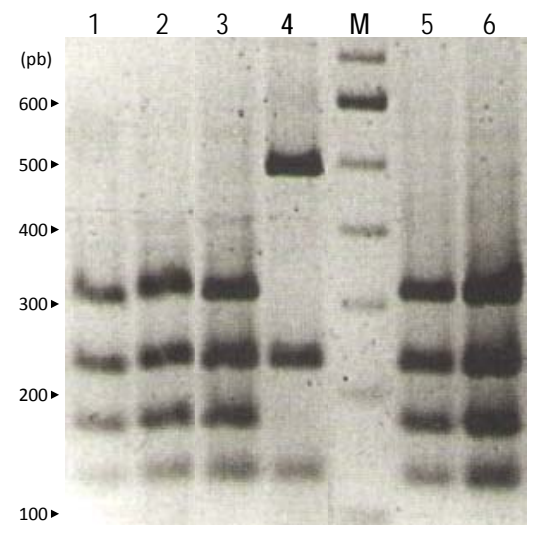

Figura 4.9: Análisis RFLP-5.8S-ITS de varias cepas aisladas en la cosecha de 2.005 para la bodega Cooperativa de los Oteros. Se observa, en los carriles 1, 2, 3, 5 y 6 , el perfil característico de la especie S. cerevisiae al tratar con la endonucleasa Haelll el amplificado de la región 5.8S-ITS (320, 230, 175 y 125 pb). En el carril 4 se observa el patrón obtenido para la levadura híbrida PB7: 500, 225 y 125 pb. Carriles: 1, cepa PB5/3; 2, PB5/4; 3, PB5/6; 4, PB5/7 (PB7); 5, PB5/9; 6, PB5/10. $\mathrm{M}$ es el marcador de peso molecular, escalera de $100 \mathrm{pb}$ (Invitrogen ${ }^{\mathrm{TM}}$ ). A la izquierda de la imagen se indica el tamaño de los fragmentos de ADN (pb).

4.1.2.1.b. Caracterización de cepas de S. cerevisiae mediante RFLP-ADNmt 
Para cada clon aislado se realizó un análisis de RFLP de ADNmt a fin de realizar un caracterización a nivel de cepa, incluyéndose en el estudio las cepas comerciales (LSAs) empleadas por la bodega.

\section{Cosecha 2.005}

El estudio de las 50 cepas seleccionadas mediante RFLP-ADNmt dio como resultado la distribución en 11 tipos o cepas diferentes, entre las que se encuentra el híbrido PB7 descrito en el apartado anterior (figura 4.10). Entre las levaduras aisladas no se encontró la levadura comercial empleada en la bodega, indicando una nula implantación respecto a la población autóctona. En este caso el fenotipo (coloración) no nos permite distinguir entre las diferentes cepas, ya que en la mayoría de los tipos detectados existen colonias con diferente coloración. Resulta Ilamativo el alto porcentaje de la cepa P5-I, ya que representa casi la mitad (48,0\%) de las cepas aisladas. Este dato podría indicar que se trata de una cepa bien adaptada a esta bodega e incluso a las características del mosto obtenido a partir de uva Prieto Picudo.

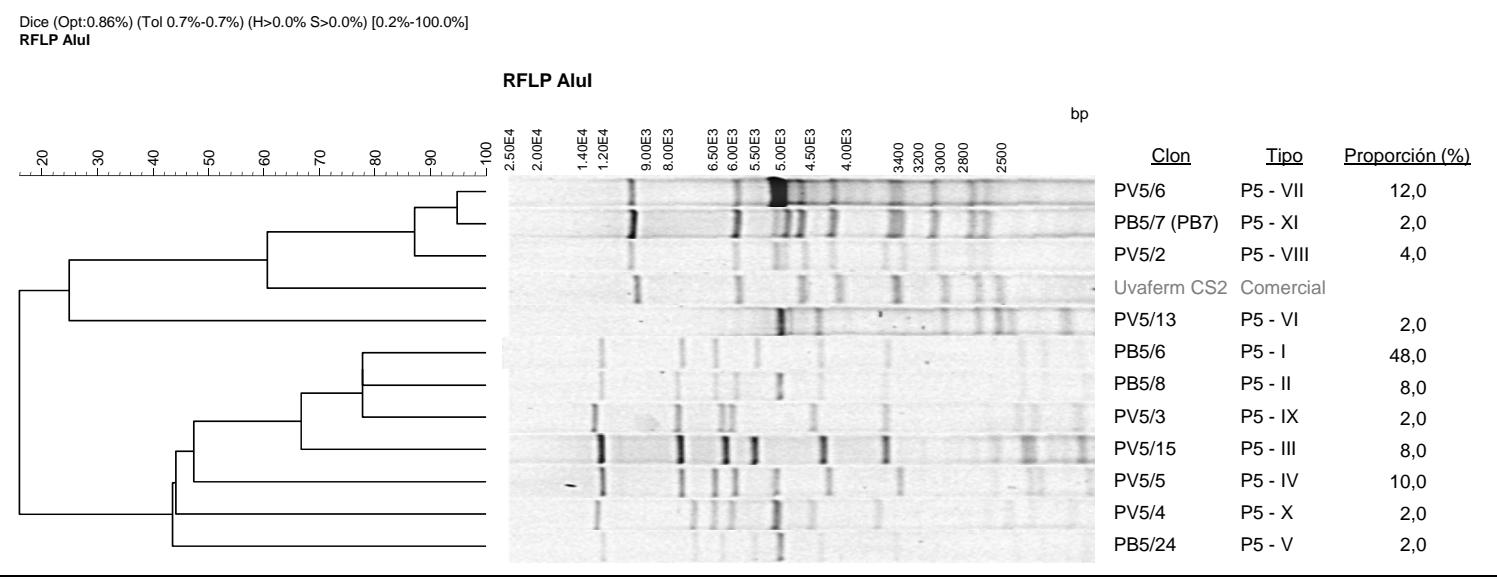

Figura 4.10: Caracterización de cepas de la bodega Cooperativa de los Oteros (cosecha 2.005). Se observan los perfiles de RFLP-ADNmt obtenidos con la endonucleasa Alul (centro). En función del bandeo obtenido se obtiene (izquierda) un dendograma que informa de la similitud entre las diferentes cepas. El clon, el tipo o cepa donde queda englobado y la proporción de los diferentes tipos en la población total se indican a la derecha.

\section{Cosecha 2.006}

En esta cosecha el análisis de las colonias aisladas, junto con la levadura comercial empleada en bodega, dio como resultado la detección de 15 cepas diferentes de S. cerevisiae (figura 4.11), no coincidiendo ninguna de ellas con la LSA empleada. El elevado número de tipos detectados ha resultado en que ninguno de ellos sea claramente predominante. El fenotipo de la colonia en placa no guarda relación con el tipo de cepa, siendo común encontrar dentro de un mismo tipo colonias de diferente color.

\section{Cosecha 2.007}

Las colonias aisladas y caracterizadas se distribuyeron en 12 tipos diferentes, no resultando ser ninguna la levadura comercial empleada en bodega (figura 4.12). Aunque el número de tipos es elevado, uno de ellos (P7-XII) representa más de la mitad de las colonias aisladas. Además, en este tipo se incluían todas las colonias con fenotipo verde junto con dos colonias con fenotipo blanco. 


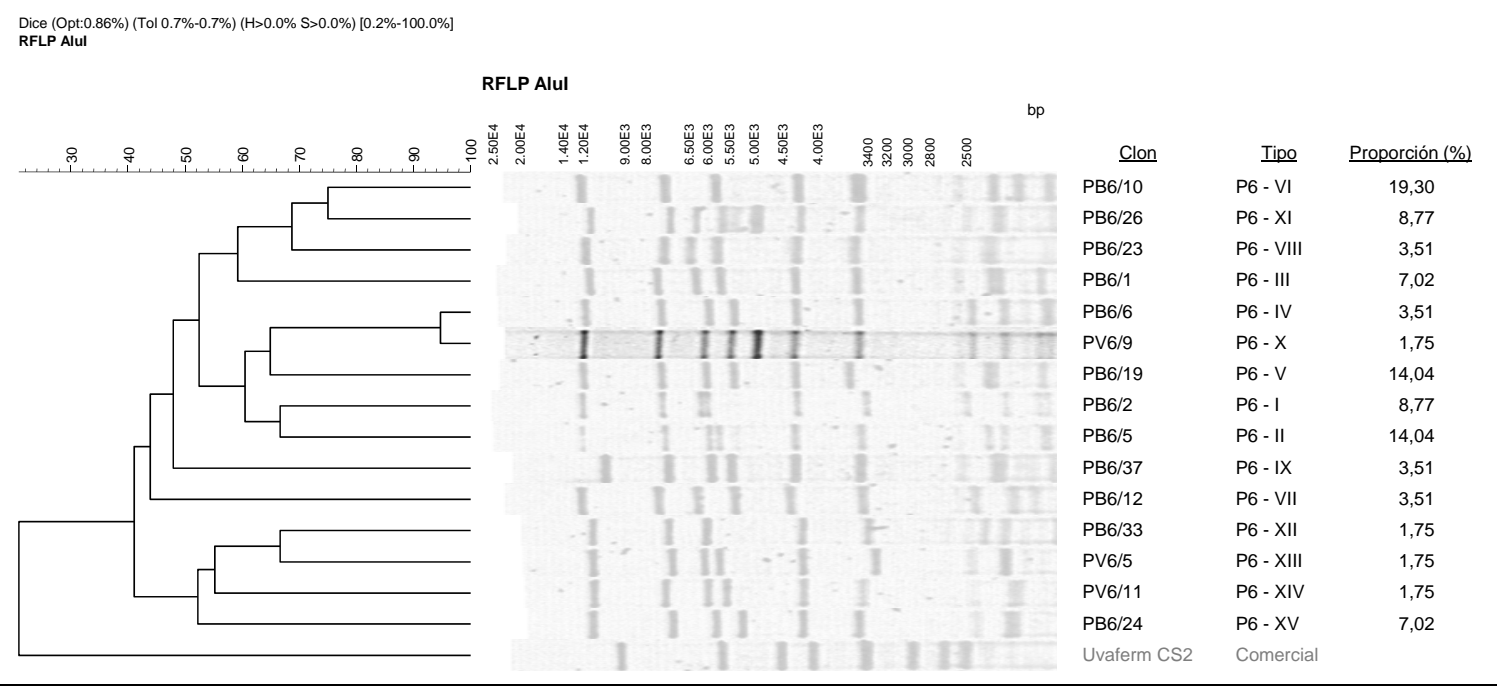

Figura 4.11: Resultado de la caracterización de cepas de la bodega Cooperativa de los Oteros en la cosecha de 2.006. Se muestran los perfiles de RFLP-ADNmt obtenidos con la endonucleasa Alul (centro) y un dendograma (izquierda) que informa de la similitud entre las diferentes cepas. A la derecha se indica el clon, el tipo donde queda englobado y la proporción de los diferentes tipos.

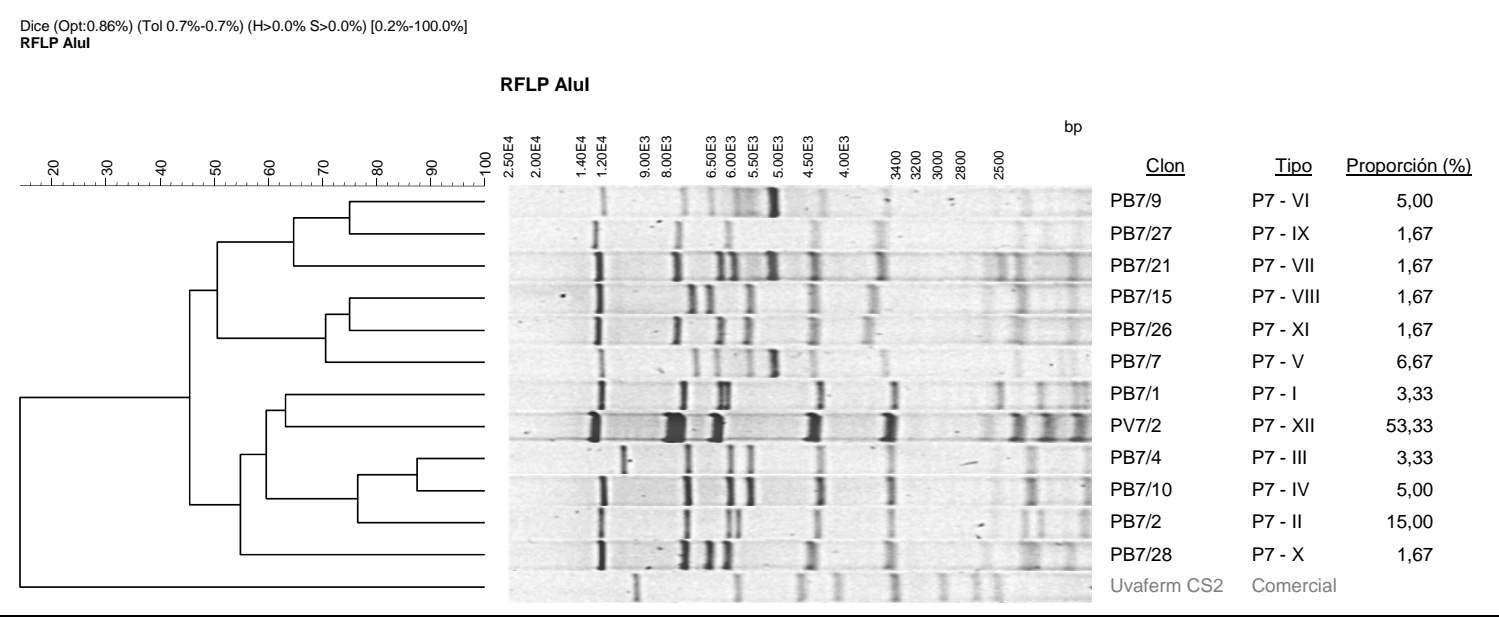

Figura 4.12: Caracterización de cepas de la bodega Cooperativa de los Oteros (cosecha 2.007). Se observan los perfiles de RFLP-ADNmt obtenidos con la endonucleasa Alul (centro). En función del bandeo obtenido se obtiene (izquierda) un dendograma que informa de la similitud entre las diferentes cepas. Se indica el clon, el tipo donde queda englobado y la proporción de los diferentes tipos (derecha).

\section{Comparación entre cosechas}

Una vez analizada cada cosecha de modo individual se realizó un estudio comparativo. De este modo podríamos detectar si existen cepas que aparezcan en más de una cosecha. Esto podría indicar que esta cepa es autóctona de la bodega e incluso de la variedad de uva. Los resultados se muestran en la figura 4.13.

En vista de los resultados obtenidos se pueden extraer varias conclusiones parciales:

- Ninguna de las cepas aisladas resultó ser la levadura comercial empleada en esta bodega. Por tanto, la implantación de la LSA sobre la población autóctona no llega a producirse.

- Un total de cinco cepas se aislaron en dos cosechas diferentes (figura 4.13, en verde), tanto en cosechas consecutivas como separadas dos años (figura 4.14). Esto puede ser una demostración de la mayor adaptación de estas cepas a las características particulares de esta variedad de uva. De entre las cepas 
coexistentes en dos cosechas, únicamente la cepa P6-VI resultó ser la cepa mayoritaria en su año $(19,30 \%$ cosecha 2.006). El resto aparecieron en porcentajes discretos en relación a la población total.

- Para las 167 colonias analizadas, se obtuvieron inicialmente un total de 38 tipos diferentes. Sin embargo como varias cepas aparecieron en dos cosechas diferentes el número final de cepas o tipos de $\mathbf{S}$. cerevisiae se redujo a 33.

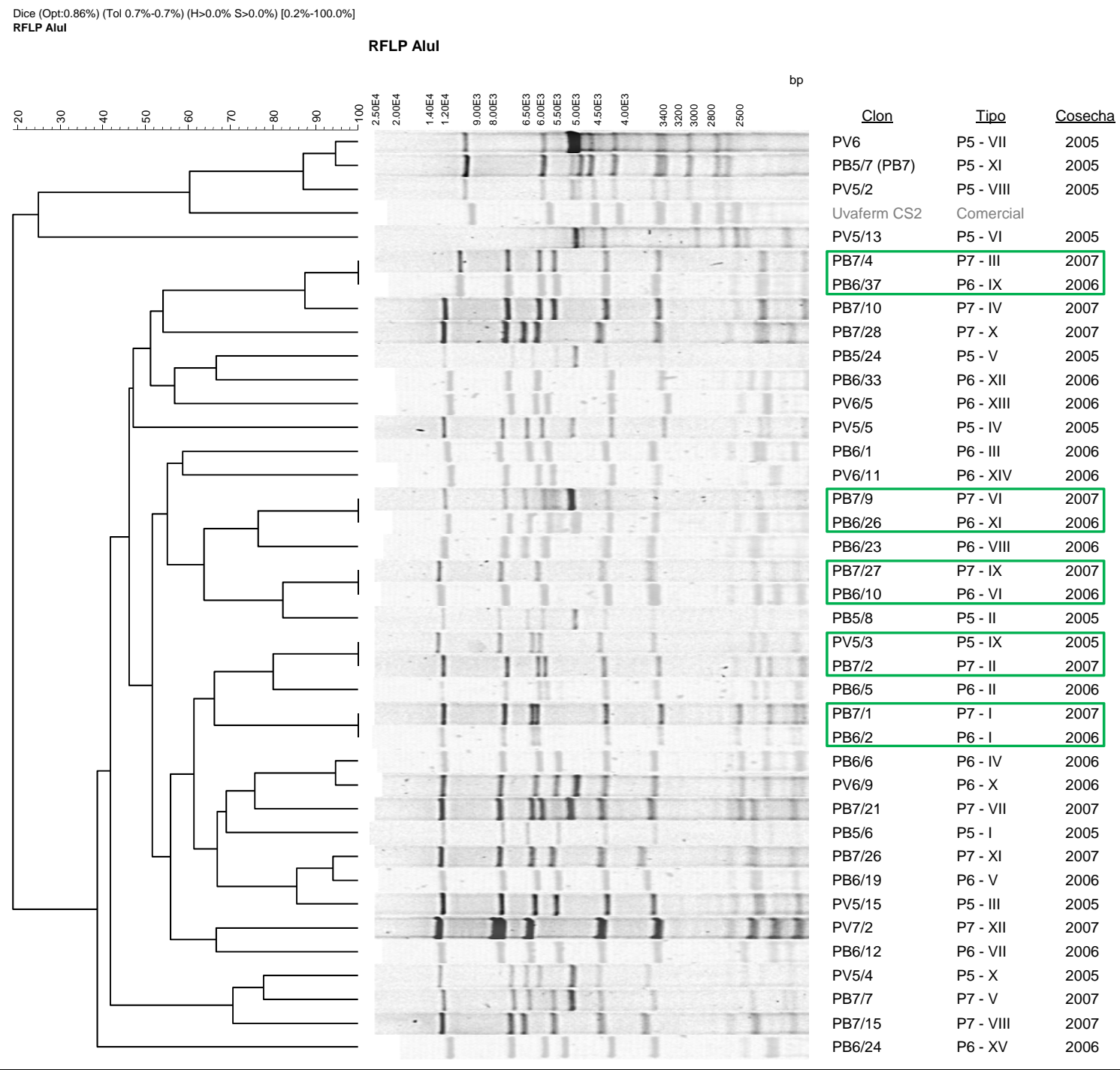

Figura 4.13: Estudio comparativo de cepas aisladas de la bodega Cooperativa de los Oteros en las cosechas 2.005, 2.006 y 2.007. Se muestran los perfiles de RFLP-ADNmt obtenidos con la endonucleasa Alul (centro), así como el dendograma obtenido a partir de éste (izquierda). Se indica, a la derecha, el clon representado en el gel, el tipo que lo engloba y la cosecha donde fueron aislados. En color verde se indican aquellas levaduras que han aparecido en dos de las cosechas indicadas. Cinco levaduras se han aislado en al menos dos cosechas diferentes. 
A

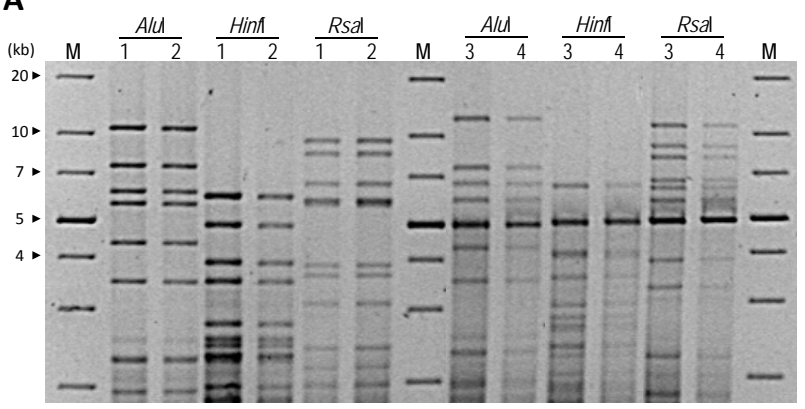

B

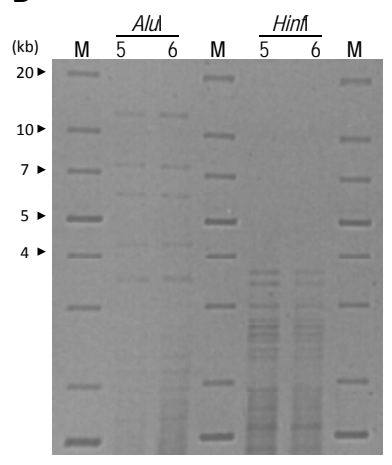

C

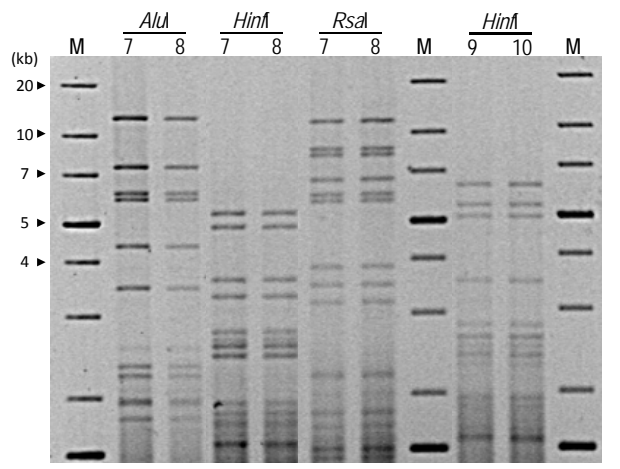

Figura 4.14: Análisis de RFLP-ADNmt de las cepas coexistentes en dos cosechas diferentes en la bodega Cooperativa de los Oteros. Se muestran los patrones de restricción con diferentes endonucleasas, aparte de la ya mencionada Alul. El empleo de otras enzimas de restricción permite asegurar que nos encontramos ante la misma cepa. Carriles: 1, cepa P6 IX; 2, P7 - III; 3, P6 - XI; 4, P7 - III; 5, P6 - VI; 6, P7 - IX; 7, P5 - IX; 8, P7 - II; 9, P6 - XI; 10, P7 - VI. M es el marcador de peso molecular escalera de $1 \mathrm{~kb}\left(\right.$ Generuler $\left.^{\mathrm{TM}}\right)$. A la izquiera de las imágenes se indica el tamaño (kb).

\section{1.3. Bodegas Pedro Casis}

\subsubsection{Aislamiento de levaduras vínicas}

A partir del vino obtenido tras la fermentación espontánea, se llevó a cabo un aislamiento de levaduras vínicas en medio sólido. En la tabla 4.5 se indican las características básicas de cada una de las microvinificaciones en las cosechas indicadas. En la cosecha de 2.007 no fue posible realizar el aislamiento de microbiota autóctona debido a una contaminación en la muestra de mosto natural por una de las levaduras comerciales empleadas por la bodega.

Tabla 4.5: Características básicas de las microvinificaciones espontáneas realizadas con mosto suministrado por la bodega Pedro Casis. Se indica, para cada cosecha, el tiempo necesario para llevar a cabo la fermentación, la densidad final del vino obtenido, el número de levaduras por unidad de volumen y la coloración (en porcentaje) de las colonias aisladas.

\begin{tabular}{cccccc}
\hline & & & & \multicolumn{2}{c}{ Coloración (\%) } \\
\cline { 5 - 6 } Cosecha & Periodo microvin. (días) & Densidad $(\mathrm{g} / \mathrm{mL})$ & Recuento (u.f.c./mL vino) & Blancas & Verdes \\
\hline 2.006 & 13 & 0,9945 & $4,77 \cdot 10^{6}$ & 98,6 & 1,4 \\
2.008 & 15 & 0,9984 & $1,17 \cdot 10^{6}$ & 98,0 & 2,0 \\
2.009 & n.d. & n.d. & $3,17 \cdot 10^{6}$ & 90,6 & 9,4 \\
\hline
\end{tabular}

\subsubsection{Caracterización genética de las levaduras vínicas}

De la gran cantidad de colonias aislada en medio sólido se seleccionaron al azar un número determinado de colonias para proceder a su caracterización genética tanto a nivel de especie como de cepa (tabla 4.6). 
Tabla 4.6: Colonias seleccionadas para su caracterización genética en la bodega Pedro Casis.

\begin{tabular}{cccc}
\hline Cosecha & Número total de colonias & Blancas & Verdes \\
\hline 2.006 & 57 & 46 & 11 \\
2.008 & 60 & 55 & 5 \\
2.009 & 60 & 35 & 25 \\
\hline
\end{tabular}

\subsubsection{2.a. Identificación a nivel de especie mediante RFLP-5.8S-ITS}

Siguiendo el protocolo descrito en el apartado 3.9.2 se obtuvo la misma conclusión para todas y cada una de las cepas estudiadas: el patrón obtenido era el correspondiente a $\mathrm{S}$. cerevisiae (figura 4.1, derecha).

\subsubsection{2.b. Caracterización de cepas de S. cerevisiae mediante RFLP-ADNmt}

Como en casos anteriores todas las cepas aisladas fueron comparadas con las LSAs (tabla 3.1) empleadas por la bodega.

\section{Cosecha 2.006}

Se identificaron un total de 9 tipos o cepas diferentes (figura 4.15). Cabe destacar el tipo C6-II que representaba el 70,18 \% de la población aislada. El fenotipo exhibido por la colonia en placa no guarda relación con la pertenencia a los diferentes tipos; el tipo mayoritario (C6II) incluía tanto colonias con coloración blanca como verde. Ninguna de las levaduras aisladas resultó ser una cepa comercial.

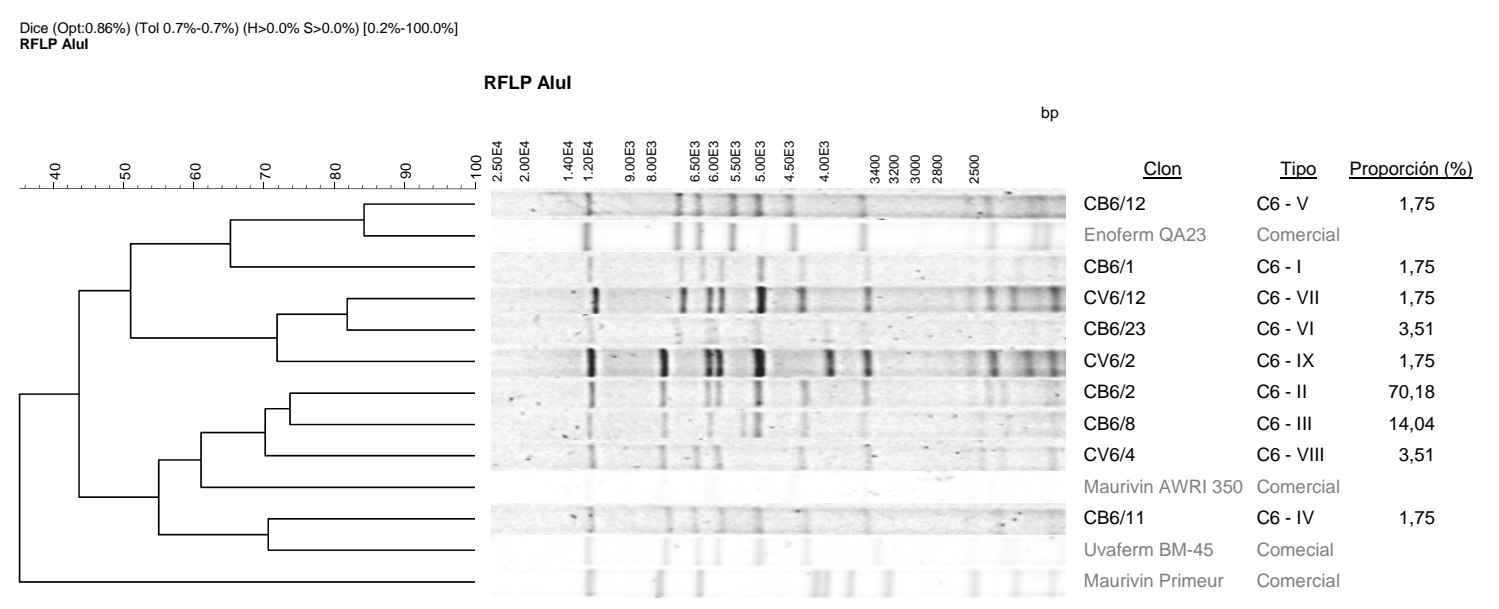

Figura 4.15: Caracterización de cepas de la bodega Pedro Casis (cosecha de 2.006). Se muestran los perfiles de RFLP-ADNmt obtenidos con la endonucleasa Alul (centro) y el dendograma que informa de la similitud entre las diferentes cepas (izquierda). Se indica el clon, el tipo donde queda englobado y la representación de los diferentes tipos (derecha).

\section{Cosecha 2.008}

En esta cosecha las levaduras analizadas se distribuyeron en 10 tipos diferentes (figura 4.16), aunque uno de ellos (C8-II) se correspondía con una de las LSAs empleadas por la bodega. El porcentaje de este tipo respecto al total no es muy elevado $(11,7 \%)$ indicando que aunque ha existido implantación por parte de la cepa comercial, no ha conseguido desplazar a la población autóctona. El tipo C8-I resultó ser el mayoritario ya que reprentaba el 56,7 \% de la población total. El fenotipo en placa no permite distribuir las colonias en tipos, ya que la mayoría de los tipos o cepas detectados contenían colonias blancas y verdes. 


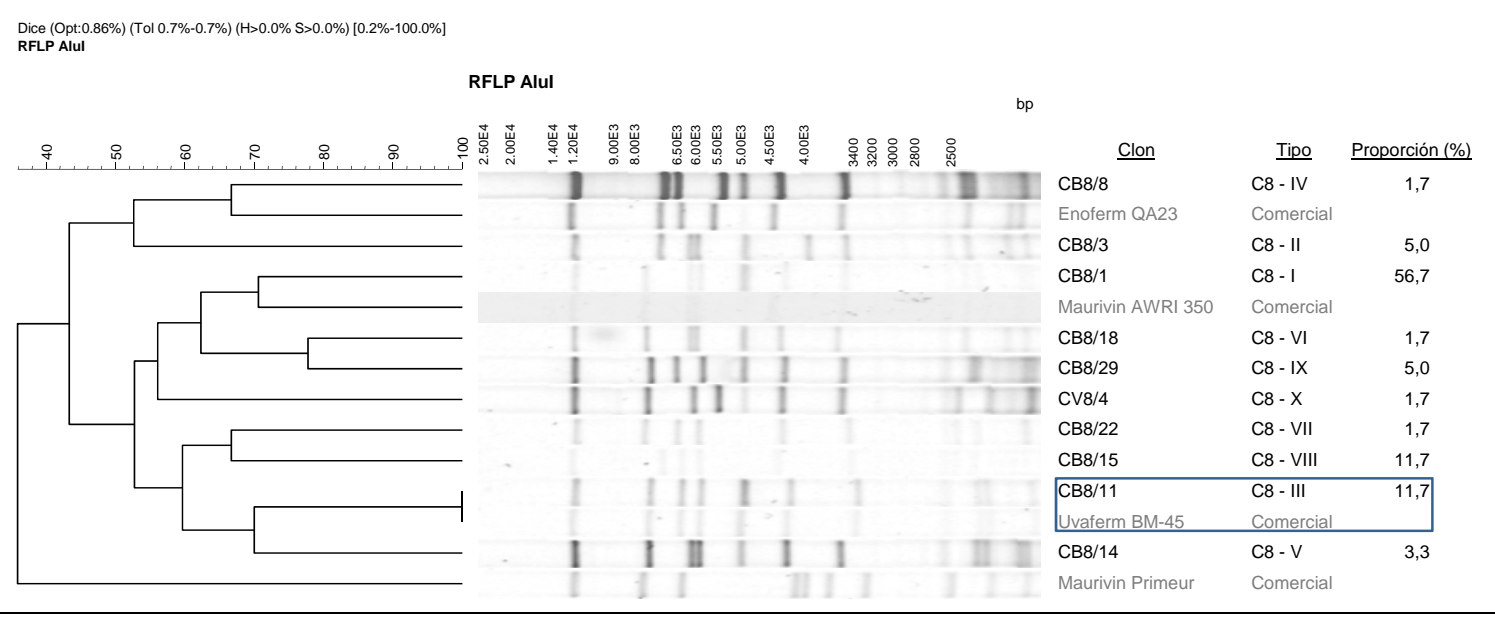

Figura 4.16: Caracterización de cepas de la bodega Pedro Casis (cosecha 2.008). Se muestran los perfiles de RFLPADNmt obtenidos con la endonucleasa Alul (centro). En función del bandeo obtenido se obtiene (izquierda) un dendograma que informa de la similitud entre las diferentes cepas. A la derecha se indica el clon, el tipo donde queda englobado y la representación de los diferentes tipos. El recuadro azul resalta la cepa que resultó ser una LSA empleada en bodega.

\section{Cosecha 2.009}

Las levaduras analizadas se distribuyeron inicialmente en 10 tipos (figura 4.17), aunque una de ellas (C9-VIII) resultó ser la LSA detectada en la cosecha de 2.008. Al igual que ocurría en la cosecha anterior la implantación de la cepa comercial no fue importante si atendemos a su porcentaje realtivo (8,33\%). De nuevo se detectó un tipo (C9-I) con un porcentaje $(60,00$ $\%$ muy superior al resto. Como en casos anteriores el fenotipo no nos permitió diferenciar a nivel de individuo, ya que cada tipo incluía colonias blancas y verdes.

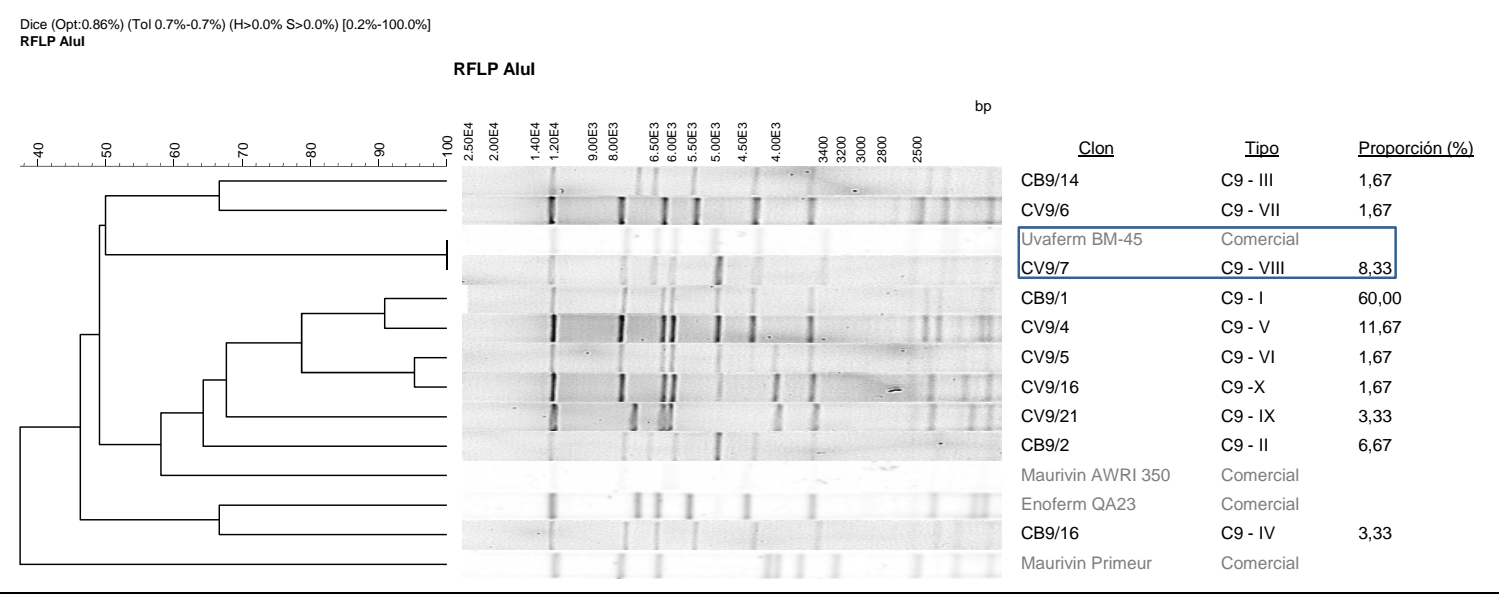

Figura 4.17: Caracterización de cepas de la bodega Pedro Casis (cosecha 2.009). Se muestran los perfiles de RFLPADNmt obtenidos con la endonucleasa Alul (centro) y el dendograma correspondiente (izquierda) que informa de la similitud entre las diferentes cepas. A la derecha se indica el clon, el tipo donde queda englobado y la representación de los diferentes tipos. El recuadro azul señala la levadura que resultó ser una LSA empleada en bodega.

\section{Comparación entre cosechas}

Los resultados de comparar las tres cosechas se muestran en la figura 4.18. Las conclusiones parciales que podemos extraer son:

- Una de las levaduras comerciales empleadas (Uvaferm BM-45) se detectó en dos de las cosechas estudiadas. Sin embargo, los porcentajes relativos con los que apareció (11,7 \% en la cosecha de 2.008 y $8,33 \%$ en la cosecha de 2.009$)$ indican una pobre implantación en bodega. 
- Varias levaduras se aislaron en dos, e incluso en las tres cosechas estudiadas (figura 4.19). Algo que resulta aún más llamativo es que la cepa predominante en cada cosecha resultó ser la misma (C9-I). Sin duda las levaduras que aparecen en más de una cosecha podrían indican la mejor adaptación a las características propias de la variedad.

- Las 177 colonias estudiadas se distribuyeron inicialmente en 29 tipos diferentes. El análisis conjunto permitió, debido a la coincidencia de alguna cepa con levaduras comerciales, junto con la aparición de cepas en diferentes cosechas, reducir el número hasta un total de $\mathbf{1 8}$ tipos $\mathbf{0}$ cepas diferentes de $\mathbf{S}$. cerevisiae.

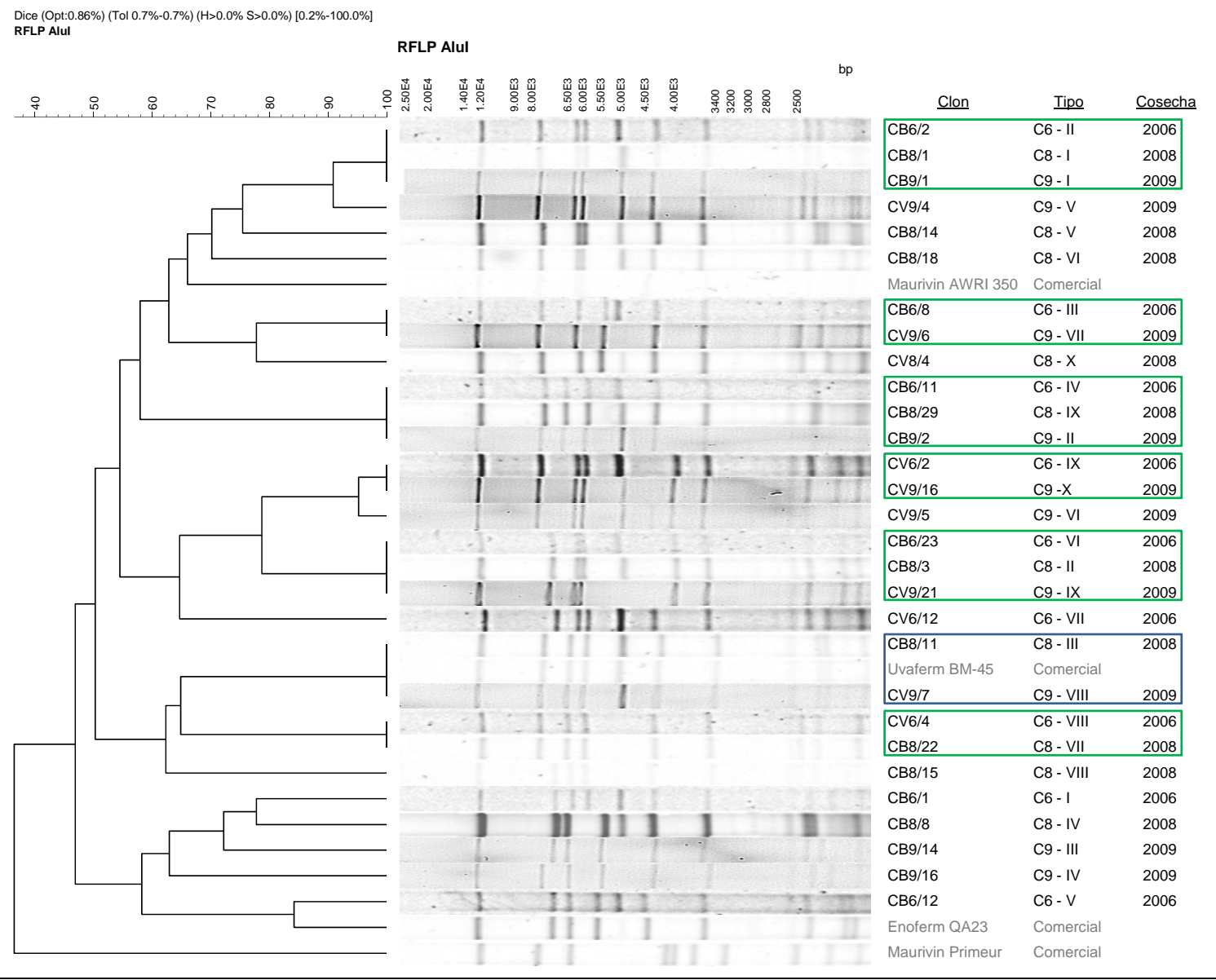

Figura 4.18: Comparación de las cepas de la bodega Pedro Casis aisladas en las cosechas de 2.006, 2.008 y 2.009. Se muestran los perfiles de RFLP-ADNmt obtenidos con la endonucleasa Alul (centro), así como el dendograma obtenido a partir de éste (izqda.). Se indica el clon representado en el gel, el tipo que lo engloba y la cosecha donde fueron aislados (derecha). En recuadros de color verde se indican aquellas levaduras que han aparecido en dos o más cosechas. En azul se indican las levaduras aisladas que resultaron ser LSA. Existen tres cepas que han aparecido en dos cosechas diferentes, mientras que otras tres los hacen en las tres cosechas indicadas. 

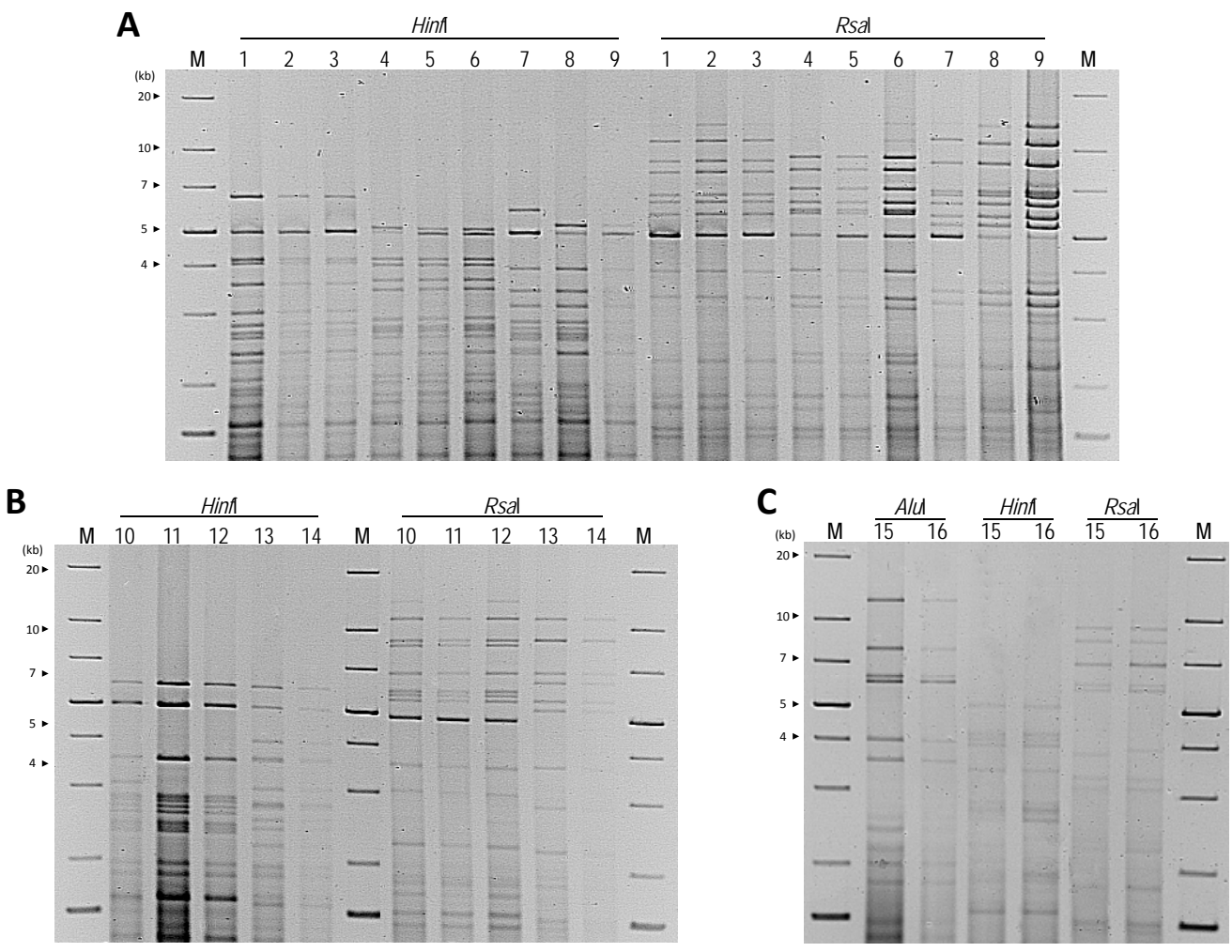

Figura 4.19: Análisis de RFLP-ADNmt de las cepas coexistentes en diferentes cosechas en la bodega Pedro Casis. Se muestran los patrones de restricción con diferentes endonucleasas, aparte de la ya mencionada Alul. Carriles: 1 , cepa C6 - IV; 2, C8 - IX; 3, C9 - II; 4, C6 - VI; 5, C8 - III; 6, C9 - IX; 7, C9 - VIII; 8, Uvaferm BM-45; 9, C8 - III; 10, C9 - I; 11, C6 - II; 12, C8 - I; 13, C6-VIII; 14, C8 - VII; 15, C6 - IX y 16, C6 - X. M es el marcador de peso molecular escalera de $1 \mathrm{~kb}\left(\right.$ Generuler $\left.^{\mathrm{TM}}\right)$. A la izquierda de las imágenes se indica el tamaño $(\mathrm{kb})$.

\subsubsection{Cooperativa Vinícola Ribera del Cea}

\subsubsection{Aislamiento de levaduras vínicas}

En este caso se analizaron las cosechas $2.006,2.007$ y 2.008 . Tras las correspondientes microvinificaciones (tabla 4.7) se llevó a cabo el aislamiento de levaduras para proceder a su caracterización genética. Resulta llamativo que en la cosecha de 2.006 , aunque se alargó el proceso de microvinificación, la densidad no consiguió bajar del umbral de $1,0 \mathrm{~g} / \mathrm{mL}$. Además todas las colonias aisladas a partir de este vino (al igual que al correspondiente a la cosecha de 2.008) presentaban morfología blanca en placa. En la cosecha de 2.007 se obtuvo una población de levaduras muy elevada, predominando la morfología blanca.

\subsubsection{Caracterización genética de las levaduras vínicas}

La caracterización genética se realizó para el número de colonias seleccionadas al azar indicadas en la tabla 4.8. La distinción realizada hasta el momento atendiendo a la coloración de las colonias no es significativa en este caso, ya que únicamente en la cosecha de 2.007 se aislaron colonias con morofología verde y en un porcentaje muy bajo $(0,3 \%$. Aún así, varias de las colonias con coloración verde aisladas se seleccionaron para el análisis.

\subsubsection{2.a. Identificación a nivel de especie mediante RFLP-5.8S-ITS}

Siguiendo el protocolo descrito en el apartado 3.9.2 se obtuvo la misma conclusión para todas y cada una de las cepas estudiadas: el patrón obtenido era el típico de $\mathrm{S}$. cerevisiae (figura 4.1, derecha). 
Tabla 4.7: Datos básicos de las microvinificaciones espontáneas a partir de mosto de uva suministrado por la bodega Cooperativa Vinícola Ribera del Cea. Se indica, para cada cosecha, el tiempo necesario para llevar a cabo la fermentación, la densidad final del vino obtenido, el número de levaduras por unidad de volumen y la coloración (en porcentaje) de las colonias aisladas.

\begin{tabular}{cccccc}
\hline & & & \multicolumn{2}{c}{ Coloración (\%) } \\
\cline { 3 - 6 } Cosecha & Periodo microvin. (días) & Densidad $(\mathrm{g} / \mathrm{mL})$ & Recuento (u.f.c./mL vino) & Blancas & Verdes \\
\hline 2.006 & 21 & 1,0082 & $2,56 \cdot 10^{6}$ & 100 & - \\
2.007 & 14 & 0,9884 & $1,21 \cdot 10^{7}$ & 97,7 & 0,3 \\
2.008 & 17 & 0,9907 & $2,18 \cdot 10^{6}$ & 100 & - \\
\hline
\end{tabular}

Tabla 4.8: Colonias seleccionadas para su caracterización genética en la bodega Cooperativa Vinícola Ribera del Cea.

\begin{tabular}{cccc}
\hline Cosecha & Número total de colonias & Blancas & Verdes \\
\hline 2.006 & 57 & 57 & 0 \\
2.007 & 60 & 53 & 7 \\
2.008 & 60 & 60 & 0 \\
\hline
\end{tabular}

4.1.4.2.b. Caracterización de cepas de S. cerevisiae mediante RFLP-ADNmt

Como en casos anteriores se realizó primero un análisis individual por cosecha y un estudio conjunto, analizando además las LSAs utilizadas por la bodega (tabla 3.1).

\section{Cosecha 2.006}

Las colonias seleccionadas en esta cosecha se distribuyeron en un total de 15 tipos diferentes (figura 4.20) lo que implica una gran diversidad de cepas, destacando los tipos R6-I y R6-VII por su mayor representatividad $(24,56 \%$ y $23,51 \%$ respectivamente). Ninguno de los tipos correspondía a las LSAs lo que indica que no hay implantación de las levaduras comerciales sobre la población autóctona.

\section{Cosecha 2.007}

En esta coseha se detectaron 12 tipos diferentes (figura 4.21). La diversidad es menor que en la cosecha anterior. Destacaban los tipos R7-I (43,33\%) y R7-II (31,67 \%) por sus altos porcentajes respecto al total (entre ambos suponen el $75 \%$ de las colonias analizadas). La coloración de la colonia no permite discriminar entre tipos, ya que las escasas colonias verdes se distribuyen entre los diferentes tipos.

\section{Cosecha 2.008}

En la cosecha de 2.008 se obtuvieron un total de 9 tipos diferentes (tipos 4.22), no coincidiendo con ninguna de las cepas comerciales empleadas en la elaboración de vinos. La diversidad es menor que en cosechas anteriores (ha ido disminuyendo progresivamente) y destaca el tipo R8-II que engloba casi la mitad de las colonias analizadas en esta cosecha $(45,00 \%$.

\section{Comparación entre cosechas}

En la figura 4.23 se muestra la comparación entre las tres cosechas analizadas, así como las cepas comerciales. 

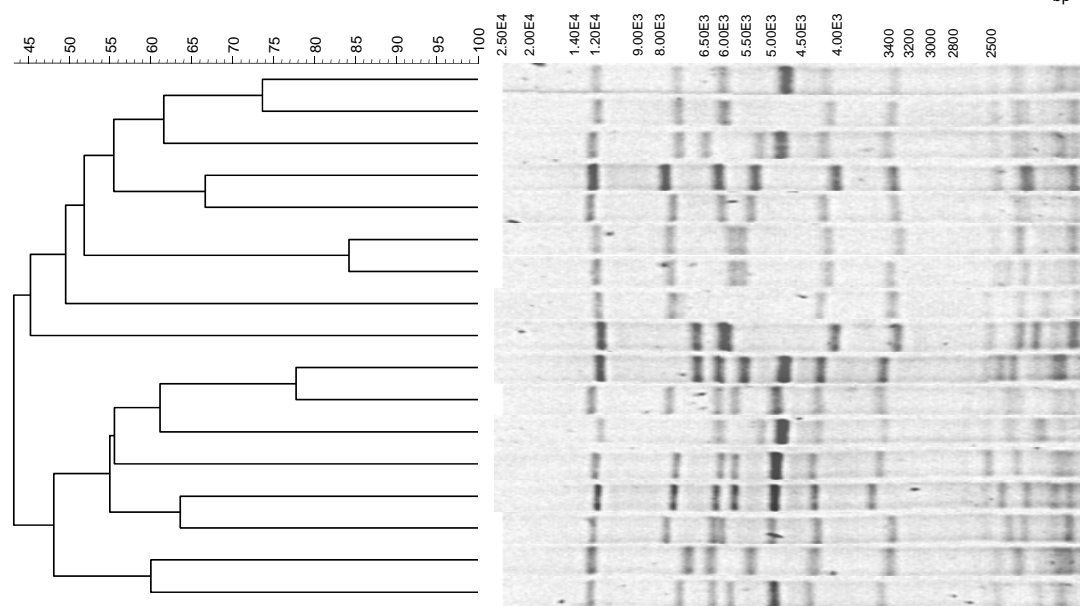

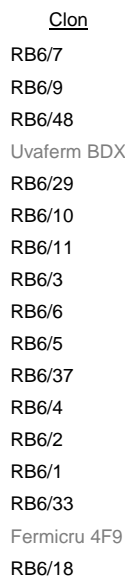
$\begin{aligned} \text { Tipo } & \text { Proporción (\%) } \\ \text { R6 - VII } & 1,75\end{aligned}$ R6 - VIII $\quad 1,75$ $\mathrm{R} 6-\mathrm{XI} \quad 1,75$ Comercial R6 - XIII $\quad 1,75$ R6 - IX $\quad 3,51$ $\mathrm{R} 6$ - X $\quad 5,26$ R6 - III $\quad 3,51$ R6 - VI 23,51 $\mathrm{R} 6-\mathrm{V} \quad 8,77$ R6 - XII $\quad 15,79$ R6 - IV 10,53 R6 - II $\quad 14,04$ R6 - I $\quad 24,56$ $\mathrm{R} 6-\mathrm{XV} \quad 1,75$

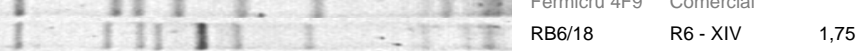

Figura 4.20: Caracterización de cepas de la bodega Cooperativa Vinícola Ribera del Cea (cosecha 2.006). Se observan los perfiles de RFLP-ADNmt obtenidos con la endonucleasa Alul (centro). En función del bandeo obtenido se obtiene (izquierda) un dendograma que informa de la similitud entre las diferentes cepas, mientras que a la derecha se indica el clon, el tipo donde queda englobado y la representación de los diferentes tipos.

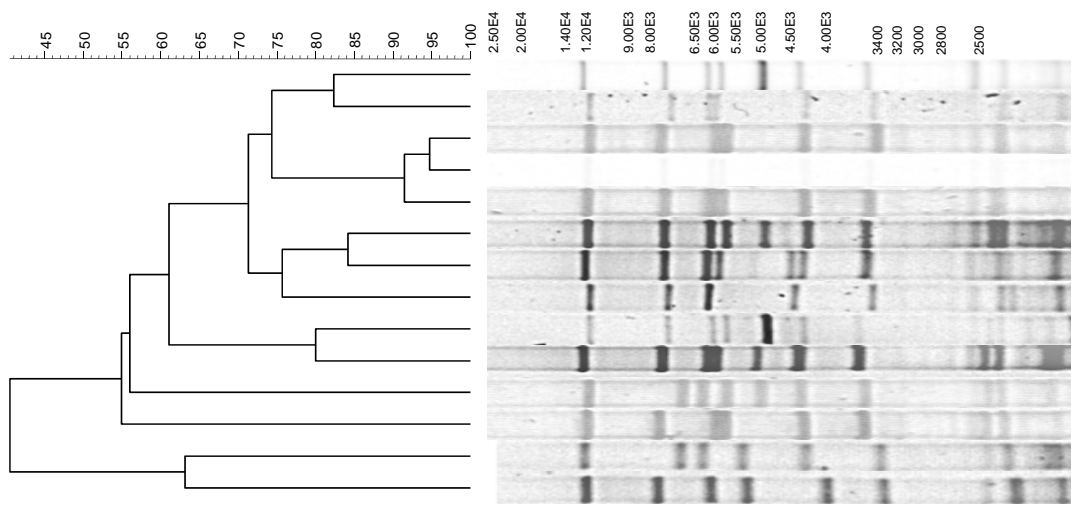

\begin{tabular}{|c|c|c|}
\hline Clon & $\underline{\text { Tipo }}$ & Proporción (\%) \\
\hline $\mathrm{RB} 7 / 32$ & R7 - VII & 3,33 \\
\hline $\mathrm{RB} 7 / 2$ & R7 - II & 31,67 \\
\hline $\mathrm{RB} 7 / 14$ & R7 - X & 1,67 \\
\hline $\mathrm{RB} 7 / 38$ & R7 - VIII & 3,33 \\
\hline $\mathrm{RB} 7 / 23$ & $\mathrm{R} 7-\mathrm{VI}$ & 3,33 \\
\hline RB7/6 & R7 - V & 3,33 \\
\hline $\mathrm{RV} 7 / 6$ & R7 - IV & 1,67 \\
\hline $\mathrm{RB} 7 / 1$ & R7 - I & 43,33 \\
\hline $\mathrm{RB} 7 / 49$ & R7 - IX & 1,67 \\
\hline $\mathrm{RV} 7 / 4$ & R7 - XII & 1,67 \\
\hline $\mathrm{RB} 7 / 18$ & R7 - III & 3,33 \\
\hline $\mathrm{RB} 7 / 24$ & $\mathrm{R} 7-\mathrm{XI}$ & 1,67 \\
\hline Fermicru 4F9 & Comercial & \\
\hline Uvaferm BDX & Comercial & \\
\hline
\end{tabular}

Figura 4.21: Caracterización de cepas de la bodega Cooperativa Vinícola Ribera del Cea (cosecha 2.007). Se muestran los perfiles de RFLP-ADNmt obtenidos con la endonucleasa Alul (centro), así como el dendograma correspondiente (izqda.). Se indica también el clon, el tipo donde queda englobado y la representación de los diferentes tipos (derecha).

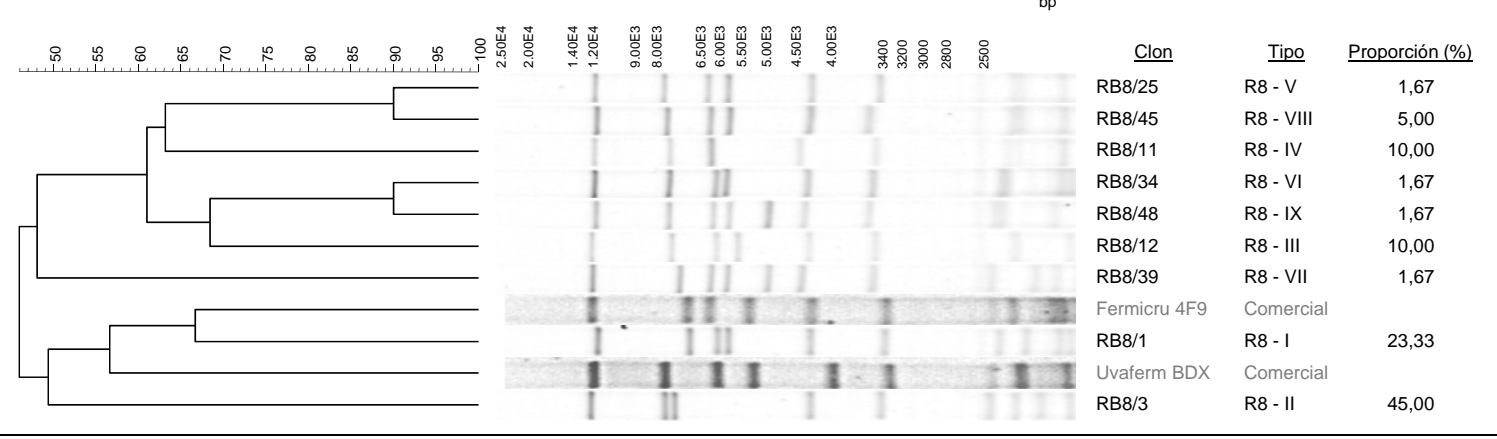

Figura 4.22: Caracterización de cepas de la bodega Cooperativa Vinícola Ribera del Cea (cosecha 2.008). Se observan los perfiles de RFLP-ADNmt para la enzima Alul (centro), el dendograma correspondiente (izqda.), así como el clon, tipo donde queda clasificado y la proporción de los diferentes tipos (dcha.). 


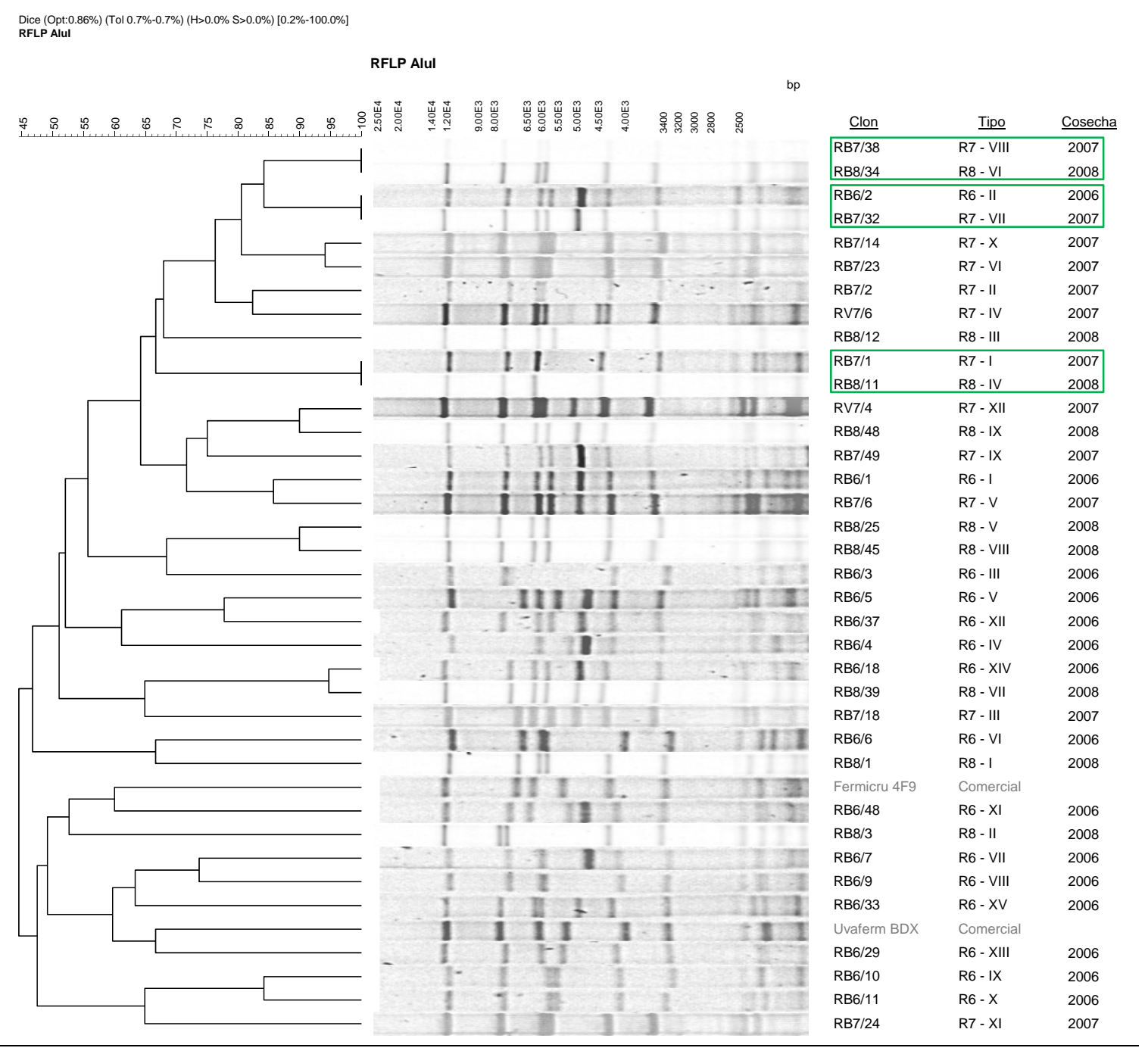

Figura 4.23: Estudio comparativo de cepas de la bodega Cooperativa Vinícola Ribera del Cea durante las cosechas 2.006, 2.007 y 2.008). Se muestran los perfiles de RFLP-ADNmt obtenidos con la endonucleasa Alul (centro), así como el dendograma obtenido a partir de éste (izqda.). Se indica el clon representado en el gel, el tipo que lo engloba y la cosecha donde fueron aislados (dcha.). Recuadradas en color verde se indican aquellas levaduras que han aparecido en dos cosechas.

Para esta bodega, se podría concluir lo siguiente:

- $\quad$ No se han detectado las levaduras comerciales empleadas en dicha bodega. Esto indica que la capacidad de implantación de estas cepas sobre las autóctonas es nula.

- Se han analizado un total de 177 colonias diferentes detectándose, a priori, 36 tipos de levadura. Debido a las coincidencias en más de una cosecha, el número se reduce hasta $\mathbf{3} 3$ cepas de $\mathbf{S}$. cerevisiae diferentes.

- Algunas cepas aparecen en dos de las tres cosechas estudiadas (figura 4.24). Resulta especialmente llamativo el tipo R7-I que aparece en dos cosechas (2.007 y 2.008), siendo además la cepa mayoritaria en la cosecha de 2.007 . 

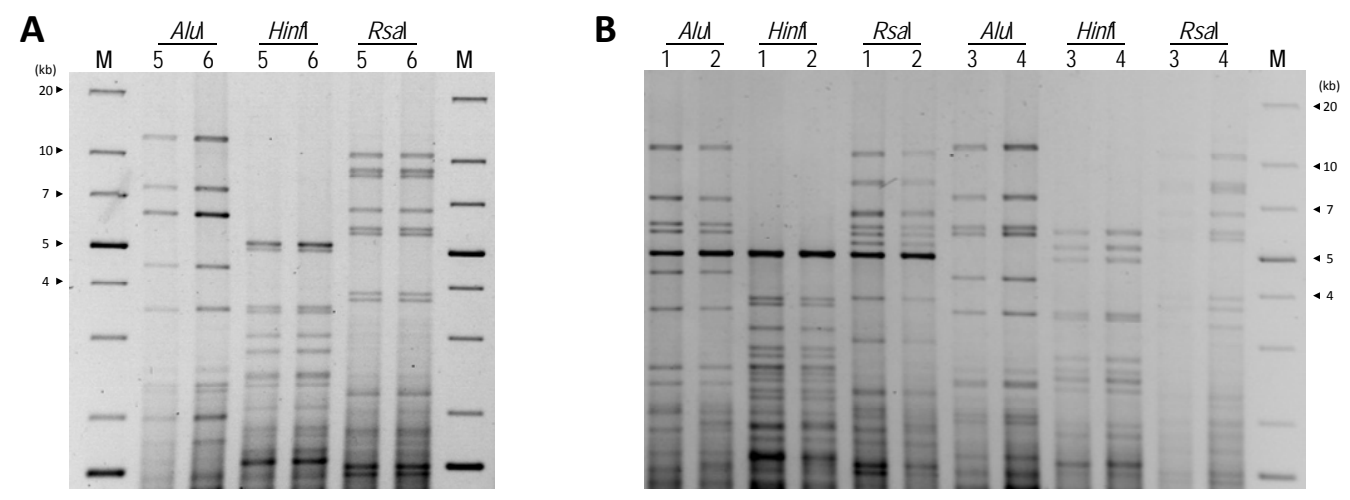

Figura 4.24: Análisis de RFLP-ADNmt de las cepas coexistentes en al menos dos cosechas en la bodega Cooperativa Vinícola Ribera del Cea. Se muestran los patrones de restricción con diferentes endonucleasas (Alul, Hinfl y Rsal). La obtención de patrones idénticos con distintas endonucleasas es una prueba inequívoca que nos garantiza que nos encontramos ante la misma cepa. Carriles:1, cepa R6 - II; 2, R7 - VII; 3, R7 - VIII; 4, R8 - VI; 5, R7 - I; 6, R8 - IV. M es el marcador de peso molecular escalera de $1 \mathrm{~kb}\left(\right.$ Generuler $\left.^{T \mathrm{M}}\right)$. A la izquiera de las imágenes se indica el tamaño (kb).

\subsubsection{Vinícola Valmadrigal}

\subsubsection{Aislamiento de levaduras vínicas}

El estudio se llevó a cabo en tres cosechas consecutivas (2.006, 2.007 y 2.008). En las cosechas de 2.006 y 2.008 los valores de densidad no alcanzaron valores inferiores a la unidad (tabla 4.9), probablemente debido a la baja población de levaduras encontrada en el vino final. Todo parece indicar que la población autóctona en bodega no es muy elevada. La coloración dominante de las colonias en placa es blanca.

Tabla 4.9: Datos básicos de las microvinificaciones realizadas con mosto de uva Prieto Picudo suministrado por la bodega Vinícola Valmadrigal. Se indica, para cada cosecha, el tiempo necesario para llevar a cabo la fermentación, la densidad final del vino obtenido, el número de levaduras por unidad de volumen y la coloración (en porcentaje) de las colonias aisladas.

\begin{tabular}{cccccc}
\hline & & & \multicolumn{2}{c}{ Coloración (\%) } \\
\cline { 5 - 6 } Cosecha & Periodo microvin. (días) & Densidad $(\mathrm{g} / \mathrm{mL})$ & Recuento (u.f.c./mL vino) & Blancas & Verdes \\
\hline 2.006 & 20 & 1.0002 & $2,60 \cdot 10^{4}$ & 98,2 & 1,8 \\
2.007 & 24 & 0,9908 & $3,76 \cdot 10^{5}$ & 91,2 & 8,8 \\
2.008 & 14 & 1,0074 & $2,76 \cdot 10^{5}$ & 100 & - \\
\hline
\end{tabular}

\subsubsection{Caracterización genética de las levaduras vínicas} 4. 10

El número y fenotipo de las colonias analizadas en cada cosecha se indica en la tabla

Tabla 4.10: Colonias seleccionadas para la caracterización genética en la bodega Vinícola Valmadrigal.

\begin{tabular}{cccc}
\hline Cosecha & Número total de colonias & Blancas & Verdes \\
\hline 2.006 & 59 & 49 & 10 \\
2.007 & 60 & 50 & 10 \\
2.008 & 60 & 60 & 0 \\
\hline
\end{tabular}




\subsubsection{2.a. Identificación a nivel de especie mediante RFLP-5.8S-ITS}

En todos los casos y tras realizar este análisis (apartado 3.9.2) se obtuvieron patrones característicos de S. cerevisiae (figura 4.1, derecha). Por tanto todas las levaduras aisladas pertenecieron a la especie con mayor importancia enológica.

4.1.5.2. b. Caracterización de cepas de S. cerevisiae mediante RFLP-ADNmt

Se llevó a cabo siguiendo las mismas pautas descritas para otras bodegas (análisis individual y conjunto incluyendo las LSAs utilizadas en la bodega).

\section{Cosecha 2006}

Se detectaron un total de 8 tipos diferentes (figura 4.25), entre si y a las levaduras comerciales. De entre todos ellos destaca el tipo V6-II (75,86 \%) que representa más de las tres cuartas partes de las levaduras analizadas. En este tipo se incluyen colonias con morfología blanca y verde, por lo que no existe relación fenotípica-genotípica en lo que a coloración de colonias se refiere.

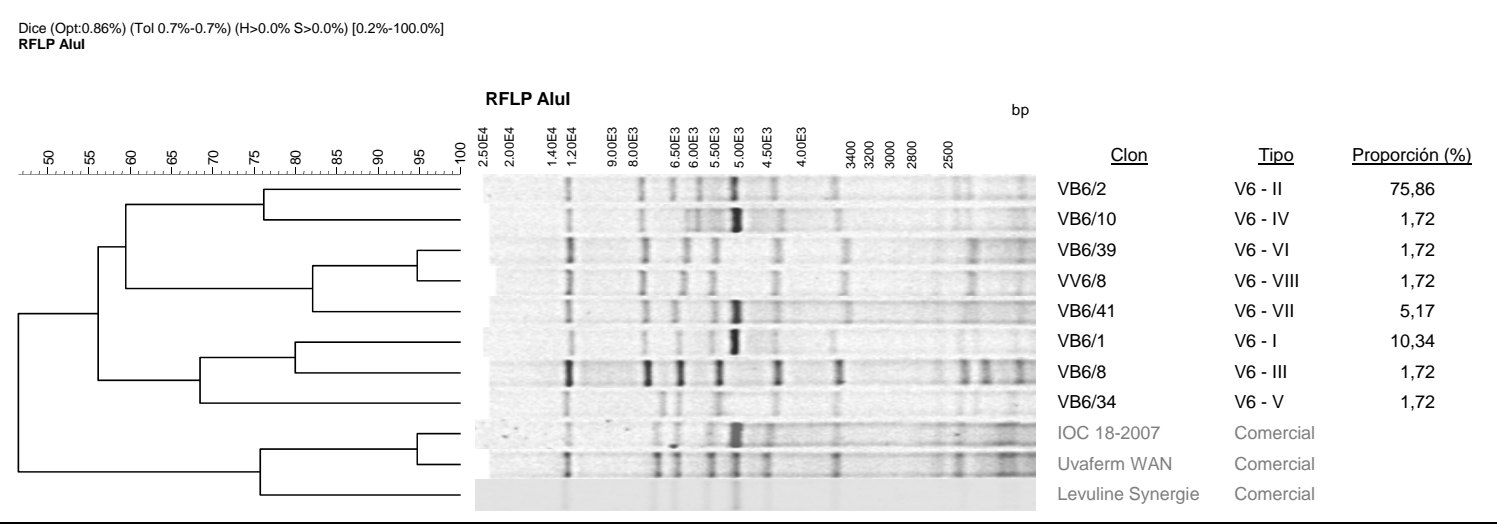

Figura 4.25: Caracterización de cepas de la bodega Vinícola Valmadrigal ( cosecha 2.006). Se observan los perfiles de RFLP-ADNmt obtenidos con la endonucleasa Alul (centro). En función del bandeo obtenido se obtiene (izquierda) un dendograma que informa de la similitud entre las diferentes cepas, mientras que a la derecha se indica el clon, el tipo donde queda englobado y la representación de los diferentes tipos.

\section{Cosecha 2.007}

En esta cosecha las levaduras analizadas se distribuyeron únicamente en 5 tipos diferentes (figura 4.26). Sin embargo el tipo más frecuente resultó ser una de las levaduras comerciales empleadas en bodega (IOC 18-2007). En este caso la coloración de la colonia no nos permite clasificar la cepa, como ya ocurría en la cosecha anterior.

\section{Cosecha 2.008}

Todas las cepas estudiadas fueron blancas ya que no se aislaron cepas con coloración verde. Inicialmente se detectaron 17 tipos diferentes (figura 4.27), aunque el tipo mayoritario (V8 - V)resultó ser una cepa comercial (la misma que en la cosecha de 2.007). Esto parece indicar que al menos esta levadura comercial se ha implantado adecuadamente sobre la población autóctona de las instalaciones. 


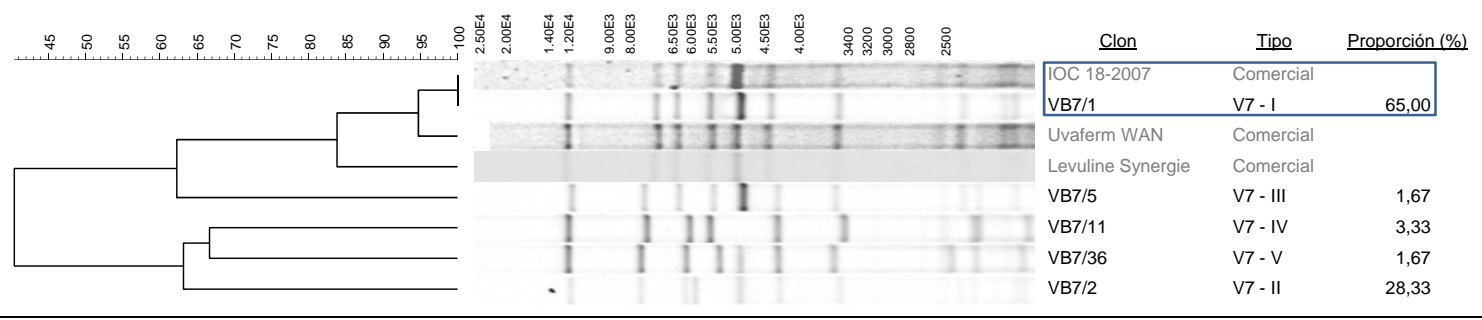

Figura 4.26: Caracterización de cepas en la bodega Vinícola Valmadrigal en la cosecha de 2.007. Se observan los perfiles de RFLP-ADNmt obtenidos con la endonucleasa Alul (centro), así como el dendograma correspondiente (izqda.). A la derecha se indica el clon, el tipo donde queda englobado y la representación de los diferentes tipos. En color azul se resalta la coincidencia de una de los tipos con la levadura comercial IOC 18-2007.

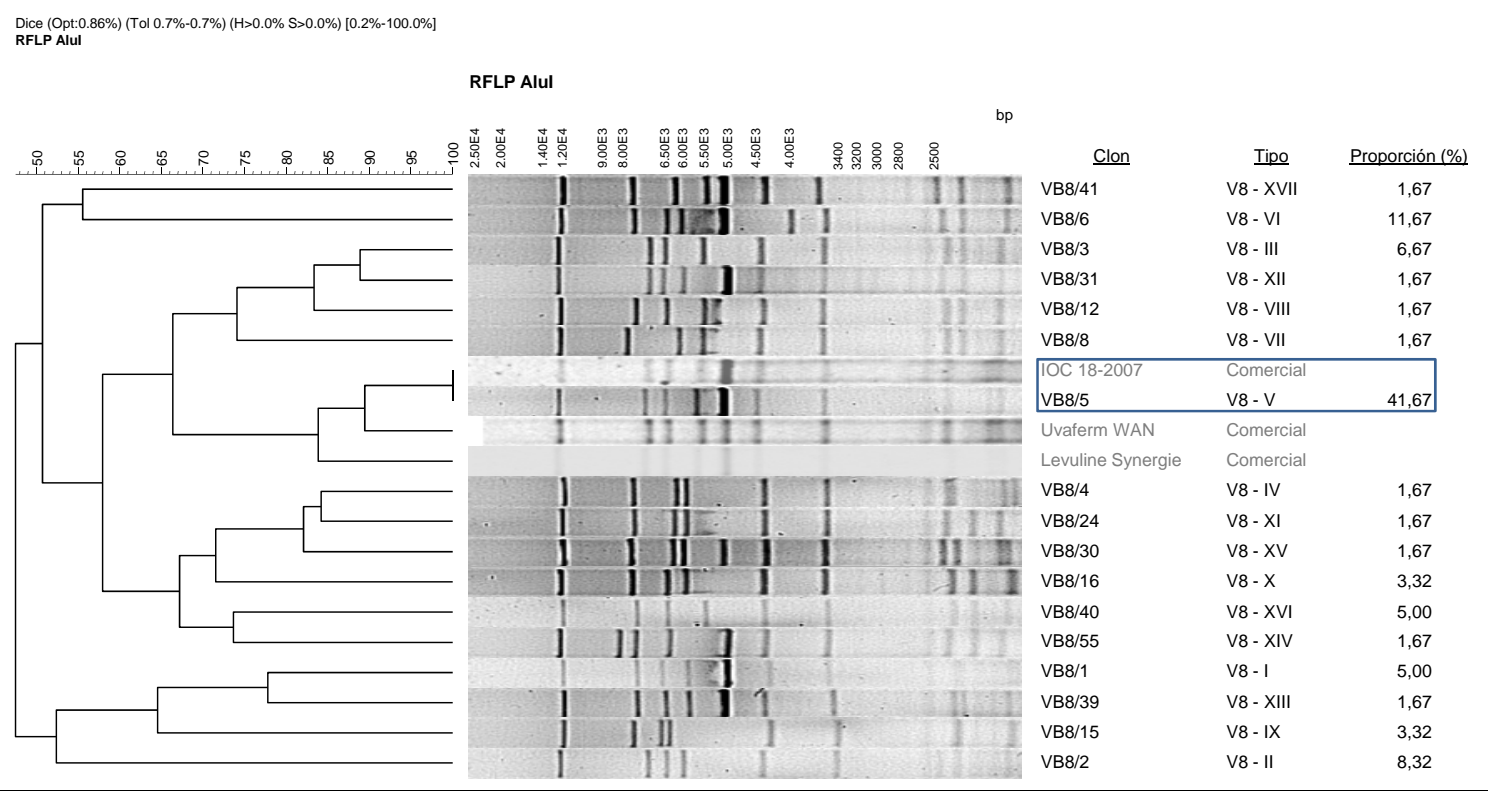

Figura 4.27: Caracterización de cepas de la bodega Vinícola Valmadrigal (cosecha 2.008). Se muestran en el centro los perfiles de RFLP-ADNmt obtenidos con la endonucleasa Alul. En función del bandeo obtenido se obtiene (izquierda) un dendograma que informa de la similitud entre las diferentes cepas. Se indica el clon, el tipo donde queda englobado y la representación de los diferentes tipos (dcha.). En la caja azul se resalta la coincidencia de una de los tipos con la levadura comercial IOC 18-2007.

\section{Comparación entre cosechas}

Una vez analizada cada cosecha por separado analizamos las tres cosechas en conjunto (figura 4.28), con la intención de encontrar cepas coexistentes en más de una cosecha.

Las conclusiones previas obtenidas serían:

- En la cosecha de 2.006 no se detectaron levaduras comerciales, mientras que en 2.007 y 2.008 las cepas mayoritarias eran LSAs. Todo parece indicar que en esta bodega se esta produciendo un desplazamiento de las levaduras autóctonas por, al menos, una de las levaduras comerciales.

- Se han detectado cuatro levaduras que aparecen en dos cosechas diferentes. Todas son cepas minoritarias, aunque el hecho de que aparezcan en dos cosechas diferentes pone de manifiesto su adaptación a las características de la variedad, a pesar de la gran competencia que supone la cepa comercial IOC 18-2007.

- Los 179 clones analizados se distribuyeron inicialmente en 30 tipos diferentes. Debido a la coincidencia con levaduras comerciales, así como la coexistencia de 
tipos en diferentes cosechas (figura 4.28 y 4.29 ) el número final se redujo hasta 24 tipos o cepas de $\mathbf{S}$. cerevisiae.

Dice (Opt:0.86\%) (Tol 0.7\%-0.7\%) (H>0.0\% S>0.0\%) [0.2\%-100.0\%]

RFLP Alul

䒴

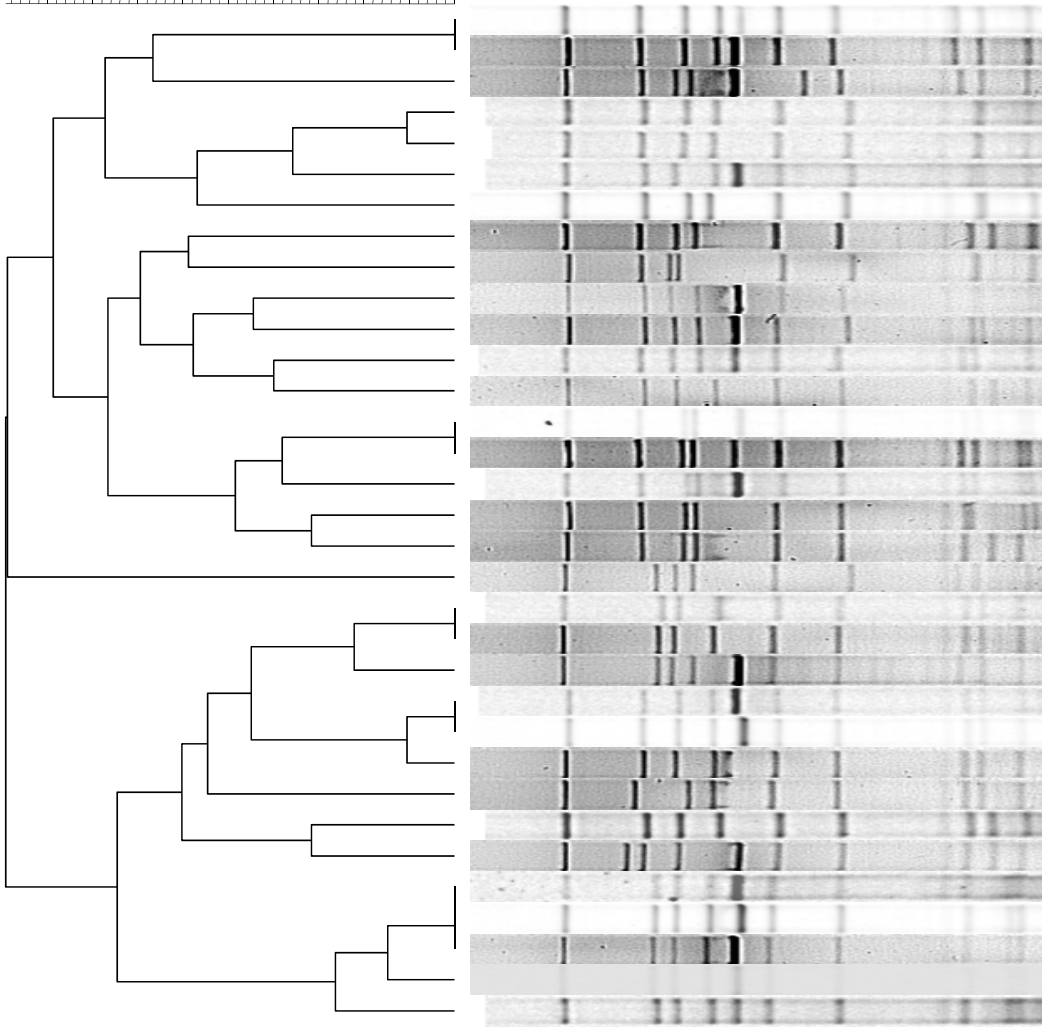

\begin{tabular}{|lll|}
\multicolumn{1}{c}{ Clon } & \multicolumn{1}{c}{ Tipo } & Cosecha \\
\hline VB7/36 & V7 - V & 2007 \\
VB8/41 & V8 - XVII & 2008 \\
\hline VB8/6 & V8 - VI & 2008 \\
VB6/39 & V6 - VI & 2006 \\
VV6/8 & V6 - VIII & 2006 \\
VB6/41 & V6 - VII & 2006 \\
VB7/11 & V7 - IV & 2007 \\
VB8/16 & V8 - X & 2008 \\
VB8/15 & V8 - IX & 2008 \\
VB8/1 & V8 - I & 2008 \\
VB8/39 & V8 - XIII & 2008 \\
VB6/2 & V6 - II & 2006 \\
VB8/40 & V8 - XVI & 2008 \\
\hline VB7/2 & V7 - II & 2007 \\
VB8/30 & V8 - XV & 2008 \\
\hline VB6/10 & V6 - IV & 2006 \\
VB8/4 & V8 - IV & 2008 \\
VB8/24 & V8 - XI & 2008 \\
VB8/2 & V8 - II & 2008 \\
\hline VB6/34 & V6 - V & 2006 \\
VB8/3 & V8 - III & 2008 \\
\hline VB8/31 & V8 - XII & 2008 \\
\hline VB6/1 & V6 - I & 2006 \\
VB7/5 & V7 - III & 2007 \\
\hline VB8/12 & V8 - VIII & 2008 \\
VB8/8 & V8 - VII & 2008 \\
VB6/8 & V6 - III & 2006 \\
VB8/55 & V8 - XIV & 2008 \\
\hline IOC 18-2007 & Comercial & \\
VB7/1 & V7 - I & 2007 \\
VB8/5 & V8 - V & 2008 \\
\hline Levuline Synergie & Comercial & \\
Uvaferm WAN & Comercial & \\
& & \\
\hline
\end{tabular}

Figura 4.28: Análisis comparativo de cepas de la bodega Vinícola Valmadrigal durante tres cosechas consecutivas. Se muestran los perfiles de RFLP-ADNmt obtenidos con la endonucleasa Alul (centro), así como el dendograma obtenido a partir de éste (izqda.). Se indica, a la derecha, el clon representado en el gel, el tipo que lo engloba y la cosecha donde fueron aislados. Recuadrado en color verde se indican aquellas levaduras que han aparecido en dos cosechas. En cuadros azules se resaltan aquellas que en realidad eran LSAs.

A

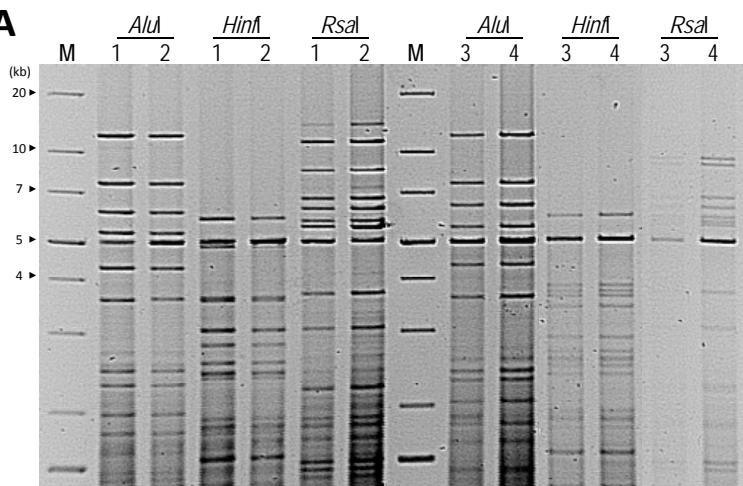

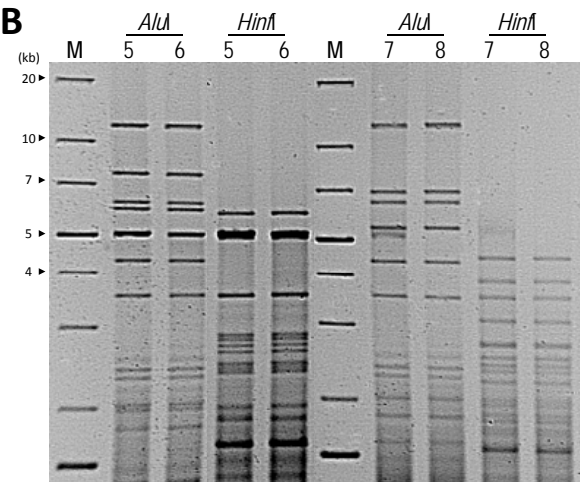

Figura 4.29: Análisis de RFLP-ADNmt de las cepas coexistentes en al menos dos cosechas para la bodega Vinícola Valmadrigal. Se muestran los patrones de restricción con diferentes endonucleasas (Alul, Hinfl y Rsal). Carriles: 1 , cepa V7 - V; 2, V8 - XVII; 3, V6 - I; 4, V7 - III; 5, V7 - II; 6, V8 - XV; 7, V6-V; 8, V8 - III. M es el marcador de peso molecular escalera de $1 \mathrm{~kb}$ (Generuler $\left.{ }^{\mathrm{T} M}\right)$. A la izquiera de las imágenes se indica el tamaño $(\mathrm{kb})$. 


\subsubsection{Comparación entre las diferentes bodegas estudiadas}

Una vez hemos analizado por separado cada una de las bodegas objeto de estudio en el presente trabajo, el siguiente paso parecía lógico: realizar una comparación conjunta entre todas ellas. Para ello descartamos en cada bodega las cepas que resultaron ser LSAs y comparamos informáticamente los perfiles de RFLP-ADNmt de los restantes tipos.

Hasta el momento habiamos comprobado como algunas cepas eran capaces de aparecer en una misma bodega en cosechas diferentes, descartando su aislamiento como fruto del azar y poniendo de manifiesto la existencia de cepas autóctonas en las bodegas. La comparación conjunta permite realizar un análisis de poblaciones interbodega, es decir, la posible existencia de uno o varios individuos en nichos diferentes (bodegas con distinta localización geográfica dentro de la DO). A partir de los perfiles obtenidos al realizar RFLP-ADNmt con la endonucleasa Alul se obtiene un dendograma que nos aporta información acerca de la similitud existente entre las diferentes cepas (figura 4.30). En nuestro caso, sólo nos resulta de interés una "similitud total", es decir, un dato que nos asegure que nos encontramos ante la misma cepa. No es por tanto un estudio de poblaciones, sino una herramienta que simplifica y automatiza la comparación entre dos o más perfiles que a simple vista presenten gran parecido.

Como resultado de este análisis global hemos comprobado que varias cepas aparecen en dos de las bodegas estudiadas (resaltadas en caj as de color verde en la figura 4.30), mientras que una (cepa G6-III / C9-II / P6-VIII / V8-I) aparece en cuatro de las cinco bodegas objetos de estudio (resaltadas en color verde en la figura 4.30). Este dato podría indicar que existen cepas que serían autóctonas no solo de las correpondientes bodegas, sino de la variedad. Lógicamente, la cepa con mayor interés es aquella que ha aparecido en cuatro localizaciones diferentes. Además dicha levadura fue aislada en las tres cosechas analizadas en la bodega Pedro Casis (figura 4.18). Para confirmar esta identidad se realizaron estudios de RFLP-ADNmt con otras endonucleasas diferentes a la indicada, de modo que perfiles idénticos con la misma enzima ponen de manifiesto que nos encontramos ante una misma cepa. Se muestra, a modo de ejemplo (figura 4.31), los perfiles de restricción, con Rsal y Hinfl, de las cuatro cepas aisladas en cuatro bodegas diferentes con perfil idéntico con la endonucleasa Alul. Esto nos asegura que realmente nos encontramos ante la misma cepa.

En la tabla 4.11 se resumen los resultados obtenidos para cada bodega y el resultado final del estudio tras la comparación conjunta. Debido a lo coexistencia de cepas en diferentes bodegas el número total de tipos obtenidos se ve sensiblemente reducido. Por tanto se podría indicar que se ha aislado una colección de $\mathbf{1 1 9}$ tipos o cepas diferentes de la especie $\mathbf{S}$. cerevisiae.

Tabla 4.11: Resumen de los resultados obtenidos tras el aislamiento y caracterización genética de levaduras vínicas autóctonas de bodegas de la DO «Tierra de León». Se indican los resultados obtenidos para cada una de las bodegas junto con el resultado final tras la comparación conjunta.

\begin{tabular}{lllcc}
\hline Bodega & Cosechas Analizadas & Cepas analizadas & Tipos caracterizados \\
\hline Gordonzello S.A. & $2.005,2.006$ y 2.007 & 177 & 22 \\
& Coop. Oteros & $2.005,2.006$ y 2.007 & 167 & 33 \\
& Bodegas Pedro Casis & $2.006,2.008$ y 2.009 & 177 & 18 \\
& Coop. Vin. Ribera Cea & $2.006,2.007$ y 2.008 & 177 & 33 \\
& Vinícola Valmadrigal & $2.006,2.007$ y 2.008 & 179 & 24 \\
\cline { 3 - 4 } & & 877 & 130 \\
Total (preliminar) & & & 11 \\
Cepas coexistentes en varias bodegas & & & $\mathbf{1 1 9}$ \\
TOTAL CEPAS DIFERENTES & & &
\end{tabular}




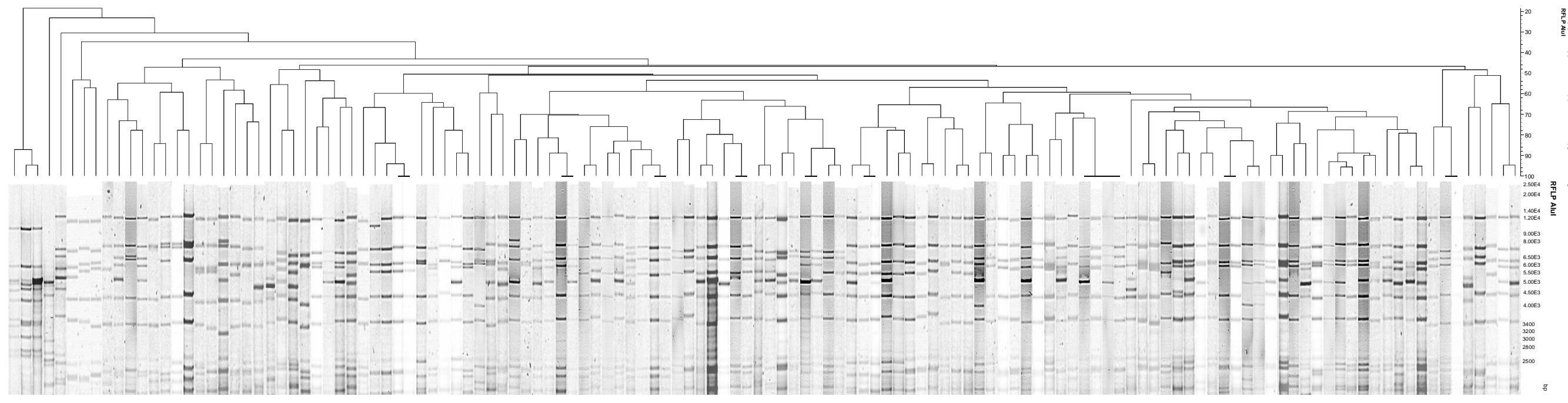

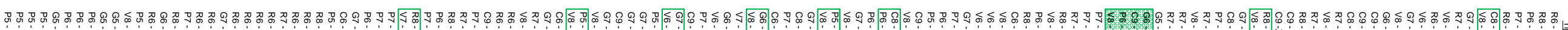

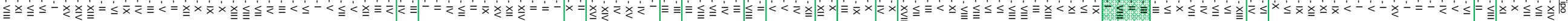

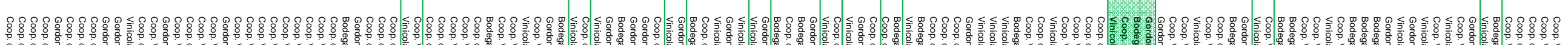

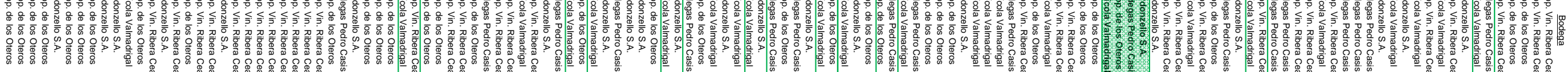

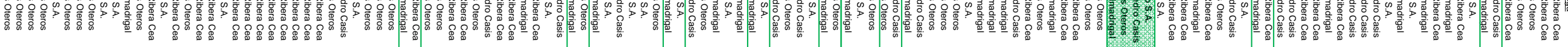

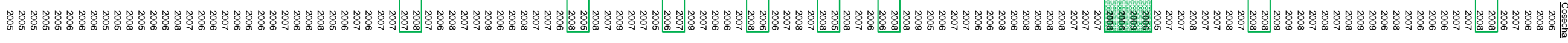

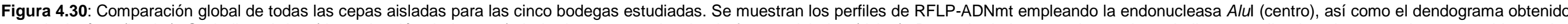

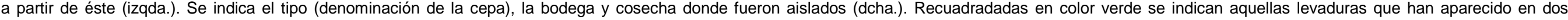
bodegas diferentes. Resulta llamativa la aparición de una misma levadura en cuatro bodegas diferentes con diferente disposición geográfica (resaltadas en color verde). 


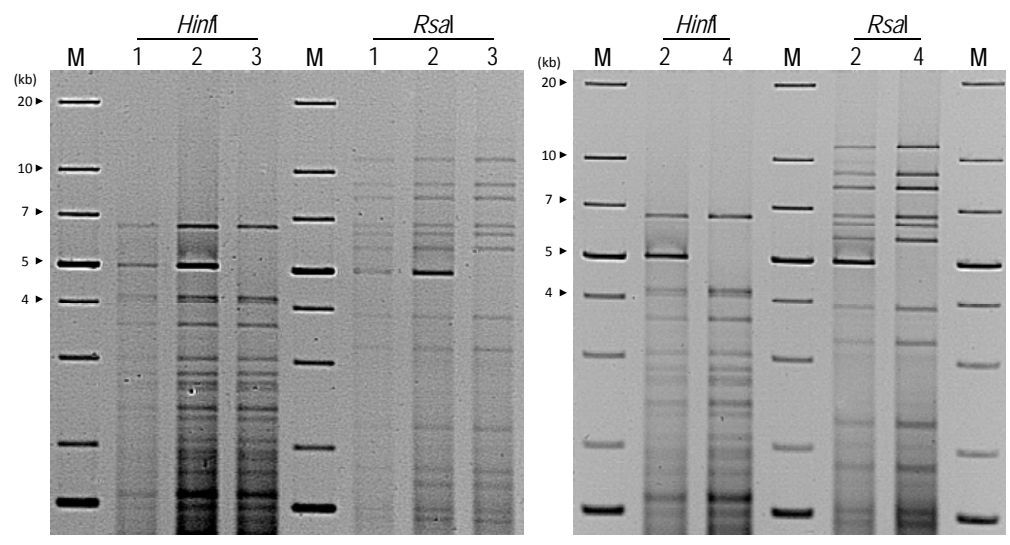

Figura 4.31: Análisis de RFLP-ADNmt de las cepas coexistentes en cuatro de las cinco bodegas estudiadas. Se muestran los patrones de restricción con las endonucleasas Hinfl y Rsal. Se observa como los patrones obtenidos con la misma endonucleasa son idénticos, al igual que ocurre con la enzima Alul (ver figura 4.30). Carriles: 1, cepa C9 - II; 2, V8 - I; 3, P6 - VIII; 4, G6 - III. M es el marcador de peso molecular escalera de $1 \mathrm{~kb}$ (Generuler ${ }^{\mathrm{TM}}$ ). A la izquiera de las imágenes se indica el tamaño $(\mathrm{kb})$.

\subsubsection{Análisis de los perfiles de RFLP-ADNmt mediante componentes principales}

Basándonos en la comparación de las cinco bodegas (figura 4.30) se generó una matriz binaria (software InfoquestFP, optimización del $2 \%$ para cada uno de los individuos (tipos de levaduras obtenidos) y cada una de las posibles bandas (denominadas alfanuméricamente, de mayor a menor tamaño: $A 0, A 1, \ldots, A 9, B 1, \ldots, B 9$, etc.). Esto es, se generó una matriz con 30 columnas (bandas posibles) y 130 filas (individuos) en las que se asignará, en cada caso, un 1 si existe banda 0 un 0 en ausencia de ésta. Realizando un análisis de componentes principales (figura 4.32) sobre la citada matriz vemos la distribución de las diferentes cepas (representado por cuadrados) y bandas (variables de agrupación, representadas por flechas) de acuerdo a las nuevas variables hipotéticas (componentes principales, CP). Si analizamos la gráfica de decaimiento (explica el porcentaje de varianza varianza explicado por cada componente principal) se obtiene que la mayoría de la varianza observada se explicaba con tres componentes principales, ya que el resto de CP explican menos de un $7 \%$ de la varianza.

La representación de los tipos y bandas (variables) en relación a las parejas de nuevas variables CP 1-CP 2 y CP 1-CP 3 nos da un resultado muy similar. La mayoría de los individuos aparecen agrupados, manteniendo constante su valor para la CP1 (explica una mayor varianza), aunque algunos aparecen más dispersos. Podríamos hablar de dos grupos: uno mayoritario y uno minoritario. Este último estaría formado por individuos que presentan un perfil de restricción bastante diferenciado. Estos son los tipos aislados en la bodega Cooperativa de los Oteros en la cosecha de 2.005. De hecho el tipo P5 - XI engloba la cepa PB5/ 7 (PB7) que en realidad se trata de un híbrido S. cerevisiae x S. kudriavzevii. La representación de los tipos y bandas respecto a las variables CP 2-CP 3 no muestra ninguna tendencia clara. 


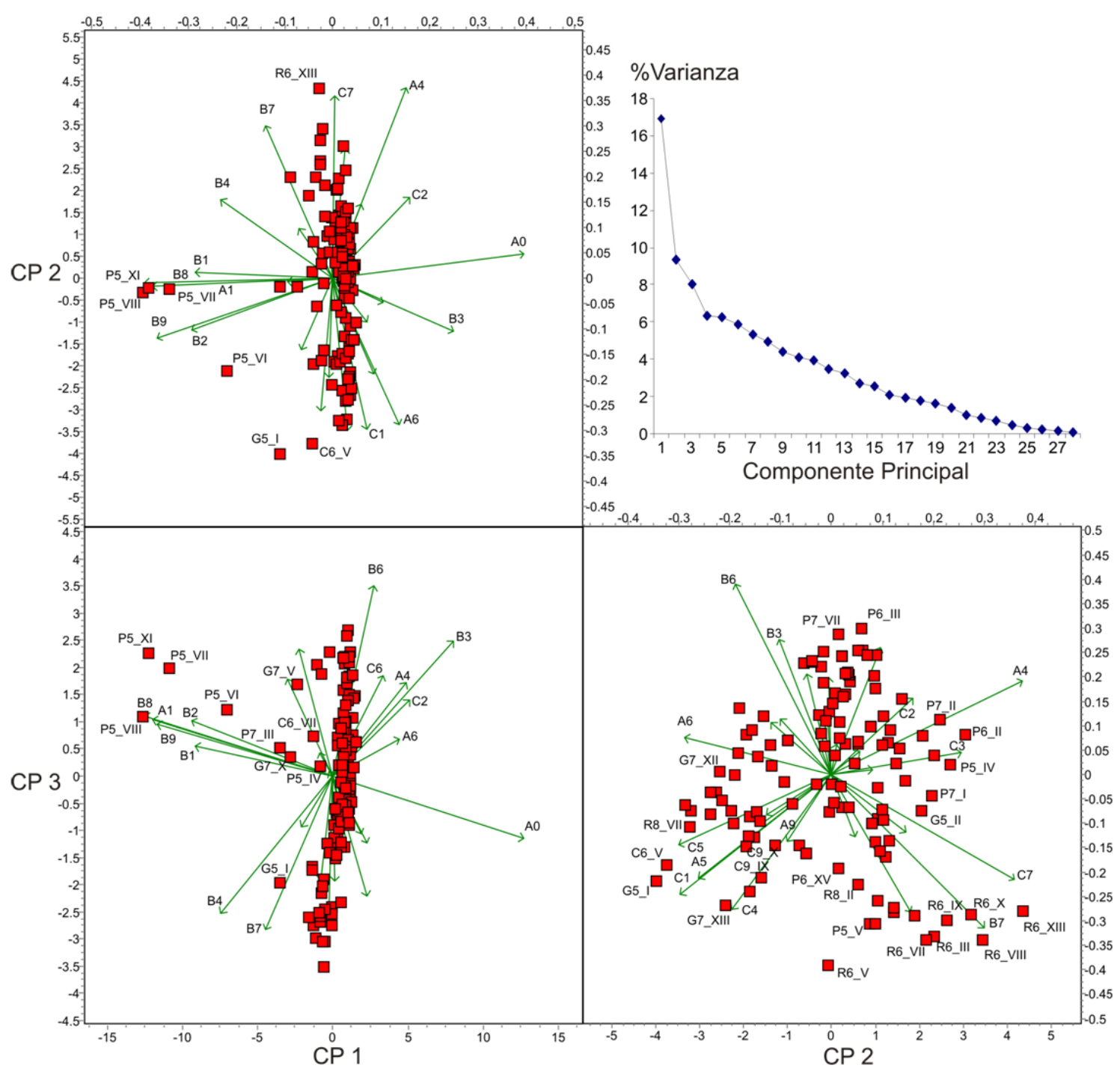

Figura 4.32: Análisis de componentes principales (CP) del estudio de RFLP-ADNmt. Se observa la distribución de los tipos de levadura (representados por cuadrados) y de las bandas (variables, representadas por flechas) en función de unas nuevas variables hipotéticas que explicarán la varianza encontrada. En la parte superior y derecha se indica la escala correspondiente a las variables (bandas), mientras que en la parte inferior e izquierda se indica la escala correspondiente a los tipos. 


\subsection{Aislamiento de levaduras desde uva a baja temperatura}

El objetivo de este aislamiento era doble: por un lado aislar levaduras de un entorno natural (uvas); por otro lado el aislamiento a bajas temperaturas nos podría permitir aislar otras especies dentro del género Saccharomyces (como S. bayanus) o incluso híbridos de S. cerevisiae con otras especies. Estas cepas son muy interesantes para realizar fermentaciones a bajas temperaturas, que en el caso de la DO «Tierra de León» son de gran interés para la producción de vinos rosados muy aromáticos (algo por lo que destaca esta variedad).

Para ello partimos de uva de la variedad Prieto Picudo, concretamente uva perteneciente a viñedos adscritos a las bodegas objeto de estudio. De este modo las muestras (tomadas lo más asépticamente posible en el propio viñedo), provendrían de regiones geográficamente dispersas (ver 3.7.1). En total se realizaron cuatro tomas de muestra, debido a que una de las bodegas, Vinícola Valmadrigal, aseguró emplear uva de viñedos asentados en Gordoncillo (León, España). En esta población se encuentra la bodega Gordonzello S. A., por lo que decidimos desechar las uvas de Vinícola Valmadrigal.

Hay que recordar que se incubaron dos tubos muestra de uva: uno contenía simplemente la uva estrujada, mientra el otro contrenía adicionalmente un $5 \%$ de etanol ( $p / p)$ a fin de favorecer el aislamiento de levaduras del género Saccharomyces frente a las levaduras salvajes. Tal como se ha indicado en el apartado 3.8.2.2 cada 15 días se sembraron en placa muestras (diluciones adecuadas) a partir de los estrujados de uva incubados a $10 \stackrel{\circ}{\circ}$. Las placas sembradas se incubaron a la misma temperatura. Una vez desarrolladas las colonias, se replicaron en una nueva placa y se procedió a su identificación mediante secuenciación de los dominidos D1-D2 del ADNr 26S. Este proceso se repitió quincenalmente, de ahí las diferentes lotes de muestreo: el lote " 0 " será la que se realizó inicialmente, mientras que el resto de lotes estaban separados por un periodo de 15 días de incubación. Las muestras se indican con el número que indica el lote y una letra consecutiva.

En la tabla 4.12 se muestran los resultados de la identificación. La incubación a baja temperatura, junto con cierto contenido en etanol realizan una presión selectiva encaminada en la dirección de aislar levaduras del género Saccharomyces, debido a su mayor criotolerancia y adaptación a medios con etanol.

Al principio del periodo de incubación (lote 0 , día 0), se aislaron principalmente levaduras salvajes y aquellas que suelen predominar en la superficie de la uva (indicado en el apartado 1.4.1.1.a). En el lote 3 de muestreo (45 días de incubación), así como en las siguientes, se obtuvieron varias colonias con morfología típica de Saccharomyces que resultaron ser efectivamente $\mathrm{S}$. cerevisiae. Así se aislaron un total de 15 cepas diferentes de S. cerevisiae a diferentes tiempos de muestreo y a partir de uvas con distintos orígenes: viñedos de Gordaliza del Pino, Gordoncillo y de Valderas (León, España).

A continuación se procedió a comparar los perfiles de RFLP de ADNmt empleando el enzima de restricción Alul (figura 4.33). Contra todo pronóstico, las cepas de S. cerevisiae aisladas resultaron ser la misma. Resulta llamativo que una misma cepa aparezca en uvas procedentes de viñedos separados por grandes distancias.

La comparación de esta cepa contra nuestra colección (119 cepas) dio un resultado negativo (figura 4.34). De este modo descartamos la posible contaminación de la muestra en el laboratorio, y aseguramos que esta cepa es diferente a cualquiera de la colección de cepas aisladas de microfermentaciones. 


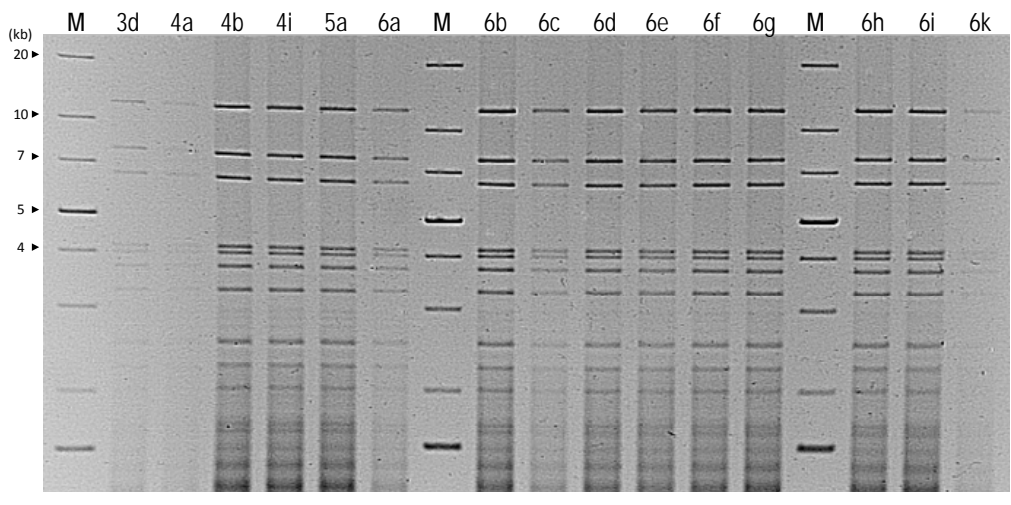

Figura 4.33: Resultado del análisis de RFLP-ADNmt con el enzima Alul sobre las levaduras $S$. cerevisiae aisladas directamente desde uva. Vemos como todas ellas presentan un perfil idéntico, pudiendo afirmar que nos encontramos ante la misma cepa. 
Tabla 4.12: Resultados de la identificación de las levaduras aisladas a partir de las muestras de uva tras su incubación a $10^{\circ} \mathrm{C}$. Se indica el lote de muestreo en el que fueron aisladas, la procedencia de las uvas, la dilución empleada en la siembra y si la muestra incubada contenía etanol. Para cada una de ellas se indica el tamaño de amplificado y la especie a la que pertenecen.

\begin{tabular}{|c|c|c|c|c|c|c|}
\hline Colonia & Tanda & Bodega & Dilucion $\left(10^{-x}\right)$ & $\mathrm{EtOH}(\%)$ & Tamaño (pb) & Identificación \\
\hline$\overline{\mathrm{Oa}}$ & 0 & Gordonzello S.A. & 0 & 0 & 680 & $\overline{\text { Cryptococcus laurentii }}$ \\
\hline $\mathrm{Ob}$ & 0 & Gordonzello S.A. & 0 & 0 & 680 & Cryptococcus terrestris \\
\hline Oc & 0 & Gordonzello S.A. & 0 & 0 & 680 & Cystofilobasidium capitatum \\
\hline Od & 0 & Gordonzello S.A. & 0 & 0 & 680 & Cryptococcus amylolentus \\
\hline $\mathrm{Oe}$ & 0 & Gordonzello S.A. & 0 & 0 & 680 & Rhodotorula nothofagi \\
\hline Of & 0 & Gordonzello S.A. & 0 & 0 & 660 & Cryptococcus flavescens \\
\hline $\mathrm{Og}$ & 0 & Gordonzello S.A. & 0 & 0 & 660 & Cryptococcus flavescens \\
\hline $\mathrm{Oh}$ & 0 & Gordonzello S.A. & 0 & 0 & 660 & Aureobasidium pullulans \\
\hline Oi & 0 & Gordonzello S.A. & 0 & 0 & 650 & Cryptococcus flavescens \\
\hline Oj & 0 & Bodegas Pedro Casis & 0 & 0 & 650 & Cryptococcus victoriae \\
\hline Ok & 0 & Coop. Oteros & 0 & 0 & 680 & Cryptococcus sp. \\
\hline $\mathrm{Ol}$ & 0 & Coop. Vin. Ribera Cea & 0 & 0 & 680 & Cryptococcus victoriae \\
\hline $\mathrm{Om}$ & 0 & Coop. Vin. Ribera Cea & 0 & 0 & 650 & Aureobasidium pullulans \\
\hline On & 0 & Bodegas Pedro Casis & 0 & 0 & 600 & Metschnikowia pulcherrima \\
\hline Oo & 0 & Bodegas Pedro Casis & 0 & 0 & 600 & Metschnikowia pulcherrima \\
\hline la & 1 & Bodegas Pedro Casis & -2 & 0 & 650 & Cryptococcus victoriae \\
\hline $1 b$ & 1 & Bodegas Pedro Casis & -2 & 0 & 600 & Metschnikowia pulcherrima \\
\hline lc & 1 & Coop. Vin. Ribera Cea & -2 & 0 & 630 & Aureobasidium pullulans \\
\hline le & 1 & Coop. Vin. Ribera Cea & -2 & 0 & 650 & Filobasidium capsuligenum \\
\hline $1 \mathrm{~h}$ & 1 & Bodegas Pedro Casis & -2 & 0 & 630 & Cryptococcus victoriae \\
\hline $2 a$ & 2 & Bodegas Pedro Casis & -3 & 0 & 600 & Hanseniaspora uvarum \\
\hline $2 b$ & 2 & Bodegas Pedro Casis & -3 & 0 & 550 & Cryptococcus amylolentus \\
\hline $2 c$ & 2 & Gordonzello S.A. & -3 & 0 & 650 & Cryptococcus amylolentus \\
\hline $2 d$ & 2 & Gordonzello S.A. & -3 & 0 & 650 & Cystofilobasidium lari-marini \\
\hline $3 a$ & 3 & Bodegas Pedro Casis & -4 & 0 & 550 & Metschnikowia fructicola \\
\hline $3 c$ & 3 & Bodegas Pedro Casis & -4 & 0 & 630 & Hanseniaspora uvarum \\
\hline $3 d$ & 3 & Bodegas Pedro Casis & -4 & 0 & 650 & Saccharomyces cerevisiae \\
\hline $3 e$ & 3 & Bodegas Pedro Casis & -2 & 5 & 550 & Metschnikowia fructicola \\
\hline $3 f$ & 3 & Bodegas Pedro Casis & -2 & 5 & 550 & Metschnikowia sp. \\
\hline $3 g$ & 3 & Bodegas Pedro Casis & -2 & 5 & 550 & Metschnikowia fructicola \\
\hline $3 \mathrm{~h}$ & 3 & Coop. Vin. Ribera Cea & -4 & 0 & 650 & Leucosporidium scottii \\
\hline $3 i$ & 3 & Gordonzello S.A. & -4 & 0 & 650 & Filobasidium capsuligenum \\
\hline $3 j$ & 3 & Gordonzello S.A. & -4 & 0 & 650 & Cystofilobasidium capitatum \\
\hline $4 a$ & 4 & Bodegas Pedro Casis & -5 & 0 & 650 & Saccharomyces cerevisiae \\
\hline $4 b$ & 4 & Bodegas Pedro Casis & -5 & 0 & 650 & Hanseniaspora uvarum \\
\hline $4 c$ & 4 & Bodegas Pedro Casis & -5 & 0 & 600 & Metschnikowia pulcherrima \\
\hline $4 d$ & 4 & Bodegas Pedro Casis & -5 & 0 & 650 & Saccharomyces cerevisiae \\
\hline $4 e$ & 4 & Gordonzello S.A. & -4 & 0 & 650 & Cystofilobasidium capitatum \\
\hline $4 f$ & 4 & Bodegas Pedro Casis & -2 & 5 & 600 & Metschnikowia pulcherrima \\
\hline $4 g$ & 4 & Bodegas Pedro Casis & -2 & 5 & 600 & Metschnikowia pulcherrima \\
\hline $4 \mathrm{~h}$ & 4 & Coop. Vin. Ribera Cea & -4 & 0 & 650 & Hanseniaspora uvarum \\
\hline $4 \mathrm{i}$ & 4 & Coop. Vin. Ribera Cea & -4 & 0 & 650 & Saccharomyces cerevisiae \\
\hline $4 \mathrm{j}$ & 4 & Coop. Vin. Ribera Cea & -4 & 0 & 600 & Metschnikowia pulcherrima \\
\hline $5 a$ & 5 & Coop. Vin. Ribera Cea & -4 & 0 & 650 & Hanseniaspora uvarum \\
\hline $5 b$ & 5 & Coop. Vin. Ribera Cea & -4 & 0 & 650 & Saccharomyces cerevisiae \\
\hline $5 c$ & 5 & Bodegas Pedro Casis & -2 & 5 & 550 & Metschnikowia fructicola \\
\hline $5 d$ & 5 & Bodegas Pedro Casis & -2 & 5 & 650 & Metschnikowia aff. fructicola \\
\hline $6 a$ & 6 & Coop. Vin. Ribera Cea & -6 & 0 & 650 & Saccharomyces cerevisiae \\
\hline $6 b$ & 6 & Coop. Vin. Ribera Cea & -5 & 0 & 650 & Saccharomyces cerevisiae \\
\hline $6 c$ & 6 & Coop. Vin. Ribera Cea & -5 & 0 & 650 & Saccharomyces cerevisiae \\
\hline $6 d$ & 6 & Bodegas Pedro Casis & -3 & 0 & 650 & Saccharomyces cerevisiae \\
\hline $6 e$ & 6 & Bodegas Pedro Casis & -4 & 0 & 650 & Saccharomyces cerevisiae \\
\hline $6 f$ & 6 & Bodegas Pedro Casis & -4 & 0 & 650 & Saccharomyces cerevisiae \\
\hline $6 \mathrm{~g}$ & 6 & Bodegas Pedro Casis & -4 & 0 & 650 & Saccharomyces cerevisiae \\
\hline $6 \mathrm{~h}$ & 6 & Bodegas Pedro Casis & -4 & 0 & 650 & Saccharomyces cerevisiae \\
\hline $6 i$ & 6 & Bodegas Pedro Casis & -4 & 0 & 650 & Saccharomyces cerevisiae \\
\hline $6 j$ & 6 & Bodegas Pedro Casis & -4 & 5 & 550 & Metschnikowia aff. fructicola \\
\hline $6 \mathrm{k}$ & 6 & Bodegas Pedro Casis & -4 & 5 & 650 & Saccharomyces cerevisiae \\
\hline
\end{tabular}



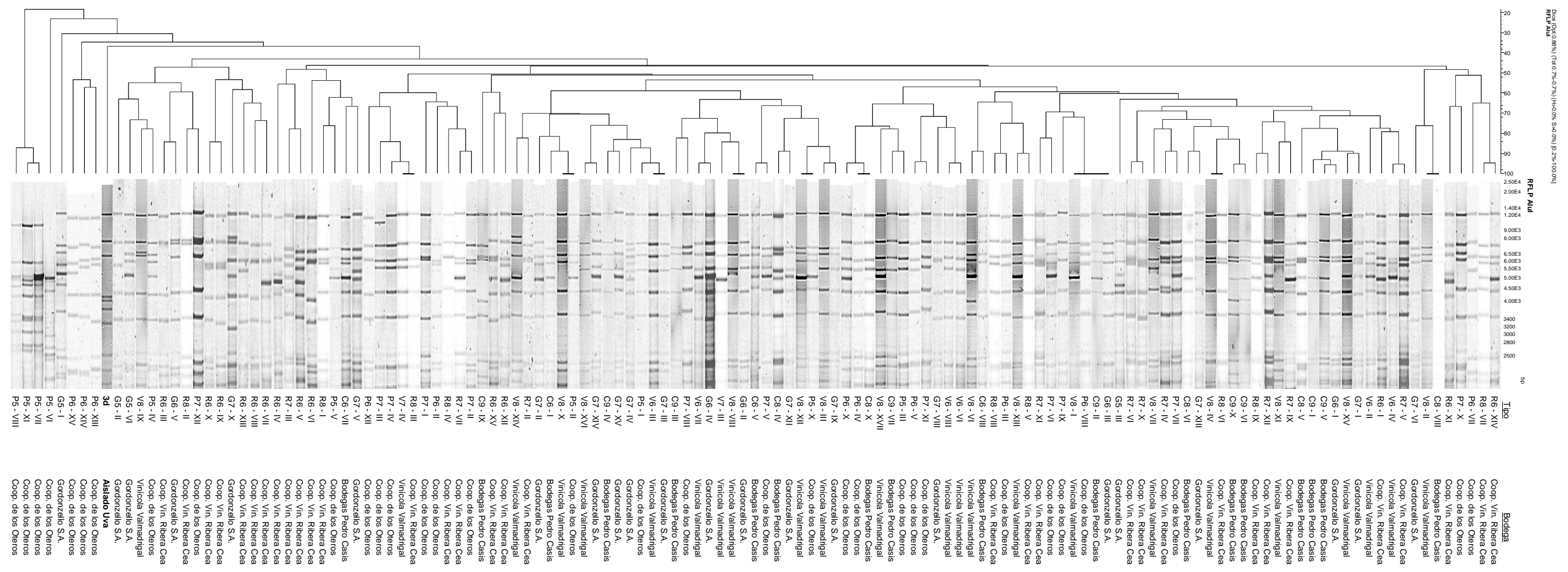

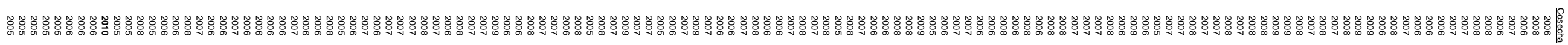

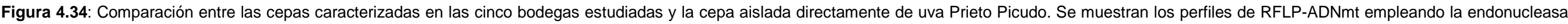

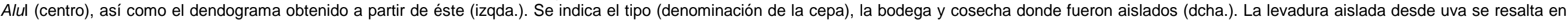
negrita. Se observa como su perfil no coincide con ninguno de los obtenidos hasta el momento. 


\subsection{Caracterización fenotípica y enológica de levaduras vínicas autóctonas de la DO «Tierra de León»}

Una vez realizada la caracterización genética que dio como resultado una colección de 119 cepas de Saccharomyces cerevisiae, decidimos analizar las características fenotípicas y enológicas de una selección de estas cepas. El análisis incluyó desde estudios bioquímicos y fisiológicos, hasta la caracterización de su capacidadsu capacidad para elaboras vinos a pequeña escala (microvinificaciones en el laboratorio).

Realizar todos los estudios que se citarán a continuación para la colección completa de levaduras era ciertamente inviable. Limitaciones de equipamiento y sobre todo de tiempo, precisaron de una preselección de cepas sobre las que se desarrollaría el estudio. Como se ha indicado, el aislamiento y caracterización de levaduras se realizó por triplicado (tres cosechas) para cada bodega, es decir era preciso un periodo mínimo de tres años para tener caracterizada la población correspondiente a una bodega. Las muestras de mosto natural, para cada bodega, fueron tomadas en años diferentes (ver tabla 3.2) existiendo cierto intervalo de tiempo entre el fin del estudio poblacional de diferentes bodegas (por ejemplo para la bodega Gordonzello S.A. se completó el estudio en la cosecha de 2.007 mientras que en la bodega Pedro Casis se dio por finalizada en la cosecha de 2.009). Debido a la limitación temporal en las investigaciones predoctorales se decidió iniciar la caracterización fenotípica y enológica para algunas bodegas previamente a la finalización de la caracterización genética completa para todas ellas.

Como el objetivo final era aislar y caracterizar levaduras autóctonas, el criterio de selección de cepas para este estudio fue el siguiente: se analizaron fenotípicamente y enológicamente las cepas mayoritarias de cada bodega en cada una de las cosechas estudiadas y las coexistentes en más de una cosecha. En total se seleccionaron un total de 30 levaduras diferentes (tabla 4.13) sobre las que se realizaron los diferentes estudios con la intención de conocer su posible capacidad para ser empleadas en procesos de vinificación a nivel industrial.

\subsubsection{Fermentación de fuentes de carbono}

Este tipo de estudios tradicionalmente se han empleado con el objetivo de identificar diferentes especies de levaduras, aunque en nuestro caso pretendíamos conocer su comportamiento nutricional. En la tabla 4.14 se muestran los resultados obtenidos, según la metodología descrita en el apartado 3.10.1, tras probar la capacidad de las cepas de fermentar D-(+)-Galactosa, D-(+)-Glucosa, D-(+)-Lactosa, D-(+)-Maltosa , Melibiosa, D-(+)Rafinosa y Sacarosa. Se consideró un resultado positivo cuando en el tubo de análisis se observaba claramente el gas producido en el proceso fermentativo (gas recogido en campana Durham).

Analizando los resultados, vemos como todas las cepas son capaces de fermentar glucosa, mientras que, por el contrario, ninguna de ellas es capaz de fermentar lactosa y melibiosa. La rafinosa y la sacarosa fueron fermentadas por todas las cepas analizadas excepto la cepa P7XII (Bodega Cooperativa de los Oteros). Resulta llamativo que esta cepa únicamente fue capaz de fermentar la glucosa (uno de los azúcares que se encuentra en mayor proporción en el mosto de uva). La maltosa era fermentada por todas las cepas, salvo G6-V (bodega Gordonzello S.A.) y la ya indicada P7-XII. En lo referente a la galactosa, aunque la mayoría eran capaces de fermentarla, vemos como existe un cierto número de cepas que no presentaron esa capacidad. 
La melibiosa es un disacárido formado por galactosa y glucosa, mientras que la rafinosa es un trisacárido formado por melibiosa y fructosa, o lo que es lo mismo galactosa y sacarosa (glucosa + fructosa). La melibiosa es degradada por el enzima a-galactosidasa para obtener los correspondientes monómeros, mientras que la rafinosa es capaz de dar lugar a melibiosa y fructosa por la acción de la invertasa. Debido a que todas las levaduras dieron positivo en la fermentación de rafinosa, y negativo en la fermentación de melibiosa, podemos indicar que todas las cepas presentaban capacidad invertasa (ya que fermentan la fructosa obtenida), no teniendo capacidad a-galactosidasa.

Tabla 4.13: Levaduras seleccionadas para la realización de la caracterización fenotípica y enológica. Se indica, para cada bodega, la denominación de la levadura e información acerca del motivo por el cual ha sido seleccionada para la caracterización.

\begin{tabular}{|c|c|c|}
\hline Bodega & Levadura & Información \\
\hline \multirow[b]{7}{*}{ Gordonzello S.A. } & G5 - II & Cepa mayoritaria en la cosecha de 2.005 (junto con G5 - III) \\
\hline & G5 - III & Cepa mayoritaria en la cosecha de 2.005 (junto con G5 - II) \\
\hline & G6-V & Cepa mayoritaria en la cosecha de 2.006 \\
\hline & G7 - I & Cepa mayoritaria en la cosehca de 2.007 \\
\hline & & Coexistente en las tres cosechas estudiadas (con G5 - IV y G6 - VI) \\
\hline & G7 - III & Coincidencia con V6 - III (levadura aislada en la bodega Vin. Valmadrigal) \\
\hline & G7 - XIV & Coexistente en dos cosechas (igual a G6 - VII) \\
\hline \multirow[b]{7}{*}{ Coop. de los Oteros } & P5 - I & Cepa mayoritaria en la cosecha de 2.005 \\
\hline & P7. I & Coexistente en dos cosechas (igual a P6 - I) \\
\hline & P7 - II & Coexistente en dos cosechas (igual a P5 - IX) \\
\hline & P7 - III & Coexistente en dos cosechas (igual a P6 - IX) \\
\hline & P7 - VI & Coexistente en dos cosechas (igual a $\mathrm{Pb}-\mathrm{XI}$ ) \\
\hline & P7 - IX & Coexistente en dos cosechas (igual a P6 - VI) \\
\hline & P7 - XII & Cepa mayoritaria en la cosecha de 2.007 \\
\hline \multirow[b]{7}{*}{ Pedro Casis } & & Coexistente en dos cosechas (igual a C6 - VIII) \\
\hline & C8 - VII & Coincidente con V8 - II (levadura aislada en la bodega Vin. Valmadrigal) \\
\hline & C9-I & Cepa mayoritaria y coexistente en las tres cosechas (con C6 - II y C8 - I) \\
\hline & C9- II & $\begin{array}{l}\text { Coexistente en las tres cosechas estudiadas (con C6 - IV y C8 - IX) } \\
\text { Aislada en cuatro de las cinco bodegas estudiadas: Coincidencia con } \\
\text { G6 - III, P6 - VIII y V8 - I (levaduras aisladas en las bodegas Gordonzello S.A., } \\
\text { Coop de los Oteros y Vinicola Valmadrigal, respectivamente) }\end{array}$ \\
\hline & C9-VII & Coexistente en dos cosechas (igual a C6 - III) \\
\hline & C9 - IX & Coexistente en las tres cosechas estudiadas (igual a C6 - VI y C8 - II) \\
\hline & C9-X & Coexistente en dos cosechas (igual a C6 - IX) \\
\hline \multirow[b]{6}{*}{ Coop. Vin. Ribera del Cea } & R6 - I & Cepa mayoritaria en la cosecha de 2.006 \\
\hline & R7 - I & $\begin{array}{l}\text { Cepa mayoritaria en la cosecha de } 2.007 \text { (junto don R7 - II) } \\
\text { Coexistente en dos cosechas (iqual a R8 - IV) }\end{array}$ \\
\hline & R7 - II & Cepa mayoriataria en la cosecha de 2.007 (junto con R7 - I) \\
\hline & R7 - VII & Coexistente en dos cosechas (igual a R6 - II) \\
\hline & R8 - II & Cepa mayoritaria en la cosecha de 2.008 \\
\hline & $\mathrm{R} 8-\mathrm{VI}$ & $\begin{array}{l}\text { Coexistente en dos cosechas (igual a R7 - VIII) } \\
\text { Coincidente con V8 - IV (levadura aislada en la bodega Vinícola Valmadrigal) }\end{array}$ \\
\hline \multirow[b]{5}{*}{ Vinícola Valmadrigal } & V6- II & Cepa mayoritaria en la cosecha de 2.006 \\
\hline & V7 - III & Coexistente en dos cosechas (igual a V6-I) \\
\hline & V8 - III & Coexistente en dos cosechas (igual a V6 - V) \\
\hline & $\mathrm{V} 8 \cdot \mathrm{XV}$ & Coexistente en dos cosechas (igual a V7 - II) \\
\hline & $\mathrm{V} 8-\mathrm{XVII}$ & Coexistente en dos cosechas (igual a V7 - V) \\
\hline
\end{tabular}


Tabla 4.14: Análisis de la fermentación de fuentes de carbono por las cepas seleccionadas. Para cada cepa (izqda., ordenadas por bodegas) se indican las fuentes de carbono (ordenadas alfabéticamente) empleadas en el estudio (arriba). (“-" indica no fermentación; "+" indica fermentación).

\begin{tabular}{|c|c|c|c|c|c|c|c|}
\hline \multirow[b]{2}{*}{ Cepa } & \multicolumn{7}{|c|}{ FUENTES DE CARBONO } \\
\hline & D--Galactosa & D--Glucosa & D--Lactosa & D-Maltosa & Melibiosa & D--Rafinosa & Sacarosa \\
\hline G5 - II & - & + & - & + & - & + & + \\
\hline G5 - III & - & + & - & + & - & + & + \\
\hline G6-V & - & + & - & - & - & + & + \\
\hline G7 - I & - & + & - & + & - & + & + \\
\hline G7 - III & + & + & - & + & - & + & + \\
\hline G7 - XIV & + & + & - & + & - & + & + \\
\hline P5 - I & + & + & - & + & - & + & + \\
\hline P7 - I & + & + & - & + & - & + & + \\
\hline P7 - II & + & + & - & + & - & + & + \\
\hline P7 - III & + & + & - & + & - & + & + \\
\hline P7 - VI & + & + & - & + & - & + & + \\
\hline P7 - IX & + & + & - & + & - & + & + \\
\hline P7 - XII & - & + & - & - & - & - & - \\
\hline C8 - VII & + & + & - & + & - & + & + \\
\hline C9-I & + & + & - & + & - & + & + \\
\hline C9 - II & + & + & - & + & - & + & + \\
\hline C9 - VII & + & + & - & + & - & + & + \\
\hline C9 - IX & + & + & - & + & - & + & + \\
\hline$C 9 \cdot x$ & + & + & - & + & - & + & + \\
\hline R6 - I & - & + & - & + & - & + & + \\
\hline R7 - I & + & + & - & + & - & + & + \\
\hline R7 - II & - & + & - & + & - & + & + \\
\hline R7 - VII & + & + & - & + & - & + & + \\
\hline R8 - II & + & + & - & + & - & + & + \\
\hline $\mathrm{R} 8$ - VI & + & + & - & + & - & + & + \\
\hline V6-II & + & + & - & + & - & + & + \\
\hline V7 - III & + & + & - & + & - & + & + \\
\hline V8 - III & + & + & - & + & - & + & + \\
\hline V8 - XV & - & + & - & + & - & + & + \\
\hline V8 - XVII & + & + & - & + & - & + & + \\
\hline
\end{tabular}

\subsubsection{Asimilación de fuentes de carbono}

La capacidad de asimilar diferentes fuentes de carbono se estudió mediante los kits comerciales Api ${ }^{\circledR} 20 \mathrm{C}$ (Biomérieux) que se han empleado tradicionalmente para identificar las levaduras en función del patrón de fuentes de carbono asimiladas. En nuestro caso esto no tenía mucho sentido, ya que de antemano conocíamos la naturaleza de las levaduras, todas ellas pertenecen a la especie S. cerevisiae. En la tabla 4.15 se muestran los resultados obtenidos.

Resultan llamativos los resultados obtenidos para la cepa P7-XII (aislada en la bodega Cooperativa de los Oteros), ya que esta cepa dio negativo para todos los azúcares ensayados. No podemos descartar que esta cepa asimile algún azúcar aunque con una tasa de asimilación tan baja que no es detectada en el citado test. En los ensayos de fermentación de fuentes de carbono esta cepa únicamente dió resultado positivo cuando era glucosa el azúcar existente en el medio. Por el contrario, la cepa G7-XIV (aislada en la bodega Gordonzello S.A) asimiló la mayoría de las fuentes de carbono que se incluyen como sustrato. 
Este estudio, debido a la diversidad de fuentes de carbono que incluye, podría tener interés de cara a una posible aplicación industrial de las levaduras diferente a la vinificación. Si se detectara que una levadura es capaz de asimilar una fuente de carbono en cuestión, generando algún subproducto de valor añadido, podría ser empleada adicionalmente para este fin.

Tabla 4.15: Estudio de asimilación de fuentes de carbono. Para cada cepa (izqda., ordenadas por bodegas) se indican las fuentes de carbono ensayadas (kit comercial $\mathrm{Api}^{\circledR} 20 \mathrm{C}$ ) que dieron resultado positivo en el ensayo de asimilación. Clave: GLU, D-Glucosa; MAL, D-Maltosa; SAC, D-Sacarosa; GAL, D-Galactosa; GLY, Glicerol; CEL, D-Celobiosa; LAC, D-Lactosa; TRE, D-Trehalosa; MLZ, D-Melezitosa; RAF, D-Rafinosa; 2KG, 2-ceto-gluconato cálcico. ("-“ indica no fermentación; "+" indica fermentación).

\begin{tabular}{|c|c|c|c|c|c|c|c|c|c|c|c|}
\hline \multirow[b]{2}{*}{ Cepa } & \multicolumn{11}{|c|}{ FUENTES DE CARBONO } \\
\hline & GLU & MAL & SAC & GAL & GLY & CEL & LAC & TRE & MLZ & RAF & $2 K G$ \\
\hline G5 - II & + & + & - & - & - & - & - & - & - & - & - \\
\hline G5 - III & + & + & + & - & + & + & + & + & + & + & - \\
\hline G6-V & + & - & + & - & + & - & - & - & - & - & - \\
\hline G7 - I & + & + & + & - & + & - & - & - & - & + & - \\
\hline G7 - III & + & + & + & + & + & + & - & - & - & + & + \\
\hline G7 - XIV & + & + & + & + & + & + & + & + & + & + & - \\
\hline P5 - I & + & + & + & + & + & - & - & - & - & + & - \\
\hline P7 - I & + & + & + & + & + & - & - & - & - & + & - \\
\hline P7 - II & + & - & + & - & - & - & - & - & - & - & - \\
\hline P7 - III & + & + & + & + & + & - & - & - & - & + & - \\
\hline P7 - VI & + & + & + & + & + & - & - & - & - & + & - \\
\hline P7 - IX & + & + & + & + & + & - & - & - & - & + & - \\
\hline P7 - XII & - & - & - & - & - & - & - & - & - & - & - \\
\hline C8 - VII & + & + & + & + & - & - & - & - & - & + & - \\
\hline C9 - I & + & + & + & + & - & - & - & - & - & + & - \\
\hline C9 - II & + & + & + & + & - & + & - & - & - & + & - \\
\hline C9 - VII & + & + & + & + & - & - & - & - & - & - & - \\
\hline C9 - IX & + & + & + & + & - & - & - & - & - & - & + \\
\hline C9 - X & + & - & - & - & - & - & - & - & - & - & - \\
\hline R6 - I & + & + & + & - & - & - & - & - & - & + & - \\
\hline R7 - I & + & + & + & + & + & - & - & - & - & + & - \\
\hline R7 - II & + & + & + & - & - & - & - & - & - & + & - \\
\hline R7 - VII & + & + & + & - & + & - & - & - & - & + & - \\
\hline R8 - II & + & + & + & + & - & - & - & - & - & + & - \\
\hline R8 - VI & + & + & + & + & - & - & - & - & - & + & - \\
\hline V6 - II & + & + & + & + & - & - & - & - & - & + & - \\
\hline V7 - III & + & + & + & + & + & - & - & - & - & + & - \\
\hline V8 - III & + & + & + & + & - & - & - & - & - & + & - \\
\hline V8 - XV & + & + & + & - & - & - & - & - & - & + & - \\
\hline V8 - XVII & + & + & + & + & - & - & - & - & - & + & - \\
\hline
\end{tabular}

\subsubsection{Capacidad fermentativa (Método Rebelein)}

El seguimiento del proceso fermentativo mediante la medida de los azúcares residuales nos permitió construir unas curvas donde se representaba el porcentaje de azúcares consumidos frente al tiempo empleado (ver apartado 3.10.3). Esa curva se ajusta matemáticamente (mediante la ecuación de Gompertz Reparametrizada), obteniendo tres parámetros que nos describirán el comportamiento de cada una de las levaduras: A' (asíntota superior) nos indica el porcentaje máximo de azúcares consumido, m’ (pendiente máxima) nos dará información acerca de la velocidad máxima de fermentación, y l' (tiempo de latencia) indica el tiempo que tarda en arrancar el proceso fermentativo. 
Los resultados de este estudio se presentan en la tabla 4.16. Como se puede observar los valores del porcentaje de azúcares consumidos son muy cercanos al valor máximo (incluso algunos superan el $100 \%$, debido a que estos valores provienen del ajuste matemático de valores experimentales), no aportando gran información sobre el comportamiento de la levadura en cuestión. En cuanto al tiempo de latencia (l'), se observa una mayor variabilidad, pero no es un dato concluyente. Se podría descartar, atendiendo a este parámetro, aquella cepa que presentara un valor elevado: una cepa empleada como iniciadora de fermentación que presentara este comportamiento podría tener dificultad para imponerse sobre la población autóctona de la bodega y por tanto no ser la encargada de dirigir el proceso.

El parámetro que nos proporciona mayor información sobre el comportamiento de la levadura será la pendiente máxima de la curva obtenida (m'): a mayor pendiente mayor capacidad fermentativa. Destacar las cepas G7-XIV (aislada en la bodega Gordonzello S.A.), C9-I (aislada en la bodega Pedro Casis) y la C9-II (aislada en cuatro de las cinco bodegas estudiadas, ver figura 4.30) que presentaron los valores más elevados, siendo las únicas capaces de superar la barrera de los 4 gramos por litro y por hora (negrita). De entre estas últimas cabe destacar la cepa C9-I cuyo valor superó en gran medida al resto, poniendo de manifiesto su gran capacidad fermentativa.

Tabla 4.16: Estudio de la capacidad fermentativa (Método Rebelein). Se muestran, para cada cepa, los valores obtenidos del ajuste matemático (Ec. Gompertz Rep.) de las curvas experimentales obtenidas. Aparecen resaltados en negrita los valores más elevados de m', mientras que en cursiva se indica, para cada bodega, el mayor valor obtenido.

\begin{tabular}{l|l|lll}
\hline \multicolumn{1}{l}{ Bodega } & \multicolumn{1}{c}{ Cepa } & \multicolumn{1}{c}{$\mathrm{A}^{\prime}$} & \multicolumn{1}{c}{$\mathrm{m}^{\prime}(\mathrm{g} / \mathrm{l} \cdot \mathrm{h})$} & \multicolumn{1}{c}{$\mathrm{I}^{\prime}(\mathrm{h})$} \\
\hline & G5 - II & 99,433 & 3,868 & 21,178 \\
& G5 - III & 99,442 & 2,664 & 20,376 \\
& G6 - V & 100,768 & 3,226 & 22,069 \\
& G7 - I & 98,922 & 3,483 & 21,687 \\
& G7 - III & 99,114 & 2,737 & 15,978 \\
& G7 - XIV & 100,075 & $\mathbf{4 , 2 7 2}$ & 16,931 \\
\hline \multirow{5}{*}{ Gordonzello S.A. } & P5 - I & 99,565 & 2,996 & 16,004 \\
& P7 - I & 100,253 & 3,224 & 17,356 \\
& P7 - II & 99,984 & 3,138 & 19,540 \\
& P7 - III & 100,995 & 3,016 & 16,401 \\
& P7 - VI & 99,621 & 3,654 & 15,804 \\
& P7 - IX & 99,948 & 3,282 & 16,676 \\
& P7 - XII & 100,557 & 3,369 & 23,424 \\
\hline & C8 - VII & 97,496 & 3,640 & 23,690 \\
& C9 - I & 97,917 & $\mathbf{5 , 5 0 8}$ & 23,178 \\
& C9 - II & 97,935 & $\mathbf{4 , 7 9 8}$ & 19,466 \\
& C9 - VII & 97,894 & 3,763 & 18,826 \\
& C9 - IX & 98,580 & 3,681 & 19,803 \\
& C9 - X & 99,658 & 3,100 & 22,839 \\
\hline & R6 - I & 95,143 & 2,947 & 14,320 \\
& R7 - I & 94,918 & 3,438 & 16,149 \\
& R7 - II & 95,454 & 2,934 & 17,689 \\
& R7 - VII & 95,485 & 3,175 & 14,926 \\
& R8 - II & 96,039 & 3,894 & 19,234 \\
& R8 - VI & 95,108 & 3,308 & 16,520 \\
\hline & V6 - II & 101,116 & 3,001 & 11,078 \\
& V7 - III & 100,444 & 3,814 & 12,981 \\
& V8 - III & 100,792 & 2,843 & 11,456 \\
& V8 - XV & 99,773 & 3,619 & 15,610 \\
& V8 - XVIII & 99,292 & 3,995 & 14,071 \\
\hline & & & &
\end{tabular}




\subsubsection{Tolerancia al etanol}

Según se ha descrito en el apartado 3.10.4 se procedió a estimar la tolerancia al etanol de las levaduras seleccionadas. La estimación de la capacidad de soportar etanol se hará en relación al modelo propuesto por Lambert y Pearson (2000) a través de dos parámetros: MIC (concentración mínima inhibitoria) y NIC (concentración no inhibitoria), siguiendo la metodología propuesta por Arroyo-López et al. (2010). Valores de etanol superiores al MIC impiden el crecimiento de la levadura, mientras que las concentraciones de etanol comprendidas entre el NIC y el MIC no reprimen su crecimiento aunque su desarrollo se ve afectado. Por debajo del NIC, el etanol no interfiere en el normal desarrollo de la levadura (figura 3.4).

En la tabla 4.17 se muestran los resultados obtenidos para cada una de las levaduras sometidas a dicho ensayo. Se indican tanto los valores del MIC como del NIC.

Tabla 4.17: Estudio de la tolerancia al etanol sobre las cepas seleccionadas. Para cada cepa (izquierda) se indican los valores de MIC (concentración mínima inhibitoria) y NIC (concentración no inhibitoria) tanto en g/L como en porcentaje de volumen (\% vol.). Los valores acompañados con letras diferentes (minúsculas para el MIC y mayúsculas para el NIC) son significativamente diferentes de acuerdo a los resultados obtenidos a partir de un análisis ANOVA $(P<0,05)$.

\begin{tabular}{|c|c|c|c|c|c|}
\hline Bodega & Cepa & $\mathrm{MIC}(\mathrm{g} / \mathrm{L})$ & MIC (\% vol.) & $\mathrm{NIC}(\mathrm{g} / \mathrm{L})$ & NIC (\% vol.) \\
\hline \multirow[b]{6}{*}{ Gordonzello S.A. } & G5 - II & 118,06 efghi & $15,10^{\text {efghi }}$ & $76,03 \mathrm{FGHI}$ & $9,72^{\mathrm{FGHI}}$ \\
\hline & G5 - III & 101,24 bcdefgh & 12,95 bcdefgh & $81,96 \mathrm{HI}$ & $10,48^{H I}$ \\
\hline & G6 - V & $122,14 \mathrm{ghi}$ & $15,62 \mathrm{ghi}$ & 65,79 CDEFG & 8,41 CDEFG \\
\hline & G7 - I & $102,52^{\text {cdefghi }}$ & 13,11 cdefghi & $77,39 \mathrm{GHI}$ & $9,90 \mathrm{GHI}$ \\
\hline & G7 - III & 107,59 defghi & $13,76^{\text {defghi }}$ & $70,18^{D E F G}$ & 8,97 DEFG \\
\hline & G7 - XIV & $121,62 \mathrm{hi}$ & $15,55 h i$ & 63,96 CDEF & $8,18^{C D E F}$ \\
\hline \multirow[b]{7}{*}{ Coop. de los Oteros } & P5 - I & $123,82^{i}$ & $15,83^{i}$ & 71,30 DEFGH & $9,12^{D E F G H}$ \\
\hline & P7 - I & 104,67 defghi & 13,38 defghi & $76,44^{\mathrm{GHI}}$ & $9,77 \mathrm{GHI}$ \\
\hline & P7 - II & 100,39 cdefghi & $12,84^{\text {cdefghi }}$ & $77,19 \mathrm{GHI}$ & $9,87 \mathrm{GHI}$ \\
\hline & P7 - III & $115,66^{\text {defghi }}$ & 14,79 defghi & 69,02 FGH & $8,83{ }^{F G H}$ \\
\hline & P7 - VI & 121,31 efghi & 15,51 efghi & $70,32 \mathrm{EFGH}$ & $8,99 \mathrm{EFGH}$ \\
\hline & P7 - IX & $125,42 \mathrm{ghi}$ & $16,04 \mathrm{ghi}$ & $69,92 \mathrm{FGH}$ & $8,94^{F G H}$ \\
\hline & P7 - XII & 121,03 efghi & 15,48 efghi & $71,67 \mathrm{FGH}$ & $9,17 \mathrm{FGH}$ \\
\hline \multirow[b]{6}{*}{ Bodegas Pedro Casis } & C8 - VII & $85,40^{a b c}$ & $10,92 a b c$ & 64,63 CDEFG & $8,27^{C D E F G}$ \\
\hline & C9 - I & 98,29 abcdef & 12,57 abcdef & 70,07 DEFG & $8,96^{D E F G}$ \\
\hline & C9 - II & $102,45^{\text {cdefgh }}$ & $13,10^{\text {cdefgh }}$ & $62,72 B C D E$ & $8,02 B C D E$ \\
\hline & C9 - VII & 108,10 defghi & 13,82 defghi & $60,94^{B C D}$ & $7,79 B C D$ \\
\hline & C9 - IX & $80,78 a b$ & $10,33 a b$ & $57,44^{B C}$ & $7,35 B C$ \\
\hline & C9 - X & $81,56^{a}$ & $10,43^{a}$ & $42,42^{A}$ & $5,42^{A}$ \\
\hline \multirow[b]{6}{*}{ Coop. Vin. Ribera Cea } & R6 - I & 99,60 bcdef & 12,74 bcdef & $54,23^{B}$ & $6,93^{B}$ \\
\hline & R7 - I & 100,25 bcdefg & 12,82 bcdefg & $54,34^{B}$ & $6,95^{B}$ \\
\hline & R7 - II & $105,16^{\text {cdefghi }}$ & 13,45 cdefghi & $61,27 B C D$ & $7,83 B C D$ \\
\hline & R7 - VII & 125,41 fghi & 16,04 fghi & $83,10^{\prime}$ & $10,63^{\prime}$ \\
\hline & R8 - II & $121,71 \mathrm{hi}$ & $15,56 h i$ & $77,16^{\mathrm{FGHI}}$ & $9,87^{F G H I}$ \\
\hline & $\mathrm{R} 8-\mathrm{VI}$ & $122,01 \mathrm{hi}$ & $15,60^{h i}$ & $86,08^{\prime}$ & 11,01 \\
\hline \multirow[b]{5}{*}{ Vinícola Valmadrigal } & V6 - II & 101,71 bcdefgh & 13,01 bcdefgh & $81,79^{\mathrm{HI}}$ & $10,46^{H I}$ \\
\hline & V7 - III & 120,22 defghi & 15,37 defghi & 63,88 DEFGH & $8,17^{D E F G H}$ \\
\hline & V8 - III & 114,31 efghi & 14,62 efghi & 68,67 CDEFG & 8,78 CDEFG \\
\hline & V8 - XV & 94,53 abcd & 12,09 abcd & $65,34^{D E F G}$ & $8,36^{D E F G}$ \\
\hline & V8 - XVII & $97,84^{\text {abcde }}$ & 12,51 abcde & 66,09 CDEFG & $8,45^{C D E F G}$ \\
\hline
\end{tabular}

Mediante observación directa de los datos mostrados en la tabla 4.17 resulta complicado realizar un análisis del comportamiento de la levadura en entornos con etanol. Sin embargo si 
representamos los datos experimentales para cada una de las cepas en un diagrama de barras, donde sus extremos sean los valores NIC y MIC, el intervalo de concentraciones de etanol donde el normal desarrollo de la levadura se ve afectado quedará perfectamente identificado, facilitadandose de esta manera enormemente el análisis y comparación de los resultados obtenidos (figura 4.35 ).

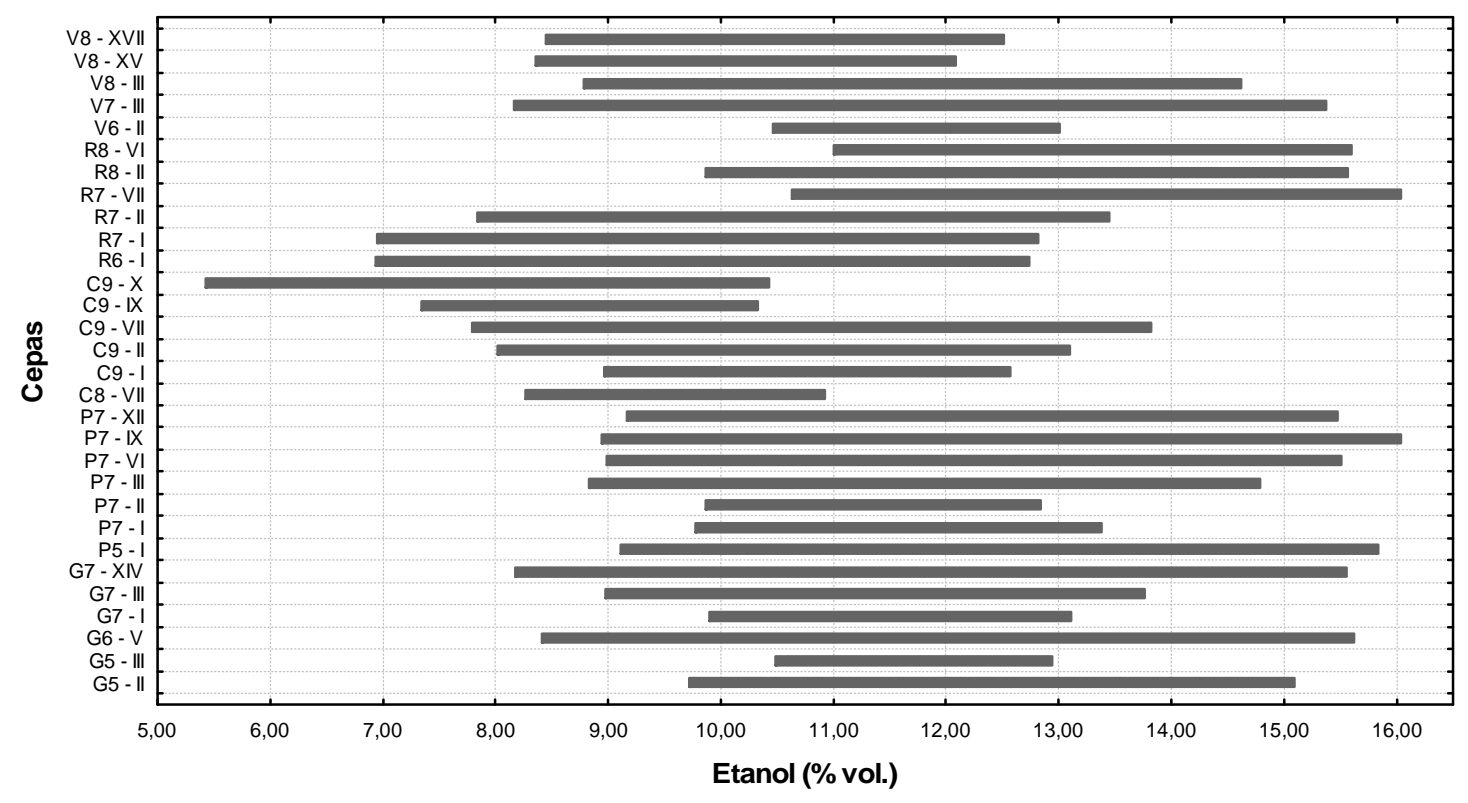

Figura 4.35: Representación gráfica de la tolerancia al etanol de las cepas seleccionadas. Se representa en forma de barra el intervalo de concentraciones de etanol donde se produce una alteración en el desarrollo de la levadura (inhibición en el crecimiento). El extremo izquierdo de cada barra corresponde al valor experimental del NIC, mientras que el derecho al valor MIC.

Analizando los datos obtenidos, desde la tabla o desde el gráfico, vemos que existen comportamientos muy dispares. En un extremo estaría la cepa C9-X (bodega Pedro Casis) que resultó ser poco alcohol-tolerante (MIC de 10,43 \% vol.), además de presentar un amplio intervalo de concentraciones de etanol que afectarían a su normal desarrollo. En el lado opuesto nos encontramos las cepas P5-I, P7-IX y R7-VII con una aparente gran tolerancia al etanol (valores MIC cercanos a $16 \%$ vol.) aunque, al igual que en el caso anterior, muestran un amplio rango de concentraciones donde su crecimiento se vería afectado. Entre ambos ejemplos existen gran cantidad de comportamientos intermedios.

Para algunas cepas se observan valores del MIC cercanos al $16 \%$ vol., que nos aseguran su gran adaptación a medios donde el etanol se encuentra en alta proporción. Quizás no sea tan importante la máxima concentración tolerable por una cepa en cuestión, sino que el intervalo donde se ve afectado su normal desarrollo sea lo menor posible. Hay que recordar que en el diseño de este experimento la levadura es inoculada en un medio que previamente contiene etanol, debiendo desarrollarse en éste. En una fermentación, el etanol es producido por la propia levadura y por tanto existirá una adaptación progresiva. Así, es conocida la capacidad de las levaduras para responder de modo gradual al estrés causado por el etanol, aumentando progresivamente su tolerancia. Son varios los autores que indican que la composición del medio (aminoácidos, lípidos, etc.) puede contribuir a la resistencia de las levaduras al etanol (Ding et al., 2009).

Algo que nos pareció llamativo fueron los altos niveles soportados por algunas cepas en relación al resto. Se consideró la posibilidad de que estas fueran capaces de respirar el etanol 
del medio, aunque por observación de las curvas de crecimiento no se pudo determinar esta posibilidad (crecimiento diaúxico). Como se ha indicado (apartado 1.5.4) S. cerevisiae presenta una mejor adaptación a los entornos con etanol por la adquisición de una nueva y modificada enzima, Adh2 (tras un proceso de duplicación que data de hace unos 80 millones de años), que presenta gran afinidad por el etanol y puede producir su respiración (Piskur et al. 2006; Thomson et al. 2005).

Este experimento también nos aporta una idea acerca del comportamiento de la levadura en fermentación. Las diferencias encontradas, dentro de cepas pertenecientes a la misma especie (S. cerevisiae) abren la posibilidad de emplear distintas cepas para obtener vinos con diferentes graduaciones alcohólicas, en un momento en el que la tendencia del mercado actual va en la dirección de los vinos con una menor graduación alcohólica.

\subsubsection{Crecimiento a bajas temperaturas}

Este estudió nos permitió predecir el comportamiento de las cepas seleccionadas en condiciones de baja temperatura. Este aspecto es de gran interés ya que los vinos elaborados a bajas temperaturas presentan unos perfiles aromáticos más intensos y con mayor complejidad, hecho especialmente interesante para la DO «Tierra de León» cuyas bodegas tienen una amplia tradición en la elaboración de vinos rosados muy aromáticos.

Siguiendo el diseñor experimental indicado en el apartado 3.10 .5 se obtuvieron las curvas de crecimiento (por triplicado) de cada una de las cepas. Tras la normalización de las curvas (figura 3.6) se procedió a su ajuste matemático (ecuación de Gompertz Repam.). De este ajuste se obtuvieron varios parámetros, aunque únicamente la pendiente máxima ( $\left.\mathbf{m}^{\prime \prime}\right)$ de la curva nos sirvió para discriminar entre las diferentes cepas. En la tabla 4.18 aparecen los resultados obtenidos en este estudio. El valor medio del parámetro m" para todas las cepas analizadas es de $0,128 \mathrm{~h}^{-1}$, de manera que aquellas cepas que mostraron unos valores superiores a dicho valor medio estarán mejor adaptadas para un crecimiento a bajas temperaturas.

Como se deduce de la tabla 4.18 se detectaron diferencias notables en el crecimiento, hasta el punto que el mayor de m" obtenido (R8-VI, bodega Coop. Vin. Ribera del Cea) es más del doble del más pequeño detectado (P7-XII, bodega Coop. de los Oteros). En la bodega Gordonzello S.A. destacaba la cepa G7-XIV frente al resto $\left(m^{\prime \prime}=0,161 \mathrm{~h}^{-1}\right)$ ya que además presenta una gran tolerancia al etanol en el medio (tabla 4.17 y figura 4.18). En la bodega Coop. de los Oteros el comportamiento de las cepas es muy parecido, salvo la cepa P7-XII ya indicada. En la bodega Pedro Casis destaca la gran adaptación a las bajas temperaturas de la cepa C9-I $\left(\mathrm{m}^{\prime \prime}=0,131 \mathrm{~h}^{-1}\right)$ en relación al resto de levaduras aisladas en la citada bodega. En la bodega Coop. Vin. Ribera del Cea destacaba la cepa R8-VI, resultando, como se ha indicado, la cepa mejor adaptada a entornos de baja temperatura (valor de m" de 0,179 $\mathrm{h}^{-1}$ ). Los resultados obtenidos con todas las cepas aisladas de la bodega Vinícola Valmadrigal resultan llamativos por su proximidad, además de presentar unos valores muy aceptables y superiores a la media. 
Tabla 4.18: Estudio de crecimiento de las cepas seleccionadas a bajas temperaturas. Se indica para cada una de las cepas (centro), seleccionadas en las diferentes bodegas (izqda.), los valores de la pendiente máxima de las curvas normalizadas (dcha.). Para cada bodega se indica en cursiva, la cepa que mostró una mejor adaptación. Los valores acompañados con letras diferentes son significativamente diferentes de acuerdos a los resultados obtenidos a partir de un análisis ANOVA $(P<0,05)$.

\begin{tabular}{|c|c|c|}
\hline Bodega & Cepa & Pendiente máxima, $\mathbf{m}^{\prime \prime}\left(h^{-1}\right)$ \\
\hline \multirow[b]{6}{*}{ Gordonzello S.A. } & G5 - II & $0,082^{a}$ \\
\hline & G5 - III & $0,145 \mathrm{klm}$ \\
\hline & G6-V & $0,107 \mathrm{~cd}$ \\
\hline & G7 - I & $0,152 \operatorname{lmn}$ \\
\hline & G7 - III & $0,139 i k$ \\
\hline & G7 - XIV & $0,161^{n}$ \\
\hline \multirow[b]{7}{*}{ Cooperativa de los Oteros } & P5 - I & $0,113^{\text {cde }}$ \\
\hline & P7 - I & $0,107 c d$ \\
\hline & P7 - ॥ & 0,124 efgh \\
\hline & P7 - III & $0,105^{c}$ \\
\hline & P7 - VI & $0,124^{\text {efgh }}$ \\
\hline & P7 - IX & 0,123 efg \\
\hline & P7 - XII & $0,074^{a}$ \\
\hline \multirow[b]{6}{*}{ Bodegas Pedro Casis } & $\mathrm{C} 8-\mathrm{VII}$ & 0,121 ef \\
\hline & C9-I & 0,133 ghii \\
\hline & C9 - II & 0,118 def \\
\hline & C9 - VII & $0,115^{\text {cdef }}$ \\
\hline & C9 - IX & $0,126^{f g h i}$ \\
\hline & $C 9-x$ & $0,093^{b}$ \\
\hline \multirow[b]{6}{*}{ Cooperativa Vinícola Ribera del Cea } & R6-I & $0,145^{\mathrm{klm}}$ \\
\hline & R7 - I & $0,156^{m n}$ \\
\hline & R7 - II & 0,122 efg \\
\hline & R7 - VII & $0,145^{\mathrm{km}}$ \\
\hline & R8 - II & $0,136 i j k$ \\
\hline & $\mathrm{R} 8-\mathrm{VI}$ & $0,174^{\circ}$ \\
\hline \multirow[b]{5}{*}{ Vinícola Valmadrigal } & V6 - II & $0,138^{i k}$ \\
\hline & V7 - III & $0,139 i k$ \\
\hline & V8 - III & $0,142^{i k l}$ \\
\hline & $\mathrm{V} 8-\mathrm{XV}$ & 0,135 hijk \\
\hline & V8 - XVII & $0,137 i j k$ \\
\hline
\end{tabular}

\subsubsection{Estudio del carácter "killer"}

El caracter "killer" de las cepas seleccionadas se analizó tal como se indica en el apartado 3.10.6. Por una parte, se estudió su capacidad de producir diferentes tóxinas capaces de "matar" a las levaduras que presenten sensibilidad a éstas; por otro, si alguna de las cepas seleccionadas presentaba sensibilidad a ciertas toxinas (se han estudiado las toxina K1, K2, K28 y Klus). Esto se hizo mediante dos diseños experimentales direrentes, aunque complementarios entre sí: ensayos en placa y mediante el estudio del material genético asociado al carácter "killer".

Ya que uno de los principales objetivos del presente trabajo sería el posible uso industrial de alguna de las cepas aisladas y caracterizadas como iniciadores de fermentación, dichas cepas deben de cumplir, en relación al carácter "killer", al menos una de las siguientes características: 
- Presentar carácter killer: asegura la imposición sobre cepas que presenten sensibilidad a dicha toxina.

- No resultar sensible a ninguna de las toxinas descritas: por tanto no sucumbirán ante ninguna cepa autóctona por este motivo.

\subsubsection{Ensayo en placa del carácter "killer"}

El carácter "killer" de las cepas seleccionadas se estudió respecto a dos cepas sensibles $\left(\mathrm{K}_{0}\right)$ : la cepa $5 X 47$ y la cepa EX33 (libre de partículas de ARN de origen vírico). Para estudiar la posible sensibilidad de nuestras cepas se emplearon las siguientes cepas: 1101 (productora de la tóxina K1); EX73 (productora de la toxina K2) y EX198 (productora de la toxina Klus); E182 (productora de la toxina K28). Recordar que entre las anteriores toxinas "killer", la tóxina K2 es la que juega un papel más importante en vinificación.

Los resultados obtenidos según la metodología descrita en el apartado 3.10.6.1 se indican en la tabla 4.19, proporcionándonos información acerca de la adecuación de las diferentes cepas para ser usadas en procesos fermentativos.

De las 30 cepas ensayadas únicamente 13 resultaron interesantes de acuerdo a su carácter "killer". Serán aquellas que presenten un carácter matador (concretamente K2), o bien, no presentando carácter matador, no presenten sensibilidad respecto a las cepas matadoras estudiadas (productoras de las toxinas K1, K2, K28 y Klus).

Si nos centramos en el conjunto de 13 cepas con un comportamiento adecuado (fenotipo K2 o no sensible), se observan dos grupos bien diferenciados. Por un lado, el grupo mayoritario incluiría 11 cepas que presentan capacidad matadora y a su vez son sensibles a la toxina K1. Las cepas productoras de toxinas $\mathrm{K} 1$ y K2 se matan mutuamente, por tanto queda claro el carácter killer K2 de éstas. En el otro grupo estarían las cepas G7-III (bodega Gordonzello S.A.) y P5-I (bodega Coop. de los Oteros) que no presentan carácter "killer" pero resultan insensibles a cualquiera de las tóxinas ensayadas. Por tanto estaríamos frente a dos cepas no sensibles.

Las cepas no recomendadas, de acuerdo a estos resultados, presentan dos tipos de comportamiento. En un grupo se encuentran las cepas sensibles (a la toxinas K1 y K2 principalmente), que no poseen "killer". En otro se encuentran las cepas que resultarón ser multisensibles a todas las toxinas ensayadas. Por tanto, estas cepas no se podrían emplear, a priori, como iniciadores de fermentación, ya que existiría el riesgo de imposición no deseada de alguna cepa autóctona con carácter killer.

Indicar que los resultados negativos obtenidos, en la mayoría de los casos, para las cepas productoras de las toxinas $\mathrm{K} 28$ y Klus pueden ser debidas a las condiciones experimentales. Estas iban encaminadas a discernir el carácter "killer" en relación a las dos tóxinas con mayor importancia, K1 y K2 (predominante en vinos).

En la figura 4.36 se muestran, a modo de ejemplo, los resultados obtenidos en los ensayos en placa para la bodega Cooperativa de los Oteros. En las cepas aisladas y caracterizadas en dicha bodega se obtuvieron todos los comportamientos reseñados anteriormente. 


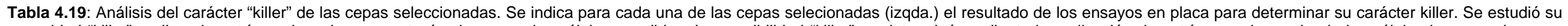

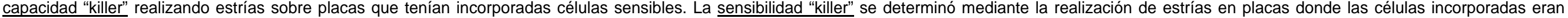
aquellas a ensayar. Se indica el resultado global del estudio, así como su viabilidad en los procesos de vinificación.

\begin{tabular}{|c|c|c|c|c|c|c|c|c|c|}
\hline \multirow[b]{2}{*}{ Bodega } & \multirow[b]{2}{*}{ Cepa } & & \multicolumn{4}{|c|}{ Sensibilidad "killer" } & \multirow[b]{2}{*}{ RESULTADO } & \multirow[b]{2}{*}{ Adecuada } \\
\hline & & $5 \times 47\left(K_{0}\right)$ & EX33 $\left(K_{0}\right)$ & $1101(\mathrm{~K} 1)$ & EX73 (K2) & F182 (K28) & EX198 (Klus) & & \\
\hline & G5 - II & $\mathrm{NO}$ & $\mathrm{NO}$ & $\mathrm{SI}$ & $\mathrm{SI}$ & NO & NO & Cepa sensible K1 y K2. & $\mathrm{NO}$ \\
\hline & G5 - III & $\mathrm{SI}$ & $\mathrm{SI}$ & $\mathrm{SI}$ & NO & NO & NO & Presenta carácter killer y es sensible a K1. Cepa K2. & SI \\
\hline & G6-V & NO & NO & $\mathrm{SI}$ & $\mathrm{SI}$ & NO & NO & Cepa sensible $\mathrm{K} 1$ y K2. & NO \\
\hline & G7 - I & SI & SI & $\mathrm{SI}$ & NO & NO & NO & Presenta carácter killer y es sensible a K1. Cepa K2. & SI \\
\hline & G7 - III & NO & NO & NO & NO & NO & NO* & Cepa no sensible. & SI \\
\hline \multirow[t]{7}{*}{ Gordonzello S.A. } & G7 - XIV & $\mathrm{SI}$ & $\mathrm{SI}$ & $\mathrm{SI}$ & NO & NO & NO* & Presenta carácter killer y es sensible a K1. Cepa K2. & SI \\
\hline & P5 - I & NO & NO & NO & NO & NO & NO & Cepa no sensible. & SI \\
\hline & P7 - I & NO & NO & $\mathrm{SI}$ & $\mathrm{SI}$ & $\mathrm{SI}{ }^{*}$ & NO* & Cepa multisensible. No recomendada. Mayor halo en césped K2. & NO \\
\hline & P7 - II & NO & NO & SI & $\mathrm{SI}$ & NO & NO & Cepa sensible K1 y K2. & NO \\
\hline & P7 - III & NO & NO & $\mathrm{SI}$ & $\mathrm{SI}$ & NO & NO & Cepa sensible K1 y K2. & NO \\
\hline & $\mathrm{P} 7 \cdot \mathrm{Vl}$ & $\mathrm{SI}$ & SI & $\mathrm{SI}$ & NO & NO & NO & Presenta carácter killer y es sensible a K1. Cepa K2. & SI \\
\hline & P7 - IX & NO & NO & $\mathrm{SI}$ & SI & NO & NO & Cepa sensible $\mathrm{K} 1$ y K2. & NO \\
\hline \multirow[t]{6}{*}{ Coop. de los Oteros } & P7 - XII & NO & NO & $\mathrm{SI}$ & $\mathrm{SI}$ & $\mathrm{SI}$ & $\mathrm{SI}$ & Cepa multisensible. No recomendada. Mayor halo en césped K2. & NO \\
\hline & $\mathrm{C} 8 \cdot \mathrm{VII}$ & NO & $\mathrm{NO}$ & $\mathrm{SI}$ & $\mathrm{SI}$ & NO & NO* & Cepa sensible K1, K2 y posiblemente Klus. & $\mathrm{NO}$ \\
\hline & C9-I & SI & SI & SI & NO & NO & NO & Presenta carácter killer y en sensible a K1. Cepa K2. & SI \\
\hline & C9-II & $\mathrm{SI}$ & SI & $\mathrm{SI}$ & $\mathrm{SI}$ & NO & NO & Presenta carácter killer, aunque es sensible a K1 y K2. & NO \\
\hline & C9 - VII & NO & NO & $\mathrm{SI}$ & $\mathrm{SI}$ & NO & NO & Cepa sensible $\mathrm{K} 1$ y $\mathrm{K} 2$. & NO \\
\hline & C9 - IX & $\mathrm{SI}$ & $\mathrm{SI}$ & $\mathrm{SI}$ & NO & NO & NO & Presenta carácter killer y es sensible a K1. Cepa K2. & SI \\
\hline \multirow[t]{6}{*}{ Bodegas Pedro Casis } & $\mathrm{C9} \cdot \mathrm{X}$ & $\mathrm{SI}$ & $\mathrm{SI}$ & $\mathrm{SI}$ & NO & NO & NO & Presenta carácter killer y es sensible a K1. Cepa K2. & SI \\
\hline & R6-I & NO & NO & $\mathrm{SI}$ & $\mathrm{SI}$ & NO & NO & Cepa sensible $\mathrm{K} 1$ y K2. & NO \\
\hline & R7 - I & NO & NO & $\mathrm{SI}$ & SI & NO & NO & Cepa sensible $\mathrm{K} 1$ y K2. & NO \\
\hline & R7 - II & NO & NO & $\mathrm{SI}$ & $\mathrm{SI}$ & NO & NO & Cepa sensible $\mathrm{K} 1$ y K2. & NO \\
\hline & R7 - VII & NO & NO & $\mathrm{SI}$ & $\mathrm{SI}$ & NO & NO & Cepa sensible K1 y K2. & NO \\
\hline & R8 - II & NO & NO & $\mathrm{SI}$ & $\mathrm{SI}$ & NO & NO & Cepa sensible K1 y K2. & NO \\
\hline \multirow[t]{5}{*}{ Coop. Vin. Ribera Cea } & $\mathrm{R} 8-\mathrm{VI}$ & NO & NO & $\mathrm{SI}$ & $\mathrm{SI}$ & NO & NO & Cepa sensible $\mathrm{K} 1$ y $\mathrm{K} 2$. & NO \\
\hline & V6-II & $\mathrm{SI}$ & $\mathrm{SI}$ & $\mathrm{SI}$ & NO & NO & NO & Presenta carácter killer y es sensible a K1. Cepa K2. & SI \\
\hline & V7 - III & $\mathrm{SI}$ & SI & $\mathrm{SI}$ & NO & NO & NO & Presenta carácter killer y es sensible a K1. Es cepa K2. & SI \\
\hline & V8 - III & NO & NO & $\mathrm{SI}$ & SI & NO & NO & Cepa sensible K1 y K2. & NO \\
\hline & $\mathrm{V} 8-\mathrm{XV}$ & $\mathrm{SI}$ & $\mathrm{SI}$ & $\mathrm{SI}$ & NO & NO & NO & Presenta carácter killer y es sensible a K1. Cepa K2. & SI \\
\hline Vinícola Valmadrigal & $\mathrm{V} 8-\mathrm{XVII}$ & $\mathrm{SI}$ & $\mathrm{SI}$ & $\mathrm{SI}$ & NO & NO & NO & Presenta carácter killer y es sensible a K1. Cepa K2. & SI \\
\hline
\end{tabular}


A

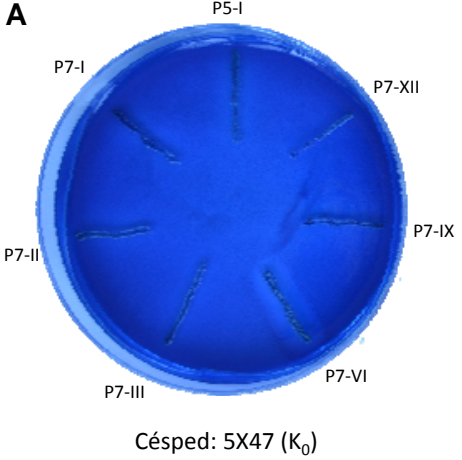

B

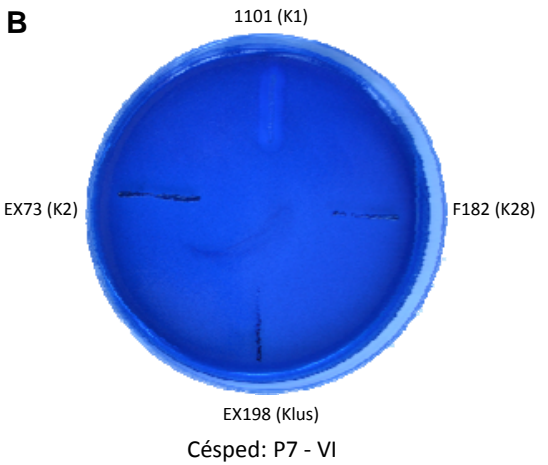

C

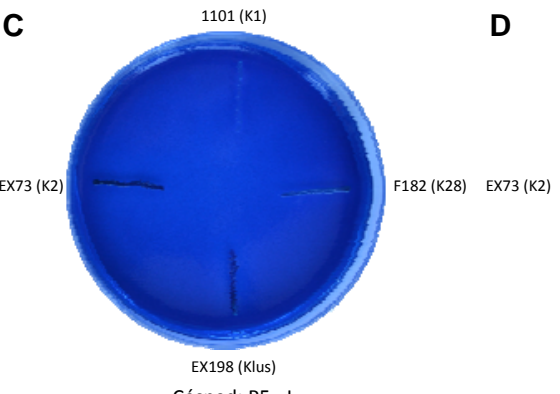

D

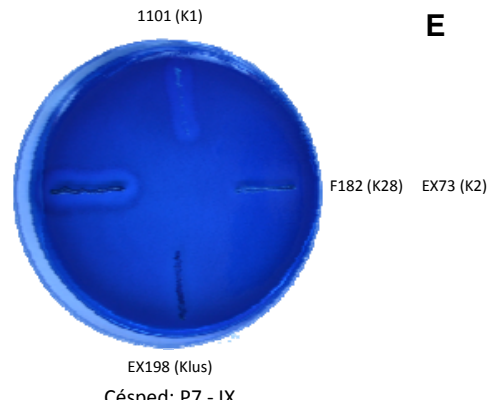

E

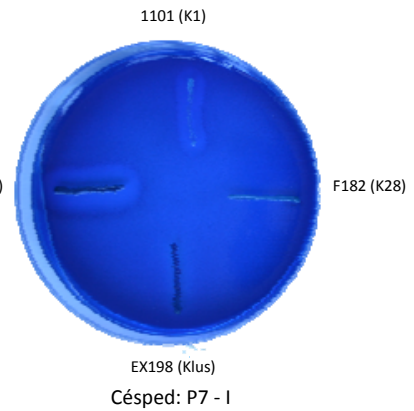

Figura 4.36: Estudio del carácter "killer" en placa de cepas aisladas de la bodega Cooperativa de los Oteros. En todas las imágenes se indica la cepa incorporada en el medio (bajo la imagen de la placa), así como las cepas con la que se han realizado las diferentes estrías (junto a cada estría). En A se realizan estrías con todas las cepas seleccionadas en esta bodega, sobre un medio que contiene la cepa sensible 5X47. Se observa como únicamente la cepa P7 - VI tiene capacidad "killer" por la aparición del halo de inhibición alrededor de su estría (se obtiene el mismo resultado cuando en el medio se incorpora la cepa sensible EX33). En B se muestra como la cepa P7 - VI (incorporada en el medio sólido) resultó sensible a la cepa K1. Con todo esto queda demostrada su capacida "killer" por producción de la toxina K2. La cepa P5 - I no presenta caracter "killer" (ver A) ni carácter sensible por la ausencia de halos alrededor de las estrías con las diferentes cepas de referencia, siendo por tando una cepa no sensible (C). Las cepas P7 - IX y P7 - I no presentan carácter "killer" (ver A). Sin embargo la primera de ellas es sensible a las toxinas K1 y K2 (D). La cepa P7 - I presenta sensibilidad a todas las toxinas ensayadas (mayor para K1 y K2), siendo por tanto una cepa multi-sensible (E).

\subsubsection{Análisis del material genético asociado al carácter "killer"}

Adicionalmente al estudio anterior se realizó un estudio para conocer la naturaleza del material genético asociado al carácter "killer". Se sabe que que estas toxinas, de naturaleza proteica, son codificadas por moléculas de ARN doble cadena (satélites M). Para el mantenimiento, duplicación y encapsidación de los citados satélites se precisa de una coinfección vírica (molécula L-A, también de doble cadena de ARN) (Marquina et al., 2002). Los tamaños descritos para estas moléculas de ARN van de 1,5 - 2,3 kb para los satélites $M$, en función de la toxina que codifiquen. En el caso de la molécula L-A su tamaño estimado asciende a 4,6 kb (Magliani et al. 1997; Rodriguez-Cousino et al. 2011).

Previo al análisis de las cepas seleccionadas se procedió a realizar una comprobación de las cepas control empleadas cuya producción de toxinas o sensibilidad se conoce. Esto nos facilitó el análisis de los resultados obtenidos para nuestras cepas, siendo posible una comparación directa de los resultados. Para tal fin, se procedió tal como se indica en el apartado 3.10.6.2.

En la figura 4.37 se muestran los resultados obtenidos para las seis cepas control empleadas en los ensayos en placa (cuatro con carácter "killer" y dos con carácter sensible). En todos los casos se trataron las muestras con ADNsa para facilitar la observación de las bandas de ARN. Se observa, salvo en la cepa EX33 (libre de partículas víricas), la molécula L-A con un tamaño cercano a las $5 \mathrm{~kb}$. La cepa EX73 (K2) presenta un satélite $M 2$ de unas 1,8 kb. La cepa 1101 tiene su correspondiente molécula M1 con un tamaño cercano a las 2,0 kb. Por 
su parte la cepa F182 presenta un satélite M28 con un tamaño aproximado de 2,2 kb. El tamaño del satélite Mlus (cepa EX198) es el de mayor tamaño, con unas 2,6 kb.
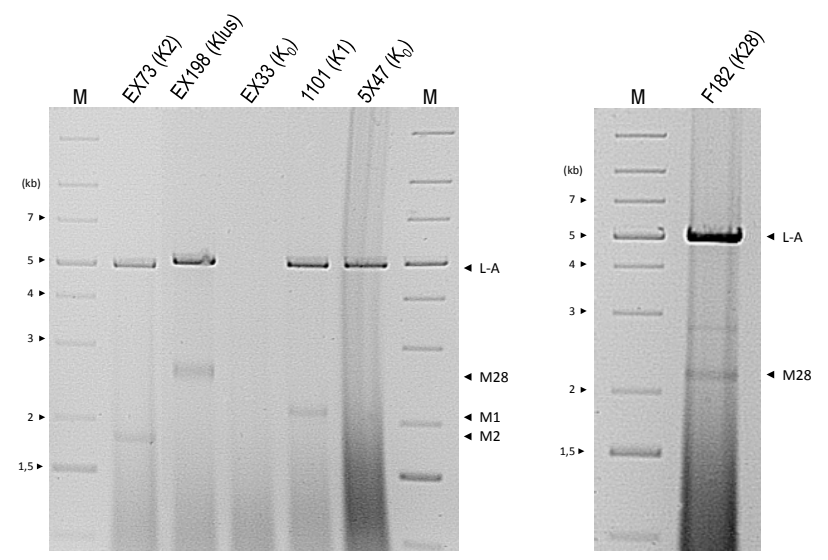

Figura 4.37: Resultado del análisis del material genético de las cepas control empleadas en el estudio del carácter "killer". Se muestran los resultados tras tratar las correspondientes soluciones de ácidos nucleicos con ADNsa para evitar la interferencia del ADN. Se observan tanto las moléculas L-A como los correspondientes satélites. A la derecha de los geles se indica la posición de los citados satélites, mientras que a la izquierda se indica el tamaño (kb). $M$ es el marcador de peso molecular escalera de $1 \mathrm{~kb}$ (Generuler ${ }^{\mathrm{TM}}$ ).

Una vez realizada la comprobación de las cepas control procedimos a realizar el estudio de las cepas seleccionadas en bodega. En la bodega Gordonzello S.A. se confirmó el resultado obtenido en placa: las cepas G5-III, G7-I y G7-XIV presentaban el satélite M2 (1,8 kb aproximadamente) junto con la molécula L-A (de un tamaño cercano a las $5 \mathrm{~kb}$ ). Ambas confieren a estas cepas el carácter K2. En el resto de cepas estudiadas no se observó ningún satélite como era de esperar.

En el caso de la bodega Cooperativa de los Oteros se repite lo indicado anteriormente ya que únicamente la cepa P6-VI (presentaba carácter "killer" en el ensayo en placa) presenta el satélite $M 2$ junto con la molécula L-A (figura $4.38 \mathrm{~A}$ ).

En la bodega Cooperativa Ribera del Cea se obtuvo un resultado llamativo. Dos cepas, R6I y R7-VII presentaban un supuesto satélite de ARN de doble cadena (cercano a las $2 \mathrm{~kb}$ ) junto con la molécula L-A (figura $4.38 \mathrm{~B}$ ). Sin embargo en los ensayos en placa no mostraban carácter "killer" respecto a las cepas sensibles control (ver tabla 4.19), de hecho resultaron ser cepas sensibles a las toxinas K1 y K2. Ya que el tamaño de las moléculas de ARN no coincide con ninguno de los descritos anteriormente y tampoco presentan el carácter en placa se podría pensar que dichas moléculas no codifican proteína alguna, o bien que por algún motivo la proteína sintetizada es inactiva. No se consideró necesario estudiar en profundidad este comportamiento debido a que la sensibilidad presentada por estas cepas no hace recomendable su uso como iniciador comercial.

Las cepas analizadas correspondientes a la bodega Vinícola Valmadrigal confirmaron el resultado obtenido en los ensayos en placa: las cepas V6-II, V7-III, V8-XV y V8-XVII presentaban carácter $\mathrm{K} 2$, si atendemos al tamaño de los satélites de ARN, aunque existen ligeras variaciones de tamaño entre ellos (figura 4.38).

En la bodega Pedro Casis se confirmó, al igual que en los ensayos en placa, que las cepas C9-I, C9-IX y C9-X presentaban carácter K2 si atendemos al tamaño que presentan los satélites de ARN. Resulta llamativo el resultado obtenido para la cepa C9-II, ya que presenta carácter "killer" y a su vez es sensible a las toxinas K1 y K2 (ver tabla 4.19). En el estudio del material genético asociado a dicho carácter se comprobó como se observaba la molécula L-A, mientras que no se observaba ningún tipo de satélite de ARN. Es posible que el método de extracción de ácidos nucleicos empleados degradara dicha molécula. El comportamiento de esta cepa quizás deba ser estudiado con mayor profundidad, aunque se escapa de la finalidad del presente trabajo. 
A

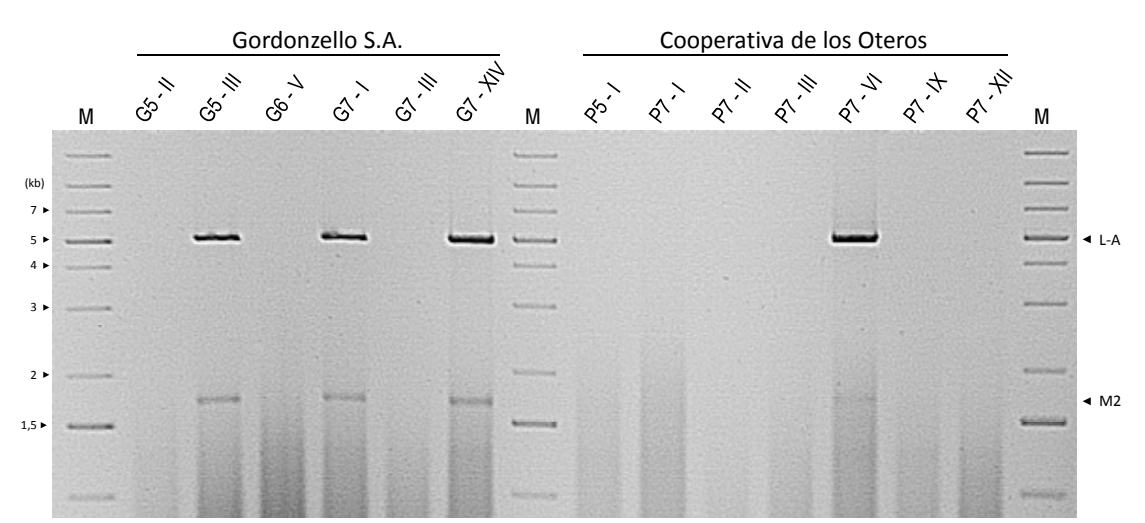

B

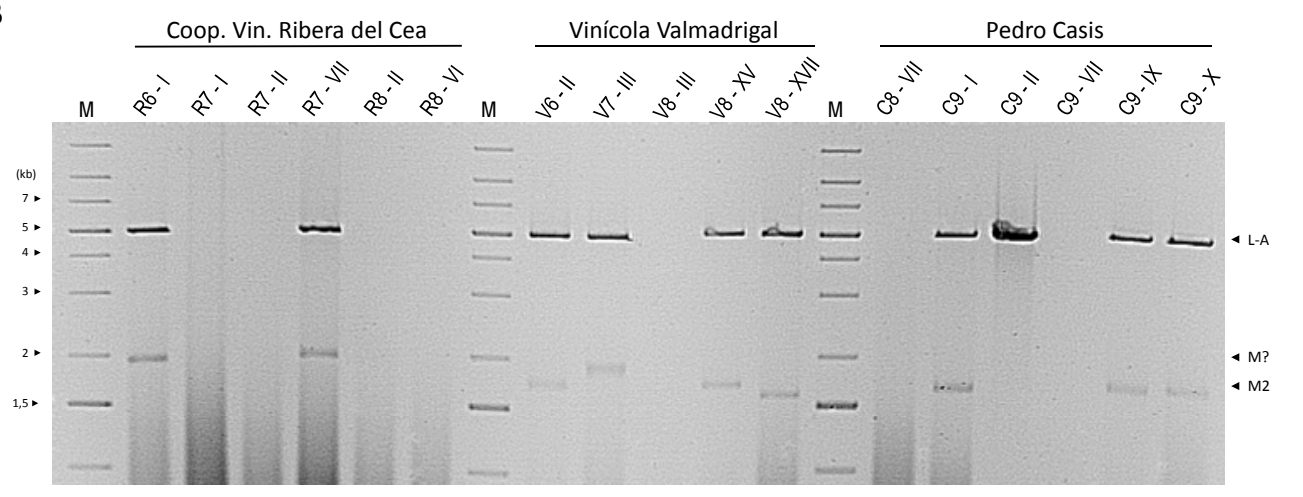

Figura 4.38: Resultado del análisis del material genético asociado al factor "killer" en las cepas seleccionadas aisladas en las diferentes bodegas. En A se muestran los resultados para la bodega Gordonzello S.A. y Cooperativa Pajares de los Oteros. En B se muestran los resultados obtenidos para las bodegas Cooperativa Vinícola Ribera del Cea, Vinícola Valmadrigal y Pedro Casis. A la derecha de las imágenes se muestra la posición de las moléculas de ARN de doble cadena. $M$ es el marcador de peso molecular escalera de $1 \mathrm{~kb}$ (Generuler $\left.{ }^{\mathrm{TM}}\right)$. A la izquierda de la imagen se indica el tamaño (pb).

\subsubsection{Microfermentaciones con levaduras seleccionadas}

Con el objetivo de comprobar el comportamiento real de nuestras cepas durante un proceso fermentativo se realizaron por duplicado una serie de microfermentaciones donde actuaban como iniciadores de fermentación. Para ello mosto natural estéril (esterilización en frío) se inoculó, en cada caso, con la correspondiente levadura, tal como se indica en el apartado 3.10.7.3. El control de las fermentaciones se llevaba a cabo por seguimiento del peso perdido de cada una de las botellas, siendo esta pérdida directamente proporcional al avance de la fermentación (ver apartado 3.10.7.4). De hecho la representación de la masa perdida acumulada respecto al tiempo de fermentación nos permitió conocer el diferente comportamiento de las cepas tras una rápida observación de las curvas obtenidas.

Finalizadas la microfermentaciones se procedió al análisis mediante HPLC de los parámetros básicos de los vinos obtenidos (ver apartado 3.10.7.5), determinándose las concentraciones de azúcares residuales (glucosa y fructosa), glicerol, etanol y ácido acético. Estos datos nos permitieron, por un lado, valorar la calidad de los vinos finales y, por otro, normalizar las curvas de fermentación anteriormente mencionadas (ver apartado 3.10.7.6). Dichas curvas, tras su ajuste matemático, quedaron definidas por una serie de parámetros que fueron sometidos a comparación con el fin de determinar los diferentes comportamientos observados en el proceso fermentativo.

En la tabla 4.21 aparecen los resultados obtenidos del análisis de los vinos. Mediante una observación directa de los resultados se observa que existen dos grupos bien diferenciados. En 
uno de ellos (vinos obtenidos con las cepas correspondientes a Gordonzello S.A. y Cooperativa de los Oteros) los vinos obtenidos destacaban por poseer una cierta cantidad de azúcares residuales, así como un elevado porcentaje de ácido acético. El otro grupo (resto de microvinificaciones) se caracterizó por obtener vinos con bajos contenidos en azúcares residuales y unos niveles de ácido acético más moderados. Esto resultaría extremadamente llamativo si no fuera porque los dos grupos indicados fueron obtenidos a partir de dos lotes diferentes de mosto, procedentes de cosechas diferentes. La mayor concentración de azúcares en el mosto del lote 1 (empleado para las bodegas Gordonzello S.A. y Cooperativa de los Oteros) respecto al lote 2 (empleado en el resto de bodegas) (ver tabla 4.21) puede justificar las diferencias encontradas. Los vinos producidos con el lote 1 alcanzan un mayor grado alcohólico (porcertantes de etanol entre 13,80 - 16,61), dejando además azúcares sin fermentar. Esto último pone de manifiesto la imposibilidad de las levaduras para fermentar el total de azúcares. Los valores de glicerol son ligeramente superiores en los vinos elaborados con el primer lote de mosto, aunque no destacan de forma llamativa sobre los vinos obtenidos con el segundo lote de mosto. Con el acético ocurre lo contratrio a lo indicado anteriormente, exiten diferencias (cercanas al doble en algunos casos) entre los diferentes lotes, aunque dentro de cada lote se observa gran variabilidad (debido al metabolismo de la propia levadura empleada en cada caso). Las grandes diferencias encontradas inicialmente pudieron ser debidas a la existencia de ácido acético en el lote 1 de mosto previo al inicio de la fermentación, provocado con casi toda seguridad por el mayor periodo de almacenamiento hata su uso (en relación al lote 2). Por tanto en los vinos elaborados con mosto del lote 1 (cepas aisladas de Bodega Gordonzello S.A. y Cooperativa de los Oteros) se estimará la concentración de ácido acético final por diferencia entre la cantidad detectada en el análisis y la existente en el mosto precursor.

Debido al empleo de dos lotes de mosto no es posible una comparación conjunta de resultados. Por tanto, se analizaron por separado los resultados obtenidos con un mismo lote de mosto, aunque dentro de cada grupo si fue posible una comparación directa.

En la bodega Gordonzello S.A. destacó la cepa G5-II por producir vinos con bajo contenido (en relación al resto) de azúcares residuales, aunque su alto contenido en ácido acético (1248 mg/L) disminuye la calidad del producto final. Sin embargo, la cepa G7-XIV, la siguiente en menor cantidad de azúcares residuales, generaban unos niveles de acético aceptables $(488 \mathrm{mg} / \mathrm{L})$ en relación al resto de vinos obtenidos con ese lote de mosto. En la bodega Cooperativa de los Oteros destacan los vinos producidos con las cepas P7-I, P7-XII y P7-VI por los bajos contenidos de azúcares finales. Si bien, únicamente la última cepa era capaz de mantener los niveles de acético $(537 \mathrm{mg} / \mathrm{L})$ en unos rangos aceptables. Ademas, la cepa P7-VI produce un vino con mayor grado alcohólico (16,61\% vol.) comparado con los otros vinos. La cepa P7-XII destacó por la producción de vinos con altos niveles de glicerol $(9,28$ g/L).

En la bodega Pedro Casis destacan las cepas C9-I y C9-II, siendo ambas capaces de generar vinos con un bajo contenido en azúcares residuales, un elevado contenido en glicerol y unos niveles ajustados de ácido acético. Un resultado similar se obtiene en la bodega Cooperativa Vinícola Ribera del Cea para la cepa R8-VI. En la bodega Vinícola Valmadrigal, destacan las cepas V7-III y V8-XVII que son capaces de producir vinos de acuerdo a las premisas indicadas, manteniendo un buen nivel de glicerol y una ajustada concentración de acético.

En la tabla 4.20 se muestran los parámetros que definen las curvas de fermentación obtenidas experimentalmente (ver apartado 3.10.7.6). De todos ellos el más importante es la pendiente máxima $(\mathrm{m})$ que será indicativa de la máxima velocidad de fermentación durante 
el proceso. Además podremos estimar el porcentaje fermentado (A, asíntota horizontal) y el tiempo de latencia (l) o tiempo necesario para que se incie el proceso de fermentación.

Los datos confirman lo indicado anteriormente: se observaban diferentes comportamientos en función del lote de mosto empleado en la elaboración de los vinos. Si nos fijamos en el porcentaje fermentado (A) se observa claramente que los vinos elaborados con el primer lote de mosto (cepas de las bodegas Gordonzello S.A. y Cooperativa de los Oteros) presentaban valores más bajos (dejaban más azúcares residuales) respecto a los elaborados con el lote 2. Si atendemos al tiempo necesario para que se iniciase el proceso de fermentación (l) vemos como los vinos fermentados con cepas aisladas de las tres últimas bodegas indicadas en la tabla (sus microfermentaciones se llevaron a cabo con el lote 2) presentaban unos valores muy pequeños. Tan pequeños que en algunos casos se obtienen valores negativos, por tratarse de un ajuste matemático que intenta explicar el resultado experimental obtenido. Asumimos que en estos casos el proceso fermentativo comenzaba de manera casi inmediata. Sin embargo, la velocidad máxima de fermentación $(\mathrm{m})$, nos informa fehacientemente del comportamiento de la cepa en cuestión en la microfermentación. De hecho, se observaban valores muy dispares dentro de los dos grupos ya mencionados. Se podría decir que este parámetro nos permitirá realizar una comparación global entre las cepas sin atender al lote de mosto con el que fueron elaborados.

\subsubsection{Análisis conjunto de las cepas de levadura analizadas}

En vista de los resultados indicados en apartados anteriores se podría resaltar para cada una de las bodegas estudiadas lo siguiente:

En la bodega Gordonzello S. A. destacaban las cepas G5-II y G7-XIV. La primera produce vinos relativamente secos (según su valor de $A$ y parámetros enológicos, en tablas 4.20 y 4.21 respectivamente), pero tanto el elevado tiempo de latencia, la alta producción de ácido acético y su carácter "killer" sensible hacen poco recomendable su utilización. Por el contrario la cepa G7-XIV, aún dejando ciertos niveles de frutosa en el vino (lote 1 de mosto), muestra buena capacidad fermentativa, bajos niveles de acético y alta tolerancia al etanol. Todo esto unido a su fenotipo "killer" y gran capacidad de crecimiento a bajas temperaturas la convierten a priori en la mejor cepa de esta bodega (entre las aisladas) para un posible uso comercial.

En la bodega Cooperativa de los Oteros son varias las cepas que presentan un comportamiento adecuado, aunque P7-VI destaca por mantener un equilibrio en las tres variables: alto porcentaje fermentado, buena velocidad de fermentación y un tiempo relativamente corto en el inicio de fermentación. Además tiene un fenotipo K2 y soporta altas concentraciones de etanol superiores al $15 \%$.

En la bodega Pedro Casis destacan dos cepas sobre el resto, la cepa C9-I y la cepa C9-II. La primera, además, presentó la mayor velocidad de fermentación del estudio (aunque no significativamente diferente de otras cepas, ver tabla 4.20), tiene fenotipo "killer" K2 y una tolerancia al etanol moderada, aunque adecuada para su uso en vinificación. Esta cepa parece cumplir con creces los requisitos de una buena inicidora de fermentación.

En la bodega Cooperativa Ribera del Cea destacó la cepa R8 - VI ya que produjo un vino relativamente seco, mediante una fermentación con inicio rápido y a ritmo adecuado (de acuerdo a los valores obtenidos de "l” y " $m$ " respectivamente). Además muestra una alta tasa de crecimiento a bajas temperaturas. Sin embargo se trata de una cepa con carácter "killer" sensible. 
En la bodega Vinícola Valmadrigal no existieron grandes diferencias reseñables acorde a los resultados experimentales obtenidos. Las cepas V6-II, V7-III y V8-XVII presentan un comportamiento adecuado, incluyendo un fenotipo $\mathrm{K} 2$ y una buena adaptación a bajas temperaturas. La primera y la úlima de las indicadas producen vinos con bajas concentraciones de azúcares residuales y altos niveles de glicerol (en relación al resto de cepas aisladas en esta bodega). Sin embargo la cepa V8-XVII es capaz de mantener el ácido acético $(855 \mathrm{mg} / \mathrm{L})$ en niveles aceptables. La tasa de fermentación de esta cepa, curiosamente, es la más baja de todas las estudiadas (tabla 4.20) lo que no le impide obtener vinos relativamente secos y con unas propiedades adecuadas (contenido en glicerol, acético y etanol).

Tabla 4.20: Resultado del ajuste matemático (Ec. Gompertz Rep.) de las curvas experimentales obtenidas (tras su normalizado) en las microfermentaciones puras. El parámetro A hace referencia al máximo porcentaje fermentado, por tanto no tiene unidades. Para el resto de parámetros se indican las unidades (entre paréntesis). Los valores de " $m$ " acompañados con letras diferentes son significativamente diferentes de acuerdo a los resultados obtenidos a partir de un análisis de ANOVA $(P<0,05)$.

\begin{tabular}{|c|c|c|c|c|}
\hline Bodega & Cepa & $A$ & m (g/L·día) & I (días) \\
\hline & G5 - II & 95,932 & $39,785^{i k / m}$ & 0,812 \\
\hline & G5 - III & 86,879 & 34,715 efghi & 0,198 \\
\hline & G6-V & 87,409 & $24,780^{a}$ & 0,750 \\
\hline & G7 - I & 88,433 & 35,447 efghii & 0,234 \\
\hline & G7 - III & 78,741 & $38,888 i i k l$ & 0,352 \\
\hline \multirow[t]{7}{*}{ Gordonzello S.A. } & G7 - XIV & 89,876 & 35,402 efghii & 0,106 \\
\hline & P5 - I & 88,285 & $31,206^{\text {cde }}$ & 0,062 \\
\hline & P7 - I & 96,715 & 37,344 ghijkl $^{2}$ & 0,617 \\
\hline & P7 - II & 96,234 & $29,467 \mathrm{bcd}$ & 0,461 \\
\hline & P7 - III & 91,336 & $33,341^{\text {cdefg }}$ & 0,328 \\
\hline & P7 - VI & 96,422 & $39,686 \mathrm{kklm}$ & 0,245 \\
\hline & P7 - IX & 90,942 & 36,572 fghijk & 0,298 \\
\hline \multirow[t]{6}{*}{ Cooperativa de los Oteros } & P7 - XII & 95,371 & 36,877 ghijk & 0,717 \\
\hline & $\mathrm{C} 8-\mathrm{VII}$ & 93,786 & $32,188^{\text {cdef }}$ & $-0,015$ \\
\hline & C9-I & 95,649 & $43,168^{m}$ & 0,185 \\
\hline & C9-II & 96,641 & $41,319 \mathrm{~lm}$ & 0,189 \\
\hline & C9 - VII & 94,019 & 33,984 efgh & $-0,014$ \\
\hline & C9 - IX & 95,651 & $40,433 \mathrm{klm}$ & 0,187 \\
\hline \multirow[t]{6}{*}{ Bodegas Pedro Casis } & C9 - X & 94,613 & 35,192 efghi & $-0,019$ \\
\hline & R6-I & 95,987 & $33,713^{\text {defg }}$ & $-0,040$ \\
\hline & R7 - I & 95,763 & 33,776 efgh & 0,185 \\
\hline & R7 - II & 97,160 & 32,014 cde & 0,147 \\
\hline & R7 - VII & 96,919 & 33,022 cdefg & 0,178 \\
\hline & R8 - II & 97,205 & 33,239 cdefg & 0,244 \\
\hline \multirow[t]{5}{*}{ Cooperativa Vinícola Ribera del Cea } & $\mathrm{R} 8 \cdot \mathrm{VI}$ & 96,460 & 38,168 hijkl & 0,087 \\
\hline & V6-II & 96,356 & 31,500 cde & 0,016 \\
\hline & V7 - III & 96,622 & $29,074 b c$ & $-0,035$ \\
\hline & V8 - III & 95,304 & $24,486^{a}$ & $-0,362$ \\
\hline & $\mathrm{V} 8 \cdot \mathrm{XV}$ & 95,501 & $26,960 a b$ & $-0,159$ \\
\hline Vinícola Valmadrigal & V8 - XVII & 96,320 & $23,561^{a}$ & $-0,331$ \\
\hline
\end{tabular}


Tabla 4.21: Resultado del análisis mediante HPLC de los vinos obtenidos tras la microfermentaciones puras. Los valores mostrados son la media de las dos réplicas (microfermentaciones) por cepa. Entre parénteis se indica la desviación estándar (SD). Además se indica la composición de los mostos empleados en obtención de los vinos (dos lotes diferentes): los valores corresponden a la media del análisis realizado por tripiclado, indicándose entre paréntesis las SD obtenida.

\begin{tabular}{|c|c|c|c|c|c|c|c|}
\hline Bodega & Cepa & Glucosa (g/L) & Fructosa $(\mathrm{g} / \mathrm{L})$ & Glicerol (g/L) & Etanol (\% vol.) & Ac. acético (mg/L) & Estimación ${ }^{1}$ ac. acético (mg/L) \\
\hline & G5 - II & $0,96(1,19)^{*}$ & $5,3(4,9)$ & $8,06(0,56)$ & $15,99(0,82)$ & $1845(160)$ & 1248 \\
\hline & G5 - III & $1,37(1,45)^{*}$ & $24,1(9,9)$ & $6,94(0,16)$ & $14,68(0,48)$ & $1414(58)$ & 817 \\
\hline & G6-V & $3,3(1,4)$ & $17,13(4,21)$ & $7,623(0,001)$ & $15,05(0,04)$ & $1686(15)$ & 1089 \\
\hline & G7 - I & $0,77(0,82)^{*}$ & $22,06(6,63)$ & $7,16(0,07)$ & $15,46(0,46)$ & $1400(85)$ & 803 \\
\hline & G7 - III & $4,9(1,3)$ & $39,58(5,63)$ & $6,67(0,46)$ & $13,02(0,68)$ & $1059(184)$ & 462 \\
\hline \multirow[t]{7}{*}{ Gordonzello S.A. } & G7 - XIV & $0,82(0,20)$ & $19,77(1,18)$ & $6,35(0,02)$ & $15,18(0,30)$ & $1085(110)$ & 488 \\
\hline & P5 - I & $0,56(0,32)$ & $19,4(5,0)$ & $7,58(0,47)$ & $15,53(0,27)$ & 2003 (129) & 1406 \\
\hline & P7 - I & $0,04(0,06)$ & $4,57(1,26)$ & $6,98(0,03)$ & $15,88(0,08)$ & $1708(75)$ & 1111 \\
\hline & P7 - II & - & $2,28(0,44)$ & $7,34(0,01)$ & $16,21(0,15)$ & $1740(10)$ & 1143 \\
\hline & P7 - III & $1,26(0,71)$ & $11,8(2,3)$ & $7,06(0,44)$ & $15,89(0,05)$ & $1194(291)$ & 597 \\
\hline & P7 - VI & - & $4,14(0,26)$ & $7,36(0,07)$ & $16,61(0,03)$ & $1134(355)$ & 537 \\
\hline & P7 - IX & $1,10(0,25)$ & $14,00(0,53)$ & $6,49(1,00)$ & $13,8(2,1)$ & $1335(273)$ & 738 \\
\hline \multirow[t]{6}{*}{ Coop. de los Oteros } & P7 - XII & $0,05(0,06)$ & $5,20(0,99)$ & $9,28(0,34)$ & $15,77(0,43)$ & 1911 (439) & 1314 \\
\hline & $\mathrm{C} 8 \cdot \mathrm{VII}$ & - & $3,52(0,63)$ & $6,04(0,28)$ & $13,27(0,02)$ & 707 (166) & \\
\hline & C9-I & - & $2,789(0,003)$ & $5,93(0,13)$ & $13,50(0,05)$ & $825(102)$ & \\
\hline & C9-II & - & $2,61(0,03)$ & $6,27(0,08)$ & $13,67(0,10)$ & 780 (39) & \\
\hline & C9-VII & - & $3,52(0,11)$ & $5,68(0,07)$ & $13,54(0,03)$ & $822(14)$ & \\
\hline & C9 - IX & - & $2,69(0,04)$ & $5,96(0,01)$ & $13,66(0,08)$ & 1101 (78) & \\
\hline \multirow[t]{6}{*}{ Bodegas Pedro Casis } & C9.X & - & $2,90(0,06)$ & $5,85(0,01)$ & $13,60(0,01)$ & $830(38)$ & \\
\hline & R6-I & - & $3,39(0,06)$ & $5,54(0,01)$ & $12,9(1,0)$ & $866(6)$ & \\
\hline & R7 - I & - & $3,05(0,09)$ & $5,544(0,005)$ & $13,41(0,20)$ & $799(84)$ & \\
\hline & R7 - II & - & $2,48(0,05)$ & $5,52(0,34)$ & $12,90(0,68)$ & $928(55)$ & \\
\hline & R7 - VII & - & $2,62(0,11)$ & $5,86(0,15)$ & $13,51(0,15)$ & $995(42)$ & \\
\hline & R8 - II & - & $2,67(0,05)$ & $5,93(0,11)$ & $13,43(0,05)$ & $781(88)$ & \\
\hline \multirow[t]{5}{*}{ Coop. Vin. Ribera Cea } & $\mathrm{R} 8 \cdot \mathrm{VI}$ & - & $2,74(0,04)$ & $5,71(0,10)$ & $13,40(0,41)$ & $716(28)$ & \\
\hline & V6- II & - & $2,75(0,09)$ & $6,20(0,10)$ & $13,33(0,07)$ & $1176(160)$ & \\
\hline & V7 - III & - & $2,97(0,22)$ & $5,74(0,04)$ & $13,09(0,00)$ & $786(29)$ & \\
\hline & V8 - III & - & $3,14(0,07)$ & $5,66(0,00)$ & $13,41(0,24)$ & $1058(25)$ & \\
\hline & $\mathrm{V} 8 \cdot \mathrm{XV}$ & - & $4,05(0,11)$ & $5,70(0,11)$ & $13,21(0,10)$ & $822(21)$ & \\
\hline \multirow[t]{2}{*}{ Vinícola Valmadrigal } & V8 - XVII & - & $3,35(0,04)$ & $6,33(0,15)$ & $13,33(0,37)$ & $855(32)$ & \\
\hline & Lote 1 & $123,6(3,2)$ & $115,3(3,8)$ & - & - & $597(73)$ & \\
\hline Mostos uva Prieto Picudo & Lote 2 & 115,3 & 105,1 & - & - & - & \\
\hline
\end{tabular}

En los vinos obtenidos a partir de mosto del lote 1 se estima la concentración de acético por diferencia entre el resultado del análisis y los vinos y el nivel de acético previamente detectado en el mosto. 


\subsubsection{Comportamiento de la levadura aislada en viñedos pertenecientes a la DO «Tierra de León»}

Como se ha indicado anteriormente (apartado 4.2) se procedió a realizar un estudio sobre la población de levaduras residentes en la uva, aislándose una única cepa de S. cerevisiae además de varias levaduras salvajes normalmente asociadas a la uva. El hecho de aislar una única levadura perteneciente a la especie S. cerevisiae en la uva resulta llamativo por sí mismo, indicando una pobre adaptación para vivir sobre la superficie del fruto. Adicionalmente, la levadura aislada se detectó en tres de los cuatro viñedos muestreados. Estos viñedos se encuentran dispersos dentro de la zona de cultivo asociada a la DO, estando separados entre sí por un mínimo de $35 \mathrm{~km}$.

En la tabla 4.22 se muestran los resultados obtenidos tras elaborar un vino empleando la levadura aislada en viñedo como iniciadora de fermentación (microfermentación pura) y mosto del lote 2 . Se observa como en el vino final se detectaron niveles relativamente altos de fructosa y un grado alcohólico $(13,06 \%$ vol.) ligeramente inferior al de la parte de los vinos obtenidos empleando cepas aisladas a partir de microfermentaciones espontáneas (ver tabla 4.21). No se detectaron diferencias aparentes en la producción de glicerol y destacando la nula presencia de acético en el vino final (no detectado en el análisis).

Los parámetros que nos informan de su comportamiento en fermentación indican que el porcentaje fermentado es relativamente bajo (parámetro A), y que la velocidad máxima de fermentación $(\mathrm{m})$ presenta un valor discreto comparado con la mayoría de las cepas pertenecientes a la colección, aunque es mejor que el exhibido por algunas de las cepas aisladas de bodega, aunque aquellas eran capaces de fermentar un mayor porcentaje de azúcares.

Tabla 4.22: Resultado de la microvinificación realizada con la cepa 3d (aislado viñedo). Se observa el resultado del análisis del vino final (mediante HPLC). Entre parénteis se indica la desviación estándar (SD). Además se muestran los parámetros correspondientes al ajuste matemático de las curvas de fermentación experimentales (normalizadas).

\begin{tabular}{|c|c|c|c|c|c|}
\hline Cepa & Glucosa (g/L) & Fructosa $(\mathrm{g} / \mathrm{L})$ & Glicerol (g/L) & Etanol (\% vol.) & Ac. Acético (mg/L) \\
\hline $3 d$ & & $10,20(0,52)$ & $6,11(0,08)$ & $13,06(0,02)$ & \\
\hline Cepa & & & m (g/L·día) & & I (días) \\
\hline $3 d$ & & & 31,144 & & 0,321 \\
\hline
\end{tabular}

También se realizó un estudio sobre su comportamiento a bajas temperaturas (apartado 4.3.5). Se obtuvo que su crecimiento era un $17 \%$ peor al que presentaba la cepa C9-I (relativamente bien adaptada a condiciones de baja temperatura, con propiedades enológicas adecuadas). Este dato indica su comportamiento discreto a bajas temperaturas, aunque algunas de las cepas aisladas en entornos fermentativos mostraron peores registros.

Resumiendo podemos decir que la cepa 3d, a pesar de ser aislada de uva, muestra unas propiedades fermentativas aceptables, en algunos aspectos pefectamente comparables a algunas de las peores cepas aisladas de entornos fermentativos.

Por tanto, parece que por características genéticas las cepas de $\mathrm{S}$. cerevisiae tienen una gran capacidad de adaptación a un mosto para desarrollar un proceso fermentativo, aunque es obvio que las levaduras autóctonas de bodega han experimentado un proceso evolutivo de adaptación al entorno industrial respecto a las existentes en entornos naturales. En otras palabras, existe un proceso de "domesticación" en respuesta a las diferentes presiones selectivas (alta concentración de azúcares, bajo contenido en oxígeno, alto contenido en 
etanol, etc.) que sufren las levaduras en los entornos fermentativos (Querol et al. 2003), de modo que el comportamiento fisiológico de cepas aisladas de entornos naturales varía respecto a las correspondientes a entornos industriales (Liti et al., 2009).

\subsubsection{Estudio global mediante componentes principales}

En la figura 4.39 se muestra la proyección de alguna de las variables estudiadas en el plano formado por unas nuevas variables, hipotéticas, denominadas componentes principales (CP). Dichas variables intentan explicar la mayor parte de la varianza existente. Las variables representadas (flechas) son los parámetros enológicos (cada uno de los compuestos analizados en los vinos), parámetros de ajuste de las curvas experimentales ( $\mathrm{A}, \mathrm{m}$ y $\mathrm{l}$ ) y los descriptores de la tolerancia al etanol mostrada (NIC y MIC). En el mismo plano se representan (mediante cuadrados) las diferentes cepas en función de los valores obtenidos en cada una de las variables indicadas. De este modo, cuanto más cerca esté una cepa (representadas mediante cuadarados) de una variable determinada (representada por flechas), mayor será su influencia (valor elevado para dicha variable).

Si analizamos el gráfico de decaimiento (indica el porcentaje de varianza explicado por cada (P), vemos como la mayoría de la variabilidad se explica mediante las tres primeras componentes principales (se explica más del $80 \%$ de la varianza). La distribución de las cepas en el plano formado por CP1-CP2 (explican el $65 \%$ de la varianza total) pone de manifiesto la existencia de dos grupos claramente diferenciados (marcados mediante elipses). Se observa el enfrentamiento existente entre el coeficiente " $A$ " y la concentracion de azúcares residuales, resultado lógico por otra parte, ya que un elevado valor de este coeficiente implica un bajo contenido en azúcares y viceversa. Dicha separación es debida, principalmente, al uso de dos lotes diferentes de mosto en la realización de las microfermentaciones.

En el plano formado por las componentes principales CP1-CP3 (explican el $55 \%$ de la variabilidad existente) se observa la disposición contraria del parámetro "A" respecto a todos los parámetros enológicos considerados. Esto parece indicar la mayor infuencia de estas variables en la formación de los dos grupos anteriomente mencionados. Se pone de manifiesto que no sólo la diferente concentración de azúcares residuales, sino también las diferentes concentraciones de etanol, ácido acético y glicerol obtenidos entre los dos grupos indicados son debidas al uso de diferentes lotes de mosto.

La representación en el plano formado por CP2-CP3 (sólo se explica el $35 \%$ de la varianza) no permite observar agrupación alguna, aunque la distribución de las variables guarda el mismo patrón indicado anteriormente, siendo su representación, con salvedades, una imagen especular de la obtenida en el plano CP1-CP3.

Este tipo de representaciones puede servir, aparte de para conocer la existencia de grupos (analizado anteriormente), para analizar el comportamiento de una cepa en particular atendiendo a su localización respecto a las diferentes variables representadas. A modo de ejemplo, si nos fijamos en la cepa G7-III, vemos una disposición alejada al resto muy cercana a los extremos de las flechas que representan los contenidos en glucosa y fructosa. Efectivamente, en la tabla 4.21 vemos como esta cepa generaba unos vinos con los contenidos más elevados en azúcares residuales. Una lectura similar se podría hacer para cada una de las cepas en función de cada una de las variables representadas. 


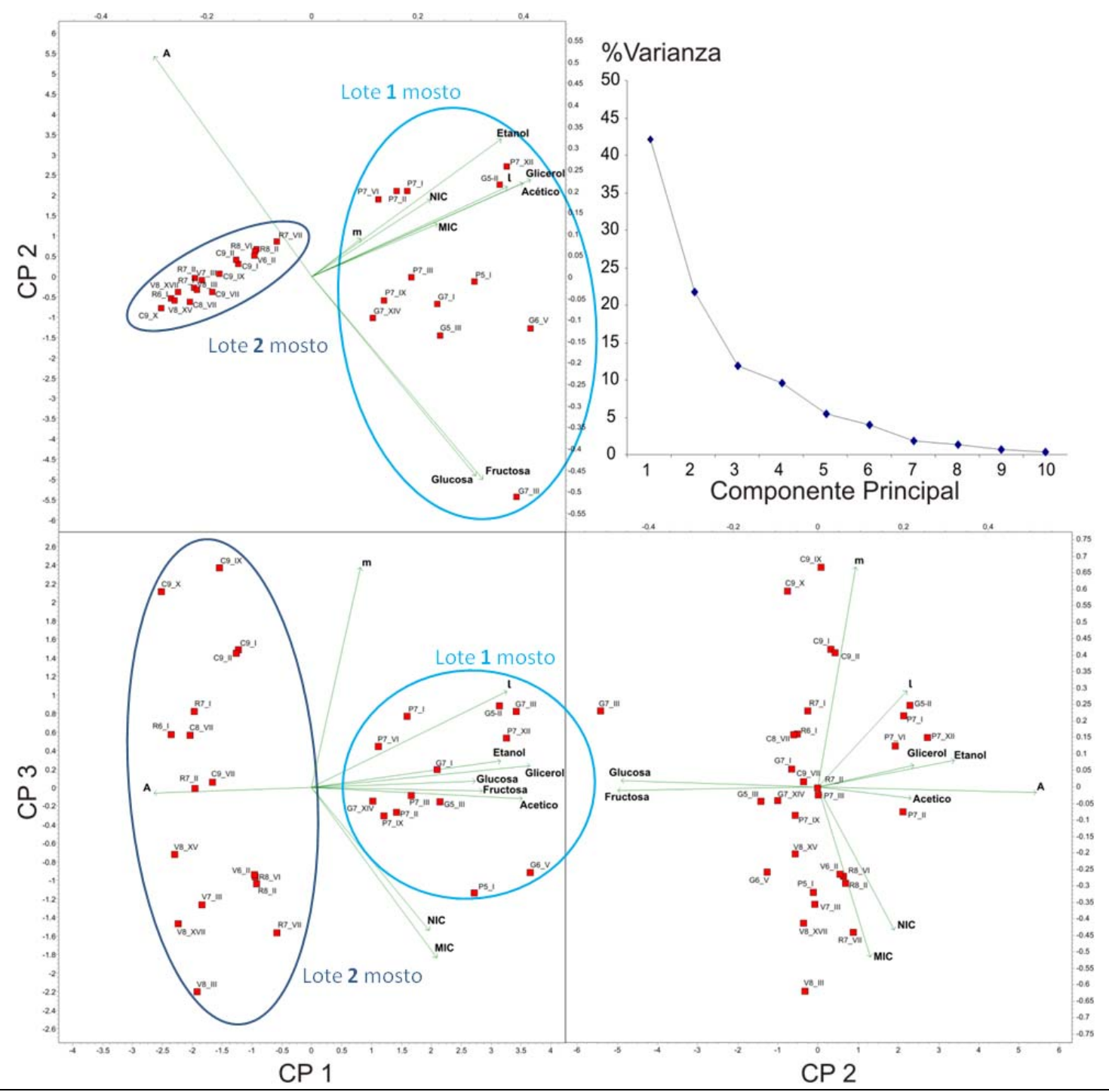

Figura 4.39: Análisis de componentes principales (CP) de los resultados obtenidos en las microfermentaciones y tolerancia al etanol. Se observa la distribución de las variables (representadas por flechas, indicadas en negrita) y de las correspondientes cepas (representadas por cuadrados) en función de unas nuevas variables hipotéticas que explicaran la varianza encontrada. En la parte superior y derecha se indica la escala correspondiente a las variables, mientras que en la parte inferior e izquierda se indica la escala correspondiente a las cepas. Se indican, mediante elipses de diferente color, los grupos que se forman debido al empleo de dos lotes de mosto diferentes.

\subsubsection{Asociaciones entre marcadores RFLP y caracteres fenotípicos}

Una vez finalizada la caracterización genotípica, fenotípica y enológica de las diferentes cepas de levadura aisladas, se comprobó si existían asociaciones en la presencia/ausencia de determinadas bandas en el análisis de restricción (RFLP-ADNmt) entre sí y si estas estaban a su vez asociadas con un comportamiento fenotípico en particular. Un objetivo más ambicioso sería llegar a predecir un comportamiento de fermentación particular a partir de un determinado perfil de restricción.

El método de trabajo para analizar asociaciones se basó en la separación de la población de cepas en dos grupos atendiendo a un determinado carácter cualitativo, normalmente presencia o ausencia de una banda determinada, y comparar estadísticamente las dos subpoblaciones para determinar si ambas muestras pueden o no incluirse en la misma población. Únicamete se han considerado aquellas bandas RFLP que se han mostrado variables (al menos dos cepas de levaduras no las mostraban). Las pruebas estadísticas utilizadas son la $U$ de Mann-Whitney y la prueba $Z$ de Kolmogorov-Smirnov, se trata de test no paramétricos, 
ya que en la mayoría de las comparaciones no se cumple la condición de normalidad de las muestras y fueron realizadas con el software SPSS. En la tabla 4.24 se indican las variables fenotípicas correspondientes a caracteres cuantitativos de la fermentación que presentan algún tipo de asociación con alguna de las variables cualitativas o categóricas, ya sean bandas del análisis de restricción o características fenotípicas de las cepas.

La comparación entre variables categóricas (genotípicas o fenotípicas) se realizó mediante tablas de contingencia, en las que se comprueba la independencia de un par de variables mediante una prueba chi-cuadrado, cuando las variables no eran independientes se recurrió a modelos log-lineales. Los modelos log-lineal tiene la forma $\left[\ln \left(F_{i j}\right)=\mu+\lambda_{i}^{A}+\lambda_{j}^{B}+\right.$ $\lambda_{\mathrm{ij}}{ }^{\mathrm{AB}}$ ], e incluye el parámetro $\left(\lambda_{\mathrm{ij}}{ }^{\mathrm{AB}}\right)$ que indica la interacción existente entre las dos variables estudiadas, y si dicha interacción es o no significativamente diferente de cero. En la tabla 4.23 se incluyen las parejas de caracteres no independientes de acuerdo con la prueba chicuadrado y que muestran valores de interacción en los modelos log-lineales significativos.

Entre las asociaciones encontradas puede destacarse las de las bandas C1 y C3 con diferentes parámetros enológicos clásicos (azúcares residuales, glicerol, etanol y ácido acético) estudiados en los vinos tras los procesos de microfermentación. Aunque la asociación de la banda $\mathrm{C} 3$ no es muy fuerte (únicamente significativa a I nivel de $5 \%$ mediante el test $U$, tabla 4.24) y puede deberse a la interacción que existe con la banda C1 ( $P=0.003$, tabla 4.23).

Son varias las bandas (A6, A8 y B3) que parecen guardar relación con la tolerancia al etanol presentada por las diferentes cepas estudiadas, aunque sus niveles de significación no llegan al 1\% (tabla 4.24). En cuanto a su comportamiento a bajas temperaturas, se observa cierta asociación de la variable m" con las bandas B6, C0, C4, C6 y C7 aunque nuevamente discha asociación no es fuerte dados los niveles de significación observados.

Adicionalmente, en la tabla 4.24 se observan relaciones entre los diferentes comportamientos nutricionales de las levaduras (asimilación de diferentes fuentes de carbono) y diferentes variables cuantitativas, en este caso es de destacar la asociación entre la capacidad de crecer sobre glicerol como única fuente de carbono con la cantidad de azúcares residuales y la producción de etanol y acético, la capacidad de utilizar glicerol como fuente de carbono también está asociada al fenotipo para las bandas C1 y C3 aunque no con mucha intensidad (tabla 4.23). Por otro lado la tolerancia a bajas temperaturas también está asociado a la capacidad de utilizar como fuente de carbono diferentes azúcares (MAL, SAC y $\mathrm{RAF})$.

Se han encontrado numerosas asociaciones entre diferentes bandas y entre bandas y la capacidad de asimilar diferentes azúcares (tabla 4.23), en este caso los análisis entre parejas de bandas se realizaron considerando todas las cepas de levadura aisladas, no únicamente las escogidas para los ensayos de fermentación.

La asociación entre bandas puede ser debida a su proximidad en el genoma mitocondrial, o porque algunos productos aislados comparten de hecho alguna región de este genoma. Hay que recordar que esto dependerá de los sitios de restricción reconocidos por la endonucleasa empleada. En cualquier caso dado el gran número de comparaciones realizadas es esperable encontrar asociaciones únicamente por azar. Si se considera únicamente las parejas que muestran interacciones a un nivel de significación superior al uno por mil se observan interacciones entre las parejas de bandas C1-C5 y A8-A9, y los grupos A5-A4-C2-C4 y A7-A6C7-C6-B7-B6-B4-B3, aunque su interpretación no parece sencilla.

En la tabla 4.23, aparte de las relaciones indicadas entre bandas, destaca la interacción encontrada entre la banda A9 y el factor "killer". Se conoce que dicho factor está relacionado 
con moléculas de doble cadena de ARN de origen vírico, la interacción detectada resulta llamativa, pero los valores de probabilidad 0,019 en la prueba chi-cuadrado y 0,031 en la interacción log-lineal son significativos únicamente al $5 \%$.

La secuenciación de las bandas asociadas entre sí o con los diferentes caracteres fenotípicos permitirá identificar la naturaleza de dichas asociaciones y comprobar la importancia que realmente puedan tener.

Tabla 4.23: Resultado de los análisis de tabla de contingencia y modelos loglineales. Se indican las parejas de variables donde se detectaron asociaciones. En la mitad izquierda se indican los resultados obtenidos mediante tablas de contingencia (un grado de libertad), mientras que en la mitad derecha se indican los resultados obtenidos empleando modelos loglineales.

\begin{tabular}{|c|c|c|c|c|}
\hline & \multicolumn{2}{|c|}{ TABLAS DE CONTINGENCIA } & \multicolumn{2}{|c|}{ MODELOS LOGLINEALES } \\
\hline & chi-cuadrado & $P$ & $\left|\lambda_{i j}^{A B}\right|$ & $P$ \\
\hline $\mathrm{MAL} * \mathrm{~A} 3$ & 5,514 & 0,019 & 2,211 & 0,042 \\
\hline $\mathrm{MAL} * \mathrm{C} 4$ & 8,726 & 0,003 & 2,752 & 0,015 \\
\hline $\mathrm{RAF} * \mathrm{~A} 3$ & 4,337 & 0,037 & 1,718 & 0,052 \\
\hline $\mathrm{RAF} * \mathrm{C} 4$ & 7,873 & 0,005 & 2,403 & 0,014 \\
\hline Killer * A9 & 5,487 & 0,019 & 1,866 & 0,031 \\
\hline $\mathrm{GLY} * \mathrm{Cl}$ & 5,129 & 0,024 & 1,669 & 0,034 \\
\hline GLY * C3 & 6,212 & 0,013 & 1,968 & 0,023 \\
\hline $\mathrm{A} 3 * \mathrm{C} 4$ & 9,107 & 0,003 & 1,526 & 0,004 \\
\hline A4 * A5 & 54,077 & 0,000 & 3,823 & 0,000 \\
\hline $\mathrm{A} 4 * \mathrm{C} 1$ & 7,643 & 0,006 & 1,021 & 0,007 \\
\hline $\mathrm{A} 4 * \mathrm{C} 2$ & 13,490 & 0,000 & 1,416 & 0,000 \\
\hline $\mathrm{A} 4{ }^{*} \mathrm{C} 4$ & 4,219 & 0,040 & 0,924 & 0,044 \\
\hline $\mathrm{A} 4 * \mathrm{C} 5$ & 5,103 & 0,024 & 0,869 & 0,026 \\
\hline $\mathrm{A} 4{ }^{*} \mathrm{C} 7$ & 5,735 & 0,017 & 1,051 & 0,022 \\
\hline $\mathrm{A} 5 * \mathrm{Cl}$ & 4,802 & 0,028 & 0,922 & 0,034 \\
\hline $\mathrm{A} 5 * \mathrm{C} 2$ & 6,554 & 0,010 & 1,063 & 0,012 \\
\hline$A 6 * A 7$ & 36,140 & 0,000 & 2,327 & 0,000 \\
\hline $\mathrm{A} 6 * \mathrm{~A} 8$ & 5,550 & 0,018 & 0,835 & 0,020 \\
\hline $\mathrm{A} 6 * \mathrm{~B} 4$ & 4,440 & 0,035 & 1,037 & 0,044 \\
\hline$A 6 * B 7$ & 4,463 & 0,035 & 0,808 & 0,038 \\
\hline $\mathrm{A} 6 * \mathrm{C} 7$ & 13,848 & 0,000 & 1,537 & 0,000 \\
\hline $\mathrm{A} 8 * \mathrm{~A} 9$ & 27,351 & 0,000 & 2,629 & 0,000 \\
\hline $\mathrm{A} 9 * \mathrm{CO}$ & 5,837 & 0,016 & 0,941 & 0,019 \\
\hline $\mathrm{B} 3 * \mathrm{~B} 4$ & 101,455 & 0,000 & 5,946 & 0,000 \\
\hline B3 $*$ B6 & 4,780 & 0,029 & 1,016 & 0,033 \\
\hline B3 * B7 & 9,433 & 0,002 & 1,422 & 0,003 \\
\hline $\mathrm{B} 3 * \mathrm{C} 4$ & 4,208 & 0,040 & 1,075 & 0,040 \\
\hline $\mathrm{B} 3 * \mathrm{C} 6$ & 4,277 & 0,039 & 0,996 & 0,048 \\
\hline $\mathrm{B} 4 * \mathrm{~B} 6$ & 4,557 & 0,033 & 1,029 & 0,038 \\
\hline B4 $*$ B7 & 12,382 & 0,000 & 1,682 & 0,001 \\
\hline$B 6 * B 7$ & 72,824 & 0,000 & 4,179 & 0,000 \\
\hline $\mathrm{B} 7 * \mathrm{C} 7$ & 12,513 & 0,000 & 1,431 & 0,001 \\
\hline $\mathrm{CO} * \mathrm{C} 6$ & 7,848 & 0,005 & 0,989 & 0,006 \\
\hline $\mathrm{CO} * \mathrm{C} 7$ & 5,669 & 0,017 & 0,971 & 0,021 \\
\hline $\mathrm{C} 1 * \mathrm{C} 2$ & 7,222 & 0,007 & 1,060 & 0,009 \\
\hline $\mathrm{C} 1 * \mathrm{C} 3$ & 9,296 & 0,002 & 1,144 & 0,003 \\
\hline $\mathrm{C} 1 * \mathrm{C} 5$ & 16,617 & 0,000 & 1,738 & 0,000 \\
\hline $\mathrm{C} 2{ }^{*} \mathrm{C} 4$ & 12,680 & 0,000 & 1,597 & 0,001 \\
\hline $\mathrm{C} 3 * \mathrm{C} 4$ & 7,504 & 0,006 & 1,680 & 0,016 \\
\hline $\mathrm{C} 3 * \mathrm{C} 7$ & 8,207 & 0,004 & 1,145 & 0,005 \\
\hline $\mathrm{C} 5 * \mathrm{C} 6$ & 6,694 & 0,010 & 1,011 & 0,012 \\
\hline $\mathrm{C} 5 * \mathrm{C} 7$ & 6,790 & 0,009 & 1,319 & 0,016 \\
\hline $\mathrm{C} 6 * \mathrm{C} 7$ & 15,113 & 0,000 & 1,675 & 0,000 \\
\hline
\end{tabular}


Tabla 4.24: Resultado de los test no paramétricos entre las diferentes variables cuantitativas y cualitativas (variables categóricas). Se indican los niveles de significación obtenidos en los test estadísiticos $U$ de Mann-Whitney y $Z$ de Kolmogorov-Smirnov. Se hace una distinción (línea discontínua) entre las variables cualitativas: bandas en análisis de restricción y asimilación de fuentes de carbono.

\begin{tabular}{|c|c|c|c|c|c|c|c|c|c|c|c|c|c|c|c|c|c|c|c|c|}
\hline \multirow{3}{*}{$\begin{array}{c}\text { VARIABLES } \\
\text { CUANTITATIVAS }\end{array}$} & \multicolumn{20}{|c|}{ VARIABLES CUALITATIVAS (VARIABLES CATEGÓRICAS) } \\
\hline & & & & & & & & & & & & & & & & & & & & \\
\hline & A3 & A4 & A6 & A8 & A9 & B3 & B6 & B7 & $\mathrm{CO}$ & $\mathrm{C} 1$ & C3 & C4 & C5 & C6 & C7 & MAL & SAC & GLY & CEL & RAF \\
\hline Glucosa & - & - & - & - & - & - & - & - & - & $*$ & $*$ & - & - & - & - & - & - & $* * * /+$ & * & - \\
\hline Fructosa & - & - & - & - & - & $\cdot$ & $\cdot$ & - & - & - & $*$ & - & - & - & - & - & - & $* * * /++$ & - & - \\
\hline Glicerol & - & - & - & - & - & - & - & - & - & $* * /++$ & - & - & - & - & - & - & - & $* /+$ & - & - \\
\hline Acetico & - & - & - & - & - & - & $\cdot$ & - & - & $* *$ & $*$ & - & - & $\cdot$ & - & - & - & - & - & - \\
\hline Etanol & - & - & - & - & - & $\cdot$ & $\cdot$ & - & - & $* /+$ & - & - & - & $\cdot$ & - & - & - & + & - & - \\
\hline A & + & $* /+$ & - & - & - & $\cdot$ & $\cdot$ & - & - & - & - & - & - & - & - & - & - & ++ & - & - \\
\hline $\mathrm{m}$ & - & - & - & - & - & - & $\cdot$ & - & - & - & - & - & - & - & - & - & - & - & - & - \\
\hline I & - & - & - & - & - & $\cdot$ & $\cdot$ & $* * /+$ & - & $* * /+$ & - & - & + & $*$ & $* * /+$ & - & - & - & - & - \\
\hline MIC & - & - & - & - & - & + & $\cdot$ & - & - & - & - & - & $\cdot$ & $\cdot$ & - & - & - & $*$ & - & - \\
\hline $\mathrm{NIC}$ & - & - & $*$ & $* /+$ & - & + & $\cdot$ & - & - & - & - & - & - & $\cdot$ & - & - & - & - & - & - \\
\hline $\mathrm{m}^{\prime \prime}$ & - & - & - & - & - & - & $*$ & - & $* /++$ & - & - & $*$ & $\cdot$ & + & $*$ & $*$ & $* * /++$ & - & - & $* * /+$ \\
\hline$A^{\prime}$ & - & - & - & - & - & $\cdot$ & $\cdot$ & - & - & - & - & - & - & $\cdot$ & - & - & - & - & - & - \\
\hline $\mathrm{m}^{\prime}$ & - & - & $\cdot$ & - & - & $\cdot$ & $\cdot$ & - & - & - & $*$ & - & - & $\cdot$ & - & - & - & - & - & - \\
\hline I' & $* * /+$ & - & - & - & + & - & - & - & - & - & - & $*$ & - & - & - & $* * /+$ & $* /+$ & - & - & $* * /++$ \\
\hline
\end{tabular}

*, Nivel de significación del $5 \%(P<0,05)$ según test $U$ de Mann-Whitney; ${ }^{* *}$, Nivel de significación del $1 \%(P<0,01)$ según test $U$ de Mann-Whitney; ${ }^{* * *}$, Nivel de significación del $1 \%$ ( $(P<0,001)$ según test $U$ de Mann-Whitney

+ , Nivel de significación del $5 \%(P<0,05)$ según test Z de Kolmogorov-Smirnov; ++ , Nivel de significación del $1 \%(P<0,01)$ según test $Z$ de Kolmogorov-Smirnov; +++, Nivel de significación del $1 \%$ o ( $(P<0,001)$ según test $Z$ de Kolmogorov-Smirnov Con un guión se indican las parejas cuyas relaciones no son significativas. 


\subsection{Caracterización aromática de vinos elaborados con uva Prieto Picudo (DO «Tierra de León»)}

\subsubsection{Selección de cepas para la posterior caracterización aromática de vinos elaborados en microfermentaciones}

Tras la caracterización fenotípica y enológica de las 30 cepas seleccionadas a partir de la colección inicial (119 cepas), se decidió hacer una caracterización aromática de los vinos elaborados en microfermentaciones empleando alguna de estas cepas. Adicionalmente se analizaron dos vinos rosados comerciales (Pardevalles 2.009 y Castro luvara 2.009 de Bodegas y Viñedos Pardevalles y Vinícola Valmadrigal, respectivamente] con el fin último de llevar a cabo la caracterización aromática de los vinos englobados bajo la DO «Tierra de León».

Realizar un estudio sobre los vinos producidos con las 30 cepas ampliamente caracterizadas fenotípica y enológicamente resultaba inviable, por lo que se llevó a cabo una nueva selección dentro del conjunto de cepas analizadas con anterioridad. La selección se hizo de acuerdo a propiedades y características diversas (tabla 4.25) que resultaban de interés, con el fin último de obtener una representación fiel de los diferentes comportamientos mostrados por las distintas cepas caracterizadas. Así, entre las 30 cepas se seleccionaron 12, que junto a la cepa híbrida PB7 (tipo o cepa P5-XI) formaron el heterogéneo grupo de 13 cepas que dio lugar a los vinos cuya caracterización aromática se describe en los siguientes apartados. Los vinos fueron obtenidos tal como se indica en el apartado 3.11.1, denominándose, en cada caso, del mismo modo que la cepa empleada en su elaboración.

Tabla 4.25: Cepas seleccionadas para la elaboración de vinos en microfermentaciones a partir de los cuales se realizó la caracterización aromática de vinos eleborados con la uva Prieto Picudo (DO «Tierra de León»)

\begin{tabular}{|c|c|c|}
\hline Bodega & Cepa & Características / Propiedades \\
\hline \multirow[b]{3}{*}{ Gordonzello S.A. } & G5 - ॥ & $\begin{array}{l}\text { Cepa mayoritaria en la cosecha de } 2.005 \\
\text { Alta producción de glicerol } \\
\text { Producción de vinos secos } \\
\text { Elevado contenido en ácido acético (no deseado) }\end{array}$ \\
\hline & G7 - III & Aislamiento en las tres cosechas caracterizadas \\
\hline & G7 - XIV & $\begin{array}{l}\text { Aislamiento en dos de las tres cosechas analizadas } \\
\text { Propiedades aceptables en todas los estudios realizados }\end{array}$ \\
\hline \multirow[b]{2}{*}{ Coop. de los Oteros } & P5 - XI & Cepa híbrida (PB7) (S. cerevisiae $\times$ S. kudriavzevii) \\
\hline & P7 - XII & $\begin{array}{l}\text { Cepa mayoritaria en la cosecha de } 2.007 \\
\text { Alta producción de glicerol }\end{array}$ \\
\hline \multirow[b]{2}{*}{ Pedro Casis } & C9-I & $\begin{array}{l}\text { Aparece en las tres cosechas analizadas (cepa mayoritaria) } \\
\text { Buen comportamiento en todos los estudios realizados }\end{array}$ \\
\hline & C9-II & Cepa coexistente en cuatro de las cinco bodegas estudiadas \\
\hline \multirow[b]{3}{*}{ Coop. Vin. Ribera del Cea } & R7 - I & $\begin{array}{l}\text { Detección en dos de las cosechas caracterizadas } \\
\text { Buen comportamiento a bajas temperaturas }\end{array}$ \\
\hline & R8 - II & $\begin{array}{l}\text { Cepa mayoritaria en la cosecha de } 2.008 \\
\text { Comportamiento aceptable en los estudios realizados }\end{array}$ \\
\hline & $\mathrm{R} 8 \cdot \mathrm{VI}$ & $\begin{array}{l}\text { Comportamiento óptimo a bajas temperaturas } \\
\text { Buen comportamiendo en fermentación }\end{array}$ \\
\hline \multirow[b]{3}{*}{ Vinícola Valmadrigal } & V6- II & $\begin{array}{l}\text { Cepa mayoritaria en la cosecha de } 2.006 \text { (75,86 \% implantación) } \\
\text { Buen comportamiento en fermentación }\end{array}$ \\
\hline & V7 - III & $\begin{array}{l}\text { Cepa aislada en dos de las cosechas estudiadas } \\
\text { Comportamiento aceptable en los estudios realizados }\end{array}$ \\
\hline & V8 - XVII & $\begin{array}{l}\text { Cepa coexistente en dos de las cosechas caracterizadas } \\
\text { Comportamiento aceptable en los estudios realizados }\end{array}$ \\
\hline
\end{tabular}




\subsubsection{Análisis descriptivo sensorial de los vinos experimentales}

Una vez elaborados por microfermentación 13 vinos utilizando para ello las 13 levaduras seleccionadas, se procedió a su caracterización mediante el procedimiento de cata ortonasal. La cata ortonasal (ver apartado 3.11.2) fue llevada a cabo por el panel sensorial de acuerdo a nueve descriptores aromáticos previamente consensuados: fruta fresca, fruta madura, fruta exótica, vegetal/terroso, hierbas aromáticas, tostado, dulce, especiado y reducción (tabla 3.13). El descriptor que mejor describe el aroma de los vinos es la familia de la fruta fresca (tabla 4.26) (definida como una mezcla de pera, plátano, fresa y piña). Los valores alcanzados para este descriptor eran bastante altos en todos ellos, con valores que oscilaban entre el $57,4 \%$ y $82,8 \%$, como es de esperar para un vino joven que únicamente ha soportado la fermentación alcohólica. Otros descriptores interesantes fueron la fruta exótica y notas dulces, con unos valores del $24,8 \%$ y $52,1 \%$ respectivamente.

Tabla 4.26: Resultado de la caracterización sensorial de los 13 vinos experimentales mediante cata ortonasal. Para cada vino (arriba) se indican los valores de frecuencia modificada [MF(\%)] obtenidos para cada uno de los descriptores aromáticos indicados (izquierda).

\begin{tabular}{|c|c|c|c|c|c|c|c|c|c|c|c|c|c|}
\hline \multirow[b]{2}{*}{ DESCRIPTORES } & \multicolumn{13}{|c|}{ VINOS EXPERIMENTALES } \\
\hline & G5-II & G7-III & G7-XIV & P5-XI & P7-XII & C9-I & C9-II & R7-I & R8-II & R8-VI & V6-II & V7-III & V8-XVII \\
\hline Fruta fresca & 58,8 & 66,7 & 65,4 & 70,3 & 73,3 & 74,5 & 82,8 & 80,5 & 67,9 & 77,0 & 57,4 & 72,6 & 66,7 \\
\hline Fruta exótica & 0,0 & 0,0 & 0,0 & 9,1 & 14,3 & 9,1 & 24,8 & 9,1 & 9,1 & 0,0 & 6,4 & 6,4 & 0,0 \\
\hline Frutos secos & 0,0 & 9,1 & 6,4 & 6,4 & 6,4 & 0,0 & 0,0 & 0,0 & 0,0 & 0,0 & 6,4 & 9,1 & 6,4 \\
\hline Vegetal & 0,0 & 11,1 & 6,4 & 0,0 & 24,0 & 12,8 & 0,0 & 6,4 & 31,4 & 6,4 & 0,0 & 6,4 & 9,1 \\
\hline Hierbasaromáticas & 17,6 & 30,4 & 6,4 & 15,7 & 28,7 & 20,8 & 12,8 & 12,8 & 22,2 & 28,7 & 19,2 & 17,6 & 30,1 \\
\hline Especiado & 7,9 & 11,1 & 12,8 & 0,0 & 27,2 & 11,1 & 11,1 & 14,3 & 14,3 & 6,4 & 11,1 & 12,8 & 11,1 \\
\hline Dulce & 28,7 & 38,0 & 40,6 & 36,6 & 25,7 & 36,9 & 52,1 & 40,6 & 32,1 & 38,0 & 22,2 & 32,1 & 23,6 \\
\hline Tostado & 12,8 & 18,1 & 15,7 & 14,3 & 0,0 & 11,1 & 14,3 & 32,1 & 15,7 & 6,4 & 14,3 & 6,4 & 32,7 \\
\hline Reducción & 48,4 & 32,7 & 32,1 & 40,6 & 28,7 & 6,4 & 6,4 & 15,7 & 26,1 & 24,8 & 14,3 & 7,9 & 24,8 \\
\hline
\end{tabular}

En la figura 4.40 (A) se muestran las proyecciones de las variables sensoriales (descriptores aromáticos) en el plano formado por los Componentes Principales CP1 y CP2 (explican un $55 \%$ de la varianza total). El CP1 (31\%) enfrenta los descriptores fruta (fruta fresca, madura y exótica) y dulce al atributo reducción. El CP2 (24 \%) queda definido por los descriptores especiado, vegetal y hierbas aromáticas. La disposición de los vinos en el plano citado se presenta en la figura 4.40 (B), de modo que los que comparten el mismo icono pertenecen a un mismo grupo, según los resultados obtenidos en un análisis de agrupamiento (HCA). Tal como se observa, los vinos están dispersos de acuerdo a los cuatro vectores aromáticos principales: reducción/tostado (vinos G5-II, G7-III, G7-XIV, P5-XI, V6-II y V8-XVII), vegetal (vinos P7-XII y R8-II), fruta exótica/fresca (vinos C9-I, R8-VI y V7-III) y frutos secos/dulce (C9-II y R7-I). Los términos vegetal/terroso y reducción son los únicos términos que varían significativametne $(P<0,01)$ entre las diferentes muestras. De acuerdo al resultado obtenido mediante el test de Duncan $(P<0,05)$ el vino P7-XII, y en menor medida el vino R8-II, muestran unas notas vegetales significativametne superiores al resto de muestras. Por otro lado, las muestras G5-II y P5-XI presentaban significativamente las mayores puntuaciones en el atributo reducción.

Ya que el fin último de este estudio es realizar una caracterización aromática de los vinos elaborados a partir de mosto de uva Prieto Picudo, de entre los trece vinos experimentales se seleccionaron aquellos vinos que presentaron las mayores diferencias en su perfil aromático para ser sometidos a posteriores análisis. De este modo se obtuvo una representación fiel de los diferentes perfiles sensoriales, influenciados en gran medida por la cepa de $\mathrm{S}$. cerevisiae empleada en cada caso. 
Con los resultados obtenidos mediante del análisis de componentes principales (ACP) y el análisis de agrupamiento (HCA), se seleccionaron los cuatro vinos localizados en los extremos de los grupos anteriomente mencionados (G5-II, P7-XII, C9-I y C9-II), como ejemplos de vinos que evocan a reducción, vegetal, fruta exótica/fresca y frutos secos/notas dulces, respectivamente. Con fines meramente comparativos también se analizó el vino R8-VI debido a que su situación en el centro del gráfico ACP indica que no presentaba máxima puntuación en ninguna de las notas aromaticas anteriormente indicadas y por tanto podría ser considerado un vino neutro.

A

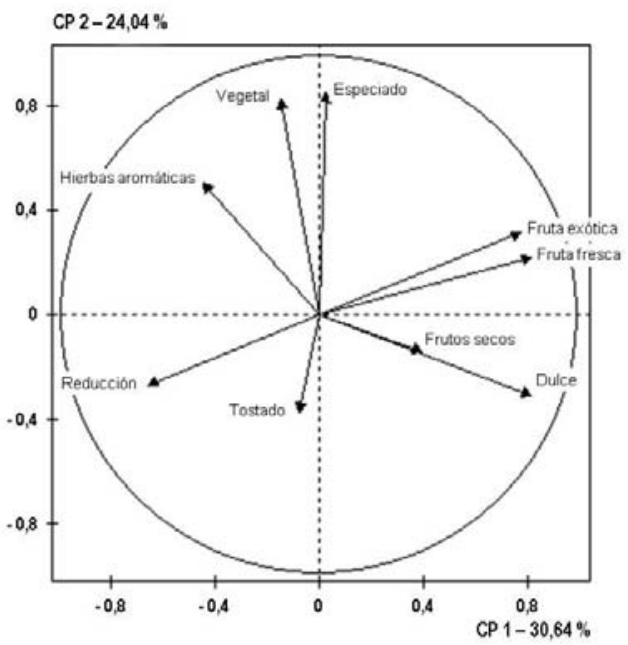

B

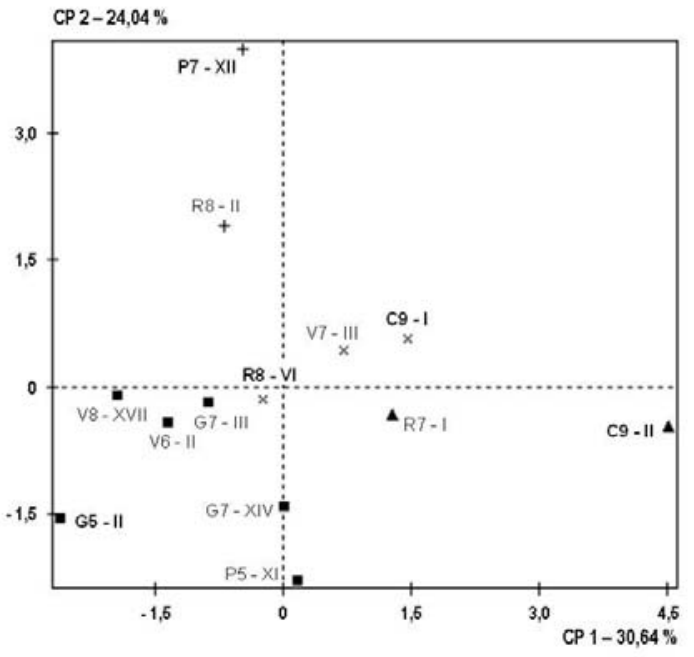

Figura 4.40: Resultado del análisis descriptivo sensorial. En A se muestra el círculo de correlación para los descriptores sensoriales en un análisis ACP (componentes principales 1 y 2). En B se muestra la proyección de los vinos en el gráfico ACP. Los vinos con el mismo icono $(+, x, \boldsymbol{\Delta}$ ó $\boldsymbol{\square})$ pertenecen al mismo grupo de acuerdo a los resultados del análisis de agrupamiento (HCA). Resaltados en negrita se indican los vinos seleccionados para ser sometidos a posteriores análisis (GC-O y análisis químicos).

\subsubsection{Parámetros enológicos convencionales}

Como los vinos empleados para la caracterización arómatica fueron elaborados únicamente para este fin fue necesario un análisis de los parámetros enológicos convencionales del producto final obtenido. En la tabla 4.27 se muestran los parámetros enológicos básicos mediante HPLC del mosto de uva, de los cinco vinos experimentales seleccionados y de los dos vinos rosados comerciales incluidos en el estudio. Los resultados incluyen un análisis de ANOVA para el factor "cepa de levadura".

Tabla 4.27: Resultado del análisis de los parámetros enológicos convencionales de los vinos empleados en la caracterización aromática. Se incluyen el mosto de uva, los cinco vinos experimentales y los dos vinos rosados comerciales (denominación comercial y cosecha). Los valores acompañados de letras diferentes son estadísticamente significativos de acuerdo a un análisis ANOVA $(P<0,05)$.

\begin{tabular}{|c|c|c|c|c|c|c|c|c|}
\hline \multirow[b]{3}{*}{ Compuestos } & \multirow[b]{3}{*}{ Mosto } & \multicolumn{5}{|c|}{ VINOS EXPERIMENTALES } & \multicolumn{2}{|c|}{ VINOS COMERCIALES } \\
\hline & & & & & & & Pardevalles & Castro Luvara \\
\hline & & G5 - II & P7 - XII & C9-I & C9 - II & $\mathrm{R} 8$ - VI & 2009 & 2009 \\
\hline Glucosa (g/L) & 115 & - & - & - & - & - & $<0,10$ & $<0,10$ \\
\hline Fructosa $(\mathrm{g} / \mathrm{L})$ & 105 & $1,12^{a b}$ & $1,18^{b c}$ & $1,36^{d}$ & $1,36^{d}$ & $1,22^{c}$ & $1,07^{a}$ & $1,23^{c}$ \\
\hline Glicerol (g/L) & & $6,7^{c}$ & $7,5^{e}$ & $5,3^{a}$ & $5,6^{b}$ & $5,6^{b}$ & $6,6^{c}$ & $7,0^{d}$ \\
\hline Etanol (\% vol.) & & $13,2^{a}$ & $13,4^{a b}$ & 13,6 bc & $13,6^{b c d}$ & $13,8^{c d}$ & $13,7 \mathrm{bcd}$ & $13,9^{d}$ \\
\hline Ác. acético (mg/L) & & $842^{d}$ & $1424^{e}$ & $588^{c}$ & $465^{b}$ & $383^{a}$ & $537 b c$ & $521 \mathrm{bc}$ \\
\hline
\end{tabular}


Aunque los cinco parámetros estudiados (niveles de glucosa, fructosa, glicerol, etanol y ácido acético) variaban significativamente entre los diferentes vinos, podemos resumir que las cinco levaduras seleccionadas eran capaces de producir, en todos los casos, vinos secos (bajos niveles de azúcares residuales) con unos niveles adecuados de etanol. Los niveles de glicerol variaban significativamente $(p<0,05)$ entre las diferentes muestras, desde los $5,33 \mathrm{~g} / \mathrm{L}$ (C9-I) hasta los 7,54 g/L (P7-XII), cuyos valores pueden ser considerados como normales (Ough et al. 1972; Scanes et al. 1998). Los niveles de ácido acético entre los vinos experimentales van desde los 383 hasta los $1424 \mathrm{mg} / \mathrm{L}$. Algunos autores afirman que son aceptable niveles de este compuesto en torno a los $600 \mathrm{mg} / \mathrm{L}$ (Romano, 1990) o entre 700 y $1.100 \mathrm{mg} / \mathrm{L}$ en función del tipo de vino (Corison et al. 1979). Existen estudios que ponen de manifiesto que concentraciones por encima de los $450 \mathrm{mg} / \mathrm{L}$ de este compuesto pueden provocar una depreciación en la percepción de las notas frutales de un vino (Campo et al. 2005). Los altos valores de ácido acético encontrados en las muestras G5-II y P7-XII concuerdan con la baja nota frutal obtenida para estos vinos en el análisis descriptivo sensorial (figura 4.40).

\subsubsection{Estudio mediante cromatografía gaseosa-olfatometría (GC-0)}

Se realizó el estudios sobre los 5 vinos experimentales seleccionados y los dos comerciales (ver apartado 3.11.3). Los resultados se muestran en la tabla 4.29. Con intención de simplificar el análisis, aquellos odorantes que no superaron una puntuación de 30 [MF(\%)] en ninguno de los vinos estudiados no se tuvieron en cuenta y se consideraron ruido. Varios odorantes que aparecen en la tabla presenta valores de frecuencia modificada superiores a 50: 2,3-butanodiona (diacetilo), los ésteres etílicos del ácido butírico y hexanoico, acetato de isoamilo, alcohol isoamilico, alcohol de B-feniletilo y ácido isovaleriánico.

Por lo genenal, el número y naturaleza de los compuestos detectados en los vinos experimentales fueron los mismos que los encontrados en los vinos comerciales, aunque con algunas excepciones. Por ejemplo, el acetato de 3-mercaptohexilo (MHA), guaiacol y furaneol se detectaron únicamente en los vinos comerciales. El primero de los indicados es un compuesto varietal asociado a variedades de uva blanca como Sauvignon Blanc (MateoVivaracho et al. 2010; Tominaga et al. 1996) y Verdejo (Campo et al. 2005; Mateo-Vivaracho et al. 2010). El guaiacol es un compuesto extraíble de la madera (Jarauta et al. 2005), pero también puede ser liberado a partir de precursores no aromáticos presentes en la uva durante el proceso de fermentación (Hernández-Orte et al. 2008; Loscos et al. 2007). El furaneol (2,5dimetil-4-hidroxi-3(2H)-furanona) es un compuesto que puede ser liberado durante el proceso de envejecimiento en madera, aunque también es posible su presencia en vinos que no hayan estado en contacto con la madera (liberación o formación durante la fermentación a partir de precursores presentes en la uva) (Jarauta et al. 2005).

Un resultado interesante fue el obtenido para los ésteres ramificados de cadena corta, como el 2-metilbutirato de etilo y 3-metilbutirato de etilo. Estos compuestos alcanzaban valores de MF (\%) superiores a 40 en los dos vinos comerciales, no detectándose en algunos de los vinos producidos en laboratorio (por ejemplo el 2-metilbutirato de etilo no se detecto en los vinos P7-XII y C9-II y el 3-metilbutirato de etilo en los vinos G5-II y P7-XII), o mostrando valores muy bajos (inferiores a 30 ).

Los componentes diferenciadores serán aquellos que jueguen un papel más importante en la apreciación de diferencias aromáticas entre las diferentes muestras. Para asignar a un compuesto en particular dicha propiedad son precisos la realización de test sensoriales, aunque mediante la observación de los datos olfatométricos es posible realizar una aproximación. En la tabla 4.28 se presenta un ranking con los odorantes que han presentado mayores diferencias de puntuacion (minimo de $40 \%$ de MF) entre los cinco vinos 
experimentales, siendo los compuestos con mayor infuencia en las diferencias sensoriales encontradas. En total se muestran 13 compuestos pertenecientes a diferentes familias aromáticas, donde destacó un inusual compuesto con un índice de retención lineal (columna polar) de 1106 que evoca notas herbales/especiadas, más concretamente a "cannabis" (situándose en la parte superior de la tabla, diferencia más marcada). Este compuesto había sido ya identificado previamente en un vino de la DO "Tierra de León" por San-Juan y Ferreira (comunicación personal) como 3-metil-but-2-en-1-tiol (MBT) por comparación del espectro de masas obtenido, así como del olor percibido en el puerto olfatométrico, con el correspondiente al compuesto puro. Este odorante únicamente se detectó en dos vinos experimentales (P7-XII y C9-I), aunque en el vino C9-I presentó un valor muy alto (71\%) siendo detectado por más de la mitad del panel sensorial como muy intenso. Este compuesto sólo ha sido descrito en vinos englobados bajo la DO "Sauternes" (Francia), cuya peculiaridad radica en que se trata de vinos elaborados a partir de uvas de las variedades Sauvignon Blanc, Semillón o Muscadelle contaminadas con podredumbre gris (Botrytis cinerea) (Bailly et al. 2006). Sin embargo, en cerveza es bien conocida la presencia de este compuesto (defecto) asociado principalmente a la degradación de las isohumolonas por acción de la luz, aunque se han descrito mecanismos de generación (en ausencia de luz) donde el sulfuro de hidrógeno generado por la levadura en fermentación tiene gran importancia (Vermeulen et al. 2006). Por tanto, se podría apuntar el origen fermentativo de este compuesto, altamente dependiente de la cepa empleada en el proceso de obtención de los vinos.

Otro compuesto que presenta unas diferencias marcadas es el 4-mercapto-4-metilpentan2-ona (4MP), que evoca aromas a "boj/fruta de la pasión". Este tiol presenta un bajo umbral aromático, de sólo $0,8 \mathrm{ng} / \mathrm{L}$ (Tominaga et al. 2000), siendo con casi toda seguridad el responsable del aroma a "fruta de la pasión" detectado en el vino C9-I (cepa aislada en la bodega Pedro Casis) en el análisis sensorial (ver figura 4.40). Cabe indicar que la muestra C9-I presenta los valores máximos de más de la mitad de los compuestos incluidos en la tabla 4.28. Esto pone de manifiesto la capacidad de la cepa C9-I para producir vinos con un perfil aromático rico y complejo, indicando su gran capacidad para liberar compuestos aromáticos durante el proceso fermentativo.

Tabla 4.28: Ranking de los odorantes con capacidad para generar diferencias aromáticas entre los vinos experimentales. Se incluyen aquellos compuestos listados en la tabla 4.29 que presentaron, entre los vinos experimentales, una mayor diferencia entre la máxima y mínima puntuación (minimo de un 40 \% MF). Se indica el compuesto, la descripción del olor que evoca, la diferencia existente entre el máximo y el mínimo y el vino en el que el compuesto en particular obtuvo la mayor puntuación.

\begin{tabular}{llcc}
\hline Compuesto Químico & Descripción del olor & max-min & Muestra con máxima puntuación \\
\hline 3-metilbut-2-en-1-tiol (MBT) & herbal, cannabis & 71 & C9-I \\
4-mercapto-4-metilpentan-2-ona (4MP) & boj, fruta tropical & 63 & C9-I \\
Z-2-nonenal & aldehídico, & 55 & C9-I \\
E-2-nonenal & jabón & 50 & C9-I \\
n.i. 1410 & champiñon, comida & 50 & R8-VI \\
p-cresol (m-cresol) & animal, establo & 50 & C9-II \\
pentano-2,3-diona & mantequilla, nata & 43 & C9-I \\
3-isopropil-2-metoxypirazina & pimiento, terroso & 43 & C9-I \\
ácido acético & vinagre & 43 & G5-II \\
o-cresol & humedad, suciedad & 42 & C9-I \\
isobutanol & fusel & 41 & C9-II \\
ácido butírico & vómito, queso & 41 & G5-II \\
butirato de etilo & frutal, fresa & 40 & C9-I \\
\hline
\end{tabular}


Tabla 4.29: Odorantes encontrados mediante análisis GC-O en los 7 vinos analizados (5 vinos experimentales y dos vinos comerciales). Para cada uno de estos odorantes se indican los datos de retención en columna, la descripción del olor en el puerto olfatométrico, el compuesto químico correspondiente y la frecuencia modifica obtenida en los diferentes vinos [MF (\%)].

\begin{tabular}{|c|c|c|c|c|c|c|c|c|c|c|}
\hline \multirow[b]{2}{*}{$I^{R L}{ }^{a}$} & \multirow[b]{2}{*}{ Descripción del olor } & \multirow[b]{2}{*}{ Compuesto Químico } & \multirow[b]{2}{*}{ G5 - II } & \multicolumn{3}{|c|}{ VINOS EXPERIMENTALES } & \multicolumn{4}{|c|}{ VINOS COMERCIALES } \\
\hline & & & & P7 - XII & C9-I & C9-II & $\mathrm{R} 8 \cdot \mathrm{VI}$ & Pardevalles (2009) & Castro luvara (2009) & Media \\
\hline 974 & mantequilla & diacetilo (butano-2,3-diona) ${ }^{b}$ & 78 & 63 & 76 & 87 & 78 & 80 & 83 & 78 \\
\hline 1035 & frutal, fresa & butirato de etilob & 76 & 43 & 83 & 78 & 80 & 65 & 75 & 71 \\
\hline 1053 & frutal, fresa & 2-metilbutirato de etilob & 29 & 0 & 33 & 0 & 19 & 43 & 54 & 25 \\
\hline 1058 & mantequilla, nata & pentano-2,3-diona ${ }^{b}$ & 0 & 0 & 43 & 22 & 17 & 22 & 19 & 18 \\
\hline 1070 & frutal, fresa & 3-metilbutirato de etilo (isovalerato de etilo) ${ }^{b}$ & 0 & 0 & 39 & 31 & 22 & 63 & 75 & 33 \\
\hline 1099 & fusel & isobutanol $^{b}+$ n.i. ${ }^{d}$ & 30 & 0 & 38 & 41 & 26 & 41 & 17 & 28 \\
\hline 1106 & herbal, cannabis & 3-metilbut-2-en-1-tiol (MBT) ${ }^{\mathrm{b}}$ & 0 & 24 & 71 & 0 & 0 & 0 & 0 & 14 \\
\hline 1125 & plátano & acetato de isoamilob & 54 & 39 & 56 & 53 & 59 & 73 & 47 & 54 \\
\hline 1216 & fusel & alcohol isoamilico $^{b}+$ geranio $^{d}$ & 85 & 83 & 91 & 88 & 80 & 76 & 93 & 85 \\
\hline 1240 & frutal, fresa & hexanoato de etilob & 83 & 66 & 65 & 80 & 83 & 78 & 63 & 74 \\
\hline 1306 & champiñon & 1-octen-3-ona ${ }^{c}$ & 17 & 17 & 24 & 0 & 26 & 17 & 30 & 19 \\
\hline 1314 & carne, barbacoa & 2-metil-3-furantiol (MF) ${ }^{c}$ & 37 & 31 & 35 & 29 & 44 & 0 & 24 & 29 \\
\hline 1383 & boj, fruta tropical & 4-mercapto-4-metilpentan-2-ona (4MP) ${ }^{\mathrm{b}}$ & 0 & 33 & 63 & 0 & 62 & 29 & 45 & 33 \\
\hline 1394 & limón, verde & (Z)-3-hexen-1-olb & 0 & 17 & 33 & 0 & 22 & 0 & 0 & 10 \\
\hline 1410 & champiñón, comida & n.i. ${ }^{d}$ & 29 & 0 & 29 & 0 & 50 & 0 & 22 & 19 \\
\hline 1444 & pimiento, terroso & 3-isopropil-2-metoxipirazinab & 0 & 0 & 43 & 19 & 0 & 25 & 31 & 17 \\
\hline $1454-1460$ & vinagre & ácido acético b & 82 & 65 & 66 & 49 & 39 & 0 & 51 & 50 \\
\hline 1511 & aldehídico & (Z)-2-nonenal ${ }^{\mathrm{b}}$ & 0 & 0 & 55 & 24 & 24 & 71 & 0 & 25 \\
\hline 1541 & jabón & (E)-2-nonenal ${ }^{b}$ & 0 & 19 & 50 & 19 & 19 & 22 & 36 & 24 \\
\hline 1632 & pan quemado & 2-acetilpirazina ${ }^{c}$ & 71 & 66 & 82 & 73 & 82 & 78 & 37 & 70 \\
\hline 1637 & vómito, queso & ácido butírico ${ }^{b}$ & 41 & 22 & 24 & 0 & 24 & 33 & 29 & 25 \\
\hline 1675 & queso & ácido isovaleriánico b & 39 & 41 & 69 & 47 & 65 & 67 & 63 & 56 \\
\hline 1730 & orina de gato & acetato de 3 mercaptohexilo $(\mathrm{MHA})^{\mathrm{b}}$ & 0 & 0 & 0 & 0 & 0 & 0 & 43 & 6 \\
\hline 1741 & cebolla, sudor & n.i. ${ }^{d}$ & 0 & 0 & 35 & 0 & 14 & 0 & 0 & 7 \\
\hline 1784 & geranio & $\beta$-citronelol ${ }^{b}$ & 31 & 0 & 31 & 0 & 22 & 38 & 47 & 24 \\
\hline 1821 & humedad & 2,4,6-tricloroanisol ${ }^{\mathrm{b}}$ & 0 & 0 & 33 & 0 & 0 & 0 & 0 & 5 \\
\hline $1823-1826$ & coco, humedad & n.i. + acetate de $\beta$-feniletilo ${ }^{b}$ & 47 & 76 & 63 & 71 & 75 & 73 & 47 & 65 \\
\hline 1826 & cirvela seca & $\beta$-damascenona ${ }^{b}$ & 54 & 47 & 78 & 54 & 51 & 65 & 47 & 57 \\
\hline 1865 & fenólico & guaiacolb $^{b}$ & 0 & 0 & 0 & 0 & 0 & 10 & 43 & 8 \\
\hline 1897 & floral & dihidrocinamato de etilob & 24 & 0 & 30 & 0 & 0 & 0 & 0 & 8 \\
\hline 1924 & rosas & alcohol de $\beta$-feniletilob & 54 & 53 & 58 & 54 & 49 & 70 & 65 & 58 \\
\hline $1996-2007$ & humeda, suciedad & o-cresol ${ }^{b}$ & 29 & 17 & 59 & 47 & 45 & 33 & 22 & 36 \\
\hline 2047 & caramelo & furaneol ${ }^{b}$ & 0 & 0 & 0 & 0 & 0 & 0 & 37 & 5 \\
\hline $2097-2104$ & animal, establo & p-cresol $(m \text {-cresol) })^{b}$ & 0 & 29 & 43 & 50 & 36 & 45 & 35 & 34 \\
\hline 2194-2201 & cuero & 4-etilfenol ${ }^{b}$ & 37 & 53 & 25 & 45 & 45 & 38 & 37 & 40 \\
\hline $2214-2231$ & especiado & sotolón ${ }^{b}$ & 45 & 63 & 65 & 63 & 47 & 73 & 71 & 61 \\
\hline
\end{tabular}

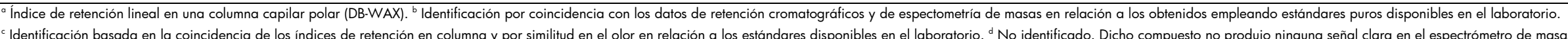




\subsubsection{Análisis químico cuantitativo de los componentes del aroma}

Los datos cuantitativos de los compuestos volátiles analizados en los vinos experimentales y comerciales se muestran en la tabla 4.30. Los valores $(\mu \mathrm{g} / \mathrm{L})$ indicados son la media de los correspondientes análisis mediante cromatografía gaseosa: tres microvinificaciones empleando una misma cepa en los vinos experimentales, mientras que en los vinos comerciales se indica el valor obtenido tras la inyección por triplicado de los correspondientes extractos. En ambos casos se indica la desviación estándar (SD) de la media. Cabría esperar una mayor SD en los vinos experimentales por tratarse de tres muestras diferentes (réplicas biológicas) que dieron lugar a tres extractos distintos, mientras que los vinos comerciales fueron analizados a partir de un único extracto.

Los resultados más significativos de este análisis son:

I. Si atendemos al número de compuestos identificados, los ésteres y acetatos forman el grupo más numeroso con un total de 17 compuestos. El éster predominante es el acetato de etilo, con un característico olor a solvente. El valor más elevado obtenido, $62 \mathrm{mg} / \mathrm{L}$, corresponde a la muestra R8-VI (vino elaborado con cepa aislada en la bodega Coop. Vin. Ribera del Cea), aunque se encuentra muy por debajo del umbral de $160 \mathrm{mg} / \mathrm{L}$ (RibéreauGayon et al. 2000). Esta misma muestra presenta los máximos valores de ésteres de etilo lineales (hexanoato de etilo) y ramificados (butirato, isobutirato, isovalerato y 2 metilbutirato de etilo), acetato de isoamilo, así como sus correspondientes ácidos grasos (ácido hexanoico, ácido butírico, ácido isobutírico y alcohol isoamílico). La mayoría de los ésteres que aparecen en las bebidas alcohólicas son generadas por las levaduras durante la fermentación. Dentro de esta amplia familia aromática, la importante contribución aromática de los ésteres de etilo de ácidos grasos, así como de los acetatos de alcoholes superiores es bien conocida (Ferreira et al. 1995). Por un lado suelen encontrarse en concentraciones superiores a su umbral aromático, y por otro, alguno de los descriptores empleados en los análisis sensoriales (cata) coincide con el propio aroma de los compuestos ("fresa/piña" y "plátano" para los ésteres de etilo y el acetato de isoamilo, respectivamente). De hecho, la muestra R8-VI obtuvo una de las puntuaciones más altas para el descriptor "fruta fresca", ya que presentó un valor de MF del $77 \%$. Así este vino fue agrupado con las muestras C9-I y V7-III (situados en la dirección del vector fruta fresca/exótica, ver figura 4.40).

II. El acetato de 2-feniletilo es otro compuesto fermentativo con gran importancia. Se encuentra por encima de su umbral en todas las muestras, aunque su valor es especialmente elevado en el vino producido con la cepa C9-II (1946 $\mathrm{g} / \mathrm{L})$. Recientes estudios acerca de la formación de compuestos varietales a partir de variedades de uvas no aromáticas (HernándezOrte et al. 2008) indican valores de este compuesto de $5876 \mu \mathrm{g} / \mathrm{L}$ cuando se emplea Hanseniaspora uvarum en la fermentación, poniendo de manifiesto que la síntesis de este compuesto es altamente dependiente del género de levadura empleado. Si atendemos a su importancia sensorial, este compuesto ha sido considerado durante décadas como un compuesto que producía un aumento en la complejidad de vinos neutros. Sin embargo, recientes estudios (Campo et al. 2005) han puesto de manifiesto su capacidad para potenciar la nota dulce en vinos blancos jóvenes. Quizás este sea el motivo por el cual el vino C9-II (bodega Pedro Casis) denotó notas dulces de acuerdo al resultado obtenido en el análisis sensorial (figura 4.40).

III. Los alcoholes son, cuantitativamente, el grupo más grande de compuestos aromáticos, tanto en los vinos experimentales como en los comerciales. Los alcoholes isobutanol, butan-1ol, alcohol isoamílico, alcohol bencílico y metionol son conocidos por su fuerte y desagradable olor y sabor. En vista de los resultados obtenidos, vemos como el uso de diferentes cepas de 
levaduras puede influir en los perfiles y concentraciones de alcoholes superiores tal como han descrito algunos autores (Giudici et al. 1990). Hay que prestar especial atención a los alcoholes con seis átomos de carbono, como el 1-hexanol y el (Z)-3-hexen-1-ol. Estos aportan notas "vegetales" y "herbáceas" en aquellos vinos donde se encuentran en unas concentraciones considerables. Así, el vino obtenido con la cepa P7-XII (Coop. de los Oteros) presenta los máximos valores para estos compuestos (2248 y $292 \mu \mathrm{g} / \mathrm{L}$, respectivamente) justificando el carácter vegetal obtenido en el análisis sensorial (ver posición de este vino en el gráfico ACP-HCA, figura 4.40).

IV. Se han cuantificado otras familias de compuestos como los terpenos, norisoprenoides, fenoles volátiles, derivados de la vainillina o lactonas. La concentración de linalol detectada en el vino comercial Castro luvara $(29,61 \mu \mathrm{g} / \mathrm{L})$ es suficiente para ser considerado un compuesto activo (también denominado como compuesto de impacto) (Ferreira et al. 2000). En estudios previos ha quedado demostrado que los niveles de terpenos son altamente dependientes de la cepa empleada (Loscos et al. 2007). Nuestros resultados confirman lo anterior, ya que la cepa P7-XII produjo vinos con los niveles más altos de terpenos (linalol, $\alpha$ terpineol, B-citronelol y genariol). Adicionalmente este vino experimental presentó los niveles más elevados en los norisoprenoides $B$-damascenona y B-ionona, con concentraciones de 6,2 y $0,32 \mu \mathrm{g} / \mathrm{L}$, respectivamente, con la excepción del vino comercial Pardevalles 2.009 que presentó niveles algo superiores (B-damascenona, $8,8 \mu \mathrm{g} / \mathrm{L}$ y $B$-ionona $0,34 \mu \mathrm{g} / \mathrm{L}$ ). Pineau et al. (2007) demostraron que la influencia de la B-damascenona en un vino puede tener más impacto indirecto que directo, por potenciación de las notas frutales. Por tanto los altos niveles de este compuesto en los vinos producidos con la cepa R8-VI potencian la acción frutal atribuida a los altos niveles de esteres de etilo presentes.

V. El estudio mediante GC-O reveló que el 2-metil-3-furantiol (MF), 4-mercapto-4metilpentan-2-ona (4MP) y 3-mercaptohexilacetato (MHA) podrían tener gran influencia en el aroma. Estos compuestos únicamente se determinaron en los vinos comerciales analizados (según protocolo descrito en apartado 3.11.4.3). En los últimos años ha quedado bien documentada la presencia e importancia aromática de estos compuestos en vinos producidos con diferentes variedades de uva. Además son las moléculas con los menores umbrales olfatométricos conocidos: 0,3 y 0,8 $\mathrm{ng} / \mathrm{L}$ para el MF y $4 \mathrm{MP}$, respectivamente (Tominaga et al. 2000). Varios autores (Darriet et al. 1995; Tominaga et al. 1996; Tominaga et al. 2000) han indicado que el aroma de boj, pasas de Corinto, tomates y fruta de la pasión son debidos a un grupo de tioles entre los que se incluyen 4MP y MHA. Además indicaron que la liberación de dichos tioles a partir de precursores existentes en el mosto era dependiente de las condiciones de fermentación y de la cepa de levadura empleada.

VI. Si nos fijamos en la tabla 4.29, vemos como los mercaptanos polifuncionales determinados en los vinos comerciales se encuentran en concentraciones superiores a sus correspondientes umbrales (Tominaga et al. 2000). Los altos niveles de 4MP detectados en los vinos comerciales ( $32 \mathrm{ng} / \mathrm{L}$ para Pardevalles y $29 \mathrm{ng} / \mathrm{L}$ para Castro luvara), son comparables a los determinados por otros autores en vinos elaborados con la variedad blanca Sauvignon Blanc. Bouchilloux et al. (1996) indicaron que los vinos de Sauvingnon Blanc con concentraciones de este compuesto de $34 \mathrm{ng} / \mathrm{L}$ eran considerados como vinos "muy típicos de la variedad, mientras que los que contuvieran una concentración menor (18 $\mathrm{ng} / \mathrm{L}$ ) únicamente eran catalogados como vinos "típicos". En un estudio más reciente (Mateo-Vivaracho et al. 2010) se analizaron los mercaptanos presentes en 57 vinos de la variedad Sauvignon blanc y en otros 73 vinos de otras variedades. Se obtuvo que los niveles de 4MP alcanzaban valores de hasta $88 \mathrm{ng} / \mathrm{L}$ en los vinos de la variedad blanca Sauvignon, mientras que en el resto de variedades la concentración de este compuesto se mantenía, en todos los casos, por debajo de los $23 \mathrm{ng} / \mathrm{L}$. El vino comercial Castro luvara presentó los valores más altos de MHA (75 
$\mathrm{ng} / \mathrm{L})$ y 3 mercaptohexanol (616 ng/L). Los altos niveles obtenidos en los diferentes mercaptanos analizados paracen indicar que la uva Prieto Picudo presenta un perfil aromático muy particular. Además los resultados de GC-O sugieren que algunas levaduras son capaces de producir altos niveles de 4MP (ver tabla 4.28).

\subsubsection{Conclusiones del estudio aromático}

El estudio aromático ha revelado que los vinos elaborados con uva Prieto Picudo presentan un perfil aromático complejo caracaterizado por niveles relativamente altos de ésteres de etilo (notal frutales), terpenoles, norisoprenoides y también de los mercaptanos $4 M P, M H$ y MHA.

El estudio se ha realizado a partir de vinos elaborados con diferentes cepas autóctonas de S. cerevisiae, poniéndose de manifiesto que las propiedades de los vinos resultantes son altamente dependientes de la cepa empleada en fermentación. Empleando un mismo mosto y variando la cepa empleada en cada caso se obtuvieron vinos cuyas diferencias sensoriales eran consecuencia de unos perfiles aromáticos diferentes en función de los compuestos químicos predominantes.

Es importante seleccionar la cepa de levadura adecuada con el fin de producir unos vinos con unas características sensoriales deseadas. De hecho, en función de la cepa de levadura empleada se han detectado dos patrones bien diferenciados en cuanto a la liberación y formación de aromas:

- Cepas capaces de producir ésteres de etilo y acetatos (ambos productos fermentativos) responsables de las notas a fruta fresca.

- Cepas capaces de liberar compuestos tiolados (mercaptanos polifuncionales), a partir de precursores aromáticos presentes en las uvas, que proporcionan notas a fruta de la pasión

Los niveles de 4-mercapto-4-metilpentan-2-ona (4MP) presente en los vinos elaborados con uva Prieto Picudo son del orden de los encontrados en los vinos elaborados con la variedad blanca Sauvignon, donde este compuesto es considerado un marcador varietal.

En cuanto a la influencia de las diferentes cepas empleadas en el estudio, la cepa C9-I (aislada en la bodega Pedro Casis) fue capaz de producir unos vinos con un perfil aromático más rico y complejo, con marcadas notas a fruta de la pasión (de acuerdo al análisis sensorial y los altos niveles de 4MP en en análisis GC-0, figura 4.40 y tabla 4.28, respectivamente) valoradas positivamente por los consumidores en los vinos jóvenes. 
Tabla 4.30: Datos químicos cuantitativos de los compuestos volátiles expresados en $\mu \mathrm{g} / \mathrm{L}$. Entre paréntesis se indica la desviación estándar (SD). En el caso de los vinos experimentales, se analizaron tres extractos diferentes correspondientes a tres microvinificaciones (réplicas). En los vinos comerciales se realizaron tres inyecciones a partir de un único extracto. Los valores que no presentan SD indican la no existencia de réplicas.

\begin{tabular}{|c|c|c|c|c|c|c|c|}
\hline \multirow[b]{2}{*}{ COMPUESTOS } & \multicolumn{5}{|c|}{ VINOS EXPERIMENTALES } & \multicolumn{2}{|c|}{ VINOS COMERCIALES } \\
\hline & G5 - II & P7 - XII & C9 - I & C9 - II & $\mathrm{R} 8-\mathrm{VI}$ & Pardevalles (2009) & Castro luvara (2009) \\
\hline $\begin{array}{l}\text { ÉSTERES LINEALES } \\
\text { propanoato de etilo } \\
\text { butirato de etilo } \\
\text { hexanoato de etilo } \\
\text { octanoato de etilo }\end{array}$ & $\begin{array}{l}17(1) \\
78(15) \\
86(19) \\
50(26)\end{array}$ & $\begin{array}{r}52(24) \\
115(29) \\
157(36) \\
42(21)\end{array}$ & $\begin{array}{c}18(1) \\
155(60) \\
213(60) \\
142(54)\end{array}$ & $\begin{array}{r}73(43) \\
220(46) \\
327(39) \\
275(37)\end{array}$ & $\begin{aligned} 41 & (20) \\
355 & (37) \\
467 & (147) \\
207 & (20)\end{aligned}$ & $\begin{array}{r}63(38) \\
439(12) \\
556(22) \\
526(21)\end{array}$ & $\begin{array}{l}211(1) \\
379(1) \\
592(6) \\
216(1)\end{array}$ \\
\hline $\begin{array}{l}\text { OTROS ÉSTERES } \\
\text { 2-metilbutirato de etilo } \\
\text { isobutirato de etilo } \\
\text { isovalerato de etilo } \\
\text { lactato de etilo } \\
\text { furoato de etilo } \\
\text { succinato de dietilo }\end{array}$ & $\begin{array}{c}0,43 \\
2,9(0,3) \\
0,74(0,10) \\
1229(238) \\
0,74(0,10) \\
460(68)\end{array}$ & $\begin{array}{c}0,22(0,03) \\
2,2(0,8) \\
0,49(0,04) \\
1961(261) \\
0,49(0,04) \\
1113(175)\end{array}$ & $\begin{array}{c}0,21 \\
3,3(0,9) \\
0,28(0,07) \\
1459(297) \\
0,28(0,07) \\
387(98)\end{array}$ & $\begin{aligned} & 0,24(0,04) \\
& 5(2) \\
& 0,9(0,1) \\
& 2135(158) \\
& 0,9(0,1) \\
& 675(20)\end{aligned}$ & $\begin{aligned} & 0,47(0,08) \\
& 13,2(0,2) \\
& 1,6(0,3) \\
& 2114(241) \\
& 1,6(0,3) \\
& 794(49)\end{aligned}$ & $\begin{aligned} & 6,3(0,5) \\
& 75(1) \\
& 9,9(0,2) \\
& 42000(486) \\
& 9,9(0,2) \\
& 3709(65)\end{aligned}$ & $\begin{array}{c}9,7(0,1) \\
66(1) \\
20(2) \\
19676(129) \\
20(2) \\
4238(6)\end{array}$ \\
\hline $\begin{array}{l}\text { ACETATOS } \\
\text { acetato de butilo } \\
\text { acetato de etilo } \\
\text { acetato de hexilo } \\
\text { acetato de isoamilo } \\
\text { acetato de isobutilo } \\
\text { acetato de } 2 \text {-feniletilo } \\
\text { acetato de linalol }\end{array}$ & $\begin{array}{c}8,0(0,3) \\
34057(1361) \\
64(20) \\
514(26) \\
58(4) \\
460(18) \\
\text { n.d. }\end{array}$ & $\begin{array}{c}3,6(0,3) \\
51014(3440) \\
86(53) \\
662(137) \\
17(1) \\
215(114) \\
0,33(0,08)\end{array}$ & $\begin{array}{c}9,0(1,9) \\
23424(1875) \\
90(32) \\
828(181) \\
68(9) \\
680(241) \\
0,72(0,09)\end{array}$ & $\begin{array}{c}8,1(0,8) \\
53476(3822) \\
168(17) \\
1824(246) \\
59(3) \\
1946(228) \\
0,35(0,01)\end{array}$ & $\begin{aligned} & 17(1) \\
& 62210(2786) \\
& 214(61) \\
& 2134(551) \\
& 139(8) \\
& 706(60) \\
& 1,1(0,1)\end{aligned}$ & $\begin{array}{c}29(1) \\
84419(1735) \\
106(199 \\
5433(124) \\
347(7) \\
2011(165) \\
\text { n.d. }\end{array}$ & $\begin{array}{c}13,70,2 \\
44103(1160) \\
32(3) \\
1420(1) \\
55(1) \\
710(15) \\
\text { n.d. }\end{array}$ \\
\hline $\begin{array}{l}\text { ÁCIDOS } \\
\text { ácido butírico } \\
\text { ácido decanoico } \\
\text { ácido hexanoico } \\
\text { ácido isobutírico } \\
\text { ácido isovaleriánico } \\
\text { ácido octanoico }\end{array}$ & $\begin{array}{l}606(324) \\
413(135) \\
1248(27) \\
344(48) \\
\text { n.d. } \\
1266(113)\end{array}$ & $\begin{aligned} 1923(119) \\
506(84) \\
2818(187) \\
884(116) \\
\text { n.d. } \\
1917(613)\end{aligned}$ & $\begin{array}{r}845(375) \\
514(254) \\
2228(122) \\
452(110) \\
\text { n.d. } \\
1863(415)\end{array}$ & $\begin{array}{r}1670(543) \\
812(128) \\
3895(274) \\
736(19) \\
\text { n.d. } \\
3077(479)\end{array}$ & $\begin{aligned} 2263(25) \\
927(124) \\
3994(85) \\
982(87) \\
\text { n.d. } \\
3771 \text { (17) }\end{aligned}$ & $\begin{array}{l}2874(55) \\
1054(126) \\
5989(57) \\
1399(51) \\
712(167) \\
6481(118)\end{array}$ & $\begin{aligned} 1972(136) \\
457(14) \\
4890(2) \\
616(8) \\
592(33) \\
5063(13)\end{aligned}$ \\
\hline $\begin{array}{l}\text { ALCOHOLES } \\
\text { isobutanol } \\
\text { butan-1-ol } \\
\text { alcohol isoamílico } \\
\text { hexan-1-ol } \\
\text { (Z)-3-hexen-1-ol } \\
\text { alcohol bencílico } \\
\text { B-feniletanol } \\
\text { metionol }\end{array}$ & $\begin{array}{c}9173(581) \\
353(16) \\
59910(3451) \\
859(100) \\
143(3) \\
82(1) \\
6885(233) \\
472(41)\end{array}$ & $\begin{array}{c}15796(133) \\
862(9) \\
132629(11813) \\
2248(39) \\
292(7) \\
139(3) \\
20663(2902) \\
466(115)\end{array}$ & $\begin{array}{c}10852(3378) \\
336(128) \\
71063(23473) \\
896(194) \\
154(42) \\
101(4) \\
10915(2582) \\
488(211)\end{array}$ & $\begin{array}{c}14308(754) \\
978(117) \\
133439(13925) \\
1499(156) \\
260(31) \\
150(23) \\
24244(3041) \\
720(40)\end{array}$ & $\begin{array}{c}20077(2389) \\
1379(28) \\
153568(31552) \\
1705(37) \\
273(15) \\
131(6) \\
19541(1680) \\
1100(21)\end{array}$ & $\begin{aligned} & 38018(1848) \\
& 1031(24) \\
& 226992(3440) \\
& 1714(16) \\
& 139(6) \\
& 295(25) \\
& 36784(705) \\
& 3855(145)\end{aligned}$ & $\begin{array}{r}23058(76) \\
1044(11) \\
265404(160) \\
2083(1) \\
60(2) \\
193(14) \\
30249(99) \\
912(39)\end{array}$ \\
\hline $\begin{array}{l}\text { COMPUESTOS CARBONÍLICOS } \\
\text { acetaldehido } \\
\text { acetoina } \\
\text { diacetilo (butano-2,3-diona) } \\
\text { fenilacetaldehido } \\
\text { siringaldehido }\end{array}$ & $\begin{array}{c}7279(482) \\
1387(232) \\
1695(399) \\
21(2) \\
4,6\end{array}$ & $\begin{aligned} & 12501(277) \\
& 2649(125) \\
& 558(196) \\
& 12(1) \\
& 1,6(0,1)\end{aligned}$ & $\begin{aligned} 4780 & (508) \\
830 & (340) \\
401 & (50) \\
24 & (2) \\
2,6 & (0,7)\end{aligned}$ & $\begin{array}{l}10937(1513) \\
1978(109) \\
1911(1999) \\
20(5) \\
2,5\end{array}$ & $\begin{array}{c}10047(145) \\
2146(166) \\
492(153) \\
30(4) \\
6,2(0,6)\end{array}$ & $\begin{aligned} & 3061(249) \\
& 13713(208) \\
& 1071(607) \\
& 181(2) \\
& 1,9(0,5)\end{aligned}$ & $\begin{array}{c}3128(181) \\
6993(114) \\
491(214) \\
119(1) \\
3,29(0,04)\end{array}$ \\
\hline $\begin{array}{l}\text { TERPENOS } \\
\text { linalol } \\
\alpha \text {-terpineol } \\
\beta \text {-citronelol } \\
\text { geraniol }\end{array}$ & $\begin{array}{l}5,07(0,01) \\
2,1(0,1) \\
4,5(1,0) \\
9,0\end{array}$ & $\begin{array}{l}2,9(0,4) \\
1,1(0,1) \\
4,0(0,3) \\
6,2(1,1)\end{array}$ & $\begin{array}{r}5,4(0,3) \\
1,9(0,1) \\
5,8(0,8) \\
14,2(0,1)\end{array}$ & $\begin{array}{l}4,1(0,2) \\
1,8(0,2) \\
4,8(0,2) \\
7,6\end{array}$ & $\begin{array}{c}7,8(0,8) \\
3,5(0,5) \\
10(2) \\
13(2)\end{array}$ & $\begin{aligned} 15,3 & (0,2) \\
7,7 & (0,1) \\
9,1 & (0,5) \\
10,1 & (0,5)\end{aligned}$ & $\begin{array}{c}29,61(0,01) \\
26,65(0,05) \\
\quad 7,0(0,3) \\
7,3(0,1)\end{array}$ \\
\hline
\end{tabular}


Tabla 4.30 (Continuación)

\begin{tabular}{|c|c|c|c|c|c|c|c|}
\hline \multirow[b]{2}{*}{ COMPUESTOS } & \multicolumn{5}{|c|}{$\underline{\text { VINOS EXPERIMENTALES }}$} & \multicolumn{2}{|c|}{$\underline{\text { VINOS COMERCIALES }}$} \\
\hline & G5 - ॥ & P7 - XII & C9-I & C9-II & $\mathrm{R} 8 \cdot \mathrm{VI}$ & Pardevalles (2009) & Castro luvara (2009) \\
\hline $\begin{array}{l}\text { NORISOPRENOIDES } \\
\text { B-damascenona } \\
\text { B-ionona }\end{array}$ & $\begin{array}{l}3,8(0,2) \\
0,10\end{array}$ & $\begin{array}{l}1,8(0,1) \\
0,1(0,01)\end{array}$ & $\begin{array}{c}3,3(0,4) \\
0,31(0,01)\end{array}$ & $\begin{array}{l}3,2(0,4) \\
0,19\end{array}$ & $\begin{array}{c}6,2(0,7) \\
0,316(0,004)\end{array}$ & $\begin{array}{c}8,8(0,1) \\
0,34(0,03)\end{array}$ & $\begin{array}{c}4,7(0,2) \\
0,27(0,01)\end{array}$ \\
\hline $\begin{array}{l}\text { FENOLES VOLÁTILES } \\
\text { guaiacol } \\
\text { m-cresol } \\
\text { o-cresol } \\
\text { 4-etilguaiacol } \\
\text { eugenol } \\
\text { 4-etilfenol } \\
\text { 4-vinilguaiacol } \\
\text { 2.6-dimetoxifenol } \\
\text { 4-alil-2,6-dimetoxifenol } \\
\text { 4-vinilfenol }\end{array}$ & $\begin{array}{r}0,31 \\
0,10 \\
0,79 \\
0,10 \\
3,0 \\
0,24 \\
4,74 \\
0,77 \\
\text { n.d. } \\
21\end{array}$ & $\begin{array}{l}0,14(0,01) \\
0,10 \\
0,7(0,4) \\
0,06 \\
1,6(0,4) \\
0,09 \\
1,9(0,4) \\
0,22(0,08) \\
\text { n.d. } \\
8,4(1,5)\end{array}$ & $\begin{array}{c}0,642(0,01) \\
0,163(0,03) \\
0,771(0,001) \\
\text { n.d. } \\
2,8(0,1) \\
0,25(0,06) \\
6,3(0,2) \\
0,54(0,03) \\
0,39(0,07) \\
37(1)\end{array}$ & $\begin{array}{r}0,26 \\
0,2 \\
0,71 \\
\text { n.d. } \\
2,6 \\
1,5 \\
6,7 \\
0,42 \\
\text { n.d. } \\
55\end{array}$ & $\begin{array}{c}0,47(0,02) \\
0,33(0,06) \\
1,3(0,1) \\
\text { n.d. } \\
4,3((0,4) \\
0,32(0,03) \\
11(3) \\
0,5(0,1) \\
\text { n.d. } \\
94(20)\end{array}$ & $\begin{array}{c}1,599(0,008) \\
0,53(0,03) \\
1,5(0,1) \\
\text { n.d. } \\
6,2(0,2) \\
0,81(0,02) \\
14,00(0,01) \\
5,3(0,3) \\
\text { n.d. } \\
15,92(0,03)\end{array}$ & $\begin{array}{c}1,334(0,003) \\
0,348(0,001) \\
1,34(0,01) \\
\text { n.d. } \\
8,3(0,1) \\
0,41(0,03) \\
9,74(0,01) \\
5,2(0,1) \\
4,4(0,2) \\
7,0(0,5)\end{array}$ \\
\hline $\begin{array}{l}\text { DERIVADOS DE LA VAINILLINA } \\
\text { vainillato de metilo } \\
\text { vainillato de etilo } \\
\text { acetovainillona }\end{array}$ & $\begin{array}{l}64 \\
10 \\
89\end{array}$ & $\begin{aligned} 15 & (4) \\
4,5 & (0,8) \\
46 & (7)\end{aligned}$ & $\begin{array}{l}36(4) \\
6,5(0,1) \\
79(4)\end{array}$ & $\begin{array}{r}21 \\
5,1 \\
67\end{array}$ & $\begin{array}{c}41(2) \\
10(1) \\
126(12)\end{array}$ & $\begin{array}{l}23,06(0,05) \\
165(1) \\
138(1)\end{array}$ & $\begin{array}{c}25,54(0,04) \\
47,7(0,3) \\
153(1)\end{array}$ \\
\hline $\begin{array}{l}\text { DERIVADOS DEL BENCENO } \\
\text { benzadelhido } \\
\text { dihidrocinamato de etilo } \\
\text { cinamato de etilo }\end{array}$ & $\begin{array}{r}\text { n.d. } \\
0,34 \\
\text { n.d. }\end{array}$ & $\begin{array}{l}\text { n.d. } \\
0,164(0,004) \\
\text { n.d. }\end{array}$ & $\begin{array}{l}\text { n.d. } \\
0,23(0,01) \\
\text { n.d. }\end{array}$ & $\begin{array}{r}\text { n.d. } \\
0,10 \\
\text { n.d. }\end{array}$ & $\begin{array}{l}\text { n.d. } \\
0,44(0,07) \\
\text { n.d. }\end{array}$ & $\begin{array}{c}3,2(0,1) \\
0,96(0,04) \\
0,45(0,02)\end{array}$ & $\begin{array}{l}\text { n.d. } \\
1,832(0,002) \\
0,46(0,09)\end{array}$ \\
\hline $\begin{array}{l}\text { LACTONAS } \\
\text { Y-nonalactona } \\
\text { Y-decalactona } \\
\text { d-decalactona } \\
\text { Y-butirolactona } \\
\text { cis-whiskylactona } \\
\text { trans-whiskylactona }\end{array}$ & $\begin{array}{l}2,8 \\
0,99 \\
25 \\
1804(189) \\
\text { n.d. } \\
\text { n.d. }\end{array}$ & $\begin{array}{c}2,2(1,3) \\
0,65 \\
10,9(0,2) \\
20571(1619) \\
\text { n.d. } \\
0,45(0,10)\end{array}$ & $\begin{array}{c}2,6(0,2) \\
0,5(0,3) \\
25(1) \\
1794(286) \\
\text { n.d. } \\
0,39(0,07)\end{array}$ & $\begin{array}{l}2,3 \\
0,7 \\
25 \\
14595(2570) \\
\text { n.d. } \\
\text { n.d. }\end{array}$ & $\begin{aligned} & 4,5(0,5) \\
& 1,367(0,004) \\
& 37(3) \\
& 15109(806) \\
& \text { n.d. } \\
& 1,0(0,1)\end{aligned}$ & $\begin{array}{c}8,82(0,01) \\
2,5(0,1) \\
33(3) \\
9238(53) \\
\text { n.d. } \\
3,26(0,02)\end{array}$ & $\begin{array}{c}7,6(0,1) \\
\text { n.d. } \\
32(1) \\
10168(173) \\
6,08(0,02) \\
3,2(0,1)\end{array}$ \\
\hline $\begin{array}{l}\text { TIOLES* } \\
\text { 4-mercapto-4-metilpentan-2-ona (4MP) } \\
\text { 3-mercaptohexilacetato (MHA) } \\
\text { 2-furfuriltiol (FFT) } \\
\text { 3-mercaptohexanol (MH) } \\
\text { benzilmercaptano (BM) } \\
\text { 2-metilfuran-3-tiol (2M3F)"* }\end{array}$ & & & & & & $\begin{array}{r}32 \\
35 \\
3 \\
315 \\
6 \\
90\end{array}$ & $\begin{array}{r}29 \\
75 \\
5 \\
616 \\
6 \\
226\end{array}$ \\
\hline
\end{tabular}

"Concentraciones expresadas en ng/L.

“ Concentración expresada en unidades de FFT, por no disponer de la curva de calibración correspondiente. 

V. Discusión General 

La tendencia actual en la industria vitivinícola pasa por el empleo de levaduras comerciales (LSA) como iniciadores de fermentación. Muchas son las ventajas de esta práctica (reproducibilidad, mayor control del proceso, fermentaciones más rápidas, etc.) (Pretorius 2000) aunque también existen ciertos inconvenientes que deben ser indicados. Teniendo en cuenta que el número de iniciadores comerciales disponibles en el mercado (o más bien los de uso más extendido) es reducido, se ha llegado a una situación en la que muchos vinos son elaborados empleando las mismas cepas. Dado que en la elaboración de los vinos está ampliamente demostrada la gran influencia de las cepas en las características organolépticas del producto final (Romano et al. 2003; Swiegers et al. 2005; Álvarez-Pérez et al., enviado ; Hernández-Orte et al. 2008; Swiegers et al. 2009), es un contrasentido utilizar un reducido número de cepas comerciales, ya que con ello se producen vinos más uniformes desde el punto de vista organoléptico.

Es por ello que en este trabajo se planteó un proceso encaminado a la obtención de levaduras iniciadoras de fermentación cuyo origen fueran las bodegas donde se elaboran los vinos englobados bajo la DO «Tierra de León», es decir, cepas "autóctonas". Estas cepas estarían mejor adaptadas a las características del mosto y a los requerimientos técnicos de la elaboración que cualquiera de las cepas comerciales, lo que sin duda repercutirá en la calidad final del producto. De este modo los vinos poseerían unas propiedades únicas, o al menos más típicas, dando lugar a productos claramente diferenciables del resto.

Para ello se planteó un proceso de aislamiento de levaduras, en varias cosechas, en algunas de las bodegas englobadas en la DO. Tras la caracterización genética (a nivel de especie y de cepa) se obtuvo una colección de levaduras autóctonas. La bondad de estas cepas en los procesos de fermentación fue estimada mediante estudios de carácter fenotípico y enológico.

Adicionalmente y como complemento de los anteriores análisis se planteó la posibilidad de realizar una caracterización aromática de vinos elaborados mediante el empleo de algunas de las cepas seleccionadas. Adicional porque se consigue una caracterización aromática de los vinos de la DO «Tierra de León», y complementario porque se pone de manifiesto la influencia de las cepas en los diferentes perfiles aromáticos encontrados.

\subsection{Aislamiento y caracterización genética de levaduras vínicas autóctonas}

El estudio se llevó a a partir de mosto natural de uva Prieto Picudo cedido por cinco bodegas pertenecientes a la DO (ver apartado 3.7.1). Dicho estudio se repitió durante tres cosechas diferentes, llegándose a analizar un toal de 877 colonias diferentes (unas 170-180 por bodega). Mediante estudios de RFLP-5.8S-ITS (ver apartados 1.7.2.2 y 3.9.2) y RFLPADNmt (ver apartados 1.7.3.1 y 3.9.3) se llevó a cabo la caracterización genética a nivel de especie y de cepa, respectivamente.

De hecho las 877 colonias analizadas se distribuyeron, inicialmente, en un total de 130 tipos o cepas diferentes, todas ellas pertenecientes a la especie $\mathrm{S}$. cerevisiae, salvo una (cepa PB7 perteciente al tipo $\mathrm{P} 5-\mathrm{XI}$ ) que resultó ser un híbrido interespecífico entre $\mathrm{S}$. cerevisiae $\mathrm{x}$ S. kudriavzevii (Peris et al., enviado). Por tanto, tras tres años de estudio en cinco bodegas diferentes se habían obtenidos un total de 130 cepas, prueba inequívoca de la gran diversidad microbiana presente en las bodegas (Pretorius 2000; Renouf et al. 2007).

Si analizamos los resultados bodega por bodega podemos llegar a la conclusión de que en ellas existe una "población residencial autóctona de levaduras", algo que ha quedado 
demostrado por el hecho que en todas las bodegas estudiadas se han detectado varias cepas en dos o más cosechas. Así, en la bodega Gordonzello S.A. aparecen 2 cepas en más de una cosecha, 3 en el caso de Coop. Vin. Ribera del Cea y 4 para la bodega Vinícola Valmadrigal. Sin embargo en las bodegas Coop. Pajares de los Oteros y bodegas Pedro Casis el número asciende a 5 y 6 cepas respectivamente. En la última bodega indicada, una misma cepa (C9-I) fue detectada en las tres cosechas estudiadas, siendo además la cepa mayoritaria en cada una de las cosechas analizadas (ver apartado 4.1.3.2.b). Estos datos ponen de manifiesto, no solo la existencia de cepas autóctonas en bodega (Frezier y Dubourdieu 1992; Vezinhet et al. 1992), sino la especial adaptación de ciertas cepas a los entornos fermentativos, quizás mejor predispuestas a un proceso de adaptación evolutiva debido a la gran cantidad de factores estresantes que se dan en los entornos industriales (alta concentración de azúcares, bajo contenido de azúcares, etc.) tan diferentes al medio natural (Liti et al. 2009). Constanti et al. (1997) realizó un seguimiento sobre la microbiota tras una primera cosecha en una bodega recién establecida. Comprobó que ciertas cepas de Saccharomyces no solo se convertían en residenciales de la bodega, sino que algunas de las cepas eran capaces de proliferar y participar activamente en los procesos de fermentación. Otros autores (Ciani et al. 2004) confirmaron que las cepas que se convierten en autóctonas son aquellas que llevan a cabo el proceso fermentativo (en fermentaciones espontáneas).

Algo que también se ha tenido en cuenta en el presente estudio ha sido la dominancia de las levaduras comerciales sobre la supuesta población autóctona. Así ha quedado patente que en tres de las cinco bodegas (Gordonzello S.A., Pedro Casis y Vinícola Valmadrigal) existe cierta implantación de alguna de las cepas comerciales sobre las residentes en bodega. En la última bodega indicada el grado de implantación fue elevado ya que en las cosechas donde fue detectada resultó ser la cepa con mayor implantación. Si tenemos en cuenta que la toma de muestra del mosto se realizaba previa a la siembra con LSAs, la aparición de una cepa comercial en el vino producido mediante microfermentación espontánea (en laboratorio) se explica por la existencia de dichas cepas como residentes en las instalaciones de la bodega (proveniente de cosechas anteriores), quedando demostrada su capacidad, aunque desigual, para competir e incluso desplazar a la población autóctona de bodega (Blanco et al. 2010). Un caso extremo sería el observado recientemente (Clavijo et al. 2010) tras realizar un estudio sobre la población existente en una bodega de nueva creación donde desde un principio se emplearon LSAs en la obtención de los vinos. Estos autores ponen de manifiesto la imposibilidad de aislar levaduras autóctonas de la bodega (tanto en tanques inoculados con LSAs como en aquellos donde se producen fermentaciones espontáneas). En todos los casos se aíslan las levaduras comerciales, indicando de algún modo que el uso de las levaduras comerciales impide el desarrollo de una población de levaduras Saccharomyces indígena. En nuestro estudio se observa una cierta implantación de las cepas comerciales sobre la población autóctona de bodega. De las tres bodegas donde se obtuvo este comportamiento, la implantación es más importante en la que tiene menor antigüedad (Vinícola Valmadrigal). El mayor grado de implantación para esta bodega no solo se explicaría con por la novedad de las intalaciones, sino porque adicionalmente en todas las cosechas obtenidas en dichas instalaciones se hayan empleado LSAs [acorde en cierto modo a lo descrito por Blanco et al. (2010)]. En el resto de bodegas estudiadas se ha determinado una mayor población de levaduras autóctonas directamente relacionado con la antigüedad de la bodega, potenciado adicionalmente en el caso de aquellas instalaciones donde en sus inicios se realizaban las fermentaciones de forma espontánea.

Una vez analizada la población de levaduras de cada una de las bodegas (considerando las levaduras comerciales correspondientes) quedaba claro que existían levaduras autóctonas a una bodega en particular, pero ¿existirían levaduras autóctonas de la variedad de uva? Para 
dar respuesta a esta pregunta se realizó una comparación entre las diferentes cepas caracterizadas en las diferentes bodegas. Curiosamente, varias cepas fueron detectadas en bodegas separadas por grandes distancias. De hecho, 8 cepas aparecieron en dos bodegas diferentes, mientras que una de ellas (C9-II) apareció en cuatro de las cinco bodegas consideradas (ver figura 4.30). Todos estos casos, y especialmente el último, reflejan la existencia de cierto número de cepas coexistentes en diferentes bodegas y que por tanto podrían ser consideradas autóctonas de la variedad. De hecho, la cepa que aparece en cuatro de las cinco bodegas representa 3,42 \% de la población de colonias analizadas durante el presente estudio. Aun no siendo un porcentaje muy elevado, teniendo en cuenta la gran diversidad encontrada (119 cepas diferentes), el porcentaje relativo a cada uno de los tipos sería únicamente el 0,8 \% (877 colonias analizadas). Este comportamiento ha sido descrito en otros estudios realizados en otras regiones de producción llegando a una conclusión similar (Vezinhet et al. 1992; Versavaud et al. 1995; Agnolucci et al. 2007; Lopandic et al. 2008).

El análisis de los perfiles RFLP-ADNmt nos ha permitido discriminar entre las diferentes cepas aisladas en el presente estudio, e incluso dilucidar aquellas que han aparecido en diferentes localizaciones dentro de la DO (figura 4.30). Los perfiles obtenidos nos dan información acerca de la similitud genética entre las cepas, aunque las agrupaciones observadas no atienden a la regionalidad de las cepas (bodegas donde fueron aisladas). Por tanto el hecho de que ciertas cepas aparezcan dispersas en diferentes localizaciones geográficas puede ser debido a la distribución por medio de agentes humanos o naturales o debido a procesos evolutivos simultáneos desde un antecesor común (Versavaud et al., 1995). Con la información disponible no podemos conocer las causas, aunque ciertamente dicho objetivo se escapa de la finalidad del presente trabajo.

También se realizó un estudio con la intención de aislar levaduras desde uva de la variedad Prieto Picudo (ver apartado 4.2). Se emplearon condiciones de baja temperatura y cierto contenido en etanol con el fin de favorecer el aislamiento de especies del género Saccharomyces frente al resto de especies normalmente asociadas a la superficie de la uva (aptdo. 1.4.1.1.a). Entre dichas levaduras se aislaron un total de 15 clones pertenecientes a la especie S. cerevisiae, cuyo análisis conjunto mediante RFLP-ADNmt reveló que se trataba de la misma cepa (figura 4.33). El hecho de aislar cepas de S. cerevisiae directamente desde la uva resulta llamativo, debido a su baja proporción en este entorno (Martini et al. 1996; Mortimer y Polsinelli 1999; Prakitchaiwattana et al. 2004). Pero lo realmente destacable es que una misma cepa haya sido aislada a partir de uvas recolectadas en tres viñedos distribuidos dentro de la zona de cultivo de la DO, concretamente viñedos situados en Gordaliza del Pino, Gordoncillo y Valderas (León, España). De nuevo parece que la hipótesis de la existencia de cepas autóctonas de la variedad de uva cobraba cierto sentido, aunque con diferente origen (viñedo frente a bodega). La comparación de esta cepa con la colección de 119 cepas disponibles, indicó que su perfil de restricción no era conincidente, presentando únicamente un $40 \%$ de similitud con las cepas más próximas (figura 4.34). Ambos resultados (no coincidencia y baja similitud entre las cepas de entornos fermentativos y entorno natural) descartaba una posible contaminación de la muestra durante la manipulación en el laboratorio.

Estos resultados parecen sugerir que el origen inicial de $\mathrm{S}$. cerevisiae aisladas en bodega será el viñedo. Estas cepas, aunque muy excasas, sufrirán una rápida selección en el entorno industrial ante la elevada presión que supone desarrollarse en un entorno fermentativo (Querol et al. 2003; Liti et al. 2009).

De esta manera y dada la gran capacidad evolutiva de los microorganismos, las excasas levaduras presentes en uva (autóctonas de variedad) evolucionarán rápidamente hacia cepas 
diferentes (autóctonas de bodega). El hecho de que la mayor parte de las cepas aisladas sean autóctonas de una bodega en concreto indica una divergencia evolutiva, de manera que la población inicial de cada bodega evoluciona hacia caminos diferentes en función de los distintas variables como las técnicas de vinificación empleadas, la competencia con cepas comerciales y otros muchos factores.

\subsection{Caracterización fenotípica y enológica de levaduras vínicas autóctonas}

El fin último de este trabajo era obtener cepas que pudieran llegar a usarse como iniciadores de fermentación autóctonos. Para ello, la cepa o cepas elegidas no solo deberían poseer ciertas características fenotípicas que la hagan adecuada para los proceso de vinificación industriales. Realizar un análisis con las 119 cepas resultaba inviable. Por tanto, se optó por una preselección de cepas sobre la que realizar el estudio. Dentro de cada bodega, se seleccionaron las cepas mayoritarias de cada una de las cosechas además de las coexistentes en al menos dos años diferentes. Este criterio de selección ya había sido empleado por otros autores (Frezier y Dubourdieu 1992; Versavaud et al. 1995) en estudios de selección de cepas, atendiendo a que su mayor porcentaje e implantación en bodega respondería a la mejor adaptación a las condiciones específicas de producción de los vinos. Así de las 119 cepas iniciales el número se redujo hasta 30 (tabla 4.13), distribuidas entre las diferentes bodegas. No obstante, es posible que un criterio de selección tan restrictivo suponga cierta pérdida de información, existiendo la posibilidad de que alguna de las cepas minoritarias desechada mostrara unas propiedades óptimas. Aun así, la colección de cepas se encuentra disponible de cara a posibles estudios adicionales.

El análisis realizado pretendía detectar entre estas 30 cepas aquellas mejor adaptadas a un proceso fermentativo. Para ello se realizaron varias pruebas: pruebas bioquímicas (fermentación y asimilación de diferentes fuentes de carbono), tolerancia al etanol, comportamiento a bajas temperaturas, estudio de su capacidad "killer" y comportamiento fermentativo en la obtención de vino a pequeña escala. Las pruebas realizadas son suficientes, en principio, para detectar las cepas fermentativamente más eficaces y descartar aquellas peor adaptadas.

Los estudios se fermentación y asimilación de diferentes fuentes de carbono no están directamente relacionados con el comportamiento en fermentación, sino con el comportamiento nutricional de las levaduras. Las principales fuentes de carbono en fermentación son glusoca y fructosa, siendo ambas fermentadas y asimiladas. Las conclusiones obtenidad de estos estudios pudieran ir encaminadas a una posible aplicación industrial paralela, si alguna de las cepas presenta la capacidad de degradar un sustrato determinado para generar un producto de alto valor añadido.

\subsubsection{Comportamiento en entornos con etanol}

Las tendencias del mercado son cambiantes incluso en el mundo del vino. Los cosumidores se decantan a día de hoy por unos vinos con un grado alcohólico moderado. Por tanto, planteamos la posibilidad de conocer el comportamiento de las cepas en entornos con concentración cambiante de etanol. De este modo se podría estimar su comportamiento en fermentación. Así según el método descrito por Arroyo-López et al. (2010) se obtuvieron, de forma inequívoca, los rangos de concentraciones donde el normal desarrollo la levadura se veía afectado (figura 4.35). Resultaron llamativas las grandes diferencias encontradas, tanto entre bodegas como a título individual, ya que el aislamiento de las levaduras se produjo en 
la fase final de microfermentaciones (apartado 3.8.2), entorno donde el contenido alcohólico es elevado. Las cepas menos tolerantes (menor valor MIC) son cepas ninoritarias en sus correspondientes bodegas (cepas C8-VII, C9-IX y C9-X en bodega Pedro Casis; cepas V8-XV y V8-XVII en bodega Vinícola Valmadrigal) con porcentajes no superiores al 3,5\%. Así aunque están presentes en el final de fermentación, no son capaces de dirigir el proceso de fermentación por encontrarse en bajo porcentaje, limitando su desarrollo por el alto contenido alcohólico. Por tanto, de nuevo se pone de manifiesto la capacidad de las cepas mejor adaptadas a imponerse en los procesos de fermentación. Por otra parte las cepas mayoritarias en cada cosecha/bodega no siempre alcanzaron los valores más altos, aunque todas ellas presentan unos valores aceptables.

\subsubsection{Fermentaciones a baja temperatura}

La DO «Tierra de León» ha tenido una amplia tradición en elaboración de vinos rosados muy aromáticos. Es bien conocida la capacidad de las fermentaciones realizadas a bajas temperaturas para producir unos vinos con mayor complejidad e intensidad aromática (Querol et al. 2003) debido a que se minimiza la pérdida de compuestos aromáticos volátiles (Belloch et al. 2008). La búsqueda en uva de levaduras del género Saccharomyces, diferentes a $S$. cerevisiae, resultó infructuosa. Es bien conocida el óptimo comportamiento en fermentaciones a baja temperatura de especies como S. bayanus, S. kudriavzevii o de los híbridos interspecíficos de cualquiera de estas especies con S. cerevisiae (González et al. 2006, 2007; Lopandić et al. 2007; Gangl et al. 2009).

Por tanto se diseño un experimento para conocer el comportamiento de nuestras levaduras en condiciones de baja temperatura. Consistió en la obtención de curvas de crecimiento a bajas temperaturas (aptdo. 3.10.5) de modo que su comportamiento quedó definido por un valor experimental proporcional a su tasa de crecimiento en estas condiciones ( $m$ ", tabla 4.18). Se obtuvieron comportamientos muy dispares que ponen de manifiesto como dentro de una misma bodega podemos aislar cepas con comportamientos muy distintos.

Hay que destacar que el clon PB7 (tipo P5-XI) era un híbrido S. cerevisiae x S. kudriavzevii (Peris et al., enviado) por lo que cabría esperar una gran adaptación de este clon a la fermentación a bajas temperaturas. Efectivamente, esta cepa presntó un comportamiento óptimo aunque comparable al mostrado por la mejor de las cepas (R8-VI) aislada desde entornos fermentativos (datos no mostrados).

La baja temperatura es uno de los factores estresantes durante la fermentación para la levadura, de manera que un mejor comportamiento indicaría la mejor adaptación de la cepa a las nuevas condiciones del entorno (Querol et al. 2003).

\subsubsection{Estudio del fenotipo "killer"}

Que una levadura sea capaz de dirigir una fermentación significa que tendrá que predominar sobre el resto de las presentes en el mosto o en la propia bodega. Aparte de controlar la cantidad de inóculo, se debe de conocer su comportamiento en relación al denominado factor "killer" (aptdo. 1.5.1.3.d) (Magliani et al. 1997; Marquina et al. 2002; Rodriguez-Cousino et al. 2011). Es bien conocida la capacidad de algunas levaduras para producir toxinas capaces de matar a aquellas cepas que presenten sensibilidad a dichas toxinas. En el presente estudio se ha llevado a cabo el análisis en placa y del material genético asociado (aptdo. 4.3.6) de las cepas seleccionadas. De las 30 cepas analizadas únicamente 13 presentaron un comportamiento óptimo para dicho fenotipo: 11 cepas resultaron ser productoras de la toxina K2, mientras que otras 2 resultaron ser neutras (sin presentar carácter matador, tampoco presentaban sensibilidad). El resto de cepas analizadas 
resultaron ser sensibles a varias toxinas, incluida la toxina K2 que es la que tiene mayor importancia en vinificación. Llama la atención que en cuatro de las cinco bodegas estudiadas se hayan aislado levaduras con carácter "killer" que convivían junto a levaduras sensibles, mientras que en la bodega restante (Coop. Vin. Ribera del Cea) las cepas seleccionadas resultaron ser sensibles. Este dato indica que quizás se esté sobreestimando la importancia del carácter "killer" como elemento para la selección de levaduras vínicas.

Si se inocula con una cepa sensible al inicio del proceso, existe la posibilidad de que sea eliminada a lo largo de la fermentación si en el medio existe alguna cepa con carácter matador. Esto nos llevaría a una fermentanción lenta e incluso a una parada del proceso. Por el contrario, el uso de un iniciador con carácter "killer" puede surprimir aquellas levaduras indeseadas, mejorando notablemente la calidad del producto final (Pérez et al. 2001). Uno de los factores determinantes en el factor "killer" radica en la relación incial existente entre células matadoras y células sensibles. En bibliografía se encuentran valores muy dispares, desde proporciones de entre el 0,01-10\% de la población total de S. cerevisiae (Hara et al. 1980; Tredoux et al. 1986; Van Vuuren y Wingfield 1986; Jacobs y Van Vuuren 1991), hasta otros que indican proporciones superiores al 50 \% (Petering et al., 1991). Un estudio más reciente pone de manifiesto que una proporción incial del 2-6\% será suficiente para controlar las posibles levaduras sensibles presentes en el mosto con capacidad de disminuir la calidad del producto final (Pérez et al. 2001). Otros factores con gran impotancia en el factor "killer" serán la presencia de sustancias capaces de absorver proteínas (por ejemplo bentonita) (Van Vuuren y Jacobs 1992), el tamaño del inóculo, la cantidad de nitrógeno disponible (Medina et al. 1997), etc. En nuestro caso particular parece lógico pensar que debido a que se trataban de fermentaciones espontáneas, donde participa toda la población residente de bodega, no fue posible el desplazamiento de las levaduras sensibles por aquellas con carácter matador (poblaciones similares).

Los resultados obtenidos tras el estudio del carácter "killer" (coexistencia de cepas de carácter matador con cepas sensibles) abren un debate sobre la importancia de emplear un iniciador de fermentación con fenotipo "killer" o neutro. La cantidad de inóculo en una fermentación dirigida suele ser muy elevada (del orden de $10^{6}$ células $/ \mathrm{mL}$ ) lo que dificultaría su supresión por alguna cepa con caracter matador presente, en una concentración más baja, en el entorno fermentativo. De hecho, existen levaduras comerciales en el mercado con un manifiesto carácter sensible, así una de las levaduras comerciales empleadas en la bodega Coop. Vin. Ribera del Cea, Enoferm BDX (tabla 3.1), presenta un fenotipo "killer sensible" a la toxina K2. A falta de realizar estudios de implantación de cepas a escala industrial, es preferible un fenotipo "killer" o neutro, aunque no excluyente. Es decir, si una cepa presenta unas propiedades enológicas adecuadas junto con un fenotipo sensible podría ser utilizada como iniciadora de fermentación, ya que su alta proporción al inicio de fermentación garantizaría con casi toda seguridad su éxito.

\subsubsection{Comportamiento en fermentación}

Una vez analizados una serie de parámetros que a priori nos podrían permitir predecir el comportamiento (mejor o peor) de una cepa durante el proceso fermentativo, parecía lógico comprobar su comportamiento en fermentaciones reales o dirigidas. Una de las pruebas llevadas a cabo fue el análisis de la "capacidad fermentativa" (aptdo. 4.3.3), mediante el seguimiento de un proceso fermentativo (por medida de azúcares residuales a diferentes tiempos) para comprobar el comportamiento en fermentación de cada una de las levaduras seleccionadas. Lógicamente se obtuvieron comportamientos diversos entre las diferentes cepas (tabla 4.16). Destacaron sobre manera la cepa G7-XIV (bodega Gordonzello S.A.) y las cepas C9-I y C9-II (bodega Pedro Casis) debido a sus altas tasas de fermentación. Estos 
resultados, aparte de informar sobre su comportamiento, vuelven a reflejar el diferente y variado comportamiento de cepas pertenecientes a una misma especie.

La realización de microfermentaciones con cada una de las levaduras seleccionadas permitió obtener una idea aproximada de cual sería su comportamiento en bodega. El seguimiento de la fermentación se realizó mediante monitorización de la pérdida de masa (método no invasivo) y la posterior estimación de su comportamiento en fermentación mediante parámetros experimentales que describen las correpondientes curvas de evolución de la fermentación (tabla 4.20). El resultado del análisis de los vinos obtenidos (tabla 4.21) fue un claro reflejo de la diferente comportamiento en fermentación. El empleo de dos lotes de mosto diferentes imposibilitó una comparación directa entre las diferentes cepas. Así los vinos elaborados con mosto del lote 1 (empleando cepas de las bodegas Gordonzello S.A y Pajares de los Oteros) dieron como resultado unos vinos con altos contenidos en azúcares residuales y niveles anormalmente altos de ácido acético. En los vinos elaborados con el mosto del lote 2 se obtuvieron vinos relativamente secos con un contenido en ácido acético aceptable. Este fenómeno se explica en parte por el mayor contenido en azúcares del lote 1 de mosto (los vinos presentan un mayor grado alcohólico) y la existencia de ácido acético al inicio de fermentación. Además, mediante el estudio de la capacidad fermentativa se pone de manifiesto que las cepas de las bodegas Gordonzello S.A. y Coop. de los Oteros son capaces de eliminar los azúcares existentes en el mosto (tabla 4.16, parámetro A'), llegando a niveles próximos e incluso superiores a los presentados por las levaduras de las otras bodegas.

Aunque los contenidos de glucosa y de fructosa son similares al inicio de fermentación, resulta llamativo que en todos los casos el azúcar residual predominante sea fructosa. Las cepas de Saccharomyces tienen preferencia por la glucosa, consumiéndola más rapidamente, con la consecuente disminución del ratio glucosa/frucosa (Berthels et al., 2004). El grado alcohólico de los vinos obtenidos refleja la eficiencia de las diferentes cepas, ya que fue inversamente proporcial al contenido de azúcares residuales: cuanto mayor era el grado alcohólico menor era el contenido de azúcares en el vino final, y viceversa.

Por otro lado, en un vino son deseables unos niveles adecuados de glicerol ya que aporta al vino ligeras notas dulces, suavidad y "cuerpo". La cantidad de glicerol producida por S. cerevisiae en fermentación se estima en una décima parte del contenido en etanol, con valores que oscilan entre los 4 y $7 \mathrm{~g} / \mathrm{L}$ (Ough et al. 1972; Scanes et al. 1998). Se obtuvieron valores de glicerol que oscilaban entre 5,5 y 9,3 g/L (valor medio $6,5 \mathrm{~g} / \mathrm{L}$ ). El contenido fue superior en los vinos obtenidos con el lote 1 de mosto (mayor contenido en azucares al inicio de fermentación y mayor grado alcohólico en el vino final) aunque resultó llamativo el valor obtenido por la cepa P7-XII (9,3 g/L).

Con el ácido acético ocurre lo contrario, debido a que los niveles elevados de este compuesto producen un aumento en la acidez volátil, resultando en una depreciación del producto final (Ribéreau-Gayon et al., 2000). Los niveles adecuados de este compuesto van desde los $600 \mathrm{mg} / \mathrm{L}$ (Romano 1990) hasta un rango comprendido entre 700 y $1100 \mathrm{mg} / \mathrm{L}$ (Corison et al. 1979) en función del tipo de vino. En nuestro caso se obtuvieron vinos con gran variabilidad en cuanto a su concentración (rango de 462 - $1406 \mathrm{mg} / \mathrm{L}$, valor medio de 887 $\mathrm{mg} / \mathrm{L}$ ). Las cepas con alta producción de este compuesto deberían ser descartadas para su uso en vinificación, aunque se debería confirmar mediante análisis sensorial (cata) su influencia sobre las características organolépticas.

Estos datos demuestran la capacidad de las diferentes cepas analizadas para influir en los parámetros enológicos clásicos (acidez volátil, contenido en glicerol, etc.) tan determinantes para la calidad del producto final (Swiegers et al. 2005). 


\subsubsection{Comparación entre las cepas aisladas de un entorno fermentativo y la aislada de un entorno natural}

Además de las cepas aisladas de entornos fermentativos disponíamos de una cepa (3d) aislada directamente desde uvas de la variedad Prieto Picudo recolectadas en diferentes viñedos adscritos a la DO «Tierra de Léon». Con esta cepa se realizaron microvinificaciones para conocer su comportamiento (aptdo. 4.3.9). Sus propiedades fermentativas fueron aceptables, comparables con algunos de los peores comportamientos descritos para las cepas aisladas de entornos fermentativos. Sin embargo, el alto contenido de azúcares residuales y su relativa baja tasa de fementación (tabla 4.22) descartan su uso a escala industrial.

Las diferencias encontradas entre cepas aisladas de diferentes entornos son una prueba experimental de como las cepas asociadas a la bodega han sufrifo un proceso evolutivo para conseguir una total adaptación al nuevo entorno. Los diferentes agentes estresantes en entornos fermentativos (alto contenido en azúcares, bajo contenido de oxígeno, alta concentración de etanol, etc.) provocan la denominada "domesticación" (Querol et al. 2003), que se pone de manifiesto mediante un comportamiento fisiológico que nada tendrá que ver con el de las levaduras ailadas en entornos naturales (Liti et al., 2009).

\subsubsection{Idoneidad de cepas como iniciadoras de fermentación}

Comprobada la gran influencia de las cepas en las características finales de los vinos con ellas producidos, parecía lógico pensar que una correcta selección de levaduras iniciadoras podría dar lugar a un producto final con unas característica enológicas óptimas. Además la selección de una cepa autóctona adaptada a las condiciones específicas de una determinada región de producción pueden ayudar a mantener su calidad, aportando cualidades distintivas al producto final (Rodríguez et al. 2010), siendo una estrategia interesante de cara a introducir variabilidad en un mercado excesivamente competitivo.

En función de los resultados obtenidos son varias las cepas que podrían resultar de interés a nivel industrial. Con todo lo visto hasta ahora vamos a hacer un análisis pormenorizado sobre cada una de las bodegas.

En la bodega Gordonzello S. A. destaca la cepa G7-XIV sobre el resto. Presentó un buen comportamiento en fermentación (tablas 4.20 y 4.21), produciendo vinos con un adecuado contenido en glicerol y niveles contenidos de ácido acético. Adicionalmente presentó una gran tolerancia al etanol (tabla 4.17), un buen comportamiento a baja temperatura (tabla 4.18) y mostró un fenotipo "killer" por producción de la toxina K2.

En la bodega Cooperativa de los Oteros la cepa P7-VI presentó unas propiedades óptimas. Los vinos con ella elaborados pueden ser considerados relativamente secos, con unos niveles aceptables de glicerol y ácido acético (en relación a lo descrito en el apartdo 5.2.4). Resaltar que fue la única cepa analizada en esta bodega que presentó fenotipo "killer", además de una gran tolerancia al etanol presente en el medio (tabla 4.17). La cepa P7-XII puede resultar de interés debido sobre todo a sus altos niveles de producción de glicerol $(9,3 \mathrm{~g} / \mathrm{L})$, muy superiores al resto. En el resto de parámetros estudiados presentó un comportamiento similar a la cepa P7-VI, salvo por una mayor producción de ácido acético. Algo que va en contra de esta cepa es su carácter sensible a las toxinas killer, aunque como se ha indicado quizás esto no sea tan determinante para su uso en procesos de vinificación (aptdo. 5.2.3).

Las cepas C9-I y C9-II destacaban sobre el resto de cepas aisladas en la bodega Pedro Casis. Los vinos obtenidos con ambas levaduras presentaron unas propiedades similares (tabla 4.21) dentro de los rangos considerados aceptables. Una mejor capacidad fermentativa 
(tablas 4.16 y 4.20 ), mejor comportamiento a bajas temperaturas (tabla 4.18) y su fenotipo K2 parecen jugar a favor de la cepa C9-I.

En la bodega Cooperativa Vinícola Ribera del Cea se destacaba la cepa R8-VI. Esta cepa produce unos vinos acordes a los estándares de calidad descritos, un buen comportamiento en fermentación y un comportamiento óptimo a bajas temperaturas (el mejor comportamiento entre todas las cepas analizadas, ver tabla 4.18). Esta cepa exhibió un fenotipo "killer" sensible compartido con el resto de cepas analizadas en esta bodega.

Las cepas analizadas en la bodega Vinícola Valmadrigal presentaron comportamientos discretos, no destacando ninguna sobre el resto. La cepa V8-XVII sin embargo produce vinos relativamente secos, con un marcado contenido en glicerol y un nivel moderado de ácido acético. Además presentó un aceptable comportamiento a bajas temperaturas y fenotipo K2.

\subsection{Caracterización aromática}

Quizás uno de los aspectos más relevantes de este trabajo haya sido la caracterización aromática de los vinos englobados en la DO «Tierra de León», mediante el estudio de vinos experimentales (elaborados empleando diferentes levaduras autóctonas) y vinos comerciales. Esta caracterización permite destacar la gran "singularidad y peculiaridad" aromática de los vinos elaborados con uva Prieto Picudo.

Los vinos experimentales se elaboraron a partir del mismo mosto natural, variando únicamente la cepa empleada en cada caso. Resultaron llamativas las grandes diferencias encontradas tanto en análisis descriptivo sensorial (tabla 4.24 y figura 4.40), análisis GC-O (tabla 4.29), así como en su composición química (tabla 4.30). De nuevo los resultados experimentales indicaban la gran influencia de las levaduras en las características organolépicas del producto final, de acuerdo a los descrito por varios autores (Fleet 2003; Romano et al. 2003; Swiegers et al. 2005; Hernández-Orte et al. 2008 ; Swiegers et al. 2009; Alvarez-Pérez et al., enviado). Recientemente, algunos autores van más allá y aseguran que los vinos elaborados empleando cepas autóctonas presentan mejores perfiles aromáticos que aquellos elaborados mediante fermentacion espontánea o empleando levaduras comerciales (Callejon et al. 2010; Cortés y Blanco 2010).

Las cepas analizadas se comportaron mediante dos patrones bien diferenciados. Unas eran capaces de producir en fermentación altos niveles de ésteres de etilo y acetatos que aportaban notas de fruta fresca al producto final, mientras otras destacaban por la liberación de compuestos tiolados (mercaptanos polifuncionales) presentes en la uva que aportaban notas a fruta de la pasión.

Sorprendentemente, uno de los mercaptanos polifunciónales, el 4-mercapto-4metilpentan-2-ona (4MP), se encontró en unas concentraciones similares a los vinos elaborados con uva Sauvignon Blanc, donde es considerado un marcador varietal (Bouchilloux et al. 1996). Mateo-Vivaracho et al. (2010) determinaron que los valores encontrados en varios vinos elaborados con otras variedades siempre eran inferiores a los resultados obtenidos en los vinos elaborados con uva Prieto Picudo.

Recientemente se ha descrito que el gen ICR7 está implicado en la liberación del 4MP desde su correspondiente presursor cisteínico, ya que codifa para una proteína con función beta-liasa (Roncoroni et al. 2011). Del mismo modo se ha descrito uno de los genes implicados en la liberación de otro compuesto tiolado, el 3-mercaptohexanol (MH) (Holt et al. 2011). En ambos casos se ha demostrado que la sobreexpresión de los genes correspondiente produce un aumento en la concentración final, mientras que su delección disminuye la concentración 
hasta niveles no detectable. Parace lógico pensar que mediante la modificación genética dirigida de las cepas se podría conseguir un aumento en las proporciones de estos compuestos con la consiguiente mejora de las características organolépticas de los vinos.

También resultó muy llamativa la detección mediante GC-0 del compuesto 3-metil-but-2en-1-tiol (MBT) en dos vinos experimentales (notas herbales/cannabis), resultando el compuesto más diferenciador y presentando la mayor intensidad para el vino elaborado con la cepa C9-I (tabla 4.28). Este compuesto, común en cerveza, únicamente se ha descrito en los vinos de Sauternes (Francia) (Bailly et al. 2006) y en otro vino comercial perteneciente a la DO «Tierra de León» (San-Juan y Ferreira, comunicación personal). Algunos autores ponen de manifiesto la importancia del sulfuro de hidrógeno producido en fermentación en varios mecanismos químicos de generación de este compuesto y otros tioles (Vermeulen et al. 2005). Por tanto a falta de estudios más exhaustivos, se podría apuntar el origen fermentativo de este compuesto en vinos, altamente dependiente de la cepa empleada en fermentación.

En cuanto a la influencia de una determinada cepa en el vino obtenido, destaca especialmente la cepa C9-I (bodega Pedro Casis). Esta cepa fue capaz de producir los vinos con un perfil aromático más complejo, ya que los compuestos más diferenciadores obtenían valores máximos (ver tabla 4.28). Además los altos niveles de 4MP detectados en el estudio GC-O explican sus notas a frutas de la pasión (figura 4.40) tan valorada por los consumidores en los vinos jóvenes.

Se ha discutido, por un lado, la capacidad fermentativa de las cepas, mientras que ahora valoramos su capacidad para producir unos perfiles sensoriales adecuados. Desgraciadamente ambos comportarmientos no siempre están relacionados y se debe de llegar a una situación de compromiso. Es preferible sacrificar una cepa con un comportamiento excelente en fermentación si produce vinos sensorialmente desagradables, y viceversa. A modo de ejemplo, podemos citar la cepa G5-II. Presentaba un buen comportamiento en fermentación (salvo por la producción elevada de ácido acético) (tablas 4.20 y 4.21). Sin embargo tras el análisis descriptivo sensorial se comprobó su alta puntuación para el atributo aromático "reducción", disminuyendo la calidad del producto final. Este resultado descartaría su uso en procesos fermentativos dirigidos.

\subsection{Perspectivas futuras}

Todas las conclusiones extraidas de este trabajo se han realizado a partir de procesos realizados a pequeña escala en laboratorio. Parece lógico pensar que sería necesario realizar un escalado a nivel industrial con alguna de las cepas seleccionadas para comprobar su comportamiento real. Realizar un proceso a gran escala supone un mayor coste (económico y de recursos), por tanto las puebas a pequeña escala permiten realizar un rastreo previo del conjunto de cepas disponibles. En nuestro caso, aunque varias cepas exhibían un comportamiento adecuado, la cepa C9-I presentaba un buen comportamiento en todas las pruebas realizadas, junto con un perfil aromático más intenso y complejo. Esta cepa será un candidato ideal para elaborar vino en un entorno industrial, de acuerdo a las prácticas empleadas en bodega, a fin de comprobar su comportamiento en una situación real.

También podría ser interesante realizar vinos coinoculando con 2 o más cepas seleccionadas, de manera que pudieran aportar características o aromas suplementarios, a fin de producir vinos más complejos y equilibrados.

Si alguna de las cepas presentara un comportamiento adecuado, podrían emplearse rutinariamente en bodega para producir vinos rosados o tintos englobados bajo la DO «Tierra 
de Léon». Existen métodos descritos para producir un inóculo viable con bajo coste y de fácil empleo (Maqueda et al. 2010), no siendo necesario recurrir a la preparación de cultivos secos activos (formato en que se suministran las LSAs comerciales).

Existe una creencia que indica que la contribución de las levaduras no Saccharomyces (levaduras pertenecientes a los géneros Hanseniaspora, Pichia, Saccharomycodes y Zygosaccharomyces, entre otras) aportan mayor complejidad al aroma de los vinos y mejora la calidad del vino final (Romano 1997; Ciani y Maccarelli 1998). Sin embargo algunas levaduras no Saccharomyces producen altos contenidos de ácido acético además de elevadas concentraciones de ciertos compuestos aromáticos no deseados como el acetato de etilo o del acetaldehido (Pretorius 2000). Sin embargo los estudios realizados sobre diferentes géneros de levaduras no Saccharomyces demuestran que el perfil aromático obtenido es más amplio que el encontrado dentro del género Saccharomyces, presentando la capacidad de producir unas proporciones adecuadas de ésteres y acetatos (Hernández-Orte et al. 2008; Viana et al. 2008). Además estas levaduras presentan una gran capacidad de producción de enzimas capaces de liberar compuestos aromáticos a partir de precursores no aromáticos presentes en la uva, con la consiguiente mejora del aroma de los vinos con ellas producidos (Fernández et al. 2000; Mendes Ferreira et al. 2001; Hernández-Orte et al. 2008). Varios autores han realizado un estudio del comportaminento en fermentación con mezclas de cultivos (no Saccharomyces junto con S. cerevisiae) obteniendo comportamientos dispares en cuanto a la producción de compuestos aromáticos (Ciani et al. 2006; Moreira et al. 2005, 2008) e incluso en las cinéticas de crecimiento durante el proceso de fermentación (Moreira et al. 2005; Ciani et al. 2006; Mendoza et al. 2007).

En el presente trabajo se han considerado fermentaciones dirigidas por una única levadura pertenecientes a la especie Saccharomyces cerevisiae. Ciertamente, esta levadura presenta presenta la mayor capacidad fermentativa y es capaz de producir y liberar (a partir de precursores presentes en la uva) una gran cantidad de compuestos aromáticos durante la fermentación, de hay que se haya ganado el título de "levadura del vino" (Pretorius 2000; Swiegers et al. 2005). Algo que se podría considerar en un futuro sería emplear como iniciadores de fermentación una mezcla de levaduras, S. cerevisiae junto con alguna cepa no Saccharomyces. La correcta elección de la cepa "complementaria" y el ratio de inóculo entre ambas cepas puede dar lugar a unos vinos con unas mayores proporciones en polisacáridos, perfiles aromáticos adecuados y un contenido en ácido acético moderado (Ciani et al. 2010; Domizio et al. 2011). Es conveniente recordar que se dispone de una colección de levaduras no Saccharomyces aisladas directamente desde la uva, que junto con la colección de cepas aisladas de entornos fermentativos, pueden dar lugar a combinaciones interesantes de cara a la obtención de un producto de calidad empleando levaduras con una regionalidad contrastada. 



\section{Conclusiones}



1. La microbiota de levaduras vínicas de la especie Saccharomyces cerevisiae perteneciente a las 5 bodegas analizadas de la DO «Tierra de León» es muy diversa como quedó demostrado tras el aislamiento de un total de 119 cepas diferentes.

2. La mayor parte de las cepas aisladas se consideran autóctonas de bodega ya que se aislaron específicamente en una determinada bodega, incluso en dos 0 más de las cosechas analizadas, no siendo posible su detección en el resto de bodegas analizadas. .

3. La proporción de levaduras consideradas autóctonas de la variedad (aquellas que aparecen en dos o más bodegas) fue relativamente baja ( 9 de 119 cepas aisladas). Destacar la aparición de una cepa en cuatro de las cinco bodegas estudiadas.

4. La presencia de cepas de S. cerevisiae en uvas de la variedad Prieto Picudo es pobre junto con una excasa variabilidad, ya que únicamente se pudo aislar una cepa que en ningú caso se detectó en bodega. Dicha cepa podría considerarse como una levadura autóctona de la variedad.

5. Las cepas de S. cerevisiae analizadas (un total de 30) mostraron una alta variabilidad fenotípica y enológica.

6. Las cepas aisladas en bodega presentaron una mayor eficiencia fermentativa en relación a la cepa aislada directamente desde la uva.

7. Las cepas de S. cerevisiae tienen una influencia muy alta sobre el perfil aromático de los vinos con ellas producidos.

8. Las cepas de S. cerevisiae caracterizadas destacan por presentar dos patrones bien diferenciados: aquellas cepas capaces de producir vinos con altos niveles de ésteres de etilo y acetatos (notas a fruta freca), mientras que otras son capaces de liberar compuestos tiolados (mercapatonos polifuncionales) a partir de presurosores inodoros presentes en el mosto.

9. Los vinos elaborados con la variedad de uva Prieto Picudo muestran un perfil aromático muy complejo, caracterizado por la presencia de niveles destacables de ésteres de etilos y acetatos (notas frutales), así como de terpenoides, norisoprenoides y mercaptanos polifuncionales.

10. En algunos de los vinos elaborados con la variedad Prieto Picudo se ha detectado del 3metilbut-2-entiol (MBT) altamente infrecuente en vinos (evoca notas herbales/ cannabis), únicamente detectado en vinos Sauternes (Francia).

11. Los niveles de de 4-mercapto-4-metilpentan-2-ona (4MP) (responsables de notas a fruta de la pasión) detectados en los vinos elaborados a partir de uva Prieto Picudo son elevados, del orden a los encontrados en los vinos elaborados con la variedad Sauvignon Blanc, donde este compuesto es considerado como un marcador varietal. 

VII. Bibliografía 

A

Adams, J., Puskas-Rozsa, S., Simlar, J., Wilke, C.M., 1992. Adaptation and major chromosomal changes in populations of Saccharomyces cerevisiae. Curr. Genet 22, 13-19.

Agnolucci, M., Scarano, S., Santoro, S., Sassano, C., Toffanin, A., Nuti, M., 2007. Genetic and phenotypic diversity of autochthonous Saccharomyces spp. strains associated to natural fermentation of "Malvasia delle Lipari". Letters in Applied Microbiology 45, 657-662.

Aguera, E., Bes, M., Roy, A., Camarasa, C., Sablayrolles, J.-M., 2010. Partial Removal of Ethanol during Fermentation to Obtain Reduced-Alcohol Wines. Am. J. Enol. Vitic 61, 53-60.

Aguilera, A., Klein, H.L., 1993. Chromosome aberrations in simpler eukaryotes, in: Kirsch, I.R. (Ed.), The Causes and Consequences of Chromosomal Aberrations. CRC Press, Boca Raton, Florida, pp. 51-90.

Alexander, M.A., Jeffries, T.W., 1990. Respiratory efficiency and metabolite partitioning as regulatory phenomena in yeasts. Enzyme Microb. Tech 12, 2-19.

Alleweldt, G., 1988. The genetic resources of Vitis: Genetic and geographic origin of grape cultivars, their prime name and synonyms. In: Bundesforschungsanstalt für Rebenzüchtung. Siebeldingen.

Álvarez-Pérez, J.M., Campo, E., San-Juan, F., Coque, J.J.R., Ferreira, V., Hernández-Orte, P., enviado. Sensory and Chemical Characterization of the aroma of Prieto Picudo rosé wines: The differential role of autochthonous yeast strains on aroma profiles.

Álvarez-Rodríguez, M.L., López-Ocaña, L., López-Coronado, J.M., Rodríguez, E., Martínez, M.J., Larriba, G., Coque, J.-J.R., 2002. Cork taint of wines: role of the filamentous fungi isolated from cork in the formation of 2,4,6-trichloroanisole by o methylation of 2,4,6trichlorophenol. Appl. Environ. Microbiol 68, 5860-5869.

Amoore, J.E., 1977. Specific anosmia and the concept of primary odors. Chemical Senses 2, 267 $-281$.

Arroyo-López, F.N., Salvadó, Z., Tronchoni, J., Guillamón, J.M., Barrio, E., Querol, A., 2010. Susceptibility and resistance to ethanol in Saccharomyces strains isolated from wild and fermentative environments. Yeast 27, 1005-1015.

Aznar, M., López, R., Cacho, J., Ferreira, V., 2003. Prediction of Aged Red Wine Aroma Properties from Aroma Chemical Composition. Partial Least Squares Regression Models. Journal of Agricultural and Food Chemistry 51, 2700-2707.

B

Bailly, S., Jerkovic, V., Marchand-Brynaert, J., Collin, S., 2006. Aroma extraction dilution analysis of Sauternes wines. Key role of polyfunctional thiols. J. Agric. Food Chem. 54, 7227-7234.

Barnett, J., 1992. The taxonomy of the genus Saccharomyces Meyen ex Reess - A short review for non-taxonomicsts. YEAST 8, 1-23.

de Barros Lopes, M., Bellon, J.R., Shirley, N.J., Ganter, P.F., 2002. Evidence for multiple interspecific hybridization in Saccharomyces sensu stricto species. FEMS Yeast Res 1 , 323-331. 
de Barros Lopes, M., Rainieri, S., Henschke, P.A., Langridge, P., 1999. AFLP fingerprinting for analysis of yeast genetic variation. International Journal of Systematic Bacteriology 49, 915 -924.

de Barros Lopes, M., Soden, A., Henschke, P.A., Langridge, P., 1996. PCR differentiation of commercial yeast strains using intron splice site primers. Appl. Environ. Microbiol 62, 4514-4520.

de Barros Lopes, M.A., Eglinton, J., Henschke, P.A., Høj, P.B., Pretorius, I.S., 2003. The connection between yeast and alcohol reduction in wine: managing the double-edged sword of bottled sunshine. Australian and New Zealand Wine Industry Journal 17-18, $20,22$.

Barthelmebs, L., Lecomte, B., Divies, C., Cavin, J.-F., 2000. Inducible Metabolism of Phenolic Acids in Pediococcus pentosaceus Is Encoded by an Autoregulated Operon Which Involves a New Class of Negative Transcriptional Regulator. J. Bacteriol. 182, 67246731.

Bartowsky, E.J., Henschke, P.A., 2004. The "buttery" attribute of wine-diacetyl-desirability, spoilage and beyond. Int. J. Food Microbiol 96, 235-252.

Bayonove, C., 1989. Incidences des attaques parasitaires fongiques sur la composate qualitative du raisin et des vins. Revue Francaise d'Oenologie 116, 29-39.

Bell, S.J., Henschke, P.A., 2005. Implications of nitrogen nutrition for grapes, fermentation and wine. Australian Journal of Grape and Wine Research 11, 242-295.

Belloch, C., Orlic, S., Barrio, E., Querol, A., 2008. Fermentative stress adaptation of hybrids within the Saccharomyces sensu stricto complex. Int. J. Food Microbiol 122, 188-195.

Bellon, J.R., Eglinton, J.M., Siebert, T.E., Pollnitz, A.P., Rose, L., de Barros Lopes, M., Chambers, P.J., 2011. Newly generated interspecific wine yeast hybrids introduce flavour and aroma diversity to wines. Appl. Microbiol. Biotechnol 91, 603-612.

Beltran, G., Torija, M.J., Novo, M., Ferrer, N., Poblet, M., Guillamón, J.M., Rozès, N., Mas, A., 2002. Analysis of yeast populations during alcoholic fermentation: a six year follow-up study. Syst. Appl. Microbiol 25, 287-293.

Berthels, N.J., Cordero Otero, R.R., Bauer, F.F., Thevelein, J.M., Pretorius, I.S., 2004. Discrepancy in glucose and fructose utilisation during fermentation by Saccharomyces cerevisiae wine yeast strains. FEMS Yeast Res 4, 683-689.

Bisson, L.F., Lucy Joseph, C.M., 2009. Yeasts, in: König, H., Unden, G., Fröhlich, J. (Eds.), Biology of Microorganisms on Grapes, in Must and in Wine. Springer Berlin Heidelberg, Berlin, Heidelberg, pp. 47-60.

Blanchard, L., Tominaga, T., Dubourdieu, D., 2001. Formation of furfurylthiol exhibiting a strong coffee aroma during oak barrel fermentation from furfural released by toasted staves. J. Agric. Food Chem 49, 4833-4835.

Blanco, J.L., 1997. La plus vieille hisoire du vin. In L'Histoire du vin, une histoire de rites, Office International de la Vigne et du Vin, eds. ed. Salomon.

Blanco, P., Orriols, I., Losada, A., 2010. Survival of commercial yeasts in the winery environment and their prevalence during spontaneous fermentations. Journal of Industrial Microbiology \& Biotechnology 38, 235-239.

Bouchilloux, P., Darriet, P., Dubourdieu, D., 1996. Quantitative determination of 4-mercapto-4methylpen-2-one in Sauvignon wines. J Int. Sci. Vligne Vin 30, 23-29. 
Bouchilloux, P., Darriet, P., Henry, R., Lavigne-Cruège, V., Dubourdieu, D., 1998. Identification of Volatile and Powerful Odorous Thiols in Bordeaux Red Wine Varieties. J. Agric. Food Chem. 46, 3095-3099.

Boulton, R.B., Singleton, V.L., Bisson, L.F., Kunkee, R.E., 1995. Principles and practices of winemaking. Chapman and Hall.

Bradbury, J.E., Richards, K.D., Niederer, H.A., Lee, S.A., Rod Dunbar, P., Gardner, R.C., 2006. A homozygous diploid subset of commercial wine yeast strains. Antonie Van Leeuwenhoek 89, 27-37.

C

Callejon, R.M., Clavijo, A., Ortigueira, P., Troncoso, A.M., Paneque, P., Morales, M.L., 2010. Volatile and sensory profile of organic red wines produced by different selected autochthonous and commercial Saccharomyces cerevisiae strains. Analytica Chimica Acta 660, 68-75.

Campo, E., Cacho, J., Ferreira, V., 2008. The Chemical Characterization of the Aroma of Dessert and Sparkling White Wines (Pedro Ximénez, Fino, Sauternes, and Cava) by Gas Chromatography-Olfactometry and Chemical Quantitative Analysis. Journal of Agricultural and Food Chemistry 56, 2477-2484.

Campo, E., Ferreira, V., Escudero, A., Cacho, J., 2005. Prediction of the wine sensory properties related to grape variety from dynamic-headspace gas chromatography-olfactometry data. Journal of Agricultural and Food Chemistry 53, 5682-5690.

Carbonneau, A., 1983. Stérilités mâle et femelle dans le genre Vitis. II. Conséquences en génétique et sélection. Agronomie 3, 5 .

Chalutz, E., Droby, S., 1998. Biological control of postharvest disease, in: Boland, G.J., Kuykendall (Eds.), Plant- Microbe Interactions and Biological Control. Marcel Dekker, New York, pp. 157-170.

Chu, G., Vollrath, D., Davis, R.W., 1986. Separation of large DNA molecules by contour-clamped homogeneous electric fields. Science 234, 1582-1585.

Ciani, M., Beco, L., Comitini, F., 2006. Fermentation behaviour and metabolic interactions of multistarter wine yeast fermentations. Int. J. Food Microbiol. 108, 239-245.

Ciani, M., Comitini, F., Mannazzu, I., Domizio, P., 2010. Controlled mixed culture fermentation: a new perspective on the use of non-Saccharomyces yeasts in winemaking. FEMS Yeast Res. 10, 123-133.

Ciani, M., Ferraro, L., 1998. Combined use of immobilized Candida stellata cells and Saccharomyces cerevisiae to improve the quality of wines. J. Appl. Microbiol 85, 247254.

Ciani, M., Maccarelli, F., 1998. Oenological properties of non-Saccharomyces yeasts associated with wine-making. World J. Microbiol. Biotechnol. 14, 199-203.

Ciani, M., Mannazzu, I., Marinangeli, P., Clementi, F., Martini, A., 2004. Contribution of wineryresident Saccharomyces cerevisiae strains to spontaneous grape must fermentation. Antonie Van Leeuwenhoek 85, 159-164.

Clavijo, A., Calderón, I.L., Paneque, P., 2010. Effect of the use of commercial Saccharomyces strains in a newly established winery in Ronda (Málaga, Spain). Antonie van Leeuwenhoek 99, 727-731. 
Clemente-Jimenez, J., Mingorance-Cazorla, L., Martinez-Rodriguez, S., Heras-Vazquez, F., Rodriguez-Vico, F., 2004. Molecular characterization and oenological properties of wine yeasts isolated during spontaneous fermentation of six varieties of grape must. Food Microbiology 21, 149-155.

Combina, M., Mercado, L., Borgo, P., Elia, A., Jofré, V., Ganga, A., Martinez, C., Catania, C., 2005. Yeasts associated to Malbec grape berries from Mendoza, Argentina. J. Appl. Microbiol 98, 1055-1061.

Constanti, M., Poblet, M., Arola, L., Mas, A., Guillamon, J.M., 1997. Analysis of Yeast Populations During Alcoholic Fermentation in a Newly Established Winery. Am. J. Enol. Vitic. 48, 339-344.

Corison, C., Ough, C., Berg, H., Nelson, K., 1979a. Must acetic-acid and ethyl-acetate as mold and rot indicators in grapes. American Journal of Enology and Viticulture 30, 130-134.

Corison, C.A., Ough, C.S., Berg, H.W., Nelson, K.E., 1979b. Must Acetic Acid and Ethyl Acetate as Mold and Rot Indicators in Grapes. Am. J. Enol. Vitic. 30, 130-134.

Corte, L., Lattanzi, M., Buzzini, P., Bolano, A., Fatichenti, F., Cardinali, G., 2005. Use of RAPD and killer toxin sensitivity in Saccharomyces cerevisiae strain typing. J. Appl. Microbiol 99, 609-617.

Cortés, S., Blanco, P., 2010. Yeast strain effect on the concentration of major volatile compounds and sensory profile of wines from Vitis vinifera var. Treixadura. World Journal of Microbiology and Biotechnology 27, 925-932.

Coulon, J., Husnik, J.I., Inglis, D.L., van der Merwe, G.K., Lonvaud, A., Erasmus, D.J., van Vuuren, H.J.J., 2006. Metabolic Engineering of Saccharomyces cerevisiae to Minimize the Production of Ethyl Carbamate in Wine. Am. J. Enol. Vitic. 57, 113-124.

Coulon, J., Perello, M.C., Lonvaud-Funel, A., de Revel, G., Renouf, V., 2010. Brettanomyces bruxellensis evolution and volatile phenols production in red wines during storage in bottles. J. Appl. Microbiol 108, 1450-1458.

Coulter, A.D., Godden, P.W., Pretorius, I.S., 2004. Succinic acid-how it is formed, what is its effect on titratable acidity, and what factorsinfluence its concentration in wine? Australian and New Zealand Wine Industry Journal 19, 16-20, 21-25.

Culleré, L., 2005. Contribución al estudio de los componentes carbonílicos del vino. Nuevos métodos de análisis y caracterización de su papel sensorial.

D

Darriet, P., Tominaga, T., Lavigne, V., Boidron, J., Dubourdieu, D., 1995. Identification of a powerful aromatic component of Vitis vinifera L. var. sauvignon wines: 4-mercapto-4-methylpentan-2-one. Flavour and Fragrance Journal 10, 385-392.

Degre, R., Thomas, D.Y., Ash, J., Mailhiot, K., Morin, A., Dubord, C., 1989. Wine Yeasts Strain Idenification. Am. J. Enol. Vitic. 40, 309-315.

De Deken, R.H., 1966. The Crabtree effect: a regulatory system in yeast. J. Gen. Microbiol 44, 149-156.

Dequin, S., Barre, P., 1994. Mixed Lactic Acid-Alcoholic Fermentation by Saccharomyes cerevisiae Expressing the Lactobacillus casei L(+)-LDH. Nat Biotech 12, 173-177. 
Ding, J., Huang, X., Zhang, L., Zhao, N., Yang, D., Zhang, K., 2009. Tolerance and stress response to ethanol in the yeast Saccharomyces cerevisiae. Appl Microbiol Biotechnol 85, 253263.

Domizio, P., Romani, C., Lencioni, L., Comitini, F., Gobbi, M., Mannazzu, I., Ciani, M., 2011. Outlining a future for non-Saccharomyces yeasts: Selection of putative spoilage wine strains to be used in association with Saccharomyces cerevisiae for grape juice fermentation. International Journal of Food Microbiology 147, 170-180.

Doneche, B., 1993. Botrytized wines, in: Fleet, G.H. (Ed.), Wine Microbiology and Biotechnology,. Harwood Academic Publishers, Chur, Switzerland, pp. 327-353.

Dravnieks, A., 1985. Atlas of odor character profiles. ASTM, Philadelphia, PA.

Drysdale, G.S., Fleet, G.H., 1988. Acetic Acid Bacteria in Winemaking: A Review. Am. J. Enol. Vitic. 39, 143-154.

Dubois, P., 1983. Volatile phenols in wine, in: Pifgott, J.R. (Ed.), Flavour of Distilled Beverages, Origins and Developments. Ellis Horwood, Chichester, UK, pp. 110-119.

E

Eickbush, T.H., Eickbush, D.G., 2007. Finely orchestrated movements: evolution of the ribosomal RNA genes. Genetics 175, 477-485.

Escudero, A., Campo, E., Fariña, L., Cacho, J., Ferreira, V., 2007. Analytical characterization of the aroma of five premium red wines. Insights into the role of odor families and the concept of fruitiness of wines. J. Agric. Food Chem 55, 4501-4510.

Escudero, A., Gogorza, B., Melús, M.A., Ortín, N., Cacho, J., Ferreira, V., 2004. Characterization of the Aroma of a Wine from Maccabeo. Key Role Played by Compounds with Low Odor Activity Values. Journal of Agricultural and Food Chemistry 52, 3516-3524.

Escudero, A., Hernandez-Orte, P., Cacho, J., Ferreira, V., 2000. Clues about the Role of Methional As Character Impact Odorant of Some Oxidized Wines. Journal of Agricultural and Food Chemistry 48, 4268-4272.

Esteve-Zarzoso, B., Belloch, C., Uruburu, F., Querol, A., 1999. Identification of yeasts by RFLP analysis of the $5.8 \mathrm{~S}$ rRNA gene and the two ribosomal internal transcribed spacers. Int J Syst Bacteriol 49 Pt 1, 329-37.

Esteve-Zarzoso, B., Hierro, N., Mas, A., Guillamón, J.M., 2010. A new simplified AFLP method for wine yeast strain typing. LWT - Food Science and Technology 43, 1480-1484.

Esteve-Zarzoso, B., Manzanares, P., Ramón, D., Querol, A., 1998. The role of nonSaccharomyces yeasts in industrial winemaking. Int. Microbiol 1, 143-148.

$\mathbf{F}$

Fay, J.C., Benavides, J.A., 2005. Evidence for domesticated and wild populations of Saccharomyces cerevisiae. PLoS Genet 1, 66-71.

Ferea, T.L., Botstein, D., Brown, P.O., Rosenzweig, R.F., 1999. Systematic changes in gene expression patterns following adaptive evolution in yeast. Proc. Natl. Acad. Sci. U.S.A 96, 9721-9726.

Fernádez-Espinar, M.T., Esteve-Zarzoso, B., Querol, A., Barrio, E., 2000. RFLP analysis of the ribosomal internal transcribed spacers and the 5.8S rRNA gene region of the genus Saccharomyces: a fast method for species identification and the differentiation of flor yeasts. Antonie Van Leeuwenhoek 78, 87-97. 
Fernández, M., Úbeda, J.., Briones, A.., 2000. Typing of non-Saccharomyces yeasts with enzymatic activities of interest in wine-making. International Journal of Food Microbiology 59, 29-36.

Ferreira, V., 2010. Volatile aroma compounds and winesensory attributes, in: Reynolds, A. (Ed.), Managing Wine Quality: Viticulatura and Wine Quality (Volume 1). Woodhead Publishing Series in Food Science, Technology and Nutrition No. 187, Brock University, Canada.

Ferreira, V., Cacho, J., 2009. Identification of Impact Odorants of Wines, in: Moreno-Arribas, M.V., Polo, M.C. (Eds.), Wine Chemistry and Biochemistry. Springer Science + Business Media, pp. 393-415.

Ferreira, V., Fernández, P., Peña, C., Escudero, A., Cacho, J.F., 1995. Investigation on the role played by fermentation esters in the aroma of young Spanish wines by multivariate analysis. Journal of the Science of Food and Agriculture 67, 381-392.

Ferreira, V., Jarauta, I., Ortega, L., Cacho, J., 2004. Simple strategy for the optimization of solidphase extraction procedures through the use of solid-liquid distribution coefficients application to the determination of aliphatic lactones in wine. J Chromatogr A 1025, 147-156.

Ferreira, V., López, R., Cacho, J.F., 2000. Quantitative determination of the odorants of young red wines from different grape varieties. Journal of the Science of Food and Agriculture $80,1659-1667$.

Ferreira, V., Ortín, N., Escudero, A., López, R., Cacho, J., 2002. Chemical characterization of the aroma of Grenache rosé wines: aroma extract dilution analysis, quantitative determination, and sensory reconstitution studies. J. Agric. Food Chem 50, 4048-4054.

Ferreira, V., Pet'ka, J., Aznar, M., Cacho, J., 2003. Quantitative gas chromatographyolfactometry. Analytical characteristics of a panel of judges using a simple quantitative scale as gas chromatography detector. J Chromatogr A 1002, 169-178.

Ferreira, V., San Juan, F., Escudero, A., Culleré, L., Fernández-Zurbano, P., Saenz-Navajas, M.P., Cacho, J., 2009. Modeling quality of premium spanish red wines from gas chromatography-olfactometry data. J. Agric. Food Chem 57, 7490-7498.

Ferreira, V., Torres, M., Escudero, A., Ortín, N., Cacho, J., 2005. Aroma composition andaromatic structure of red wines made with Merlot, in State of the art in Flavour Chemistry and Biology, proceedings from the 7th Wartburg Symposium. Hofman PST, Deutusche Forsch. Lebensm. Garching, Germany, pp. 292-299.

Fleet, G.H., 1993. The microorganisms of winemaking-isolation, enumeration and identification, in: Fleet, G.H. (Ed.), Wine Microbiology and Biotechnology,. Harwood Academic Publishers, Chur, Switzerland, pp. 1-27.

Fleet, G.H., 1998. The microbiology of alcoholic beverages, in: Wood, B.J.B. (Ed.), Microbiology of Fermented Foods, Vol 1, BJB (ed). Springer, pp. 217-262.

Fleet, G.H., 2001. Wine, in: Doyle, M.P., Beuchat, L.R., Montville (Eds.), Food Microbiology Fundamentals and Frontiers. ASM Press, Washington, DC, pp. 747-772.

Fleet, G.H., 2003a. Yeast interactions and wine flavour. Int. J. Food Microbiol 86, 11-22.

Fleet, G.H., 2003b. Yeasts in fruit and fruit products, in: Boekhout, T., Robert, R. (Eds.), Yeasts and Food. Beneficial and Detrimental Aspects. Behrs Verlag, Hamburgo, pp. 267-288.

Fleet, G.H., 2008. Wine yeasts for the future. FEMS Yeast Research 8, 979-995. 
Fleet, G.H., Heard, G.M., 1993. Yeast - grown during fermentation, in: Fleet, G.H. (Ed.), Wine Microbiology and Biotechnology,. Harwood Academic Publishers, Chur, Switzerland, pp. 27-55.

Fleet, G.H., Prakitchaiwattana, G., Beh, A., Heard, G., 2002. The Yeast ecology of wine grapes, in: Ciani, M. (Ed.), Biodiversity and Biotechnology of Wine Yeasts. Research Signpost, pp. 1-17.

Foury, F., Roganti, T., Lecrenier, N., Purnelle, B., 1998. The complete sequence of the mitochondrial genome of Saccharomyces cerevisiae. FEBS Letters 440, 325-331.

Fowles, G.W.A., 1992. Acids in grapes and wines: a review. J. of Wine Res. 3, 25-41.

Frezier, V., Dubourdieu, D., 1992. Ecology of Yeast Strain Saccharomyces cerevisiae During Spontaneous Fermentation in a Bordeaux Winery. Am. J. Enol. Vitic. 43, 375-380.

Fugelsang, K.C., 1997. Wine Microbiology. Chapman and Hall, New York.

G

Gangl, H., Batusic, M., Tscheik, G., Tiefenbrunner, W., Hack, C., Lopandic, K., 2009. Exceptional fermentation characteristics of natural hybrids from Saccharomyces cerevisiae and $\mathrm{S}$. kudriavzevii. N Biotechnol 25, 244-251.

Giudici, P., Romano, P., Zambonelli, C., 1990. A biometric study of higher alcohol production in Saccharomyces cerevisiae. Can. J. Microbiol 36, 61-64.

Giudici, P., Solieri, L., Pulvirenti, A.M., Cassanelli, S., 2004. Strategies and perspectives for genetic improvement of wine yeasts. Appl Microbiol Biotechnol 66, 622-628.

Giudici, P., Zambonelli, C., Passarelli, P., Castellari, L., 1995. Improvement of Wine Composition with Cryotolerant Saccharomyces Strains. Am. J. Enol. Vitic. 46, 143-147.

González, S.S., Barrio, E., Gafner, J., Querol, A., 2006. Natural hybrids from Saccharomyces cerevisiae, Saccharomyces bayanus and Saccharomyces kudriavzevii in wine fermentations. FEMS Yeast Res 6, 1221-34.

González, S.S., Barrio, E., Querol, A., 2008. Molecular characterization of new natural hybrids of Saccharomyces cerevisiae and S. kudriavzevii in brewing. Appl. Environ. Microbiol 74, 2314-2320.

González, S.S., Gallo, L., Climent, M.D., Barrio, E., Querol, A., 2007. Enological characterization of natural hybrids from Saccharomyces cerevisiae and S. kudriavzevii. International Journal of Food Microbiology 116, 11-18.

Grosch, W., 1993. Detection of potent odorants in foods by aroma extract dilution analysis. Trends in Food Science \& Technology 4, 68-73.

Guillamón, J.M., Querol, A., Jiménez, M., Huerta, T., 1993. Phylogenetic relationships among wine yeast strains based on electrophoretic whole-cell protein patterns. Int. J. Food Microbiol 18, 115-125.

Guillamón, J.M., Sabaté, J., Barrio, E., Cano, J., Querol, A., 1998. Rapid identification of wine yeast species based on RFLP analysis of the ribosomal internal transcribed spacer (ITS) region. Archives of Microbiology 169, 387-392.

Guth, H., 1997. Quantitation and Sensory Studies of Character Impact Odorants of Different White Wine Varieties. Journal of Agricultural and Food Chemistry 45, 3027-3032. 
H

Hansen, J., Piškur, J., 2004. Fungi in brewing: biodiversity and biotechnology perspectives, in: Aurora, D.K. (Ed.), Handbook of Fungal Biotechnology. pp. 233-248.

Hara, S., limura, Y., Otsuka, K., 1980. Breeding of Useful Killer Wine Yeasts. Am. J. Enol. Vitic. 31, 28-33.

Hartmann, H.T., Kester, D.E., Davies, F.T., 1990. General aspects of propagation, in: Plant Propagation: Principles and Practices. Prentice-Hall, New Jersey, pp. 1-14.

Henschke, P.A., 1997. Wine yeast, in: Zimmermann, F.K., Entian, K.D. (Eds.), Yeast Sugar Metabolism: Biochemistry, Genetics, Biotecnology and Applications. Lancaster, pp. 527-560.

Hernández-Orte, P., Cersosimo, M., Loscos, N., Cacho, J., Garcia-Moruno, E., Ferreira, V., 2008. The development of varietal aroma from non-floral grapes by yeasts of different genera. Food Chemistry 107, 1064-1077.

Hierro, N., González, A., Mas, A., Guillamón, J.M., 2006. Diversity and evolution of nonSaccharomyces yeast populations during wine fermentation: effect of grape ripeness and cold maceration. FEMS Yeast Res 6, 102-111.

Holt, S., Cordente, A.G., Williams, S.J., Capone, D.L., Jitjaroen, W., Menz, I.R., Curtin, C., Anderson, P.A., 2011. Engineering Saccharomyces cerevisiae to release 3Mercaptohexan-1-ol during fermentation through overexpression of an S. cerevisiae Gene, STR3, for improvement of wine aroma. Appl. Environ. Microbiol. 77, 3626-3632.

Hough, J.S., 1990. Biotecnología de la cerveza y de la malta. Acribia.

I

Ihmels, J., Bergmann, S., Gerami-Nejad, M., Yanai, I., McClellan, M., Berman, J., Barkai, N., 2005. Rewiring of the yeast transcriptional network through the evolution of motif usage. Science 309, 938-940.

Infante, J.J., Dombek, K.M., Rebordinos, L., Cantoral, J.M., Young, E.T., 2003. Genome-wide amplifications caused by chromosomal rearrangements play a major role in the adaptive evolution of natural yeast. Genetics 165, 1745-1759.

Izquierdo, P.M., Briones, A.I., Ubeda, J.F., 1996. Relationship Between the Chromosomal Profile and the Whole-cell Protein Patterns of Wine Yeast Strains. LebensmittelWissenschaft und-Technologie 29, 738-742.

J

Jackson, R.S., 2008. Grape Species and Varieties, in: Wine Science: Principles and Applications. Academic Press, pp. 15-50.

Jacobs, C.J., Van Vuuren, H.J.J., 1991. Effects of Different Killer Yeasts on Wine Fermentations. Am. J. Enol. Vitic. 42, 295-300.

Jarauta, I., Cacho, J., Ferreira, V., 2005. Concurrent Phenomena Contributing to the Formation of the Aroma of Wine during Aging in Oak Wood: An Analytical Study. J. Agric. Food Chem. 53, 4166-4177.

Le Jeune, C., Lollier, M., Demuyter, C., Erny, C., Legras, J.-L., Aigle, M., Masneuf-Pomarède, I., 2007. Characterization of natural hybrids of Saccharomyces cerevisiae and Saccharomyces bayanus var. uvarum. FEMS Yeast Res 7, 540-549. 
Jia, K., Zhang, Y., Li, Y., 2010. Systematic engineering of microorganisms to improve alcohol tolerance. Engineering in Life Sciences 10, 422-429.

Johnston, M., 1999. Feasting, fasting and fermenting. Glucose sensing in yeast and other cells. Trends Genet 15, 29-33.

Jolly, N.P., Augustym, O.P.H., Pretorius, I.S., 2006. The Role and Use of Non-Saccharomyces Yeasts in Wine Production. S. Afr. J. Enol. Vitic. 27, 15-39.

de Jonge, P., de Jongh, F.C., Meijers, R., Steensma, H.Y., Scheffers, W.A., 1986. Orthogonalfield-alternation gel electrophoresis banding patterns of DNA from yeasts. Yeast 2 , 193-204.

Josepa, S., Guillamon, J.M., Cano, J., 2000. PCR differentiation of Saccharomyces cerevisiae from Saccharomyces bayanus/Saccharomyces pastorianus using specific primers. FEMS Microbiol. Lett 193, 255-259.

K

Kassemeyer, H.H., Berkelmann-Löhnertz, G., 2009. Fungi of Grapes, in: König, H., Unden, G., Fröhlich, J. (Eds.), Biology of Microorganisms on Grapes, in Must and in Wine. Springer Berlin Heidelberg, Berlin, Heidelberg, pp. 61-87.

Kellis, M., Birren, B.W., Lander, E.S., 2004. Proof and evolutionary analysis of ancient genome duplication in the yeast Saccharomyces cerevisiae. Nature 428, 617-624.

Klis, F.M., Boorsma, A., De Groot, P.W.J., 2006. Cell wall construction in Saccharomyces cerevisiae. Yeast 23, 185-202.

Kocková-Kratochvílová, A., 1990. Yeasts and yeast-like organisms. VCH.

Kodama, Y., Kielland-Brandt, M., Hansen, J., 2005. Lager brewing yeast, in: Sunnerhagen, P., Piškur, J. (Eds.), Comparative Genomics; Using Fungi as Models. Spinger-Verlag, Berlin, pp. $145-164$.

Kurtman, C., Fell, J., 1998. The Yeast, A Taxonomic Study, fourth edition. Elsevier Science, Amsterdam.

Kurtzman, C., 2003. Phylogenetic circumscription of Saccharomyces, Kluyveromyces and other members of the Saccharomycetaceae, and the proposal of the new genera Lachancea, Nakaseomyces, Naumovia, Vanderwaltozyma and Zygotorulaspora. FEMS YEAST RESEARCH 4, 233-245.

Kurtzman, C.P., Robnett, C.J., 1998. Identification and phylogeny of ascomycetous yeasts from analysis of nuclear large subunit (26S) ribosomal DNA partial sequences. Antonie Van Leeuwenhoek 73, 331-371.

$\mathbf{L}$

Lambert, R.J., Pearson, J., 2000. Susceptibility testing: accurate and reproducible minimum inhibitory concentration (MIC) and non-inhibitory concentration (NIC) values. J. Appl. Microbiol 88, 784-790.

Leffingwell, J., 2002. Olfaction (Sence of Smell). Cosmetics \& Medicine (Moscow) 4.

Legras, J., Karst, F., 2003. Optimisation of interdelta analysis for Saccharomyces cerevisiae strain characterisation. FEMS Microbiology Letters 221, 249-255.

Lieckfeldt, E., Meyer, W., Börner, T., 1993. Rapid identification and differentiation of yeasts by DNA and PCR fingerprinting. J. Basic Microbiol 33, 413-425. 
Liti, G., Carter, D.M., Moses, A.M., Warringer, J., Parts, L., James, S.A., Davey, R.P., Roberts, I.N., Burt, A., Koufopanou, V., Tsai, I.J., Bergman, C.M., Bensasson, D., O’Kelly, M.J.T., van Oudenaarden, A., Barton, D.B.H., Bailes, E., Nguyen, A.N., Jones, M., Quail, M.A., Goodhead, I., Sims, S., Smith, F., Blomberg, A., Durbin, R., Louis, E.J., 2009. Population genomics of domestic and wild yeasts. Nature 458, 337-41.

Lodder, J., 1970. The yeasts, a taxonomic study. North Holland Publising Company, Amsterdam, the Netherlands.

Longo, E., Vezinhet, F., 1993. Chromosomal rearrangements during vegetative growth of a wild strain of Saccharomyces cerevisiae. Appl. Environ. Microbiol 59, 322-326.

Lonvaud-Funel, A., Joyeux, A., Desens, C., 1988. Inhibition of malolactic fermentation of wines by products of yeast metabolism. J. Sci. Food Agric 44, 183-191.

Lopandić, K., Gangl, H., Wallner, E., Tscheik, G., Leitner, G., Querol, A., Borth, N., Breitenbach, M., Prillinger, H., Tiefenbrunner, W., 2007. Genetically different wine yeasts isolated from Austrian vine-growing regions influence wine aroma differently and contain putative hybrids between Saccharomyces cerevisiae and Saccharomyces kudriavzevii. FEMS Yeast Res 7, 953-965.

Lopandic, K., Tiefenbrunner, W., Gangl, H., Mandl, K., Berger, S., Leitner, G., Abd-Ellah, G.A., Querol, A., Gardner, R.C., Sterflinger, K., Prillinger, H., 2008. Molecular profiling of yeasts isolated during spontaneous fermentations of Austrian wines. FEMS Yeast Res. 8, 1063-1075.

Lopes, C.A., Lavalle, T.L., Querol, A., Caballero, A.C., 2006. Combined use of killer biotype and mtDNA-RFLP patterns in a Patagonian wine Saccharomyces cerevisiae diversity study. Antonie Van Leeuwenhoek 89, 147-56.

López, R., Aznar, M., Cacho, J., Ferreira, V., 2002. Determination of minor and trace volatile compounds in wine by solid-phase extraction and gas chromatography with mass spectrometric detection. J Chromatogr A 966, 167-177.

López, V., Querol, A., Ramón, D., Fernández-Espinar, M.T., 2001. A simplified procedure to analyse mitochondrial DNA from industrial yeasts. International Journal of Food Microbiology 68, 75-81.

Loscos, N., Hernandez-Orte, P., Cacho, J., Ferreira, V., 2007. Release and formation of varietal aroma compounds during alcoholic fermentation from nonfloral grape odorless flavor precursors fractions. J. Agric. Food Chem 55, 6674-6684.

Loscos, N., Hernández-Orte, P., Cacho, J., Ferreira, V., 2009. Comparison of the Suitability of Different Hydrolytic Strategies To Predict Aroma Potential of Different Grape Varieties. Journal of Agricultural and Food Chemistry 57, 2468-2480.

M

Maarse, H., Vischer, C.A., 1989. Volatile Compounds in Food. Alcoholic Beverages. Qualitative and Quantitative Data. TNO-CIVO, Food Analysis Institute, AJ Zeist, the Netherlands.

Madigan, M.T., Martinko, J.M., Parker, J., 2004. Genética microbiana, in: Brock, Biología De Los Microorganismos. Pearson Alhambra, pp. 304-356.

Magliani, W., Conti, S., Gerloni, M., Bertolotti, D., Polonelli, L., 1997. Yeast killer systems. Clin. Microbiol. Rev. 10, 369-400.

Main, G.L., Threlfall, R.T., Morris, J.R., 2007. Reduction of Malic Acid in Wine Using Natural and Genetically Enhanced Microorganisms. Am. J. Enol. Vitic. 58, 341-345. 
Manzano, M., Cocolin, L., lacumin, L., Cantoni, C., Comi, G., 2005. A PCR-TGGE (Temperature Gradient Gel Electrophoresis) technique to assess differentiation among enological Saccharomyces cerevisiae strains. Int. J. Food Microbiol 101, 333-339.

Maqueda, M., Zamora, E., Rodríguez-Cousiño, N., Ramírez, M., 2010. Wine yeast molecular typing using a simplified method for simultaneously extracting mtDNA, nuclear DNA and virus dsRNA. Food Microbiol 27, 205-209.

Marquina, D., Santos, A., Peinado, J.M., 2002. Biology of killer yeasts. Int. Microbiol 5, 65-71.

Martini, A., Ciani, M., Scorzetti, G., 1996. Direct enumeration and isolation of wine yeasts from grape surfaces. Am. J. Enol. Vitic 47, 435-440.

Masneuf, I., Hansen, J., Groth, C., Piskur, J., Dubourdieu, D., 1998. New hybrids between Saccharomyces sensu stricto yeast species found among wine and cider production strains. Appl. Environ. Microbiol 64, 3887-3892.

Masuda, M., Okawa, E., Nishimura, K., Yunome, H., 1984. Identification of 4,5-dimethyl-3hydroxy-2(5H)-furanone (sotolon) and ethyl 9-hydroxynonanoate in botrytised wine and evaluation of the roles of compounds characteristic of it. Agricultural and Biological Chemistry 48, 2707-2710.

Mateo-Vivaracho, L., Zapata, J., Cacho, J., Ferreira, V., 2010. Analysis, occurrence, and potential sensory significance of five polyfunctional mercaptans in white wines. J. Agric. Food Chem 58, 10184-10194.

McGovern, P.E., 2004. Ancient Wine: The Search for the Origins of Viniculture. Princeton University Press.

McGovern, P.E., Glusker, D.L., Exner, L.J., Voigt, M.M., 1996. Neolithic resinated wine. Nature 381, 480-481.

McGrew, J., 1982. Fungal diseases: a factor in a wine culture. Developments in Industrial Mlcrobiology 23, 87-90.

Medina, K., Carrau, F.M., Gioia, O., Bracesco, N., 1997. Nitrogen availability of grape juice limits killer yeast growth and fermentation activity during mixed-culture fermentation with sensitive commercial yeast strains. Appl Environ Microbiol 63, 2821-2825.

Mendes Ferreira, A., Clímaco, M.C., Mendes Faia, A., 2001. The role of non-Saccharomyces species in releasing glycosidic bound fraction of grape aroma components--a preliminary study. J. Appl. Microbiol. 91, 67-71.

Mendoza, L.M., Nadra, M.C.M., Farías, M.E., 2007. Kinetics and metabolic behavior of a composite culture of Kloeckera apiculata and Saccharomyces cerevisiae wine related strains. Biotechnology Letters 29, 1057-1063.

Moreira, N., Mendes, F., Guedes de Pinho, P., Hogg, T., Vasconcelos, I., 2008. Heavy sulphur compounds, higher alcohols and esters production profile of Hanseniaspora uvarum and Hanseniaspora guilliermondii grown as pure and mixed cultures in grape must. Int. J. Food Microbiol. 124, 231-238.

Moreira, N., Mendes, F., Hogg, T., Vasconcelos, I., 2005. Alcohols, esters and heavy sulphur compounds production by pure and mixed cultures of apiculate wine yeasts. Int. J. Food Microbiol. 103, 285-294.

Moreno, J.A., Zea, L., Moyano, L., Medina, M., 2005. Aroma compounds as markers of the changes in sherry wines subjected to biological ageing. Food Control 16, 333-338. 
Mortimer, R., Polsinelli, M., 1999. On the origins of wine yeast. Res. Microbiol 150, 199-204.

Mullins, M.G., Bouquet, A., Williams, L.E., 1992. Biology of the grapevine. Cambridge University Press.

$\mathbf{N}$

N'guessan, K., Brou, K., Jacques, N., Casaregola, S., Dje, K., 2011. Identification of yeasts during alcoholic fermentation of tchapalo, a traditional sorghum beer from Cte d'Ivoire. Antonie van Leeuwenkoek Interntional Journal of General and Molecular 99, 855-864.

Nadal, D., Carro, D., Fernández-Larrea, J., Piña, B., 1999. Analysis and dynamics of the chromosomal complements of wild sparkling-wine yeast strains. Appl. Environ. Microbiol 65, 1688-1695.

Naumova, E.S., Naumov, G.I., Masneuf-Pomarède, I., Aigle, M., Dubourdieu, D., 2005. Molecular genetic study of introgression between Saccharomyces bayanus and $\mathrm{S}$. cerevisiae. Yeast 22, 1099-1115.

Negrul, A.M., 1938. Evolucija Kuljturnyx from vinograda. C.R. Acad. Sci. URSS 18.

Nisiotou, A.A., Nychas, G.-J.E., 2007. Yeast populations residing on healthy or botrytis-infected grapes from a vineyard in Attica, Greece. Appl. Environ. Microbiol 73, 2765-2768.

Noble, A.C., Bursick, G.F., 1984. The Contribution of Glycerol to Perceived Viscosity and Sweetness in White Wine. Am. J. Enol. Vitic. 35, 110-112.

Núñez, D.R., Walker, M.J., 1989. A review of palaeobotanical findings of early Vitis in the mediterranean and of the origins of cultivated grape-vines, with special reference to new pointers to prehistoric exploitation in the western mediterranean. Review of Palaeobotany and Palynology 61, 205-237.

Nykänen, L., 1986. Formation and Occurrence of Flavor Compounds in Wine and Distilled Alcoholic Beverages. Am. J. Enol. Vitic. 37, 84-96.

0

Ortega, C., López, R., Cacho, J., Ferreira, V., 2001. Fast analysis of important wine volatile compounds development and validation of a new method based on gas chromatographic-flame ionisation detection analysis of dichloromethane microextracts. J Chromatogr A 923, 205-214.

Ough, C.S., Amerine, M.A., 1988. Methods Analysis of Musts and Wines, 2nd Edition, 2nd ed. Wiley-Interscience.

Ough, C.S., Fong, D., Amerine, M.A., 1972. Glycerol in Wine: Determination and Some Factors Affecting. Am. J. Enol. Vitic. 23, 1-5.

$\mathbf{P}$

Palomo, E.S., Pérez-Coello, M.S., Díaz-Maroto, M.C., González Viñas, M.A., Cabezudo, M.D., 2006. Contribution of free and glycosidically-bound volatile compounds to the aroma of muscat "a petit grains" wines and effect of skin contact. Food Chemistry 95, 279289.

Pardo, I., Garcia, M., Zuñiga, M., Uruburu, F., 1989. Dynamics of microbial populations during fermentation of wines from the Utiel-Requena region of Spain. Applied and Enviromental Microbiology 55, 539-541. 
Pérez, F., Ramírez, M., Regodón, J.A., 2001. Influence of killer strains of Saccharomyces cerevisiae on wine fermentation. Antonie Van Leeuwenhoek 79, 393-399.

Peris, D., Belloch, C., Lopandić, K., Álvarez-Pérez, J.M., Querol, A., Barrio, E., enviado. The molecular characterization of new types of $\mathrm{S}$. cerevisiae $\mathrm{x} \mathrm{S}$. kudriavzevii hybrid yeast unveils a high genetic diversity.

Petering, J.E., Symons, M.R., Langridge, P., Henschke, P.A., 1991. Determination of killer yeast activity in fermenting grape juice by using a marked Saccharomyces wine yeast strain. Appl. Environ. Microbiol. 57, 3232-3236.

Pineau, B., Barbe, J.-C., Van Leeuwen, C., Dubourdieu, D., 2007. Which impact for betadamascenone on red wines aroma? J. Agric. Food Chem. 55, 4103-4108.

Piskur, J., Langkjaer, R.B., 2004. Yeast genome sequencing: the power of comparative genomics. Mol. Microbiol 53, 381-389.

Piskur, J., Rozpedowska, E., Polakova, S., Merico, A., Compagno, C., 2006. How did Saccharomyces evolve to become a good brewer? Trends in Genetics 22, 183-186.

Pizarro, F., Vargas, F.A., Agosin, E., 2007. A systems biology perspective of wine fermentations. Yeast 24, 977-991.

Pouget, R., 1988. Vitis vinifera, histoire et évolution, in: La Vigne Et Le Vin. Graficas, pp. 15-25.

Prakitchaiwattana, C.J., Fleet, G.H., Heard, G.M., 2004. Application and evaluation of denaturing gradient gel electrophoresis to analyse the yeast ecology of wine grapes. FEMS Yeast Res 4, 865-877.

Pretorius, I., Van der Westhuizen, T., 1991. The impact of yeast genetics and recombinant DNA technology on the wine industry-a review. South African Journal of Enology and Viticulture 12, 3-31.

Pretorius, I.S., 2000. Tailoring wine yeast for the new millennium: novel approaches to the ancient art of winemaking. Yeast 16, 675-729.

Pronk, J.T., Yde Steensma, H., Van Dijken, J.P., 1996. Pyruvate metabolism in Saccharomyces cerevisiae. Yeast 12, 1607-1633.

Punter, P.H., 1983. Measurement of human olfactory thresholds for several groups of structurally related compounds. Chemical Senses 7, 215 -235.

Q

Querol, A., Barrio, E., Ramón, D., 1992. A comparative study of different methods of yeast strain characterization. Appl. and Environ. Microbiol. 15, 439-446.

Querol, A., Fernandez-Espinar, M., del Olmo, M., Barrio, E., 2003. Adaptive evolution of wine yeast. Int. J. Food Microbiol 86, 3-10.

Querol, A., Jimenez, M., Huerta, T., 1990. Microbiological and Enological parameters during fermentation of musts from poor and normal grape harvests in the region of Alicante (Spain). Journal of Food Science 55, 1603-1606.

$\mathrm{R}$

Radler, G.H., 1993. Yeast: Metabolism of organic acids, in: Fleet, G.H. (Ed.), Wine Microbiology and Biotechnology,. Harwood Academic Publishers, Chur, Switzerland, pp. 165-182.

Rankine, B.C., 1967. Influence of yeast strain and pH on pyruvic acid content of wines. Journal of the Science of Food and Agriculture 18, 41-44. 
Rankine, B.C., 1968. Formation of $\alpha$-ketoglutaric acid by wine yeasts and its oenological significance. Journal of the Science of Food and Agriculture 19, 624-627.

Rankine, B.C., Pocock, K.F., 1969. Influence of yeast strain on binding of sulphur dioxide in wines, and on its formation during fermentation. Journal of the Science of Food and Agriculture 20, 104-109.

Rapp, A., 1998. Volatile flavour of wine: correlation between instrumental analysis and sensory perception. Nahrung 42, 351-363.

Rayne, S., Eggers, N.J., 2007. 4-ethylphenol and 4-ethylguaiacol in wines: estimating nonmicrobial sourced contributions and toxicological considerations. J Environ Sci Health B $42,887-897$.

Rayne, S., Eggers, N.J., 2008. 4-Ethylphenol and 4-Ethylguaiacol Concentrations in Barreled Red Wines from the Okanagan Valley Appellation, British Columbia. Am. J. Enol. Vitic. 59, 92-97.

Reed, G., Nagodawithana, T.W., 1988. Technology of Yeast Usage in Winemaking. Am. J. Enol. Vitic. 39, 83-90.

Rementeria, A., Rodriguez, J.A., Cadaval, A., Amenabar, R., Muguruza, J.R., Hernando, F.L., Sevilla, M.J., 2003. Yeast associated with spontaneous fermentations of white wines from the "Txakoli de Bizkaia" region (Basque Country, North Spain). Int. J. Food Microbiol 86, 201-207.

Renouf, V., Claisse, O., Lonvaud-Funel, A., 2007. Inventory and monitoring of wine microbial consortia. Appl. Microbiol. Biotechnol 75, 149-164.

Ribereau-Gayon, P., 1985. New Developments In Wine Microbiology. Am. J. Enol. Vitic. 36, 110.

Ribéreau-Gayon, P., Dubourdieu, D., Donèche, B., Lonvaud, A., 2000. Harvest and Pre-Fermentation Treatments, in: Handbook of Enology. The Microbiology of Wine and Vinifications. Jonh Wiley \& Sons, Chichester, Inglaterra, pp. 299-325.

Rodríguez, M.E., Infante, J.J., Molina, M., Domínguez, M., Rebordinos, L., Cantoral, J.M., 2010. Genomic characterization and selection of wine yeast to conduct industrial fermentations of a white wine produced in a SW Spain winery. J. Appl. Microbiol 108, 1292-1302.

Rodriguez-Cousino, N., Maqueda, M., Ambrona, J., Zamora, E., Esteban, R., Ramirez, M., 2011. A New Wine Saccharomyces cerevisiae Killer Toxin (Klus), Encoded by a DoubleStranded RNA Virus, with Broad Antifungal Activity Is Evolutionarily Related to a Chromosomal Host Gene. Appl. Environ. Microbiol. 77, 1822-1832.

Romano, P., 1990. La purezza fermentativa in Saccharomyces cerevisiae. Industrie delle Bevande 19, 320-321.

Romano, P., 1997. Metabolic characteristics of wine strains during spontaneous and inoculated fermentation. Food Technology and Biotechnology 35, 255-260.

Romano, P., Fiore, C., Paraggio, M., Caruso, M., Capece, A., 2003. Function of yeast species and strains in wine flavour. Int. J. Food Microbiol 86, 169-180.

Roncoroni, M., Santiago, M., Hooks, D.O., Moroney, S., Harsch, M.J., Lee, S.A., Richards, K.D., Nicolau, L., Gardner, R.C., 2011. The yeast IRC7 gene encodes a $\beta$-lyase responsible for production of the varietal thiol 4-mercapto-4-methylpentan-2-one in wine. Food Microbiology 28, 926-935. 
Rosini, G., Federici, F., Martini, A., 1982. Yeast flora of grape berries during ripening. Microbial Ecology 8, 83-89.

Royer, C., 1988. Mouvement historiques de la vigne dans le monde, in: La Vigne Et Le Vin. Graficas.

\section{S}

San-Juan, F., Pet'ka, J., Cacho, J., Ferreira, V., Escudero, A., 2010. Producing headspace extracts for the gas chromatography-olfactometric evaluation of wine aroma. Food Chemistry $123,188-195$.

Sato, M., Kishimoto, M., Watari, J., Takashio, M., 2002. Breeding of brewer's yeast by hybridization between a top-fermenting yeast Saccharomyces cerevisiae and a cryophilic yeast Saccharomyces bayanus. J. Biosci. Bioeng 93, 509-511.

Scanes, K., Hohmann, S., Prior, B., 1998a. Glycerol production by yeast Saccharomyces cerevisiae and its relevance to wine: a review. South African Journal of Enology and Viticulture 19, 17-24.

Scanes, K.T., Hohmann, S., Prior, B.A., 1998b. Glycerol production by the yeast Saccharomyces cerevisiae and its Relevance to wine: a review. S. Afr. J. Enol. Vitic.

Schmitt, M.J., Breinig, F., 2002. The viral killer system in yeast: from molecular biology to application. FEMS Microbiol. Rev 26, 257-276.

Schreier, P., 1979. Flavor composition of wines: a review. CRC Crit Rev Food Sci Nutr 12, 59111.

Schuller, D., Valero, E., Dequin, S., Casal, M., 2004. Survey of molecular methods for the typing of wine yeast strains. FEMS Microbiol. Lett 231, 19-26.

Schulthess, D., Ettlinger, L., 1978. Influence of the concentrationof branched chain amino acids on the formation of fusel alcohols. Journal of the Institute of Brewing 84, 240-243.

Schwartz, D.C., Cantor, C.R., 1984. Separation of yeast chromosome-sized DNAs by pulsed field gradient gel electrophoresis. Cell 37, 67-75.

Silva Ferreira, A.C., Rodrigues, P., Hogg, T., Guedes De Pinho, P., 2003. Influence of some technological parameters on the formation of dimethyl sulfide, 2-mercaptoethanol, methionol, and dimethyl sulfone in port wines. J. Agric. Food Chem 51, 727-732.

Sipiczki, M., 2010. Diversity, variability and fast adaptive evolution of the wine yeast (Saccharomyces cerevisiae) genome-a review. Ann Microbiol 61, 85-93.

Soden, A., Francis, I.L., Oakey, H., Henschke, P.A., 2000. Effects of co-fermentation with Candida stellata and Saccharomyces cerevisiae on the aroma and composition of Chardonnay wine. Australian Journal of Grape and Wine Research 6, 21-30.

van Solingen, P., van der Plaat, J.B., 1977. Fusion of yeast spheroplasts. J Bacteriol 130, $946-$ 947.

Stevenson, A.C., 1985. Studies in the Vegetational History of S. W. Spain. II. Palynological Investigations at Laguna de las Madres, S. W. Spain. Journal of Biogeography 12, 293314.

Suárez, J.A., Íñigo, B., 1992. Microbiología enológica: fundamentos de vinificación. MundiPrensa Libros. 
Swiegers, J., Bartowsky, E., Henschke, P., Pretorius, I., 2005. Yeast and bacterial modulation of wine aroma and flavour. Australian Journal of Grape and Wine Research 11, 139-173.

Swiegers, J.H., Kievit, R.L., Siebert, T., Lattey, K.A., Bramley, B.R., Francis, I.L., King, E.S., Pretorius, I.S., 2009. The influence of yeast on the aroma of Sauvignon Blanc wine. Food Microbiol 26, 204-211.

\section{$\mathbf{T}$}

Tautz, D., Renz, M., 1983. An optimized freeze-squeeze method for the recovery of DNA fragments from agarose gels. Analytical Biochemistry 132, 14-19.

This, P., Lacombe, T., Thomas, M.R., 2006. Historical origins and genetic diversity of wine grapes. Trends Genet 22, 511-519.

Thomson, J.M., Gaucher, E.A., Burgan, M.F., De Kee, D.W., Li, T., Aris, J.P., Benner, S.A., 2005. Resurrecting ancestral alcohol dehydrogenases from yeast. Nat. Genet 37, 630-635.

Togores, J.H., 2003. Tratado de enología. Mundi-Prensa Libros.

Du Toit, M., Pretorius, I.S., 2000. Microbial spoilage and preservationof wine: using weapons from nature's own arsenal-areview. S. Afr. J. Enol. Vitic. 21, 74-96.

Tominaga, T., Baltenweck-Guyot, R., Gachons, C.P.D., Dubourdieu, D., 2000. Contribution of Volatile Thiols to the Aromas of White Wines Made From Several Vitis vinifera Grape Varieties. Am. J. Enol. Vitic. 51, 178-181.

Tominaga, T., Darriet, P., Dubourdieu, D., 1996. Identification of 3-mercaptohexyl acetate in Sauvignon wine, a powerful aromatic compound exhibiting box-tree odor. VITIS 35, 207-210.

Tominaga, T., Guimbertau, G., Dubourdieu, D., 2003. Contribution of benzenemethanethiol to smoky aroma of certain Vitis vinifera L. wines. J. Agric. Food Chem 51, 1373-1376.

Torija, M.J., Rozès, N., Poblet, M., Guillamón, J.M., Mas, A., 2001. Yeast population dynamics in spontaneous fermentations: comparison between two different wine-producing areas over a period of three years. Antonie Van Leeuwenhoek 79, 345-352.

Tredoux, H.G., Tracey, R.P., Tromp, A., 1986. Killer factor in wineyeasts and its effect on fermentation. S. Afr. J. Enol. Vitic. 7, 105-112.

U

Ubeda, J.F., Fernández-González, M., Briones, A.I., 2009. Application of PCR-TTGE and PCRRFLP for intraspecific and interspecific characterization of the genus Saccharomyces using actin gene (ACT1) primers. Curr. Microbiol 58, 58-63.

V

Valero, E., Cambon, B., Schuller, D., Casal, M., Dequin, S., 2007. Biodiversity of Saccharomyces yeast strains from grape berries of wine-producing areas using starter commercial yeasts. FEMS Yeast Res 7, 317-329.

Verbelen, P.J., De Schutter, D.P., Delvaux, F., Verstrepen, K.J., Delvaux, F.R., 2006. Immobilized yeast cell systems for continuous fermentation applications. Biotechnol. Lett 28, 15151525.

Vermeulen, C., Gijs, L., Collin, S., 2005. Sensorial Contribution and Formation Pathways of Thiols in Foods: A Review. Food Revs. Int. 21, 69-137. 
Vermeulen, C., Lejeune, I., Tran, T.T.H., Collin, S., 2006. Occurrence of polyfunctional thiols in fresh lager beers. J. Agric. Food Chem. 54, 5061-5068.

Versavaud, A., Courcoux, P., Roulland, C., Dulau, L., Hallet, J.N., 1995. Genetic diversity and geographical distribution of wild Saccharomyces cerevisiae strains from the wineproducing area of Charentes, France. Appl. Environ. Microbiol 61, 3521-3529.

Verstrepen, K.J., Iserentant, D., Malcorps, P., Derdelinckx, G., Van Dijck, P., Winderickx, J., Pretorius, I.S., Thevelein, J.M., Delvaux, F.R., 2004. Glucose and sucrose: hazardous fast-food for industrial yeast? Trends Biotechnol 22, 531-537.

Vezinhet, F., Blondin, B., Hallet, J.-N., 1990. Chromosomal DNA patterns and mitochondrial DNA polymorphism as tools for identification of enological strains of Saccharomyces cerevisiae. Appl Microbiol Biotechnol 32.

Vezinhet, F., Hallet, J.-N., Valade, M., Poulard, A., 1992. Ecological Survey of Wine Yeast Strains by Molecular Methods of Identification. Am. J. Enol. Vitic. 43, 83-86.

Viana, F., Gil, J.V., Genovés, S., Vallés, S., Manzanares, P., 2008. Rational selection of nonSaccharomyces wine yeasts for mixed starters based on ester formation and enological traits. Food Microbiology 25, 778-785.

Vivier, M.A., Pretorius, I.S., 2000. Genetic improvement of grapevine: tailoring grape varieties for the third millennium - a review. S. Afr. J. Enol. Vitic. 21, Special Issue, 5-26.

Vos, P., Hogers, R., Bleeker, M., Reijans, M., van de Lee, T., Hornes, M., Frijters, A., Pot, J., Peleman, J., Kuiper, M., 1995. AFLP: a new technique for DNA fingerprinting. Nucleic Acids Res 23, 4407-4414.

Van Vuuren, H.J.J., Van Der Meer, L., 1987. Fingerprinting of Yeasts by Protein Electrophoresis. Am. J. Enol. Vitic. 38, 49-53.

Van Vuuren, H.J.J., Jacobs, C.J., 1992. Killer Yeasts in the Wine Industry: A Review. Am. J. Enol. Vitic. 43, 119-128.

Van Vuuren, H.T.T., Wingfield, B.D., 1986. Killer yeast - Cause of stuck feremtnation in a wine cellar. S. Afr. J. Enol. Vitic. 7, 113-118.

W

Wang, S., Bai, F., 2008. Saccharomyces arboricolus sp nov., a yeast species from tree bark. International Journal of Systematic and Evolutionary Microbiology 58, 510-514.

White, T.J., Bruns, T., Lee, S., Taylor, J., 1990. Amplification and direct sequencing of fungal ribosomal RNA genes for phylogenetics, in: PCR Protocols. A Guide to Methods and Applications. Academic Press, San Diego, C.A., pp. 315-322.

Williams, J.G., Kubelik, A.R., Livak, K.J., Rafalski, J.A., Tingey, S.V., 1990. DNA polymorphisms amplified by arbitrary primers are useful as genetic markers. Nucleic Acids Res 18, 6531-6535.

Wolfe, K.H., Shields, D.C., 1997. Molecular evidence for an ancient duplication of the entire yeast genome. Nature 387, 708-713.

Wood, C., Siebert, T.E., Parker, M., Capone, D.L., Elsey, G.M., Pollnitz, A.P., Eggers, M., Meier, M., Vössing, T., Widder, S., Krammer, G., Sefton, M.A., Herderich, M.J., 2008. From Wine to Pepper: Rotundone, an Obscure Sesquiterpene, Is a Potent Spicy Aroma Compound. Journal of Agricultural and Food Chemistry 56, 3738-3744. 
Y

Yamamoto, N., Yamamoto, N., Amemiya, H., Yokomori, Y., Shimizu, K., Totsuka, A., 1991. Electrophoretic karyotypes of wine yeasts. American Journal of Enology and Viticulture 42, 358-363.

Yanagida, F., Ichinose, F., Shinohara, T., Goto, S., 1992. Distribution of wild yeasts in the white grape varieties at central Japan. Journal of General and Applied Microbiology 38, 501504.

Z

Zoecklein, B.W., Fugelsang, K.C., Gump, B.H., 1999. Wine Analysis and Production. Springer.

Zohary, D., 1995. Domestication of the Gravevine Vitis Vinifera L. in the Near Esast, in: In The Origins and Ancient History of Wine. Gordon and Breach, pp. 23-30. 
